\title{
ASSESSMENT OF MOLECULARLY IMPRINTED POLYMERS AS SUSTAINABLE PHOSPHATE SORBENTS
}

\author{
A Thesis \\ Submitted to the Graduate Faculty \\ of the \\ North Dakota State University \\ of Agriculture and Applied Science
}

By

Cody Lee Ritt

In Partial Fulfillment of the Requirements

for the Degree of

MASTER OF SCIENCE

Major Department:

Civil and Environmental Engineering

June 2017

Fargo, North Dakota 


\section{North Dakota State University}

Graduate School

Title

ASSESSMENT OF MOLECULARLY IMPRINTED POLYMERS AS SUSTAINABLE PHOSPHATE SORBENTS

By

Cody Lee Ritt

The Supervisory Committee certifies that this disquisition complies with North Dakota

State University's regulations and meets the accepted standards for the degree of

MASTER OF SCIENCE

SUPERVISORY COMMITTEE:

Achintya Bezbaruah

Chair

Bret Chisholm

Eakalak Khan

Long Jiang

Approved:

$07 / 07 / 2017$

Date

Dinesh Katti

Department Chair 


\begin{abstract}
Wastewater effluents and agricultural runoff are major sources of phosphorus overloading in surface waters. Phosphorus overloading ignites eutrophication, which devastates aquatic ecosystems. On the other hand, phosphorus, which is currently produced from phosphate rock, is a critical component of fertilizer mixes. However, the world is predicted to face a shortage of phosphate supply beyond 2033 due to unsustainable mining. This research aims to develop a polymeric sorbent that recovers low-concentration phosphorus for eutrophication prevention and fertilizer reuse. Available polymer-based products have underwhelmed expectations by having poor selectivity or lacking appropriate biodegradation rates. This research identified molecularly imprinted polymers (MIPs) as possible sorbents for overcoming the deficiencies of reported technologies. Screening of several MIPs resulted in one potentially feasible MIP for phosphate sorption. Further studies showed a sorption capacity of $\sim 28 \mathrm{mg} \mathrm{PO} 4^{3--P / g}$ and partial phosphate-selectivity. Potential phosphate removal mechanisms were identified, providing foresight into MIPs' viability as phosphorus sorbents.
\end{abstract}




\section{ACKNOWLEDGEMENTS}

This research was funded by the North Dakota Department of Commerce (NDDoC Grant \#: 14-11-J1-70), the National Institute of Food and Agriculture (NIFA-USDA Grant \#: 2015-607022-22996), and the North Dakota Water Resources Research Institute (NDWRRI). The following people and departments are thanked for their contributions to this research:

- Dr. Achintya Bezbaruah, research advisor

- Dr. Bret Chisholm, collaborator and committee member

- Dr. Long Jiang, committee member

- Dr. Eakalak Khan, committee member

- Deepjyoti Kalita, collaborator

- Scott Payne, electron microscopy

- Jayma Moore, electron microscopy

- Ryan Burgett, FTIR spectroscopy

- Research 1 at NDSU, facilities use

- Civil and Environmental Engineering Department at NDSU, facilities use This material is based upon work supported by the National Science Foundation under Grant No. 0619098 and 0923354. Any opinions, findings, and conclusions or recommendations expressed in this material are those of the author(s) and do not necessarily reflect the views of the National Science Foundation. 


\section{DEDICATION}

To the Baker Near-Wilderness Settlement for sparking my inspiration in environmental

stewardship, and for continuing to provide the same opportunities to children across the state of Minnesota. 


\section{TABLE OF CONTENTS}

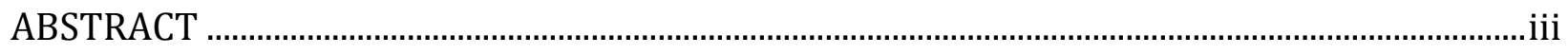

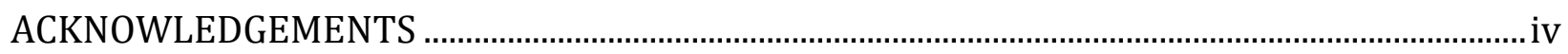

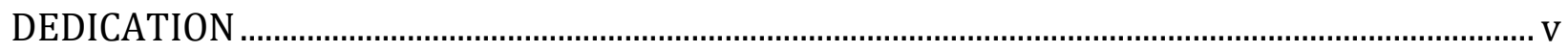

LIST OF TABLES

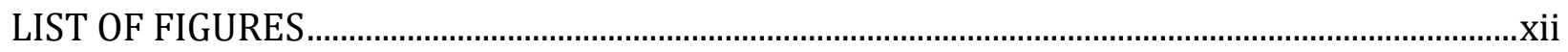

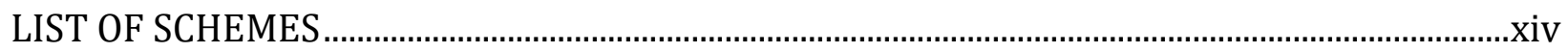

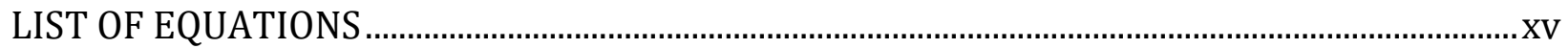

LIST OF APPENDIX TABLES...........................................................................................................

CHAPTER 1. LITERATURE REVIEW ………………………...................................................

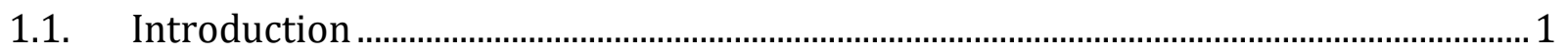

1.2. Established P Reduction Plans and Technologies for Non-point and Point Sources, and in-situ Lake Remediation .......................................................................... 5

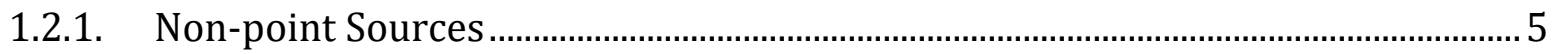

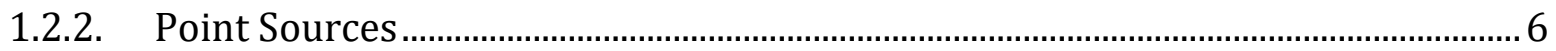

1.2.3. In-situ Lake Remediation................................................................................................ 7

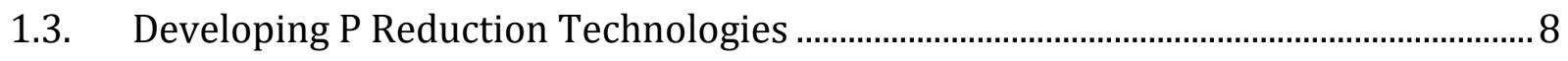

1.3.1. Waste By-products ...................................................................................................

1.3.2. Ion and Ligand Exchangers ...................................................................................

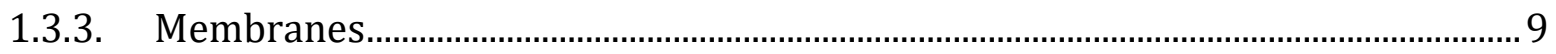

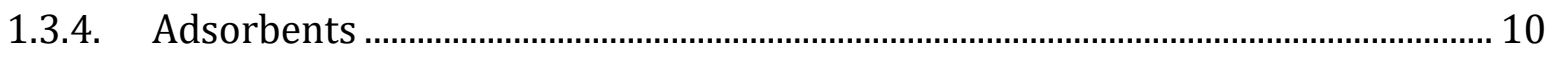

1.3.4.1. Non-polymeric Adsorbents ............................................................................ 11

1.3.4.2. Polymeric Adsorbents ................................................................................. 12

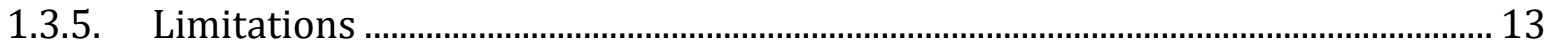

1.4. Trend toward Sustainability............................................................................................ 14 
1.5. Need Statement

1.6. Molecularly Imprinted Polymers ..................................................................................... 18

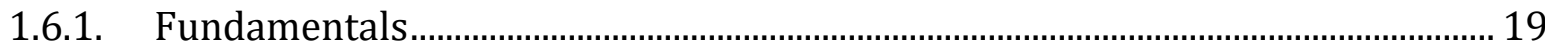

1.6.1.1. Synthesis and Characteristics of MIPs ........................................................ 20

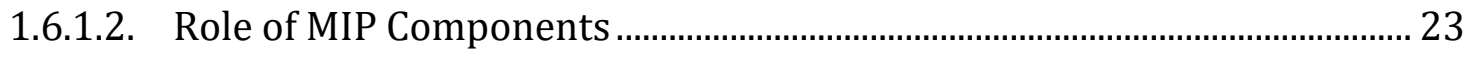

1.6.1.3. Optimization of Components........................................................................ 26

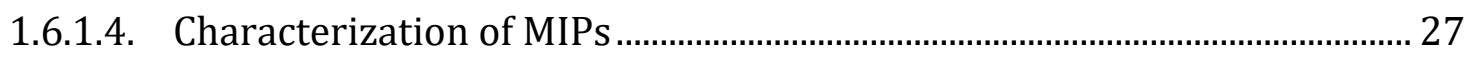

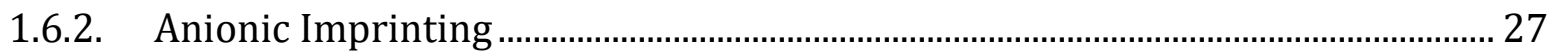

1.6.2.1. Phosphate Imprinting................................................................................ 28

1.7. Research Objectives ............................................................................................... 33

CHAPTER 2. ASSESSMENT OF MOLECULARLY IMPRINTED POLYMERS AS SUSTAINABLE PHOSPHATE SORBENTS................................................................... 35

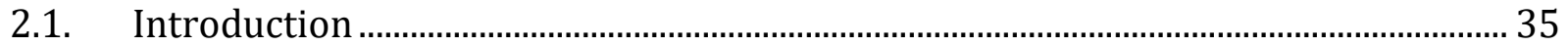

2.2. Materials and Methods …………………………………………………………….... 42

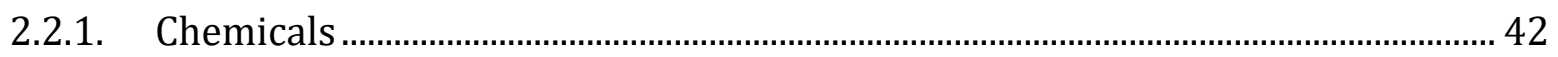

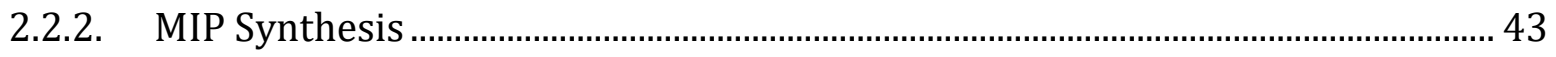

2.2.3. Point of Zero Charge and pH Study ........................................................................ 44

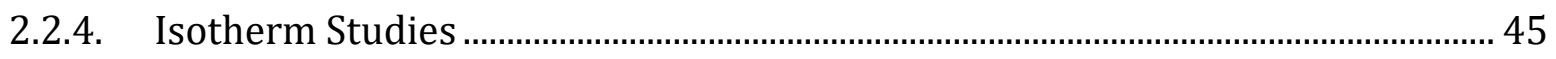

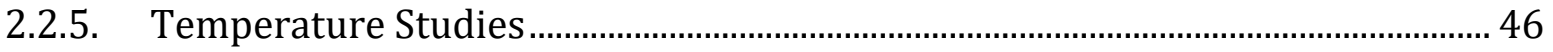

2.2.6. Kinetic Studies ……........................................................................................... 46

2.2.7. Interference and Partial-selectivity Studies............................................................... 47

2.2.7.1. Interference Studies.................................................................................. 47

2.2.7.2. Partial-Selectivity Studies ............................................................................. 47

2.2.8. Lake Water Study ………………….................................................................. 48

2.2.9. Biodegradability Studies ................................................................................... 48 


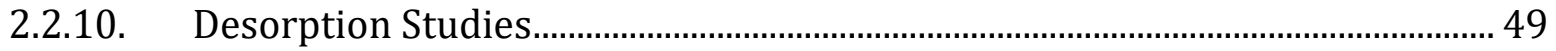

2.2.11. Phosphate, Nitrate, Sulfate, and Chloride Analysis ............................................. 50

2.2.12. Material Characterization …………………........................................................ 50

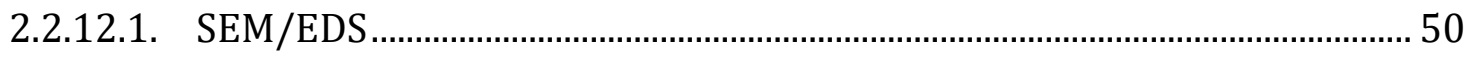

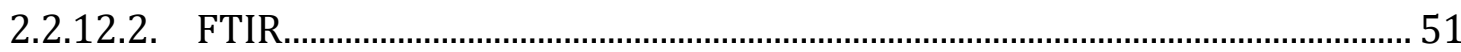

2.2.12.3. Swelling Studies, and Prediction of Porosity and Hydrated Diameter . 51

2.2.13. Statistical Analysis ………………………………………………………..... 52

2.3. Results and Discussion .......................................................................................... 53

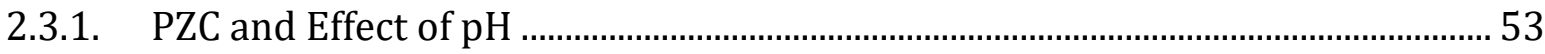

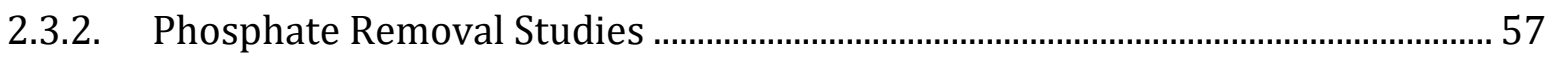

2.3.2.1. Sorption Capacity of Polymers......................................................................... 57

2.3.2.2. Interference Studies......................................................................................... 60

2.3.2.3. Effect from Increasing Template:Monomer Ratio........................................... 64

2.3.2.4. Removal from Low Concentration Phosphate from Lake Water............... 69

2.3.2.5. Influence from Temperature …………………………………………….... 70

2.3.3. Biochemical Availability and Potential for P Recovery ............................................ 71

2.3.3.1. Biodegradability …………………………………………………………….... 71

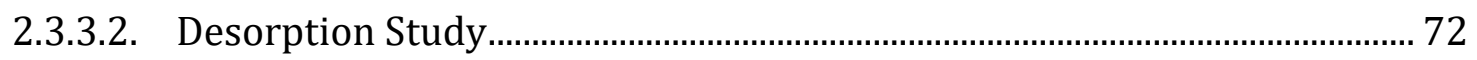

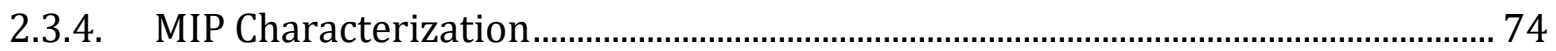

2.3.4.1. SEM/EDS Analysis ……………………………………………………….... 74

2.3.4.2. FTIR Spectroscopy ……………………………………………………...... 78

2.3.4.3. Swelling Studies, and Prediction of Porosity and Hydrated Diameter .... 81

2.3.5. Mechanism of Phosphate Removal .............................................................................. 81

2.3.5.1. Investigation of Partial-selectivity ………………………………………... 81

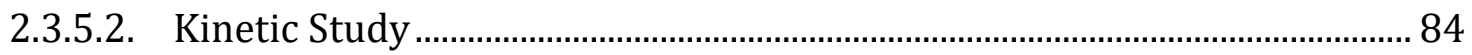




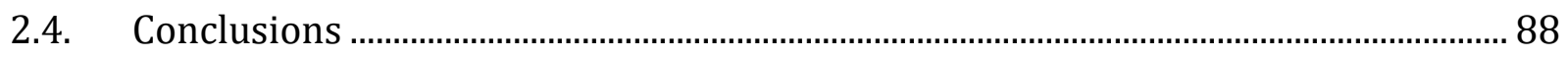

2.5. Significance and Future Perspective ………………………………………………...... 89

CHAPTER 3. SUMMARY OF WORK, CONCLUSIONS, AND FUTURE PERSPECTIVES ................ 91

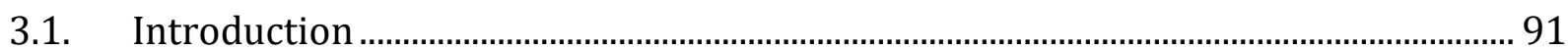

3.2. Evaluation of Several MIPs for P Removal ……………................................................. 92

3.3. Potential for P Recovery/Reuse with METAC MIPs ………………………………...... 92

3.4. P Removal Characteristics and Mechanism of Removal for METAC MIPs............... 93

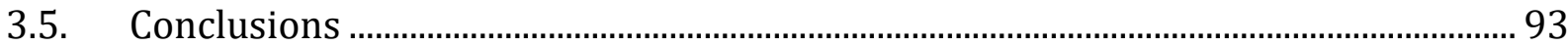

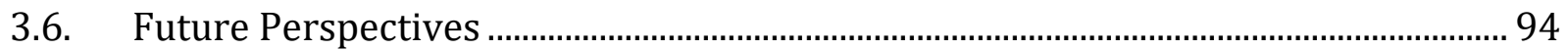

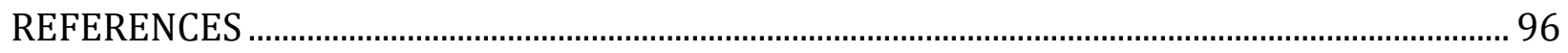

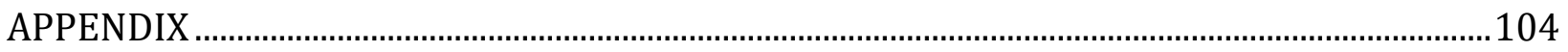

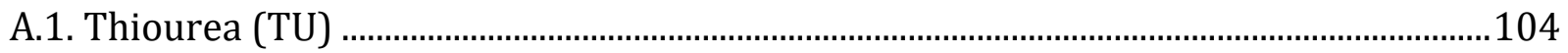

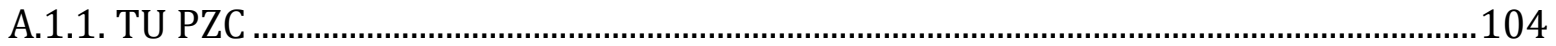

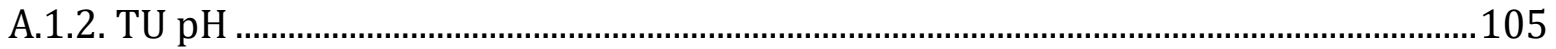

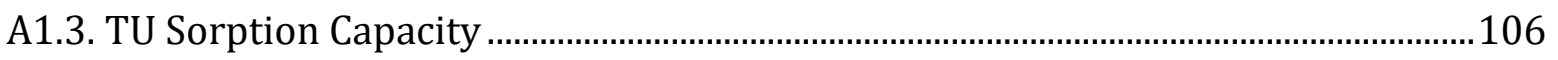

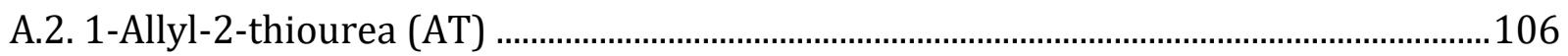

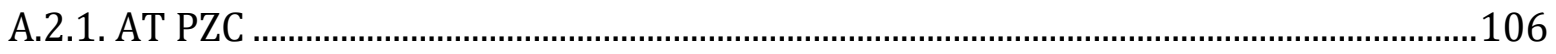

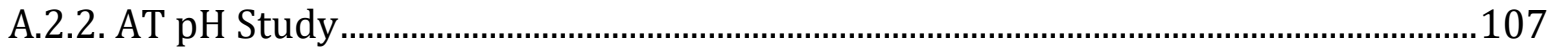

A.2.3. AT Sorption Capacity …………………………………………………………….... 108

A.2.4. AT Interference Study …………………………………………………………..... 109

A.2.5. AT Statistical Analysis ..............................................................................................

A.3. 2-Methacryloyloxyethyltrimethylammonium Chloride (METAC) ................................119

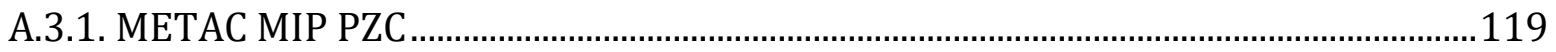

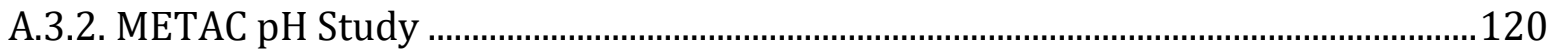

A.3.3. METAC Sorption Capacities (MN, MM, MM4, and MM12) ........................................120 
A.3.4. METAC Interference Study (MM, MM4, and MM12)..............................................123

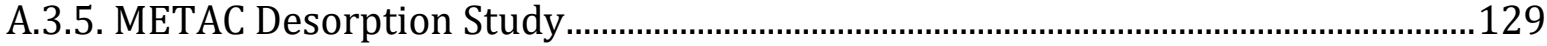

A.3.6. METAC Biodegradability Respirometer Data................................................................129

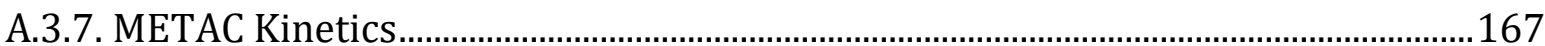

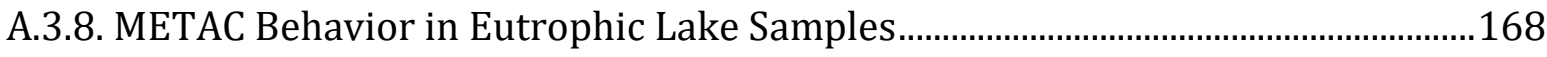

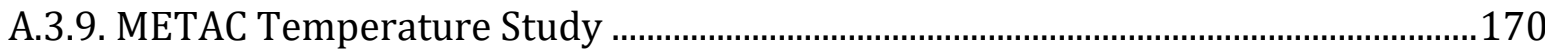

A.3.10. METAC Partial-Selectivity Study..............................................................................170

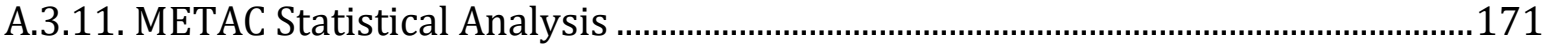




\section{LIST OF TABLES}

Table

1. Summary of P Management for Eutrophic Lakes ................................................................... 38

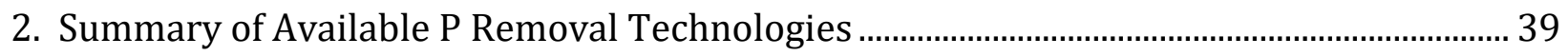

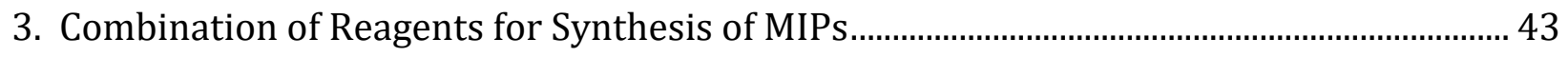

4. Components for METAC Reagent Mixtures with Various Template:Monomer

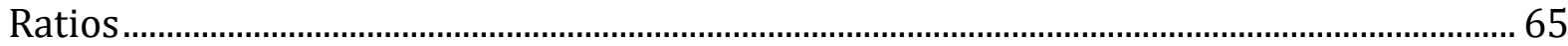

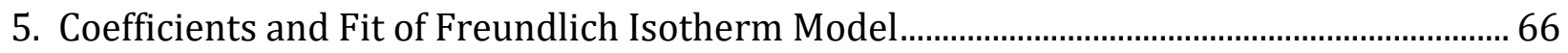

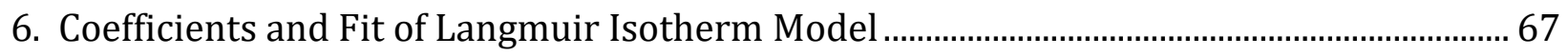

7. Swelling, Predicted Porosity, and Predicted Hydrated Diameter of Hydrated MM12 particles 


\section{LIST OF FIGURES}

Figure $\quad \underline{\text { Page }}$

1. PZC of TU MIP. The PZC was found to be 2.9 ……….......................................................... 54

2. PZC of AT MIP. The PZC was found to be 8.9.

3. PZC of METAC MIP. The PZC was found to be 10.9 …………………………………............. 55

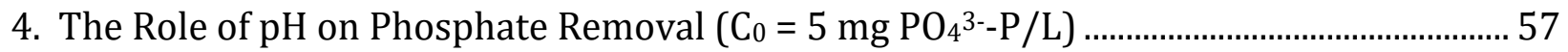

5. Sorption Capacities of TU NIP and MIP …………………………………………………….... 59

6. Sorption Capacities of AT NIP and MIP.................................................................................... 59

7. Sorption Capacities of METAC NIP and MIP ………………………………………………..... 60

8. Competition of Common Coexisting Anions and Compounds for Binding Sites

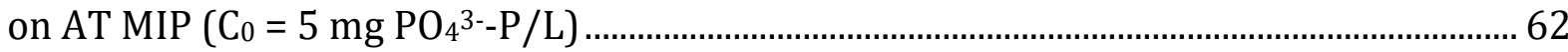

9. Competition of Common Coexisting Anions and Compounds for Binding Sites

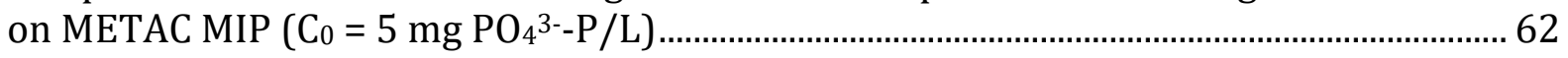

10. The Effect of Negative Charge Present in Solution on Phosphate Removal $\left(\mathrm{C}_{0}=5 \mathrm{mg} \mathrm{PO} 4^{3-}-\mathrm{P} / \mathrm{L}\right)$

11. The Effect of Negative Charge Present in Solution on Phosphate Removal by METAC MIPs with Varying Template:Monomer Ratios ( $\left.\mathrm{C}_{0}=5 \mathrm{mg} \mathrm{PO} 4^{3-} \mathrm{P} / \mathrm{L}\right)$ 66

12. Comparison of METAC Freundlich Isotherm Model with Varying Template:Monomer Ratios

13. Comparison of METAC Langmuir Isotherm Model with Varying Template:Monomer Ratios 68

14. Phosphate Removal from Select Minnesota Lakes with MM12 …………………………..... 70

15. Influence of Temperature on Phosphate Removal Efficiency with MM12 $\left(\mathrm{C}_{0}=5 \mathrm{mg} \mathrm{PO} 4^{3-}-\mathrm{P} / \mathrm{L}\right)$

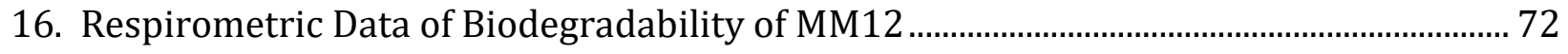

17. Phosphate Release from MM12 during Desorption Study ……………………………….... 74

18. Low-resolution SEM Characterization of MN (a), MM (b), MM4 (c), and MM12 (d). 
19. High-resolution SEM Characterization of MN (a), MM (b), MM4 (c),

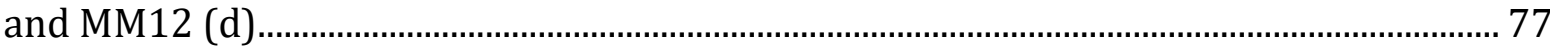

20. EDS Data from Analysis on Blank MM12 ……………………………………………………... 78

21. EDS Data from Analysis with Adsorbed Phosphate …………………………………………... 78

22. FTIR Spectra of MM12 during Different Phases of Life Cycle................................................ 80

23. Comparison of Sorption Capacities between Non-specific Binding

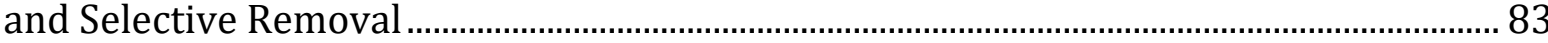

24. Phosphate Removal after Saturation of Electrostatic Attraction Sites ................................. 84

25. Assessment of MM12's Phosphate Removal Rate at Varying Initial Concentrations...... 85

26. Expected Phosphate Removal Rate Behavior of MM12 …………………………………..... 86

27. Hypothesized Electric Double Layer Phenomenon with MM12.......................................... 88 


\section{LIST OF SCHEMES}

Scheme

Page

1. Current non-sustainable phosphorus cycle in modern society (modified after (Desmidt et al., 2014))

2. Desired and sustainable phosphorus cycle for future societies

(modified after (Desmidt et al., 2014)) 17

3. Synthesis procedure for producing molecularly imprinted polymers (modified after (Wu, 2012)) 21

4. Chemical Reaction Scheme of METAC MIP Synthesis ................................................................ 43

5. Chemical Reaction Scheme of TU MIP Synthesis ……................................................................ 44

6. Chemical Reaction Scheme of AT MIP Synthesis...................................................................... 44

7. General MIP Synthesis Procedure............................................................................................... 44 


\section{LIST OF EQUATIONS}

Equation $\quad \underline{\text { Page }}$

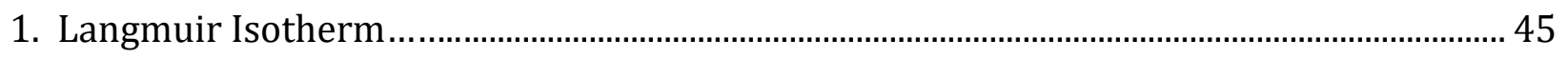

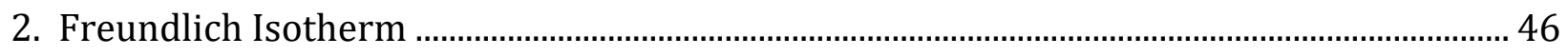

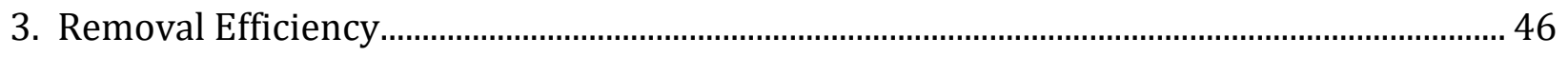

4. Percent Weight Change.................................................................................................. 52

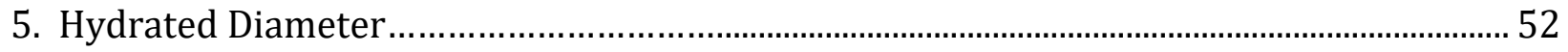

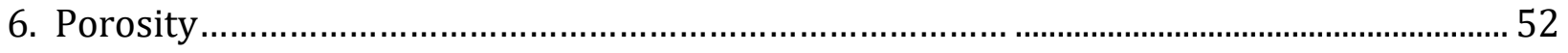




\section{LIST OF APPENDIX TABLES}

Table

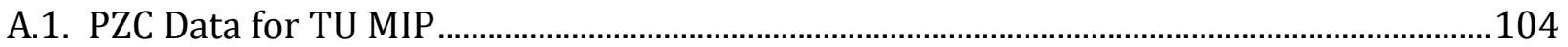

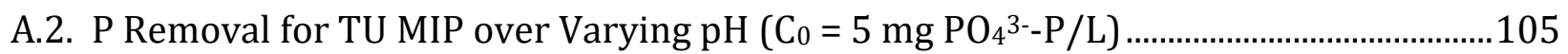

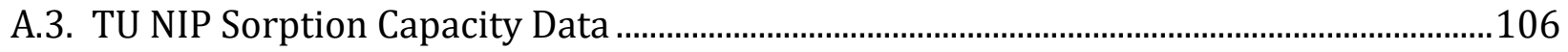

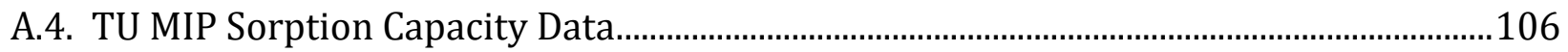

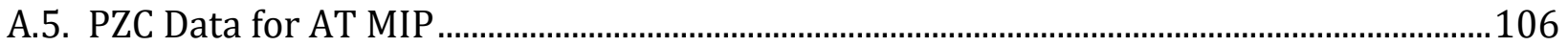

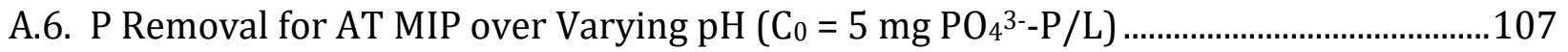

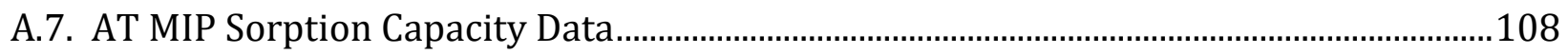

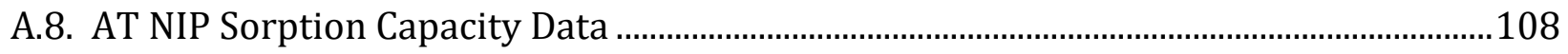

A.9. P Removal by AT MIP amongst Competing Anions $\left(\mathrm{C}_{0}=5 \mathrm{mg} \mathrm{PO}_{4}{ }^{3-}-\mathrm{P} / \mathrm{L}\right)$.....................109

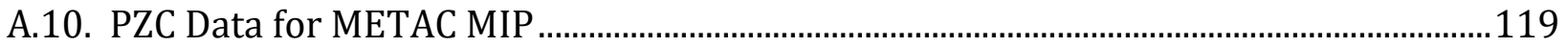

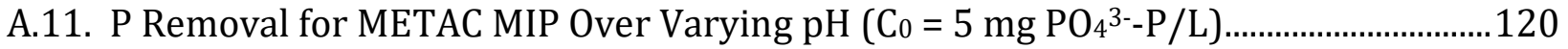

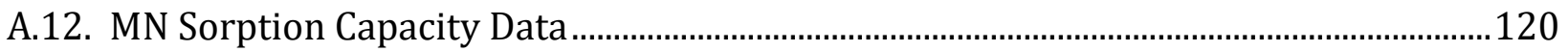

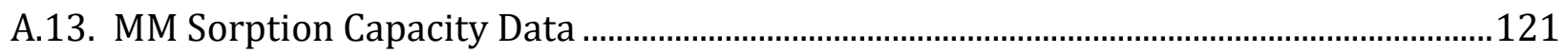

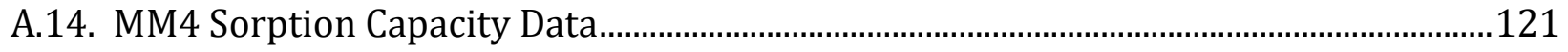

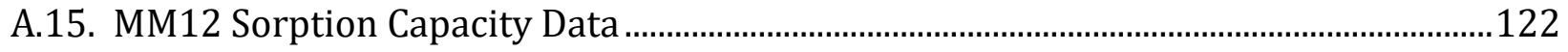

A.16. P Removal by MM Amongst Competing Anions ( $\left.\mathrm{C}_{0}=5 \mathrm{mg} \mathrm{PO}_{4}{ }^{3-}-\mathrm{P} / \mathrm{L}\right) \ldots \ldots \ldots \ldots \ldots \ldots \ldots \ldots . . . .123$

A.17. P Removal of METAC MIPs in the presence of various competing charges $\left(\mathrm{C}_{0}=5 \mathrm{mg} \mathrm{PO} 4^{3--\mathrm{P} / \mathrm{L})}\right.$

A.18. Desorption of P from MM12 Over Six Time-Variable Cycles ..........................................129

A.19. BOD of Blank and Sample with $100 \mathrm{mg}$ MM12 …............................................................129

A.20. P Removal by MM12 over Varying Times of Exposure ........................................................167

A.21. P Removal by MM12 from Eutrophic Lakes and Low Conc. Synthetic Lab Water .....168

A.22. P Removal Data by MM12 Under Varying Temperature Conditions..............................170 
A.23. Anion Removal by MM12 (Anion $\mathrm{C}_{0}=110$ meq/L)......................................................170

A.24. $\mathrm{P}$ Removal by MM12 after Anion Saturation (Anion $\mathrm{C}_{0}=110 \mathrm{meq} / \mathrm{L}$ )

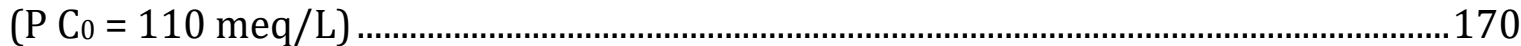




\section{CHAPTER 1. LITERATURE REVIEW}

\subsection{Introduction}

Phosphorus (P) is an element that has raised a lot of attention in research with its contradictory influences in the environment and agriculture. $\mathrm{P}$ is a nonmetal of the nitrogen group and is an essential macronutrient for all life on earth (Desmidt et al., 2014, You et al., 2015). $\mathrm{P}$ is primarily found as phosphate $\left(\mathrm{PO}_{4}{ }^{3-}\right)$ instead as a free element due to its high reactivity (Desmidt et al., 2014). The role P plays as an essential macronutrient gives it an extremely important role in agriculture. However, the supply of mineral $\mathrm{P}$ is finite and is concentrated in only a few countries (Rittmann et al., 2011). The varying control of P between countries could result in political strife as Morocco possesses dominant control over the Western Saharan reserves, being the largest in the world. China is already drastically reducing their exports of P to try and secure future domestic supply, the United States is estimated to have less than 30 years of domestic supply left, and Western Europe and India are already completely dependent upon P imports (Cordell et al., 2009). This mineral $P$ is mined as a phosphate rock, and it is predicted that deposits of this mineral will only last for another 60 - 240 years (Cornel and Schaum, 2009, USGS, 2012). The vast majority of mined phosphate rock around the globe is used in agricultural products or combined with sulphuric acid, nitrogen and potassium for fertilizer-based applications (Desmidt et al., 2014, Cordell et al., 2009). Currently, the world mines about 180 - 190 million tons of phosphate rock annually. Initial observations of trends in phosphate mining indicated that the peak amount of mined phosphate rock was reached in 2009. An upward trend has been expected to increase by $50-100 \%$ by 2050 with an 
increase in global food demand, changing population diets, and increased usage of plant derived biofuels (Desmidt et al., 2014, Cordell et al., 2009). At the current rate of mining alone, existing phosphate rock reserves would be fully depleted in approximately 369 years (time approximation based on adjusted value reported (Desmidt et al., 2014)). As production and demand continue to increase, the estimated period will likely be less than 369 years. With over 800 million people without sufficient access to food, ensuring food security is considered a global priority (UN, 2000, 2005). Reduction in fertilizer supply can result in reduced crop yields, which will make it impossible to meet the world's increasing food demands (Desmidt et al., 2014). Conservative analysis done by Cordell et al. (2009) predicts that the peak in global P production could occur by 2033. A peak in P production does not mean complete depletion of supply, but it is indicative of the depletion of high quality and easily accessible reserves (Cordell et al., 2009). After this point, the quality of the remaining reserves becomes lower with harder accessibility, resulting in uneconomical mining and processing (Cordell et al., 2009). Along with an increasing demand for phosphate rock, the cost of mining phosphate rock is increasing due to the decline in the quality of phosphate rock present in easily accessible mines and extracting higher quality phosphate rock from deeper layers is relatively expensive (Desmidt et al., 2014).

While short supply of P can cause reduced crop productivity, excessive loading of $\mathrm{P}$ into surface waters can promote eutrophication of lakes, rivers, reservoirs, estuaries, and parts of the oceans (USEPA, 1983, 1998). Eutrophication is the process in which aquatic ecosystems experience an increase in the abundance of algae and aquatic plants. These organisms die after their life cycle is complete, allowing for microorganisms to degrade their remnants. This biodegradation results in the microorganisms consuming oxygen from 
the aquatic ecosystem and thus depleting oxygen from the rest of the water body. A lack in adequate levels of oxygen often leads to stress and death of important ecosystem components. Altered nutrient regimes are one of the many stressors leading to species endangerment and $\mathrm{P}$ is the key growth-limiting nutrient for algae in this eutrophication process, which leads to an overall degradation of precious water resources (Smith, 2003, Dodds et al., 2009). In fact (USEPA, 1996) reported that eutrophication accounted for nearly half of impaired lakes and 60\% of impaired river reaches within the United States. The intensive nature of agriculture to meet global food demands has led to an increase in fertilizer application on croplands to improve profitability. This intensification has been a major influence in the eutrophication rates of aquatic ecosystems as more than half a century of generous applications of $\mathrm{P}$ and nitrogen $(\mathrm{N})$ fertilizers has resulted in North American agricultural soils having surpassed 'critical' P levels (Smith, 2003, Cordell et al., 2009, McDowell et al., 2016). This overly nutrient-rich cannot contain much of the additional P which is applied annually (McDowell et al., 2016). Approximately $80 \%$ of mined P is used in agricultural fields, but only about $40 \%$ of what is applied is actually available for crops to uptake. The rest of the P, that is not immobilized in soil, results in Prich runoff and leads to impairment of surface water quality (Rittmann et al., 2011, USGS, 2010).

Eutrophication is not only extremely detrimental to aquatic ecosystems, but also to the economic well-being of communities. Lakes and rivers provide drinking water, recreation, and aesthetic benefits, all of which can be negatively influenced by eutrophication. Lakes contain up to $68 \%$ of the global liquid surface fresh water are essential for economic vitality and quality of life across the globe (Beeton, 2002). These 
water sources, which often support municipal water supplies, can exhibit an increase in the frequency and severity of potentially toxic cyanobacterial blooms under eutrophic conditions (Dodds et al., 2009). Toxic algal growth can lead to human health problems and is not aesthetically pleasing. Additionally, the detrimental effect of algal growth toward the surface water's viability as drinking water supply results in higher water treatment costs (Smith, 2003). Recreational use of such water bodies is reduced as angling and boating activities can be physically impeded while other water users are less likely to swim during heavy algal blooms due to health risks, unfavorable appearance, or unpleasant odors. Reduction in these recreational and aesthetic characteristics of the water body can also decrease shoreline property values. Combined losses due to freshwater eutrophication are approximately $\$ 2.2$ billion annually in the United States (Dodds et al., 2009). USGS (2010) found that of 190 streams studied in the United States, which are in agricultural and urban watersheds, 90 percent of them exceeded natural background levels ( $34 \mu \mathrm{g} / \mathrm{L})$ of orthophosphate and total phosphorus (TP). The streams in agricultural and urban areas were found to have a median TP concentration of $0.25 \mathrm{mg} / \mathrm{L}$, which is about 6 times greater than background levels. Two agricultural practices were found to significantly contribute to the transport of nutrients in streams within the United States. First, the prevalent use of tile drains and ditches in the Midwest, which help to drain clay-rich soils, facilitates the immediate transport of nutrients to streams. Secondly, the large amount of irrigationreturn flow contributes to the transport of nutrients. Most P entering surface waters comes via erosion and runoff from non-point sources (such as agricultural croplands and urban areas), and has been identified as the primary reason that approximately $52 \%$ of monitored rivers, lakes, and estuaries are not clean enough for recreational uses (USEPA, 
2015). However, point sources, such as wastewater effluent, have also been identified as significant contributors to excessive P loading and eutrophication in surface waters as approximately $8 \%$ of globally mined $\mathrm{P}$ is discharged from wastewater treatment plants (Rittmann et al., 2011). The P concentration discharged from wastewater effluent generally ranges from 5 - $10 \mathrm{mg} / \mathrm{L}$, which is far higher than the allowable level in surface waters. Concern about wastewater effluent causing rapid rates of eutrophication has resulted in the United States establishing a goal of regulating P limits in treated wastewater effluent to $10 \mu \mathrm{g} / \mathrm{L}$ by 2027 (Hansen, 2006). Reaching this goal will reduce point source pollution below excessive loading rates, allowing natural water bodies to self-regulate and maintain healthy ecosystems.

\subsection{Established P Reduction Plans and Technologies for Non-point and Point Sources, and in-situ Lake Remediation}

The problems associated with phosphate pollution have been long recognized by the United States and other countries, and there are established plans and technologies to mitigate them.

\subsubsection{Non-point Sources}

Non-point sources of $\mathrm{P}$ pollution are difficult to treat as they come from extended areas, and sometimes their sources are not clearly identified. Best Management Practices (BMPs) such as infiltration basins, rain gardens, constructed wetlands, and soil amendments are accepted methods of water pollution control for non-point sources. BMPs can be effective for non-point sources but cannot remove all of the $\mathrm{P}$ transported from an area. Additionally, some BMPs suffer from site-specific design restraints, low P capacity, and desorption/leaching of P (Perry et al., 2009, USDA, 2006, Robalds et al., 2015). 
Many states in the United States have begun to develop proactive means to reducing P loading by adopting Total Maximum Daily Loads (TMDLs) and the National Pollution Discharge Elimination System (NPDES) regulations. However, non-point sources such as agricultural runoff are exempt from NPDES programs and TMDL regulations. Policies and guidelines have been set by the United States Department of Agriculture (USDA) for nutrient management in agricultural areas. States generally customize their own approaches and procedures that vary from purely voluntary measures (nutrient management planning, soil testing, and conservation adoption) to more restrictive requirements. Voluntary efforts and fee paying schemes have been pushed by some states. Nevertheless, land use practice that leads to substantial losses of P into surface runoff still occur (McDowell, 2016). This wide range of flexibility makes non-point source P mitigation highly variable from state to state and an unreliable system for P removal in the United States.

\subsubsection{Point Sources}

On a regulatory level, TMDLs can be established for all point sources and may be enforceable. Specifically, a TMDL identifies the pollutant load reduction needed so that a waterbody can maintain water quality standards. NPDES is also viable for point source regulation with permits to limit $\mathrm{P}$ discharges from the sources (McDowell, 2016). The primary technologies that are currently used for removing P from point sources, such as wastewater, are chemical precipitation and biological remediation (Rittmann, 2011, Jenkins and Hermanowicz, 1991, Stensel, 1991, Pan et al., 2009). Chemical precipitation of P can be achieved through the addition of cations such as iron, aluminum, calcium, magnesium, or ammonium to produce a chemical sludge which is then removed from 
wastewater effluent and disposed in landfills (Rittmann et al., 2011). Biological remediation of $\mathrm{P}$ is an ecological approach which produces $\mathrm{P}$-containing biosolids as polyphosphate accumulating organisms (PAOs). These biosolids are removed from wastewater effluent and can be applied as a soil amendment for cropland or disposed in landfills (Oehmen et al., 2007, Rittmann et al., 2011, Ekama, 2015). These conventional methods tend to be technically difficult or economically unsustainable to meet increasingly stringent $\mathrm{P}$ discharge limits. Precipitation and biological methods for $\mathrm{P}$ removal are inadequate at reducing P concentrations below environmentally significant levels (100 $\mu \mathrm{g} / \mathrm{L}$ ) and only well-suited for high P concentration waste streams (Pan et al., 2009, Chouyyok et al., 2010, You et al., 2015). Other issues with these conventional methods involve sludge disposal/recovery problems, and sensitivity of the processes to P loading rates and temperature (Jenkins and Hermanowicz, 1991, Stensel, 1991).

\subsubsection{In-situ Lake Remediation}

Several methods for in-situ removal of P from lakes have been developed over the years. Some of the physico-chemical methods include sediment dredging, hypolimnetic withdrawal, hypolimnetic aeration, and phosphorus inactivation. Sediment dredging can remove internal nutrient loadings from lake systems, but it also destroys the sedimentwater interface which is known to play a key role in the stabilization of lake systems. This dredging acts as only a brief moment of relief as the lake can be reloaded with P over time from pre-existing external sources. Therefore, mitigation of pre-existing external P sources is necessary to achieve long-term desired effects with dredging (Jing et al., 2015). The hypolimnion is the lowest layer of water to come in contact with the sediment after lake stratification and it often contains the highest $\mathrm{P}$ concentration. Thus, treating or removing 
this layer of P-rich water through physical methods has been identified as a viable strategy for lake remediation. Hypolimnetic withdrawal and aeration have been practiced, however these hypolimnetic altering methods can be inefficient, cost prohibitive, or cause excessive disturbance to the ecosystem. Phosphorus inactivation is a common chemical restoration method. Phosphorus inactivation caps the P-rich sediment with a stable material that can bind with P. Alum is one of the most commonly used materials for this application. Issues with capping materials such as alum are its inefficiency over a wide range of $\mathrm{pH}$ and release of toxic materials via hydrolysis after long residence in water (Goldyn et al., 2014, Lewtas et al., 2016, Singh, 1982).

\subsection{Developing P Reduction Technologies}

\subsubsection{Waste By-products}

Waste by-products have been extensively investigated for P removal due to their great economic feasibility. They are low-cost materials which are typically easily acquirable and renewable. Their use can also reduce imminent disposal costs (Boyer et al., 2011). Examples of waste by-products used are cationized wood residues (Unnithan et al., 2002, Tshabalala et al., 2004, Karthikeyan et al., 2004), iron oxide tailings (Zeng et al., 2004), alum and ferric sludge (Babatunde and Zhao, 2010, Song et al., 2011), alkaline fly ash (Cheung and Venkitachalam, 2000), egg-shell waste (Yeddou Mezenner and Bensmaili, 2009), red mud (Huang et al., 2008), blast furnace slag (Oguz, 2004), and waste lime (Siobhan Dunets and Zheng, 2014, Ahn and Speece, 2010). Some concerns with these lowcost materials are that they are typically not homogenous, have a wide range of $\mathrm{P}$ removal efficiencies, and may cause undesirable secondary changes in water chemistry. 


\subsubsection{Ion and Ligand Exchangers}

Ion exchangers have been found to have extremely high P recovery potentials. Ion exchangers allow $\mathrm{P}$ to be recovered as calcium phosphate or struvite upon the addition of calcium nitrate or ammonium chloride and magnesium sulfate (Sengupta and Pandit, 2011). This recovered material has potential for reuse as fertilizer. Many researchers looked into developing fixed-bed processes for P removal due to their technical simplicity and adaptability to fluctuations in the composition and flow rates of effluent wastewater (Blaney et al., 2007). Polymeric materials were viewed as the optimal material for developing fixed-bed processes as they offer the desired durability and mechanical strength. However, commercially available anion exchangers still suffer from a lack of $\mathrm{P}$ selectivity, poor mechanical strength, low regeneration efficiency, and high cost. Some studies have reported the development of polymeric ligand exchangers (PLEs) which have shown very high P selectivity. Nevertheless, these PLEs require a chelating polymer which is cost prohibitive (Blaney et al., 2007, Choi et al., 2012). Research has also branched into incorporating nanoparticles (NPs) in anion exchangers for P removal due to the extremely high surface area to volume ratio that NPs offer. These characteristics can produce fast kinetics and enhanced sorption capacity. While these nano-based anion exchangers were shown to be highly regenerable, they suffered from poor P selectivity. NPs are not suitable for direct application in fixed-bed columns due to their poor durability, agglomeration, and contribution toward excessive pressure drop across the column (Sarkar et al., 2011).

\subsubsection{Membranes}

Membrane technology has also been studied for P removal from wastewater. P removal using membrane bioreactors (MBRs) and reverse osmosis/nanofiltration (RO/NF) 
membrane systems are the predominant methods so far studied (Park et al., 2017, Luo et al., 2016, Dolar et al., 2011). MBRs are a promising technology as they have a small physical footprint and high biomass retention (Park et al., 2017). MBRs showed to recover P from permeate as amorphous calcium phosphates under high $\mathrm{pH}$. However, a common issue with membrane use in wastewater is its tendency to foul with an excessive build-up of organic matter and ammonia in the draw solution. This fouling extremely limited the MBR's efficiency when removing P (Luo et al., 2016). Additionally, MBRs long solids retention time with large quantities of biomass reduces effective P control as P removal primarily relies on sludge waste (Park et al., 2017). RO/NF treatment also showed high retention of fluoride and phosphate ions, but also faced the same complications as previously discussed with MBRs (Dolar et al., 2011).

\subsubsection{Adsorbents}

Adsorption-based processes have been among the most heavily studied for $\mathrm{P}$ removal. Adsorption refers to the transfer of liquid-phase solutes to solid-phase adsorbents (Crittenden, 2005). P separation by adsorption during coagulation, followed by removal through sedimentation and filtration was first used in the 1950s and has since been applied to treat water and wastewater using a variety of sorbents (Rittmann et al., 2011).

Adsorption processes have advantages over other techniques in terms of infrastructure cost, modular design, simplified technological design, higher P removal rates, and low-cost operation (Sowmya and Meenakshi, 2014, Pan et al., 2009, Chouyyok et al., 2010). Though there are many characteristics that make adsorption processes highly beneficial, cost effectiveness is identified as the primary criterion in the selection of an adsorption technology for P removal (Mishra, 2010). Adsorption processes regulate the mobility of 
aqueous anions by competing with coexisting anions for the adsorbent surface binding sites. The capacity of adsorbents depends on the number active binding sites, surface areato-volume ratio and porosity (Nthumbi et al., 2012). Many adsorbents, both polymeric and non-polymeric, incorporate immobilized metals because they can develop inner-sphere complexes with phosphate. In fact, formation of inner-sphere complexes between transition metals and anions is more preferential toward phosphate than other inorganic anions (Zhu and Jyo, 2005). While this does not give transition metals explicit selectivity toward P removal, it does allow them to overcome some interference issues with coexisting anions.

\subsubsection{Non-polymeric Adsorbents}

There is a wide sampling range of non-polymeric adsorbents. Hydrated ferric oxides (Pan et al., 2009, You et al., 2015, You et al., 2016), magnetic-based adsorbents (Janos et al., 2013, Lai et al., 2016, de Vicente et al., 2011), layered double hydroxides (Das et al., 2006, Cheng et al., 2009), synthesized minerals (Peleka and Deliyanni, 2009, Chitrakar et al., 2006), hydroxides (Guan et al., 2006), modified clays (Copetti et al., 2016, Reitzel et al., 2013), modified biochars (Jung and Ahn, 2016, Li et al., 2016), oxides (Xie et al., 2015, Park et al., 2017), immobilized transition metals (Mahaninia and Wilson, 2015, An et al., 2014, Ogata et al., 2011, Liu and Zhang, 2015), and nanoparticles (Zheng et al., 2016, Chouyyok et al., 2010, You et al., 2016, Almeelbi and Bezbaruah, 2012, Lai et al., 2016) have been extensively studied for P removal. Many of these materials have shown high P selectivity, high P sorption capacity, environmentally benign, stable under a wide pH range, low cost, fast removal rate even at low $\mathrm{P}$ concentrations, or P recovery capabilities. 


\subsubsection{Polymeric Adsorbents}

In this section, polymeric adsorbents are defined as adsorbents where the polymer(s) are the responsible component for P removal. Polymeric adsorbents have garnered a lot of attention due to their advantageous properties. Polymeric adsorbents can remove low concentration $\mathrm{P}$ and are cost effective in terms of regeneration and disposal. Additionally, they can be easily modified to better fit varying applications (Kioussis and Kofinas, 2005a, 2005b, Mahaninia and Wilson, 2016). Polymeric adsorbents also tend to be non-toxic, environmentally stable, and require minimal effort or capital to prepare (Hammud et al., 2015).

Several studies developed hydrogels for P remediation from wastewater. Kioussis and Kofinas (2005a) developed a cross-linked cationic hydrogel which could bind to anions in contaminated slurries. Ionic polyamine hydrogels have also been developed to remove anions from wastewater and were found to have high sorption capacities. Gel morphology and formation were found to influence the cross-linking density/uniformity as well as the swelling response, which results in changes in their anion binding capacity (Kioussis and Kofinas, 2005b, Kofinas and Kioussis, 2003). Chitosan, a widely studied and well-known polymer, was shown to have a capacity for P adsorption after modification. A study conducted by Mahaninia and Wilson (2016) found that cross-linking chitosan with glutaraldehyde and epichlorohydrin at varying compositions introduced new functional groups to chitosan's surface which allowed it to remove P. This modified chitosan polymer was also found to remove P effectively in highly alkaline $\mathrm{pH}$ conditions, a feat which is often difficult to be found in other polymer adsorbents. Another study reported the copolymerization of chitosan with polyacrylamide to remove P. However, the resulting 
sorption capacity was too low to be considered feasible (Nthumbi et al., 2012). Electrostatic interactions and ion exchange are the believed modes of interaction between polymers such as chitosan and phosphate that contribute to adsorption. Another potential mechanism could be hydrogen bonding between the polar functional groups of chitosan with the donor-acceptor groups of phosphate (Mahaninia and Wilson, 2016). Polypyrrole is a polymer shown to have very high P sorption capacity, but its removal at concentrations below $10 \mathrm{mg} / \mathrm{L}$ were unproven (Hammud et al., 2015). Aminopolystyrene copolymerized with 4-amino-N-azobenzenesulfamide was another polymer shown to have an affinity toward P (Basargin et al., 2007).

\subsubsection{Limitations}

Many of the developing technologies have an abundance of potential for being viable options for P removal. However, none of these technologies currently succeed in meeting all of the desired criteria for an optimal P adsorbent such as:

- P selectivity

- P removal from concentrations below $100 \mu \mathrm{g} / \mathrm{L}$ in solution

- Cost effective

- Environmentally stable and benign
- High P sorption capacity

- Stable and effective over a wide range of $\mathrm{pH}$

- Fast removal rate

- $\quad$ P recoverability and reusability The most common setback holding these technologies from becoming industrially and commercially effective is P selectivity (Chitraka, 2006, Saha, 2009). Many of these technologies, such as ones that utilize transition metals, witness high P sorption capacities, but are not truly selective toward P as they also bind with many other anions. This lack of selectivity can lead to a reduction in $\mathrm{P}$ sorption capacity and overall interference with $\mathrm{P}$ 
removal from coexisting anions. Technologies that were selective toward P, such as PLEs, were far too expensive to be economically viable options (Blaney et al., 2007, Choi et al., 2012). Many technologies cannot remove $P$ below $100 \mu \mathrm{g} / \mathrm{L}$, which is the typical level of $P$ in eutrophic lakes. This is a significant issue as $50 \mu \mathrm{g} / \mathrm{L}$ has been identified as the level of $\mathrm{P}$ needed for which eutrophication can ignite (Smith, 2003). While these technologies can remove $\mathrm{P}$, many of them are not able to remove it in a recoverable form for reuse in fertilizer. The importance and current trend toward recoverability will be discussed further in the following section.

\subsection{Trend toward Sustainability}

As discussed in Section 1.1, P supplies are dwindling while demand is trending upward. Conventional approaches to finding new P supplies are to continue exploration for new phosphate rock mines and further intensify the exploitation of existing mines. This also includes expanding more into off-shore and low grade deposits. However, this approach fails to address the issue of the finite nature of phosphate rock reserves in the long term (Cordell et al., 2009). A primary goal toward solving this issue was identified as generating non-conventional P sources. Capturing P from municipal effluent, surface runoff, and other waste products have been recognized as the most viable means for reaching this goal (Rittmann et al., 2011, Cordell et al., 2009). In order to accomplish this, $\mathrm{P}$ removal technologies can no longer be optimized for just pollution prevention. The resultant product will need to be suitable for use in agriculture and other applications (Cordell et al., 2011). P removal only aims at obtaining a P-free effluent by transferring P to sludge or some other media for disposal. P recovery aims at obtaining a P-free effluent while producing a P-containing product that can be reused either in agriculture or in the $\mathrm{P}$ 
industry (Desmidt et al., 2014). Of late, P recovery from wastewater has been the P source to receive the most attention due to its higher relative concentration and ease of implementing technology changes/upgrades. However, eutrophic lakes are also being looked into as veritable sources for P recovery.

For $\mathrm{P}$ to be reusable, recovery methods must produce products that have $\mathrm{P}$ which is biochemically available to plants and preferably contains the appropriate nitrogen:phosphorus:potassium (N:P:K) ratio that is found in common fertilizers. Other parameters for successful recovery include the P-containing product to be non-odorous, socially acceptable, and logistically feasible for field application (Cordell et al., 2011). Metal phosphate salts, such as iron or aluminum, have been reported to be implausible for reuse in agriculture by virtue of being biochemically unavailable for plants under normal $\mathrm{pH}$ conditions (Desmidt et al., 2014). On the other hand, it has been reported by Almeelbi and Bezbaruah (2012) that iron phosphate salts formed from nanoscale zero-valent iron (NZVI) were in fact bioavailable to plants and even helped fortify plants that were deficient of iron. Therefore, it is still unclear as to whether or not recovery technologies which result in metal phosphate salts will be feasible for fertilizer reuse. Additionally, heavy metals and toxic organics which can be removed by non-selective technologies, such as transition metals, can be detrimental to plant health. This makes wastewater, which often contains these harmful contaminants, a questionable source for P recovery and reuse (Desmidt et al., 2014). Only technologies that selectively bind $\mathrm{P}$, and none of the potentially harmful contaminants, would be appropriate for use in wastewater. This selectivity is not as essential for removal from eutrophic lake water as they typically do not contain the same harmful contaminants. 
Further research is still required to determine the most sustainable means for recovering $\mathrm{P}$ and reusing the final product as a fertilizer. Such research needs to take into account life cycle costs, energy consumption, bioavailability, farmer accessibility, resource use, and potential pollution from the product (Cordell et al., 2011).

\subsection{Need Statement}

The phosphorus cycle in today's society (Scheme 1) is unsustainable. To develop a more sustainable cycle, P needs to be reclaimed from non-conventional sources and reused for agricultural and industrial applications (Scheme 2). There are other factors associated with the phosphorus cycle which need to be improved to develop a sustainable system, but recovery and reuse from surface waters has been identified as one of the methods to reduce human dependence on phosphate rock (Desmidt et al., 2014). In order to reach this goal, a technology must be developed that can successfully recover $\mathrm{P}$ from natural water bodies that will make $\mathrm{P}$ bioavailable for plants as fertilizer. Selective removal of $\mathrm{P}$ is necessary in order to make wastewater a usable source of P recovery.

Without selective removal, P recovered from wastewater runs the risk of having high associations with toxic heavy metals which tend to coexist in wastewater sources. The presence of those toxic metals would reduce the applicability of the recovered P to fertilizer application as they can have severely detrimental effects on overall plant growth and health. There are many coexisting constituents other than heavy metals found in wastewater and eutrophic lakes which, in large quantities, could also have detrimental effects on crops. Therefore, a technology with selective removal of $\mathrm{P}$ is ideal for producing a usable recovery product. Many of the technologies available (i.e. bioremediation, chemical precipitation, etc.) cannot remove $\mathrm{P}$ below levels which are commonly found in eutrophic 
lakes $(100 \mu \mathrm{g} / \mathrm{L})$. The lack of this capability not only makes it extremely difficult to restore the health of important surface waters, but it also eliminates another major source of recoverable $\mathrm{P}$ for reuse in fertilizer applications. In addition to these two innately important criteria for successful P recovery and reuse, the technology must have sorption capacities that are competitive enough to be considered economically justifiable for use. A sorption capacity of approximately $10-26 \mathrm{mg}$ P/g can be considered as competitive with many of the technologies currently available.

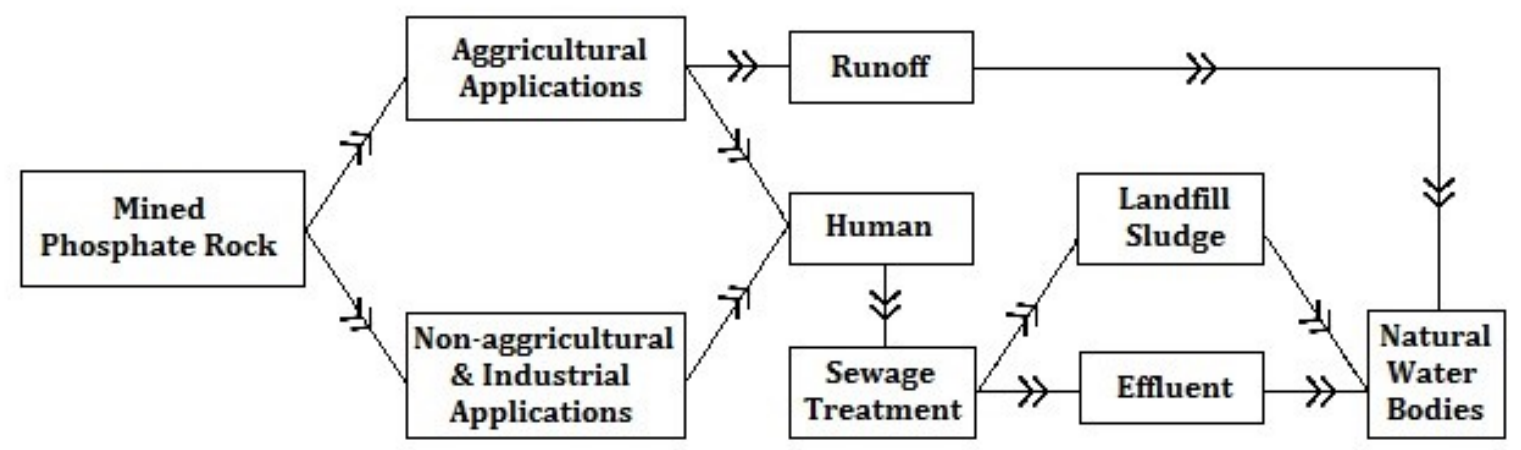

Scheme 1. Current non-sustainable phosphorus cycle in modern society (modified after (Desmidt et al., 2014))

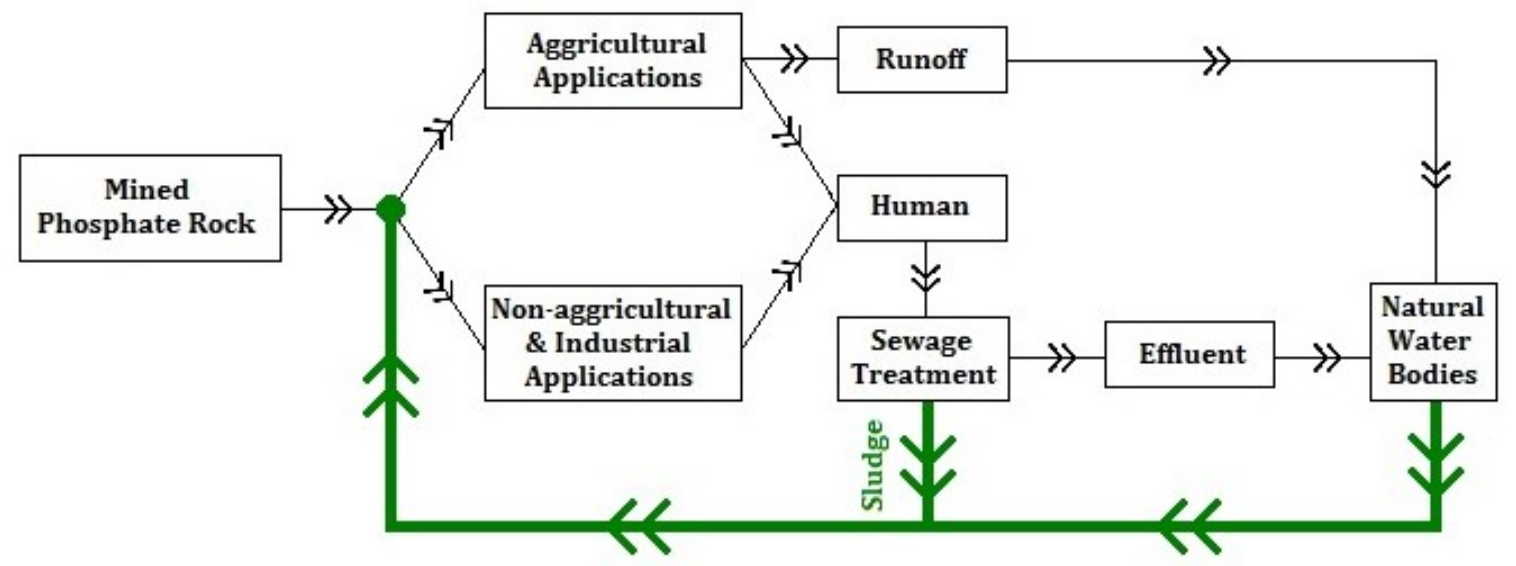

Scheme 2. Desired and sustainable phosphorus cycle for future societies (modified after (Desmidt et al., 2014)) 
The goal of this research was to assess the feasibility of using molecularly imprinted polymers as recoverable and reusable P sorbents. These polymers show potential to provide selective removal of $\mathrm{P}$ at environmentally significant concentrations. Further discussion on molecularly imprinted polymers can be seen in Section 1.6.

\subsection{Molecularly Imprinted Polymers}

Molecular imprinting technology (MIT) has been developed as a viable synthetic approach to design robust molecular recognition materials. The design of synthetic materials, which can mimic recognition processes found in nature, is a well-studied area of research in recent years. Molecularly imprinted polymers (MIPs) are versatile materials which have shown to be able to recognize both biological and chemical molecules. Some molecules that have been thoroughly studied for recognition with this technology are proteins, nucleotide derivatives, pollutants, drugs, and food. This has led to MIPs having promising applications in separation sciences and purification (Vasapollo et al., 2011, Khorami and Edrisi, 2010, Amut et al., 2010, Lee et al., 2010), solid phase extraction (Vasapollo et al., 2011, Bravo et al., 2007, Al-Degs et al., 2009, Alexiadou et al., 2008, Tse Sum Bui and Haupt, 2010, Ensing et al., 2002), chemical sensors (Vasapollo et al., 2011, Greene and Shimizu, 2005, Lakshmi et al., 2009), catalysis (Vasapollo et al., 2011), drug delivery (Vasapollo et al., 2011, Alvarez-Lorenzo and Concheiro, 2004), biological antibodies (Vasapollo et al., 2011), receptor systems (Vasapollo et al., 2011), and recently as adsorbents (Lee and Doong, 2012).

The main advantages of MIPs are their high selectivity and affinity for the target molecules, excellent environmental stability, low cost, and relative ease to design, synthesize, and modify (Vasapollo et al., 2011, Wu, 2012). Properties of MIPs that 
contribute to their excellent environmental stability are their high physical robustness, strength, and inertness towards acids, bases, metal ions, and organic solvents (Vasapollo et al., 2011). These properties are likely contributions from their tendencies to have much higher cross-link densities than most other polymers. For adsorption processes, selectivity has been identified as the primary means toward effectiveness of adsorbent products (Chitraka, 2006, Saha, 2009). However, many current technologies lack the necessary selective removal at low concentrations. This is likely due to the fact that as concentrations of $\mathrm{P}$ decrease, the number of matrix components that can potentially interfere with removal increase (Ensing et al., 2002). Thus, MIPs' selective recognition of molecules at extremely low concentrations is the foundation of their potential use as adsorbents for $\mathrm{P}$ removal.

\subsubsection{Fundamentals}

Creating a MIP is based on the formation of a complex between an analyte (commonly referred to as the template) and a functional monomer. In the presence of a large excess of cross-linking agent, a three-dimensional polymer network will form around the complex (Ramstrom and Mosbach, 1999). Removal of these imprinted molecules leaves cavities with a size, shape, and chemical functionality complimentary to those of the template (Tse Sum Bui and Haupt, 2010). The development of this synthetic receptor allows for MIPs to recognize the analyte of interest in solution and selectively remove it (Vasapollo et al., 2011). In this work, the template will be used as reference to the molecule used during the imprinting procedure. The term 'analyte' will be used in reference to the molecule targeted for removal (i.e. $\mathrm{PO}_{4}{ }^{3-}$ ) from aqueous solution. 


\subsubsection{Synthesis and Characteristics of MIPs}

There are two primary techniques for synthesizing MIPs (Scheme 3). The selection of the techniques depends on the nature of the pre-polymerization interactions between the template and the monomer. These techniques are self-assembly and preorganization.

The self-assembly approach, which was utilized in this research, uses non-covalent forces such as hydrogen bonds, Van der Waals forces, ion/hydrophobic interaction, and metal coordinations (Vasapollo et al., 2011, Beltran et al., 2010, Tom et al., 2012, Wu, 2012). The geometry and recognition of the cavities in the polymer matrix for this approach is determined by the size and shape of the anionic target molecule. The functional groups from the monomers that are attached to the polymer network provide the driving force to pull analytes into the imprinted cavities (Beltran et al., 2010). This non-covalent method allows for easy removal of the template/analyte and reversible binding during later use (Tom et al., 2012). The non-covalent self-assembly approach is the most frequently utilized technique for the preparation of MIPs due to the simplicity of complex formation and availability of functional monomers that can be used to interact with a wide variety of templates. The drawback of the non-covalent self-assembly technique is that tends to produce a lower binding affinity, kinetics, and capacity for the target analyte than MIPs synthesized using the pre-organized covalent approach (Vasapollo et al., 2011, Wu, 2012). Additionally, the monomer-template complexes in non-covalent MIPs are unstable. Thus, a heterogeneous distribution of the imprinted templates is found $(\mathrm{Wu}, 2012)$. 


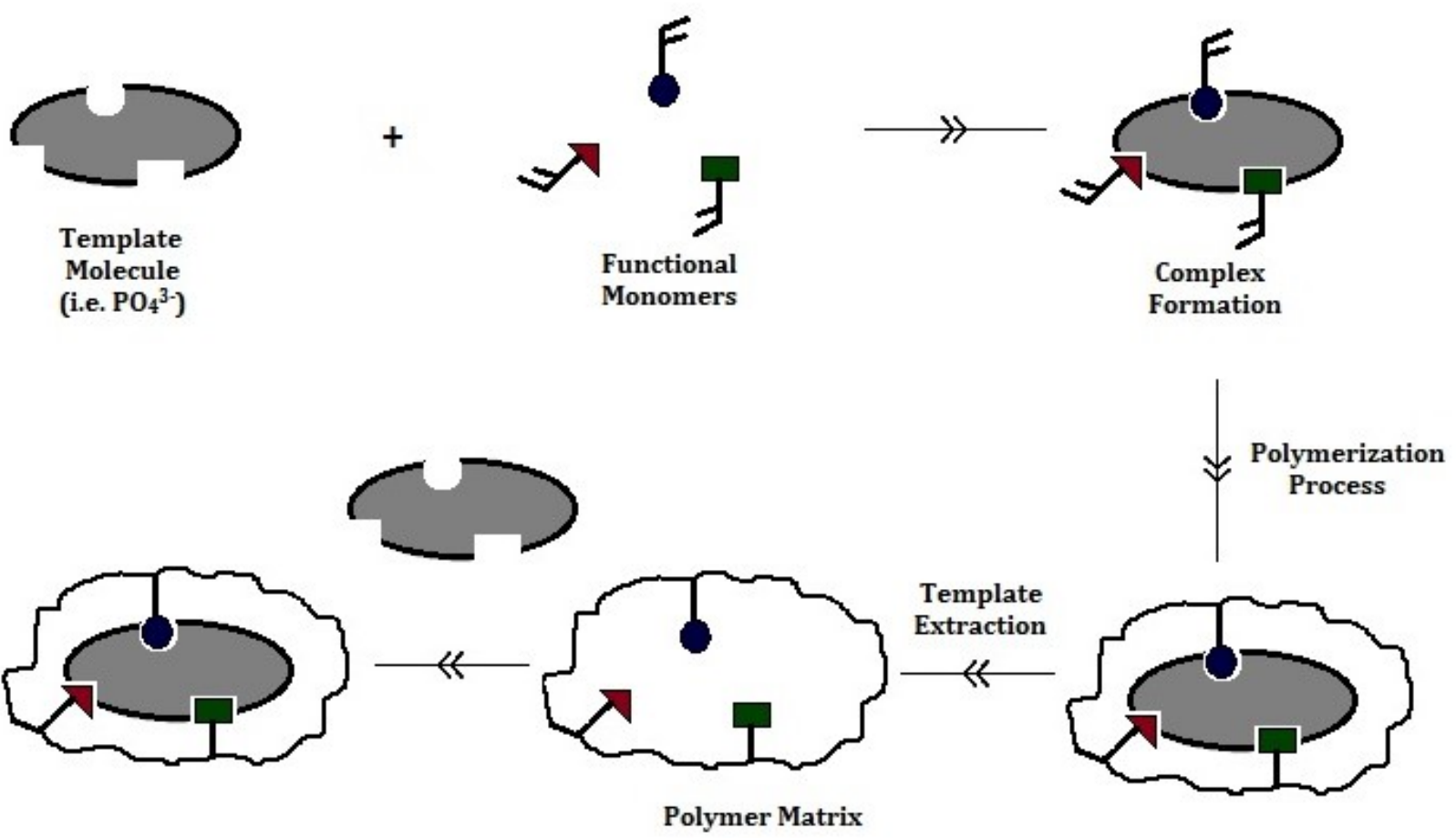

Scheme 3. Synthesis procedure for producing molecularly imprinted polymers (modified after $(W u, 2012))$

Free radical polymerization is employed as the most popular synthetic method in the preparation of MIPs. Synthesis is typically conducted under mild conditions (at atmospheric pressure with temperatures lower than $80^{\circ} \mathrm{C}$ ). Free radical polymerization is typically very rapid and tends to have great compatibility for a wide range of functional monomers and templates (Vasapollo et al., 2012, Wu, 2012). The synthesis conditions can play a major role on MIP properties. It has been reported that non-covalent MIPs synthesized with the free radical polymerization method have shown better selectivity and higher binding capacity when synthesized under lower temperatures (Wu, 2012).

Typically, researchers polymerize MIPs in bulk and then grind the resulting polymer. The polymer particles are then sieved into desired ranges according to their intended application. This method is so widely used because it is simplistic. However, 
grinding the particles is a tedious and time-consuming procedure which commonly results in particles of irregular shape and size (Vasapollo et al., 2011). Moreover, the grinding of these polymers results in the destruction of some recognition sites. The destruction of these recognition sites can lead to reduced analyte loading capacity (Vasapollo et al., 2011, $\mathrm{Wu}, 2012$ ). Alternative synthesis methods can prepare different MIP formats such as beads, membranes, in situ prepared monoliths, surface imprinting, and monolayers (Poma et al., 2010).

After synthesizing and grinding the MIPs, extraction of the template needs to be carried out to generate the cavities for analyte recognition. Extraction is typically performed by exhaustive washing through rinsing the MIP continuously with a solvent. Soxhlet extractors are commonly employed to achieve this continuous rinsing over periods of 16 - 48 hours. Although, it is well known that even after exhaustive washing steps, much of the original template will still remain in the polymer matrix (Vasapollo et al., 2011). This inefficient template extraction is due, in large, to the high cross-link nature of the polymer. Many of the template molecules become trapped in the polymer matrix, making them unreachable for solvent extraction. Without extraction, these recognition sites remain inaccessible for rebinding with the target analyte. Additionally, the relaxation of polymer chains and subsequent swelling of MIPs by solvent can also lead to the inaccessibility of some recognition sites ( $\mathrm{Wu}, 2012)$. Furthermore, not all of the recognition sites are selective. Some recognition sites in non-covalent MIPs are located outside of the cavities formed after extraction. These outside recognition sites tend to have non-specific binding (Rotello and Thayumanavan, 2008). This inefficiency in template extraction results in only 
$10-15 \%$ of the recognition sites being available for analyte rebinding (Sellegren and Shea, 1993).

\subsubsection{Role of MIP Components}

Some works have demonstrated that all components of the MIP (functional monomer, cross-linker, template, solvent, and initiator) play a significant role in affecting the template complexation (Karlsson et al., 2009, 0'Mahony et al., 2007). The important role that each component specifically plays will be discussed further herein.

\subsection{Functional Monomers}

The functional monomer is the most important and influential component of the MIP. To synthesize a MIP with stable complexes and selective recognition capabilities, the monomer must first be found to have good interactions with the template (Vasapollo et al., 2011, Beltran et al., 2010). In non-covalent MIPs, monomer-template complexes are governed by equilibrium, and monomers are usually applied in excess (compared to the template) to favor the formation of these complexes. The monomer:template molar ratio to generate optimal complex formation has generally been seen as 4:1. However, Tom et al., (2012) showed that the imprinting factor (IF), a measure of the amount of successfully generated recognition sites, for MIPs increased as the monomer:template molar ratio was increased to 6:1. In spite of this trend, a significantly higher molar ratio of 15:1 was shown to essentially eliminate the imprinting effect. Consequently, this lopsided ratio has led to varying complex configurations and affinities. Also, it is seen as the reason for heterogeneous distribution of binding sites (Vasapollo et al., 2011). One option to increase the selectivity of MIPs is to synthesize the functional monomer used according to the 
functionalities present in the target molecule. Doing so may provide extra interaction points between the monomer and template (Beltran et al., 2010).

\subsection{Cross-linking Agent}

In MIPs, the cross-linker also assumes important roles. The cross-linker is important in controlling the morphology of the polymer matrix, stabilizing the recognition sites, and imparting mechanical stability to the polymer. This allows the MIP to maintain its robust nature and recognition capability (Sellergren, 1999). High cross-link ratios have generally been used to generate macroporous materials with adequate mechanical stability. Ethyleneglycol dimethacrylate (EGDMA) and trimethylolpropane trimethacrylate (TRIM) tend to be among the most commonly utilized cross-linkers (Vasapollo et al., 2011). Previous researches have distinguished that cross-linkers largely influence physical characteristics of MIPs, but have little effect on the specific interactions between the monomer and template (Molinelli et al., 2005, Navarro-Villoslada et al., 2004, Shi et al., 2007). Contrarily, Tom et al. (2012) found that in the case of a sulfadimethoxine targeting MIP, reducing the amount of cross-linker in the pre-polymerization mix improved the IF.

\subsection{Template Molecule}

The template used for MIP synthesis is typically dictated by the analyte molecule being targeted for removal as they are generally one and the same. But, that is not always the case. In some cases, the target analyte is not compatible with one or more of the other components in the pre-polymerization mixture. Therefore, using the target analyte itself as the template molecule is futile as it will not result in the development of monomertemplate complexes. Nonetheless, MIPs can still be synthesized by using a close structural analogue of the analyte as the template. These templates are commonly referred to as 
'dummy templates.' These dummy templates have a close enough resemblance to the target analyte in shape, size, and chemical composition that it can generate very similar recognition cavities. These comparable recognition sites are also able to capture the target analyte, although it is not always as efficient (Maier et al., 2004, Rayane et al., 2008).

\subsection{Solvent}

The nature and volume of solvent also have a key role in the imprinting process. The solvent serves to bring all of the components together into one phase. Additionally, it is responsible for creating the pores throughout the polymer. Solvents commonly used for synthesizing MIPs are toluene, chloroform, dichloromethane, or acetonitrile. To be a practical solvent for MIP synthesis, the solvent must produce large pores to assure adequate flow-through properties. Increasing the volume of the solvent used in prepolymerization mixes increases the pore volume throughout the polymer. Solvents are commonly referred to as 'porogens' due to its influence on these properties (Vasapollo et al., 2011). In non-covalent MIPs, the solvent can play a major role in monomer-template interactions. Less polar solvents increase the complex formation, which facilitates polar interactions between the monomer and template such as hydrogen bonding. More polar solvents tend to dissociate the non-covalent interactions as they form hydrogen bonds with template and/or receptors, prohibiting the formation of monomer-template complexes (Vasapollo et al., 2011, Wu, 2012). However, it has been observed in several papers that successful imprinted polymers have been developed in polar solvents. These solvents are generally a combination of water and a less polar solvent like methanol or acetonitrile (Scorrano and Vasapollo, 2010). It has also been found that the rebinding process of MIPs 
functions optimally when the MIP is rebinding with target analytes in the same solvent that it was synthesized in (Vasapollo et al., 2011).

\subsection{Initiatiator}

The initiator does not play a very influential role in the polymerization process, but it is just as crucial a component as the rest. Small amounts of initiator $(0.2-5 \mathrm{wt} \%)$ kickstarts the polymerization reaction $(\mathrm{Wu}, 2012)$. Azo-initiators, such as N-N'-bis isobutyronitrile (AIBN), are commonly used to perform this role. The reactions is typically very rapid and can be initiated by thermal or photochemical sources (Vasapollo et al., 2011). Photo-initiation at low temperatures decreases the kinetic energy of the prepolymerization mixes, which has shown to increase complex stability and allow for better binding capacity and selectivity than thermal initiation. This is due, in large, to thermal initiation raising the kinetic energy of the pre-polymerization mix as it requires temperatures higher than $40^{\circ} \mathrm{C}$ (Puoci et al., 2007, Athikomrattanakul et al., 2009, Spivak et al., 1997).

\subsubsection{Optimization of Components}

Design of new MIPs requires a lot of time and effort for synthesis, washing, and testing. As can be seen from the discussion in Section 1.6.1.2, many of the components can generate different characteristics in MIPs after just being altered slightly. This requires many attempts to be made, by changing various parameters, to achieve optimum conditions (Vasapollo et al., 2011). In order to expedite this process, combinatorial chemistry can be applied (Lanza and Sellergren, 1999, Martin-Esteban and Tadeo, 2006, Dirion et al., 2003). Dirion et al. (2003) developed a high-throughput synthesis and screening (HTS) system in a 96-well plate format. This HTS system allows researchers to 
optimize recognition properties of MIPs in a short amount of time by the use of filter plates for rapid template removal and a multifunctional plater reader for parallel analysis of supernatant fractions (Vasapollo et al., 2011).

\subsubsection{Characterization of MIPs}

To begin developing MIPs for removal of specific analytes, knowledge on the formation of monomer-template complexes is often desired. UV-Vis, NMR, and theoretical models are often employed to investigate the potential formation of these complexes (Molinelli et al., 2005, Wei et al., 2007, Karlsson et al., 2009, Del Sole et al., 2009, Yañez et al., 2010, Pietrzyk et al., 2009, O'Mahony et al., 2007). Job's method, titration curves, and binding isotherms are methods currently being used to determine the nature of interactions, the complex coordination number, and the association constant (Vasapollo et al., 2011).

MIPs, themselves, are very difficult to characterize. Much of this difficulty arises from their insoluble nature. To determine their chemical composition, analytical methods such as solid-state NMR, elemental micro-analysis, and FTIR spectroscopy can be applied. In order to obtain their morphological characteristics, light microscopy and scanning electron microscopy (SEM) are commonly used (Del Sole et al., 2007, Cacho et al., 2004).

\subsubsection{Anionic Imprinting}

Cationic and neutral templates have been more extensively studied than the anionic templates (Bianchi and Bowman-James, 1997, Beer and Gale, 2001). Anionic molecules are larger in size than their cationic counterparts (Shannon, 1976), giving them a lower charge to radius ratio. This smaller ratio has limited the usefulness of anionic imprinting as the 
electrostatic interactions are far weaker than in cationic imprinting (Wu, 2012).

Additionally, the application of anionic imprinted polymers has been strained due to the $\mathrm{pH}$ sensitivity of anions. At low $\mathrm{pH}$, anions become protonated, resulting in a loss of their negative charge (Wu, 2012). A change in the charge of the analyte would make recognition by the MIP very difficult, or even impossible. Therefore, anionic imprinted polymers must be synthesized with the expected environmental $\mathrm{pH}$ range in mind. Generally the $\mathrm{pH}$ range cannot be large, therefore limiting the usefulness of anionic imprinted polymers. Synthesis of imprinted polymers with ionic moieties is termed ion-imprinted polymers (IIP).

However, most works can be seen defining their polymers as MIPs due to the tendencies of many works to revert to molecular analogues. While these analogues may not show the same selectivity, they are generally easier to imprint.

\subsubsection{Phosphate Imprinting}

$\mathrm{PO}_{4}{ }^{3-}$ is a tetrahedral anion which currently has not been studied extensively for imprinting technologies. Most examples involving phosphate are for organophosphorylated/organophosphonylated molecules, not phosphate itself $(\mathrm{Wu}, 2012$, Wu et al., 2008). Furthermore, almost all of the work done on phosphate recognition with imprinting technologies has had sensor application in mind, not recoverable adsorbents.

Some of the complexities involved in developing MIPs with effective recognition of phosphate, which may explain a general want of available research, may arise from the physical and chemical nature of the molecule. Phosphate is a relatively large oxyanion. While this may cause some issues with the charge to radius ratio, as discussed before, there are more issues with selective recognition of $\mathrm{PO}_{4}^{3-}$ over other oxyanions similar in shape and size, such as sulfate ( $\mathrm{SO}_{4}^{2-}$ ) (Katayev, 2006). Additionally, phosphate is not soluble in 
non-polar organic solvents. This lack of solubility in organic solvents greatly limits the range of components that can be used to directly imprint phosphate. However, some works have managed around these traits to develop imprinted polymers for phosphate recognition.

(Özkütük et al., 2008) was one of few reported works to develop a phosphate IIP and look into its application as an adsorbent. To achieve this feat, Özkütük et al. (2008) first synthesized a monomer, Fe(III)-chitosan-succinate, which could dissolve in water while also maintaining groups that could develop a complex with the phosphate anion. After phosphate anions were mixed and allowed to form complexes with Fe(III), the metalchelate polymer was then cross-linked with epichlorohydrin to form the polymer matrix. After removal of the template from the polymer matrix, this polymer showed a relatively low sorption capacity of approximately $11 \mathrm{mg} \mathrm{P} / \mathrm{g}$ polymer. The non-imprinted polymer (NIP), acting as the control, had the same sorption capacity and characteristics as the IIP. This leads to the belief that the mechanism of removal was not from selective recognition sites, but more likely from the Fe(III)'s electronegativity. Preferential removal of phosphate over other anions was observed; this is likely attributed to phosphates stronger affinity to form inner-sphere complexes with transition metals than other anions. When rinsed with a high $\mathrm{pH}$ solution $(\mathrm{KOH})$, the bound phosphate anions desorbed efficiently resulting in a sorption capacity decrease of only $1 \%$ after seven repeated adsorption-desorption cycles. Instead of investigating the potential to recover $\mathrm{P}$ by directly applying the metal-chelate polymer into fertilizer, this work was more concerned with the reusability of the polymer sorbent. 
The Kugimiya group has been the most prominent group in the development of imprinted polymers for phosphate recognition. As opposed to the last discussed work, this group has been developing MIPs for recognition of phosphate with the use of structurally similar analogue molecules for templates. 1-Allyl-2-thiourea (AT) was the group's primary monomer studied for the selective removal of phosphate as it has been seen that thiourea groups have a strong binding affinity to phosphate (Nishizawa et al., 1999, Aoki et al., 2003). Their studies reported that when $40 \mathrm{mg}$ of polymer was applied, the amount of phosphate bound to the imprinted polymer was reported as nearly $90 \%$ compared to the non-imprinted polymer which showed a phosphate binding of only $4 \%$ (at $25 \mu \mathrm{M} \mathrm{PO}_{4}{ }^{3}$ ). However, when studying the interaction of the monomer with other anions, they also found strong interactions. While an explicit interference study with competing anions was not conducted, it can be assumed that interference would be present (Kugimiya and Takei, 2006, 2007, 2008, Kugimiya and Babe, 2011). The Kugimiya group also attempted to develop their own monomer for MIP phosphate recognition. In their work, the group also tried applying methacrylic acid and N-methyl-N'-(4-vinylphenyl)-thiourea as functional monomers for MIP phosphate recognition. However, both of these monomers showed little to no phosphate binding activity (Kugimiya and Takei, 2006). Additionally, one work investigated the effectiveness of using different structural analogues for phosphate templating (phenylphosphonic acid and diphenylphosphate). This work showed that phenylphosphonic acid imprinting resulted in better phosphate recognition (Kugimiya and Takei, 2006). This superior recognition is likely due to the fact that phenylphosphonic acid is more closely related to phosphate than is diphenyl phosphate. Phenylphosphonic acid maintains essentially the same structure as phosphate except with one oxygen atom 
replaced with a benzene ring. Diphenyl phosphate is the same way except it replaces two oxygen atoms with benzene rings.

Work done by Warwick et al. introduced some new potential monomers for MIP phosphate recognition with the goal of sensor development in mind. In this work, computational modeling was performed using the molecular modelling software program CentOS Linux-based hardware, SYBYL, version 7.3 (Tripos International, 2006). Over 30 functional monomers were screened using this computational modeling. Four monomers, allylamine, 2-(diethylamino)ethylmethacrylate (DEAEM), 2methacryloyloxyethyltrimethylammonium chloride (METAC), and N-phenylethylene diamine methacrylamide (NPEDMA) were selected from the screening for further study. Warwick et al. selected thiourea as a control, citing its thorough study from the Kugimiya group. However, this appears to be a clear misunderstanding as the Kugimiya group thoroughly studied 1-Allyl-2-thiourea (AT), which simply contains a thiourea group. Therefore, the report from this study stating thiourea as a control for comparison from previous works is erroneous. Accordingly, the analytical comparison between the sorption capacities of the thiourea MIP and AT MIP, reported by Warwick et al., is a fallacy. Nevertheless, the data acquired on the reported polymers appears to be reliable and valid. Allylamine, DEAEM, and NPEDMA all had removal efficiencies that were nearly identical between their imprinted and non-imprinted versions. This showed that removal did not result from imprinting, but merely from electrostatic interactions of the polymers with phosphate. The imprinted and non-imprinted forms of METAC showed to each remove $100 \%$ of $\mathrm{P}$ from solution $(0.78 \mathrm{mg} \mathrm{P} / \mathrm{L})$. Thus, it is unknown from this report as to whether imprinting occurred or not. Lastly, the thiourea imprinted polymer showed to bind $22 \%$ of 
the phosphate, while the non-imprinted polymer (NIP) only bound 1\%. This was, however, not entirely convincing of thiourea's ability to be effectively imprinted as the thiourea MIP deviated largely from the mean (Warwick et al., 2014a).

A later work conducted by Warwick et al. examined the effectiveness of varying cross-linkers on the successful imprinting phosphate analogues and recognition of phosphate anions for sensor development. Commonly used cross-linkers diethyleneglycol diacrylate (DEGDA), ethylene glycol dimethacrylate (EGDMA), tetra(ethylene glycol) diacrylate (TTEGDA), N,N'-methylenebis(acrylamide) (Bisacrylamide), and trimethylolpropane trimethacrylate (TRIM) were compared. Of these cross-linking reagents, EGDMA was found to be the most effective cross-linker for developing phosphate recognition sites while bisacrylamide was a close second. This was described to be a likely result of the physical characteristics of EGDMA and phosphate. Phosphate and its structural analogues are relatively small templates for imprinting. Imprinting such a template will thus result in small cavities. Therefore, it was deemed that shortest cross-linkers, such as EGDMA and bisacrylamide, would likely be more appropriate to enhance the rigidity of the polymeric matrix and uphold the integrity of the recognition sites (Warwick et al., 2014b). It seems reasonable that maintaining more active recognition sites would lead to higher $\mathrm{P}$ removal, and the data backing this explanation appears to act as validation.

Some other studies have worked on imprinting phosphate containing molecules. While this is not directly impacting the area of research for phosphate sensing/removal with MIPs, it has provided some valuable information which may influence future MIP development. For instance, it was thought that the use of multifunctional monomers in MIPs may lead to some problems for selective removal of analytes. Using multifunctional 
monomers creates more interaction points around the monomer:template complex, which is good for selective recognition. However, having these multifunctionalities may also increase the number and the binding affinity of untemplated binding sites such as those formed in NIPs due to the preorganization of the functional groups. These background sites would typically have lower selectivity and would compete with more selective recognition sites, thus diminishing the magnitude of the imprinting effect and the overall selectivity of the polymer (Alexandratos, 2004, Filby, 2006, Weck, 2007). This potential problem for phosphate binding MIPs was studied by (Wu et al., 2008). In contrary to the potential problem at hand, Wu et al. (2008) showed that phosphate binding MIPs prepared with multifunctional monomers actually exhibited better binding capacity and selectivity than MIPs prepared with monofunctional monomers. While this work was focused on organophosphates, it still provides evidence to suggest that MIPs developed for specifically targeting orthophosphates will exhibit increased efficiency with multifunctional monomers.

\subsection{Research Objectives}

With society trending toward more sustainable methods to utilize crucial resources, more advanced technologies are needed to achieve these goals. For P specifically, new sources need to be exploited to reduce the pressure on natural and finite sources of phosphate rock. Surface waters, which serve as a typical landing point for P from wastewater effluent or that which is not uptaken by agricultural plants, serve to act as a reasonable alternative. In tandem to generating new recoverable P sources from surface waters, the health of economically significant lakes could be restored; thus, saving billions for the United States and other countries annually. Currently established technologies do 
not contain all of the essential characteristics needed for enlisting a completely effective $\mathrm{P}$ adsorbent. Technologies most commonly lack one or more of the following characteristics: (1) effective removal at environmentally relevant concentrations of $100 \mu \mathrm{g} P / \mathrm{L}$ or lower, (2) selective removal of P amongst coexisting constituents, (3) cost-efficiency, and (4) recoverability of a useful P product for reuse in agriculture. Molecularly imprinted polymers (MIPs) serve as a potential vehicle for meeting all of these desired traits. MIPs developed for phosphate recognition (sensors) have shown to work for concentrations below $100 \mu \mathrm{g} \mathrm{P} / \mathrm{L}$. These polymers are also known for high analyte selectivity due to their specific recognition sites. Additionally, MIPs are generally biodegradable polymers. While they can typically be biodegraded, their robust physical nature is expected to maintain their physical structure and recognition site integrity while in the field. This study focused on three MIPs found in literature that were previously studied only for P sensing. The selection of these MIPs was based on the presence of potential imprinting effect. The three MIPs were then assessed to see if MIT could be a feasible technology for P removal and recovery. Sorption capacities were studied to determine whether or not these MIPs could be competitive when compared to currently available technologies. Several experiments were conducted to understand the selective nature of the MIPs and the mechanisms of $\mathrm{P}$ release/removal. The goal was to understand the MIPs' behavior under typical environment conditions so that predictions could be made as to how these polymers function as sorbents and how to overcome potential limitations in the future. 


\section{CHAPTER 2. ASSESSMENT OF MOLECULARLY IMPRINTED}

\section{POLYMERS AS SUSTAINABLE PHOSPHATE SORBENTS}

\subsection{Introduction}

The role phosphorus (P) plays as an essential macronutrient in plants is extremely important. P is also extremely important for microorganisms. However, the supply of mineral P is finite and it is predicted that deposits of this mineral will only last for another 60 - 240 years (Cornel and Schaum, 2009, USGS, 2012). The vast majority of mined phosphate rock around the globe is used in agricultural products such as fertilizers to increase crop production and meet food demands of the global population (Desmidt et al., 2014, Cordell et al., 2009). As the global population continues to grow, demand for Pcontaining fertilizer will increase to maintain sufficient crop yields and sustain global food security (UN, 2000, 2005). Along with an increasing demand for $\mathrm{P}$, the cost of mining phosphate rock is increasing due to the decline in the quality of deposits (Desmidt et al., 2014).

While being innately important in agriculture and global food sustainability, $\mathrm{P}$ has more complications than just being a nonrenewable resource; excessive loading of $\mathrm{P}$ into surface waters can promote eutrophication of lakes, rivers, reservoirs, estuaries, and parts of the oceans (USEPA, 1983, 1998). P is the key growth-limiting nutrient for algae in the eutrophication process, which leads to an overall degradation of precious water resources (Smith, 2003, Dodds et al., 2009). Eutrophication is not only extremely detrimental to aquatic ecosystems, but also to the economic well-being of communities. Lakes and rivers provide drinking water, recreation, and aesthetic benefits, and all of these can be negatively 
influenced by eutrophication (Beeton, 2002). Combined costs of freshwater eutrophication due to these effects were estimated at approximately $\$ 2.2$ billion annually in the United States (Smith, 2003). Recovering P from surface water for its reuse in agricultural applications has been identified as a means to establish renewable P sources while also restoring surface waters to acceptable (non-eutrophic, $<50 \mu \mathrm{g} / \mathrm{L}$ ) P limits (Rittmann et al., 2011, Cordell et al., 2009, 2011).

Methods such as sediment dredging, hypolimnetic withdrawal, hypolimnetic aeration, and $\mathrm{P}$ inactivation are a few techniques currently used for P remediation from surface water. Dredging and hypolimnetic withdrawal/aeration techniques typically only provide temporary relief and can cause excessive disturbance to lake ecosystems. Additionally, they are often cost inefficient. P inactivation is a commonly applied chemical restoration method. Alum is one of the most commonly used materials for this application, but it is ineffective over a wide $\mathrm{pH}$ range and thus needing $\mathrm{pH}$ adjustments; furthermore, it can release toxic materials after long exposure to hydrolysis (Goldyn et al., 2014, Lewtas et al., 2016, Singh, 1982). The technologies that are the most well-established and utilized for P removal from aqueous media are chemical precipitation and biological remediation (Rittmann et al., 2011, Jenkins and Hermanowicz, 1991, Stensel, 1991, Pan et al., 2009). These technologies are chiefly designated for removal of $\mathrm{P}$ from wastewater but are technically challenging and not cost effective to meet the increasingly stringent $\mathrm{P}$ discharge goals. These techniques are also inadequate at reducing $\mathrm{P}$ concentration when present in environmentally significant levels of $100 \mu \mathrm{g} / \mathrm{L}$ or less (Pan et al., 2009, Chouyyok et al., 2010, You et al., 2016). Other technologies which have been developed for P removal from aqueous media include waste by-products (i.e. cationized wood residues (Unnithan et al., 
2002, Tshabalala et al., 2004, Karthikeyan et al., 2004), iron oxide tailings (Zeng et al., 2004), alum and ferric sludges (Babatunde and Zhao, 2010, Song et al., 2011), alkaline fly ash (Cheung and Venkitachalam, 2000), egg-shell waste (Yeddou Mezenner and Bensmaili, 2009), red mud (Huang et al., 2008), blast furnace slag (Oguz, 2004), and waste lime (Siobhan Dunets and Zheng, 2014, Ahn and Speece, 2010)), ion and ligand exchangers (Blaney et al., 2007, Sarkar et al., 2011, Sengupta and Pandit, 2011, Choi et al., 2012), membranes (Park et al., 2017, Luo et al., 2016, Dolar et al., 2011), and adsorbents (i.e. hydrated ferric oxides (Pan et al., 2009, You et al., 2015, You et al., 2016), magnetic-based adsorbents (Janos et al., 2013, Lai et al., 2016, de Vicente et al., 2011), layered double hydroxides (Das et al., 2006, Cheng et al., 2009), synthesized minerals (Peleka and Deliyanni, 2009, Chitrakar et al., 2006), modified clays (Copetti et al., 2016, Reitzel et al., 2013), modified biochars (Jung and Ahn, 2016, Li et al., 2016), immobilized transition metals (Mahaninia and Wilson, 2015, An et al., 2014, Ogata et al., 2011, Liu and Zhang, 2015), polymers (Dimitri et al., 2005, Mahaninia and Wilson, 2016, Hammud et al., 2015), and nanoparticles (Zheng et al., 2016, Chouyyok et al., 2010, You et al., 2016, Almeelbi and Bezbaruah, 2012, Lai et al., 2016)). Many of these technologies have the potential for being viable options for P removal; however, none of these technologies currently succeed in meeting the desired criteria for an optimal P removal which include: (1) P selectivity, (2) high P removal capacity, (3) environmental stability and harmlessness, (4) effective removal over a wide $\mathrm{pH}$ range, (5) low cost, (6) fast removal rate, (7) removal from concentrations below $100 \mu \mathrm{g} / \mathrm{L}$, and (8) recoverability and reusability. 
Table 1. Summary of P Management for Eutrophic Lakes

\begin{tabular}{|c|c|c|}
\hline $\begin{array}{l}\text { Phosphorus Management } \\
\text { Method }\end{array}$ & $\begin{array}{l}\text { Technology } \\
\text { Advantages }\end{array}$ & $\begin{array}{c}\text { Technology } \\
\text { Disadvantages }\end{array}$ \\
\hline Dredging & $\begin{array}{l}\text { Remove nutrient-rich soil, deepen lake, } \\
\text { immediately improve water quality }\end{array}$ & $\begin{array}{l}\text { High cost, ecological } \\
\text { risks }\end{array}$ \\
\hline Hypolimnetic Aeration & $\begin{array}{l}\text { Limit } \mathrm{P} \text { release sediments, no } \\
\text { resuspension }\end{array}$ & $\begin{array}{l}\text { Ineffective control } \\
\text { of } \mathrm{P}\end{array}$ \\
\hline $\begin{array}{l}\text { Hypolimnetic } \\
\text { Withdrawal }\end{array}$ & $\begin{array}{l}\text { Reduces nutrients, eliminates low } \\
\text { oxygen water }\end{array}$ & $\begin{array}{l}\text { Detrimental to } \\
\text { downstream waters }\end{array}$ \\
\hline Nutrient Inactivation & $\begin{array}{l}\text { Removes } P \text { and algae from water } \\
\text { column, acts as barrier on sediment }\end{array}$ & Ecological risks \\
\hline Dilution & $\begin{array}{l}\text { Flushes out algae and high nutrient } \\
\text { water }\end{array}$ & High cost, inefficient \\
\hline In-situ Sediment Capping & $\begin{array}{l}\text { Highly effective and environmentally } \\
\text { friendly }\end{array}$ & Site dependent \\
\hline $\begin{array}{l}\text { Thermally Treated } \\
\text { Attapulgite }\end{array}$ & Transforms mobile $\mathrm{P}$ into inert $\mathrm{P}$ & Energy intensive \\
\hline
\end{tabular}


Table 2. Summary of Available P Removal Technologies

\begin{tabular}{|c|c|c|c|c|}
\hline $\begin{array}{l}\text { Phosphorus } \\
\text { Removal } \\
\text { Technology }\end{array}$ & $\begin{array}{l}\text { Removal } \\
\text { Capacity }\end{array}$ & $\begin{array}{l}\text { Recovery } \\
\text { Value }\end{array}$ & $\begin{array}{l}\text { Technology } \\
\text { Advantages }\end{array}$ & $\begin{array}{c}\text { Technology } \\
\text { Disadvantages }\end{array}$ \\
\hline $\begin{array}{l}\text { Chemical } \\
\text { Precipitation }\end{array}$ & $\begin{array}{l}(48 \text { - } 230 \mathrm{mg} \\
\mathrm{P} / \mathrm{g} \\
\text { precipitant })\end{array}$ & Low & $\begin{array}{l}\text { Well-established } \\
\text { technology }\end{array}$ & $\begin{array}{l}\text { Low recyclability, } \\
\text { can't remove } \mathrm{P}<100 \\
\mu \mathrm{g} / \mathrm{L}\end{array}$ \\
\hline $\begin{array}{l}\text { Biological } \\
\text { Remediation }\end{array}$ & $\begin{array}{l}(50-300 \mathrm{mg} \\
\mathrm{P} / \mathrm{g} \text { PAOs })\end{array}$ & Moderate & $\begin{array}{l}\text { Well-established } \\
\text { technology, no } \\
\text { chemical usage }\end{array}$ & $\begin{array}{l}\text { Highly variable } \mathrm{P} \\
\text { removal, extensive } \\
\text { sludge handling, } \\
\text { difficulty removing } \\
\mathrm{P}<100 \mu \mathrm{g} / \mathrm{L}\end{array}$ \\
\hline $\begin{array}{l}\text { Waste By- } \\
\text { product } \\
\text { (WBP) } \\
\text { Removal }\end{array}$ & $\begin{array}{l}(0.6-26 \mathrm{mg} / \mathrm{g} \\
\text { WBP })\end{array}$ & Low & $\begin{array}{l}\text { Low-cost, efficient use } \\
\text { of renewable waste }\end{array}$ & $\begin{array}{l}\text { Low selectivity, low } \\
\text { reusability }\end{array}$ \\
\hline $\begin{array}{l}\text { Ion and } \\
\text { Ligand } \\
\text { Exchange }\end{array}$ & $\begin{array}{l}(2.5-26 \mathrm{mg} / \mathrm{g} \\
\text { resin) }\end{array}$ & High & $\begin{array}{l}\text { High selectivity, high P } \\
\text { recoverability, high } \\
\text { exchanger } \\
\text { regenerability }\end{array}$ & High-cost \\
\hline $\begin{array}{l}\text { Filtration/Me } \\
\text { mbrane } \\
\text { Rejection }\end{array}$ & $\begin{array}{l}(65-98 \% \\
\text { rejection })\end{array}$ & None & $\begin{array}{l}\text { Easy to use, small } \\
\text { physical footprint }\end{array}$ & $\begin{array}{l}\text { High-cost, no useful } \\
\text { product }\end{array}$ \\
\hline Adsorption & $\begin{array}{l}(6-200 \mathrm{mg} / \mathrm{g} \\
\text { adsorbent })\end{array}$ & Low & $\begin{array}{l}\text { Effective at low } \\
\text { concentrations }\end{array}$ & $\begin{array}{l}\text { Regeneration issues, } \\
\text { low selectivity }\end{array}$ \\
\hline
\end{tabular}

Molecularly imprinted polymers (MIPs) are synthetic recognition materials capable of being tailored to selectively recognize a wide range of molecules. Some molecules that have been thoroughly studied for recognition with this technology are proteins, nucleotide derivatives, pollutants, drugs, and food. This has led to MIPs having promising applications in separation sciences and purification (Vasapollo et al., 2011, Khorami and Edrisi, 2010, Amut et al., 2010, Lee et al., 2010), solid phase extraction (Vasapollo et al., 2011, Bravo et al., 2007, Al-Degs et al., 2009, Alexiadou et al., 2008, Tse Sum Bui and Haupt, 2010, Ensing et al., 2002), chemical sensors (Vasapollo et al., 2011, Greene and Shimizu, 2005, Lakshmi 
et al., 2009), catalysis (Vasapollo et al., 2011), drug delivery (Vasapollo et al., 2011, AlvarezLorenzo and Concheiro, 2004), biological antibodies (Vasapollo et al., 2011), and as adsorbents (Lee and Doong, 2012). The main advantages of MIPs are their (1) high selectivity and affinity for the target molecule, (2) excellent environmental stability, (3) low cost, and (4) relative ease to design, synthesize, and modify (Vasapollo et al., 2011, Wu, 2012). Selectivity has been identified as the primary means toward commercial effectiveness of adsorbent products (Chitraka, 2006, Saha, 2009). The demonstrated nature of MIPs to selectively recognize molecules at extremely low concentrations is the foundation of their potential use as an adsorbent for P removal.

Phosphate $\left(\mathrm{PO}_{4}^{3-}\right)$ has been studied in a very limited fashion for imprinting technologies. Most examples involving phosphate are for organophosphorylated/organophosphonylated molecules, not $\mathrm{PO}_{4}{ }^{3-}$ itself $(\mathrm{Wu}, 2012$, Wu et al., 2008). Furthermore, among the limited work done on phosphate recognition with imprinting technologies, almost all had sensing applications in mind, not phosphate adsorption. Work done by Ozkutuk et al. (2008) was one of the only to produce an ionically-imprinted polymer (IIP) for phosphate adsorption with reusability in mind. While this product exhibited some sorption capacity, it was shown to have no actual selective removal of phosphate. Preferential removal of phosphate over other anions was observed, though this is likely attributed to phosphate's stronger affinity to form inner-sphere complexes with transition metals than other anions. The Kugimiya group has been the most prominent group in the development of imprinted polymers for phosphate recognition. As opposed to the last discussed work, this group has developed MIPs for recognition of phosphate with the use of structurally similar analogue molecules for templates. 1-Allyl-2- 
thiourea was the group's primary monomer studied for the selective sensing of phosphate due to thiourea groups having a strong binding affinity to phosphate (Nishizawa et al., 1999, Aoki et al., 2003, Kugimiya and Takei, 2006, 2007, 2008, Kugimiya and Babe, 2011). Work done by Warwick et al. introduced other monomers for MIP phosphate recognition with the use of computational modeling, some of which showed promising P removal traits (Warwick et al., 2014).

As mentioned before, almost the entirety of the work completed for P recognition by MIPs has been aimed toward the development of sensor technology. MIPs show potential to be a viable solution to solving the critical P problem, yet none of the work on MIPs has looked into their feasibility as sorbents.

In this work, a survey of all MIPs developed for phosphate removal was conducted. Three monomers which showed the greatest traits that could potentially lead to them being viable MIP sorbents were selected for further study. The three monomers selected were (1) 1-Allyl-2-thiourea (AT), (2) thiourea (TU), and (3) 2methacryloyloxyethyltrimethylammonium chloride (METAC). The feasibility of the resultant MIPs from these monomers for sorbent applications was assessed by studying their sorption capacities, resistance to interference by coexisting anions, and their potential for P recovery. The influence of some design parameters were studied to analyze how MIPs can be optimized for sorption applications. Additionally, the mechanism of phosphate removal was studied to gain insight into how the MIPs function, where some limitations have originated from, and how to potentially overcome those limitations in the future. 


\subsection{Materials and Methods}

\subsubsection{Chemicals}

The chemicals used in this study include: potassium dihydrogen phosphate $\left(\mathrm{KH}_{2} \mathrm{PO}_{4}, 99 \%\right.$ pure, EMD), 1-Allyl-2-thiourea (>98\%, TCI America), thiourea (99\%, Alfa Aesar), 2-methacryloyloxyethyltrimethylammonium chloride (80 wt. \% in $\mathrm{H}_{2} \mathrm{O}$, Sigma Aldrich), ethylene glycol dimethacrylate (EGDMA) (98\%, stabilized with 100ppm 4methoxyphenol, Alfa Aesar), phenylphosphonic acid ( $\geq 98 \%$, TCI America), acetonitrile (ACS Grade, BDH), and 2,2'-Azobis(2-methylpropionitrile) (AIBN) (98\%, Sigma Aldrich), methanol (ACS Grade, BDH), potassium nitrate $\left(\mathrm{KNO}_{3}, 99 \%\right.$ pure, Alfa Aesar), potassium hydroxide (KOH, ACS Grade, $\mathrm{BDH})$, potassium sulfate $\left(\mathrm{K}_{2} \mathrm{SO}_{4}\right.$, ACS Grade, $\left.\mathrm{HACH}\right)$, potassium chloride ( $\mathrm{KCl}$, ACS Grade, $\mathrm{BDH})$, potassium bicarbonate ( $\mathrm{KHCO}_{3}$, ACS Grade, Alfa Aesar), natural organic matter (Suwannee River NOM, RO isolation, IHSS), humic acid (H1452, Spectrum), sulfuric acid (Solution $6.0 \mathrm{~N}, \mathrm{BDH}$ ), antimony potassium tartrate ( $\geq 99 \%$, Spectrum), ammonium molybdate tetrahydrate (ACS Grade, BDH), ascorbic acid ( $\geq 98 \%$, Alfa Aesar), NitraVer X Reagent Set (Test 'N Tube, Hach), hydrochloric acid (Solution 6.0 N, BDH), ethanol (Denatured, 95\%, BDH), glycerol (Laboratory Reagent Grade, BDH), barium chloride dihydrate (ACS Grade, BDH), and sodium carbonate (Anhydrous, ACS Grade, BDH) . All the chemicals were used as received unless otherwise specified. The solutions were prepared with deionized (DI) water, which was previously passed through E-pure system (Series 1090, Barnstead). 


\subsubsection{MIP Synthesis}

MIP synthesis requires chemical reactions between the monomer, template, and cross-linker during polymerization (Schemes 4 - 6). The overall polymerization process involved the combination of reagents (functional monomer, cross-linker, solvent, and template) following the addition of the initiator and nitrogen flushing to remove oxygen, which is a reaction inhibitor. After flushing, the combined reagent mixture was then polymerized by free radical polymerization in a water bath at $65^{\circ} \mathrm{C}$ for 24 hours. The phosphate anion analogue, phenylphosphonic acid, was selected as a template to overcome solubility issues associated with phosphate anions in organic media. In addition to preparing MIPs, negative controls were prepared, non-imprinted polymers (NIPs), which followed the same procedure but omitted the phosphate template. After the polymerization process was complete, the polymers were blended and then purified using Soxhlet extraction with methanol overnight and then dried at $30^{\circ} \mathrm{C}$ to remove remaining methanol from the surface (Scheme 7).

Table 3. Combination of Reagents for Synthesis of MIPs

\begin{tabular}{|l|c|c|c|c|}
\hline Name & Monomer Qty. & Cross-linker $^{1}$ & Solvent $^{2}$ & Template \\
\hline METAC & $830 \mathrm{mg}(4 \mathrm{mmol})$ & $3.8 \mathrm{~mL}(20 \mathrm{mmol})$ & $5 \mathrm{~mL}$ & $158 \mathrm{mg}(1 \mathrm{mmol})$ \\
\hline TU & $305 \mathrm{mg}(4 \mathrm{mmol})$ & $3.8 \mathrm{~mL}(20 \mathrm{mmol})$ & $6 \mathrm{~mL}$ & $158 \mathrm{mg}(1 \mathrm{mmol})$ \\
\hline AT & $465 \mathrm{mg}(4 \mathrm{mmol})$ & $3.8 \mathrm{~mL}(20 \mathrm{mmol})$ & $6 \mathrm{~mL}$ & $158 \mathrm{mg}(1 \mathrm{mmol})$ \\
\hline
\end{tabular}

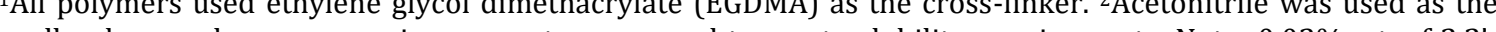
Azobis(2-methylpropionitrile) (AIBN) was used as the initiator for each polymer.<smiles>C=C(C)C(=O)OCCOC(=O)[N+](C)(C)CCOC(=O)C(=C)C</smiles>

Scheme 4. Chemical Reaction Scheme of METAC MIP Synthesis 
<smiles>C=C(C)C(=O)OCCOC(=O)C(=C)C</smiles>

Scheme 5. Chemical Reaction Scheme of TU MIP Synthesis<smiles>C=CCNC(N)=S</smiles>

Scheme 6. Chemical Reaction Scheme of AT MIP Synthesis

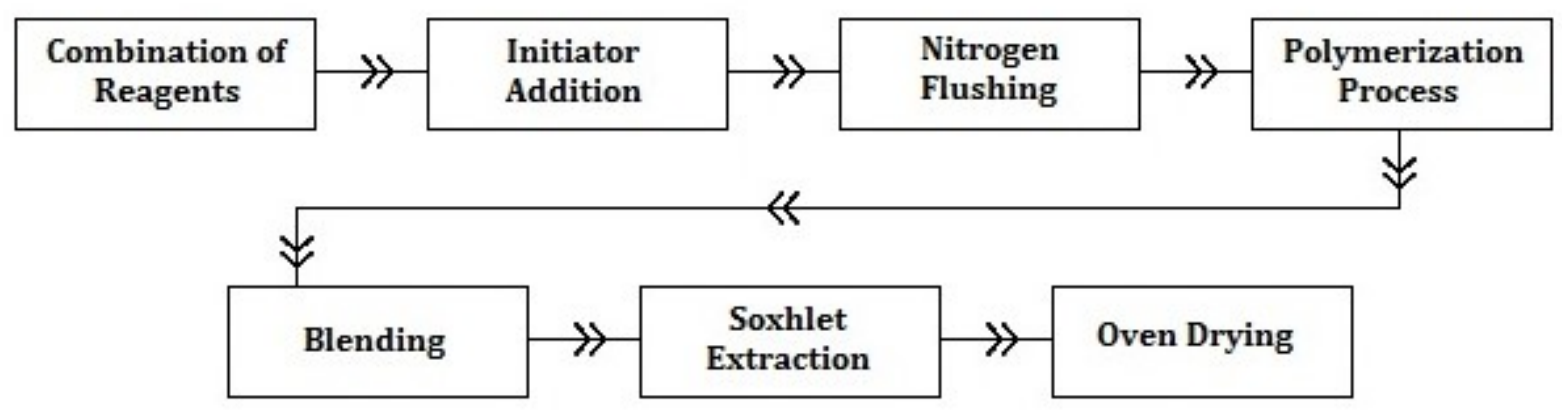

Scheme 7. General MIP Synthesis Procedure

\subsubsection{Point of Zero Charge and pH Study}

The point of zero charge (PZC) of a material is defined as the $\mathrm{pH}$ value at which the net charge on the solid surface is zero. PZC for the MIPs was determined by following the potentiometric mass titrations technique (Vakros et al., 2002). In brief, three solutions of equivalent potassium nitrate were created, but with varying amounts of MIP (0.5 g/100 $\mathrm{mL}, 1.0 \mathrm{~g} / 100 \mathrm{~mL}$, and $1.5 \mathrm{~g} / 100 \mathrm{~mL}$ ). The polymer was then left in the $\mathrm{KNO}_{3}$ solution for 24 hours (in a sealed nitrogen environment) to allow the surface complexes to be saturated with nitrate. After the 24-hour waiting period, the $\mathrm{pH}$ of each solution was adjusted with $\mathrm{KOH}$ to approximately 11.5 - 12. After reaching this $\mathrm{pH}$ range, the samples were then titrated with $\mathrm{HCl}$ to a $\mathrm{pH}$ value of approximately 3 or lower. $\mathrm{pH}$ was measured continuously 
with each volume addition of $\mathrm{HCl}$. The volume of titrant is then plotted against the $\mathrm{pH}$-value for all three concentrations of the MIP. The point that all three samples intersect is the $\mathrm{pH}$ at which the PZC is reached (Vakros et al., 2002).

The effect of $\mathrm{pH}$ on phosphate removal by MIPs was investigated at $\mathrm{pH}$ values of 3,4 , $5,6,7,8,9,10,11$, and 12 . To reach these $\mathrm{pH}$ levels, the $\mathrm{pH}$ was adjusted by the addition of $1 \mathrm{M} \mathrm{HCl}$ and $1 \mathrm{M} \mathrm{KOH}$ to the phosphate solution (5 mg PO $\left.4^{3-}-\mathrm{P} / \mathrm{L}\right)$.

\subsubsection{Isotherm Studies}

Batch experiments were conducted to understand the isotherm behavior of the MIPs during phosphate removal. Each batch reactor $(50 \mathrm{~mL})$ contained $1 \mathrm{~g}$ of MIP and 50 $\mathrm{mL}$ of phosphate solution. The polypropylene plastic test reactors and controls (no MIP, only phosphate solution) were then rotated at room temperature $\left(22 \pm 2{ }^{\circ} \mathrm{C}\right)$ at $28 \mathrm{rpm}$ in a tailor-made end-over-end shaker to reduce mass transfer resistance. All samples were run in triplicate. Reactors were withdrawn after 24 hours and the used MIPs were separated from the reactors by centrifugation. The phosphate concentration in the bulk solution was measured to calculate the sorption capacity of the MIP. Initial concentration of phosphate was varied from $0.1-3500 \mathrm{mg} \mathrm{PO} 4^{3--} \mathrm{P} / \mathrm{L}$. The data were fit to Langmuir and Freundlich isotherm models. The Langmuir isotherm assumes monolayer sorption and that adsorption only occurs at a finite number of localized sites. Further, the Langmuir isotherm refers to homogenous sorption, describing all sites as possessing equal affinity for the sorbate (Eq. 1).

$$
q=\frac{K_{L} q_{m} C_{e}}{1+K_{L} C_{e}}
$$


Where, $\mathrm{q}_{\mathrm{m}}$ is the maximum loading of the sorbent ( $\mathrm{mg} \mathrm{PO}_{4}{ }^{3-}-\mathrm{P} / \mathrm{g}$ sorbent) and $\mathrm{K}_{\mathrm{L}}$ is the Langmuir sorption constant (L/mg sorbent).

The Freundlich isotherm describes heterogeneous and reversible sorption not restricted to the formation of a monolayer (Eq. 2).

$$
q=K C_{e}^{\frac{1}{n}}
$$

Where, $\mathrm{K}$ is the sorption Fruendlich constant ( $\mathrm{mg} \mathrm{PO}_{4}{ }^{3--} \mathrm{P} / \mathrm{g}$ sorbent) $(\mathrm{mg} / \mathrm{L})^{-1 / n}$, and $\mathrm{n}$ is the Fruendlich exponent. Values of $\mathrm{n}>1$ represent favorable sorption.

\subsubsection{Temperature Studies}

In order to assess the behavior of MIPs removal under various temperature conditions, a temperature study was conducted. A range of relevant temperatures that MIPs may experience when in the environment $\left(4,10,15,20,25,30\right.$, and $\left.35^{\circ} \mathrm{C}\right)$ were selected. Phosphate solution was first placed in an environmental chamber for 2 hours to reach the desired temperature before MIPs were introduced into the reactors. The same batch study procedure as discussed previously was used. The phosphate removal efficiency ( $\eta$ ) was calculated using (Eq. 3).

$$
\eta=\frac{C_{0}-C_{e}}{C_{0}}
$$

\subsubsection{Kinetic Studies}

Kinetic studies were conducted to delve into the mechanism of phosphate removal. This testing was also conducted as a batch study, with the same procedure as previously

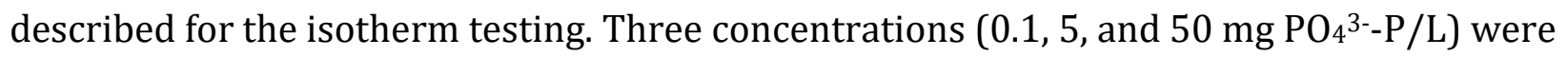
chosen for the kinetic studies. The $0.1 \mathrm{mg} \mathrm{PO} 4^{3--} \mathrm{P} / \mathrm{L}$ concentration was selected to gain insight into the kinetics of removal at environmentally relevant $\mathrm{P}$ concentrations (100 
$\mu \mathrm{g} / \mathrm{L}$ ) found in eutrophic lakes. Sets of three sacrificial reactors were withdrawn at specific time intervals $(4,6,8,10,15,30,60,90,120,180,360,720,1080$, and $1440 \mathrm{~min})$ to have the phosphate concentrations in the bulk solutions measured. The phosphate removal efficiency $(\eta)$ was calculated using (Eq. 3).

\subsubsection{Interference and Partial-selectivity Studies}

\subsubsection{Interference Studies}

Effects of possible competing ions and compounds on phosphate sorption by MIPs were investigated by adding common coexisting anions and natural organic matter (NOM) to the phosphate solution. Interference studied were carried out with chloride (Cl-, 50 $500 \mathrm{mg} / \mathrm{L})$, bicarbonate $\left(\mathrm{HCO}_{3}{ }^{-}, 10-100 \mathrm{mg} / \mathrm{L}\right)$, sulfate $\left(\mathrm{SO}_{4}{ }^{2-}, 50-1000 \mathrm{mg} / \mathrm{L}\right)$, nitrate $\left(\mathrm{NO}_{3}, 10-100 \mathrm{mg} / \mathrm{L}\right)$, humic acid $(2-10 \mathrm{mg} / \mathrm{L})$, and Suwanee River NOM (10 - 50 mg/L) mixed with phosphate solution ( $5 \mathrm{mg} \mathrm{PO} 4^{3--} \mathrm{P} / \mathrm{L}$ ). These tests were conducted as batch studies, with the same procedure as previously described for the isotherm studies.

\subsubsection{Partial-Selectivity Studies}

Further studies were needed to assess whether or not the recognition sites of the MIP showed any sort of selectivity. To evaluate this, $1 \mathrm{~g}$ of the MIP was saturated with excessive amounts of a competing anion $\left(110 \mathrm{meq} / \mathrm{L} \mathrm{NO}_{3}{ }^{-}, \mathrm{Cl}^{-}\right.$, and $\left.\mathrm{SO}_{4}^{2-}\right)$. The batch reactors were rotated at $28 \mathrm{rpm}$ for 24 hours to allow sufficient time for all non-selective binding sites to become saturated and electrostatic interactions to be completed. After saturation, the saturated MIP was filtered using a $0.45 \mu \mathrm{m}$ pore size cellulose nitrate membrane filter (Whatman, 47-mm-diameter). The remaining bulk anion solution was tested to examine non-phosphate anion removal, which in turn was used to estimate the 
amount of anions adsorbed onto the MIP. The saturated MIP was then placed in $50 \mathrm{~mL}$ polypropylene tubes with equal parts (110 meq/L) solution of phosphate and other competing anions (nitrate, sulfate, chloride). The samples were then run in same manner as described in the isotherm study. The bulk solution of each sample was tested for phosphate and for the competing anion.

\subsubsection{Lake Water Study}

Eutrophic lake water samples were collected in April 2017 from the following lakes located in Minnesota, USA: Lake Katrina $\left(45.012913^{\circ} \mathrm{N},-93.623659^{\circ} \mathrm{W}\right)$, Holy Name Lake $\left(45.014284^{\circ} \mathrm{N},-93.532872^{\circ} \mathrm{W}\right)$, Lake Ardmore $\left(45.032101^{\circ} \mathrm{N},-93.636703^{\circ} \mathrm{W}\right)$, Lake Independence $\left(45.026063^{\circ} \mathrm{N},-93.636109^{\circ} \mathrm{W}\right)$, and Half Moon Lake $\left(45.028521^{\circ} \mathrm{N}\right.$, $93.628103^{\circ} \mathrm{W}$ ). The lake water samples were filtered using a $0.45 \mu \mathrm{m}$ pore size cellulose nitrate membrane filter (Whatman, 47 -mm-diameter) and stored in glass bottles at $4{ }^{\circ} \mathrm{C}$ for further analyses. This testing was also conducted as a batch study, with the same procedure as previously described for the isotherm studies.

\subsubsection{Biodegradability Studies}

To assess the potential for the MIP to be broken down biologically, a biodegradation study was conducted. Biodegradability of a material can be determined by indirect measure of the parent compound's bioconversion (i.e. biochemical oxygen demand (BOD)) by monitoring the BOD over time using a respirometer. The experiment followed the Hach Standard Method (Hach, 1995). BOD was monitored using an automated closed-system respirometer (BODTrak Apparatus, Hach, USA). BODTrak correlates the quantity of oxygen consumed to the change in headspace pressure. As the organic matter in the sample is 
biodegraded, the headspace pressure will decrease. BOD data were automatically collected by the BODTrak via a data-logger and stored on a computer connected to the instrument during the 30-day test period. Mixed liquor suspended solids (MLSS) was collected from the City of Moorhead Wastewater Treatment Plant (Moorhead, MN) and used immediately to preserve the integrity of the microorganisms. The MLSS served as the seed for the bacteria population. The biodegradation studies were conducted in $500 \mathrm{~mL}$ amber bottles and ran in triplicate. BOD nutrient solution was prepared by mixing a BOD nutrient buffer pillow (Hach, USA) with 6L of DI water which had previously been oxygenated for 24 hours. Next, each reactor was filled with MIP (100 mg), BOD nutrient (155 mL), and MLSS (5 mL). Upon filling each reactor, a seal cup was placed on the reactor and $\mathrm{LiOH}$ was added to adsorb generated $\mathrm{CO}_{2}$. Special care was taken to ensure the $\mathrm{LiOH}$ did not spill into the solution. Recorded BOD values were corrected for dilution and seeding factors.

\subsubsection{Desorption Studies}

A desorption study was conducted to evaluate the release pattern of sorbed phosphate from the spent MIP. For this, $1 \mathrm{~g}$ of MIP was placed in polypropylene tubes filled

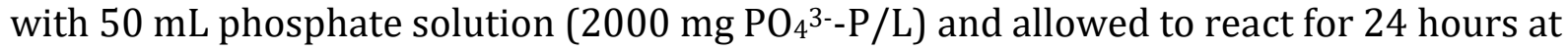
$28 \mathrm{rpm}$ in the end-over-end shaker. The spent MIP was then filtered using a $0.45 \mu \mathrm{m}$ pore size cellulose nitrate membrane filter (Whatman, 47-mm-diameter). The bulk phosphate concentration was measured in the samples. After separation from the solution, the spent MIP was placed in a $50 \mathrm{~mL}$ polypropylene tube filled with DI water. The reactors were then

run for a 4-day period with desorption data collected at different cycle times $(0.25,0.5,1,2$, 3 , and $4 \mathrm{~d}$ ). After each cycle had completed, the reactors were taken out from the shaker. The MIP was filtered out from solution and placed in $50 \mathrm{~mL}$ reactors with fresh DI water. 
The bulk water after each cycle was analyzed for P content to determine how much P was released by the MIP over those periods.

\subsubsection{Phosphate, Nitrate, Sulfate, and Chloride Analysis}

To quantify the P content in supernatants, the Ascorbic Acid Method was employed (Eaton et al., 2005). Nitrate-nitrogen and total chlorine concentrations were each determined with the use of Hach Test 'N Tube reagent kits. The concentration of sulfate present was measured using a turbidimetric method (Method \#375.4) developed by the United States Environmental Protection Agency (USEPA) (USEPA, 1978).

\subsubsection{Material Characterization}

\subsubsection{SEM/EDS}

MIP particles were characterized using scanning electron microscopy with energy dispersive spectroscopy (SEM/EDS) to analyze the surface morphology of the particles and characterize the elemental composition of the polymer. Fresh (before phosphate removal) and spent (after phosphate removal) MIP samples were used for imaging and EDS analyses.

For high-resolution SEM/EDS, samples were attached to aluminum mounts using silver paint (SPI Products, West Chester, Pennsylvania, USA) or double-stick carbon tape (Ted Pella, Redding, California, USA), and then coated with a conductive layer of carbon in a high-vacuum evaporative coater (Cressington 208c, Ted Pella Inc., Redding, California). Images were obtained with a JEOL JSM-7600F scanning electron microscope (JEOL USA, Inc., Peabody, Massachusetts.) Energy-dispersive spectroscopy information was acquired using an UltraDry silicon drift X-ray detector and NSS-212e NORAN System 7 X-ray Microanalysis System (Thermo Fisher Scientific, Madison, Wisconsin.) 
For low-resolution SEM/EDS, samples were attached to aluminum mounts with silver paint (SPI Products, West Chester, Pennsylvania, USA) or double-stick carbon tape (Ted Pella, Redding, California, USA), and then sputter coated (Cressington 108 auto, Ted Pella, Redding, California, USA) with a conductive layer of gold. Images were obtained with a JEOL JSM-6490LV scanning electron microscope (JEOL USA, Inc., Peabody MA, USA); energy-dispersive X-ray information was collected using a Nanotrace EDS detector with a NORVAR light-element window and Noran System Six imaging system (ThermoFisher Scientific, Madison WI, USA) at an accelerating voltage of $15 \mathrm{kV}$.

\subsubsection{FTIR}

Fourier transform infrared spectroscopic (FTIR) spectra were obtained ex-situ on fresh and spent MIPs using a Nicolet 8700 FTIR Spectrometer operated with OMNIC software. All spectra were obtained in the range of $4000-400 \mathrm{~cm}^{-1}$ using potassium bromide $(\mathrm{KBr})$ as a background. Prior to analysis, samples were dried in a vacuum oven at $30^{\circ} \mathrm{C}$ under nitrogen gas for 48 hours. Pellets were formed by crushing the dried samples with $\mathrm{KBr}$ (sample: $\mathrm{KBr}$ mass ratio of 1:10). Spectra were recorded at a resolution of $4 \mathrm{~cm}^{-1}$ with each spectrum corresponding to 64 scans. The background collected from $\mathrm{KBr}$ was subtracted from the sample spectra. Spectra information collected was plotted in the same scale on the wavenumber axis ( $\mathrm{x}$-axis).

\subsubsection{Swelling Studies, and Prediction of Porosity and Hydrated Diameter}

Swelling studies were conducting using dry MM12 particles. The term dry refers to the state of the particles after extraction and vacuum drying of excess methanol. Swelling studies were carried out in DI water. Accurately weighed amounts of MM12 particles 
(ranging from 1 to $2 \mathrm{~g}$ ) were immersed in $25 \mathrm{~mL}$ of DI water for 30 minutes. After immersion, the MM12 particles were filtered with a fiber-glass filter (Whatman, 47-mmdiameter). Immediately, they were weighed. The weight change of the beads was calculated according to the formula:

$$
\% \text { weight change }=\frac{W_{s}-W_{i}}{W_{i}} * 100 \%
$$

where $\mathrm{W}_{\mathrm{s}}$ is the weight of the MM12 particles in the swollen state and $\mathrm{W}_{\mathrm{i}}$ is the initial weight of the MM12 particles.

Upon MM12 immersion in DI water, the average hydrated diameter (D), and the average porosity $(\varepsilon)$ of swollen MM12 particles were estimated using Eqs. 5\&6. The hydrated diameter is based on the assumption that the shape of the particle can be approximated as a sphere.

$$
\begin{aligned}
& D=\left[6 * \frac{\left(W_{i} / \rho_{M M 12}\right)+\left(\left(W_{s}-W_{i}\right) / \rho_{w}\right)}{\pi}\right]^{1 / 3} \\
& \varepsilon=\frac{\left(W_{s}-W_{i}\right) / \rho_{w}}{W_{i} / \rho_{M M 12}+\left(W_{s}-W_{i}\right) / \rho_{w}} * 100 \%
\end{aligned}
$$

where $\rho_{\mathrm{w}}$ is the density of water $\left(1.0 \mathrm{~g} / \mathrm{cm}^{3}\right)$ and $\rho_{\text {Mм12 }}$ is the estimated density of MM12 $\left(1.063 \mathrm{~g} / \mathrm{cm}^{3}\right)$.

\subsubsection{Statistical Analysis}

The results are presented as the mean $\pm \mathrm{SD}$ (standard deviation, $\mathrm{n}=3$ ). The data were checked for homogeneity of variance. One-way analysis of variance (ANOVA) was performed using General Linear Model, followed by a Tukey's pairwise comparison where appropriate. All statistical analysis was performed on Minitab version 17. Significance was determined based on whether $p$-values were less than 0.05 or not. 


\subsection{Results and Discussion}

\subsubsection{PZC and Effect of $\mathrm{pH}$}

The PZC for the polymers gives an idea as to which pH the MIPs will be positively or negatively charged on the surface. Determining these values will help understand when the MIPs may remove coexisting anions along with phosphate due to non-selective electrostatic attractions under varying $\mathrm{pH}$ regimes.

The PZCs for the TU, AT, and METAC MIPs were obtained by using the potentiometric mass titration method and found to be 2.9 for TU (Figure 1), 8.9 for AT(Figure 2), and 10.9 for METAC (Figure 3). The TU MIP not reaching its PZC until an extremely low $\mathrm{pH}$ indicates that it has strong negatively charged surface sites above that $\mathrm{pH}$. Therefore, non-selective electrostatic interactions with other anions are not anticipated. The AT and METAC MIPs were found to have PZCs above the typical pH range for eutrophic lakes (7.5 - 8.5, Michaud, 1991). This will provide active sites for electrostatic interaction and removal of phosphate, although it will also attract coexisting anions. 


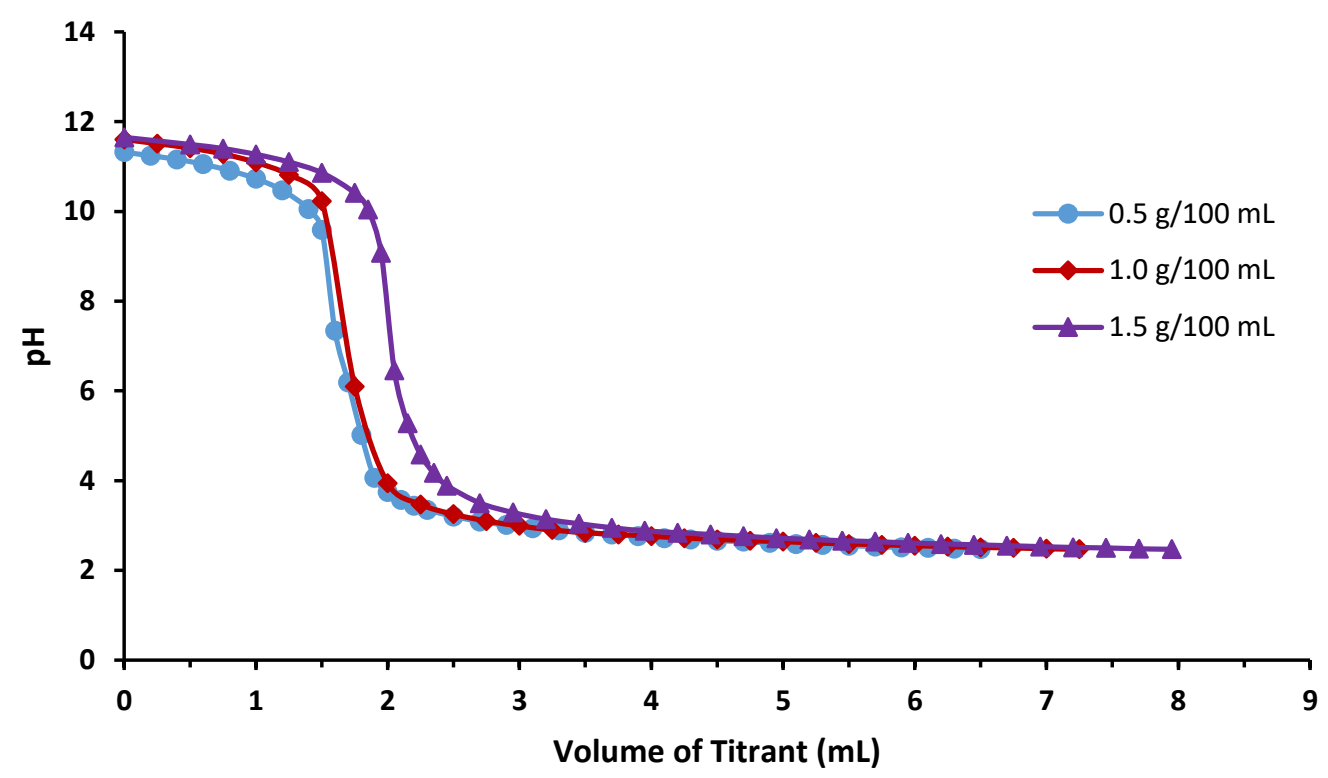

Figure 1. PZC of TU MIP. The PZC was found to be 2.9.

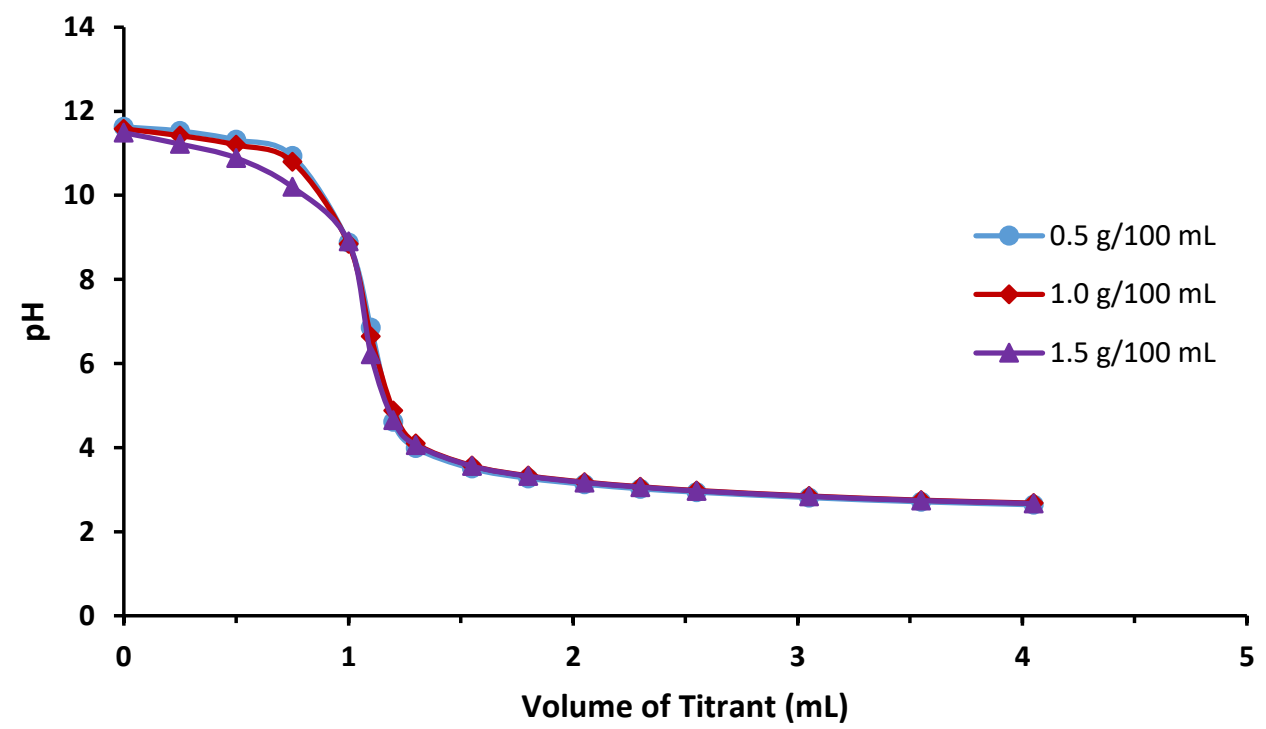

Figure 2. PZC of AT MIP. The PZC was found to be 8.9. 


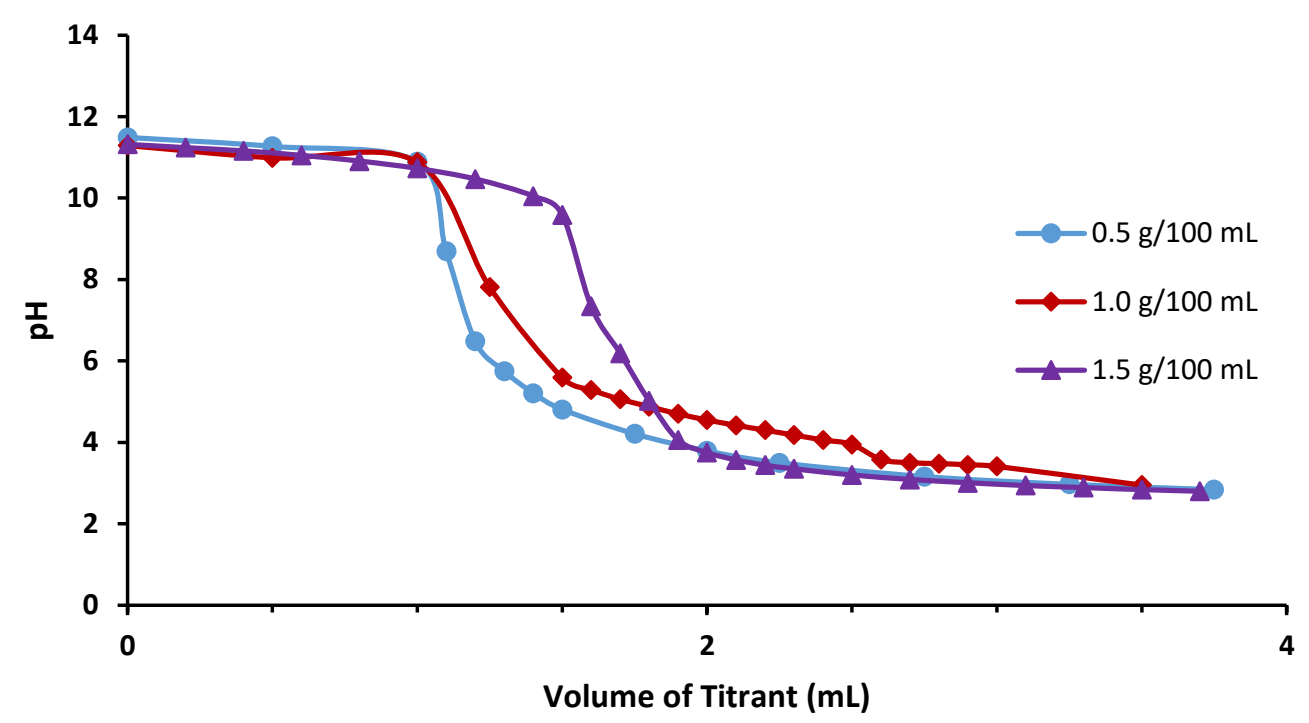

Figure 3. PZC of METAC MIP. The PZC was found to be 10.9.

To confirm the behavior of these MIPs in varying $\mathrm{pH}$ regimes, a $\mathrm{pH}$ study was conducted in a range of 3 - 12 (Figure 4). The TU MIP was shown to have relatively zero phosphate sorption over the entire $\mathrm{pH}$ range studied. The lack of removal indicates that there are no electrostatic attractions occurring, which confirms the lack of positively charged surface sites previously found in the PZC analysis.

The AT MIP showed different adsorption behaviors at different $\mathrm{pH}$ values. The AT MIP's behavior under different $\mathrm{pH}$ ranges is indicative of several things. First, the phosphate removal efficiency above $\mathrm{pH} 8$ is lower than that in the ranges of $\mathrm{pH} 6$ - 8. Oneway ANOVA testing under a 95\% confidence interval (CI) showed that the difference in removal percentages between these two regions is not statistically significant. However, it is believed that this change in removal efficiency likely corresponds to the polymer's PZC. Above $\mathrm{pH} 8.9$, the positively charged surface sites that contribute to electrostatic removal of anions will be saturated by hydroxides and, therefore, unavailable for removal of 
phosphate. Although, it can be observed that even though the electrostatic attraction sites are saturated, there is still some phosphate removal occurring. This leads to the belief that the AT MIP is removing phosphate through its imprinted recognition sites. As the $\mathrm{pH}$ decreased below 6, the AT MIP showed decreased removal efficiency as well. One-way ANOVA testing under a 95\% CI confirmed that the removal percentages from $\mathrm{pH} 3-5$ and pH 6 - 8 differ significantly. This is attributed to one of two potential phenomena. First, as the $\mathrm{pH}$ decreases, the speciation of phosphate in solution will trend more toward phosphoric acid $\left(\mathrm{H}_{3} \mathrm{PO}_{4}\right)$. It is possible that these phosphoric acid compounds may have reduced or negligible recognition by the imprinted sites on the MIP. Additionally, as anionic phosphate speciation trends toward phosphoric acid with a formal charge of zero, the polymer surface will become more positively charged due to continued protonation from decreasing $\mathrm{pH}$. This will reduce or possibly eliminate any presence of electrostatic attraction between the compound and the polymer surface. The second phenomenon arises from the dissociation of hydrochloric acid $(\mathrm{HCl})$ used to reduce the $\mathrm{pH}$. Reducing the $\mathrm{pH}$ every 1 unit requires an order of magnitude more $\mathrm{HCl}$ than the previous unit. As the amount of $\mathrm{HCl}$ increases in the phosphate solution, more chloride $\left(\mathrm{Cl}^{-}\right)$anions dissociate. These anions may compete for non-specific electrostatic binding sites or other available binding sites. These phenomena could consequently reduce the phosphate removal efficiency.

For the METAC MIP, the phosphate removal remains relatively constant from a range of $\mathrm{pH} 4$ - 12. Once below a pH of 4, one-way ANOVA testing under a 95\% CI shows the removal efficiency exhibiting a significant decrease. This can also likely be explained by the same phenomena used to describe the AT MIP's behavior at low $\mathrm{pH}$. The general 
behavior of the METAC MIP over varying $\mathrm{pH}$ regimes shows that it is stable and reliable across a wide range of $\mathrm{pH}$.

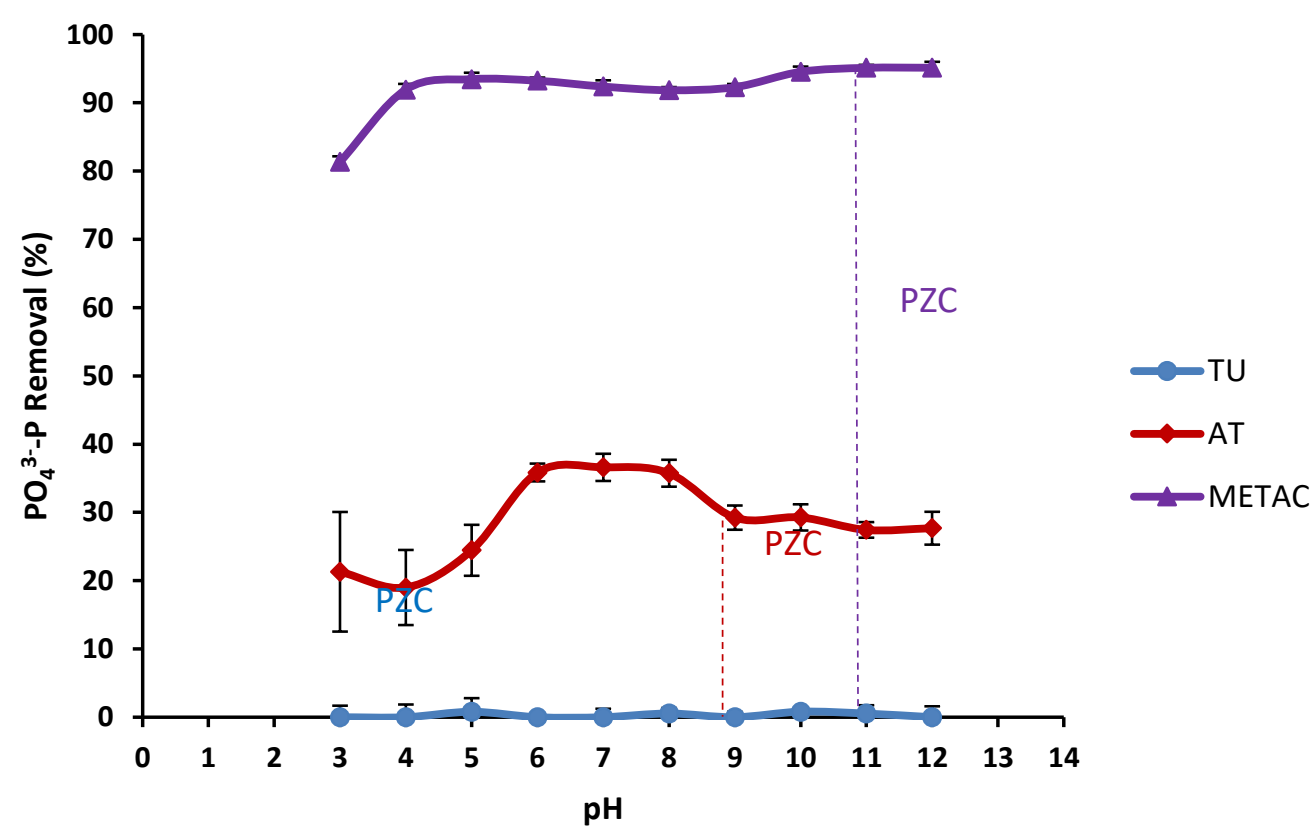

Figure 4. The Role of $\mathrm{pH}$ on Phosphate Removal $\left(\mathrm{C}_{0}=5 \mathrm{mg} \mathrm{PO} 4^{3-} \mathrm{P} / \mathrm{L}\right)$

\subsubsection{Phosphate Removal Studies}

\subsubsection{Sorption Capacity of Polymers}

The experimental data from phosphate sorption of the TU (NIP \& MIP), AT (NIP \& MIP), and METAC (NIP \& MIP) are shown (Figures 5-7). Neither the TU NIP nor MIP showed successful phosphate removal. Any removal of phosphate found was typically associated with standard error. The results from this study corresponds those reported by Warwick et al. (2014a) who indicated that TU NIP was able to remove only $1 \%$ phosphate at $\mathrm{C}_{0}=0.78 \mathrm{mg} \mathrm{PO} 4^{3-} / \mathrm{L}$. However, this contradicts the same work done by Warwick et al. (2014a) who reported the TU MIP removing $22 \%$ phosphate at $\mathrm{C}_{0}=0.78 \mathrm{mg} \mathrm{PO}_{4}{ }^{3-} / \mathrm{L}$. This 
finding is not entirely surprising as Warwick et al. (2014a) also reported large error associated with phosphate removal by TU MIP.

Difference in P sorption between the AT MIP and its non-imprinted counterpart was deemed as insignificant based on one-way ANOVA testing under a 95\% CI interval. While the means show significant differences, the lack of statistical significance is likely due to the large error associated with the sorption results. Additionally, the sorption capacity found for the AT MIP ( $\sim 1 \mathrm{mg} \mathrm{PO} 4^{3--} \mathrm{P} / \mathrm{g}$ polymer) is not high enough to be considered competitive with technologies that are already available (Table 2).

The METAC MIP showed a sorption capacity that could very well be considered competitive with available technologies ( $\sim 11 \mathrm{mg} \mathrm{PO}_{4}{ }^{3--} \mathrm{P} / \mathrm{g}$ polymer). The METAC MIP also had a much lower standard error in the phosphate removal data, making the phosphate removal process more reliable and predictable. However, one-way ANOVA testing under a 95\% CI showed that the difference in sorption capacities between the METAC MIP and NIP was not significant. This indicates that electrostatic attraction of phosphate due to a positive surface charge of the METAC polymer significantly contributes to phosphate removal, while the assumedly selective binding sites from imprinting phenlyphosphonic acid possibly only contribute marginally. 


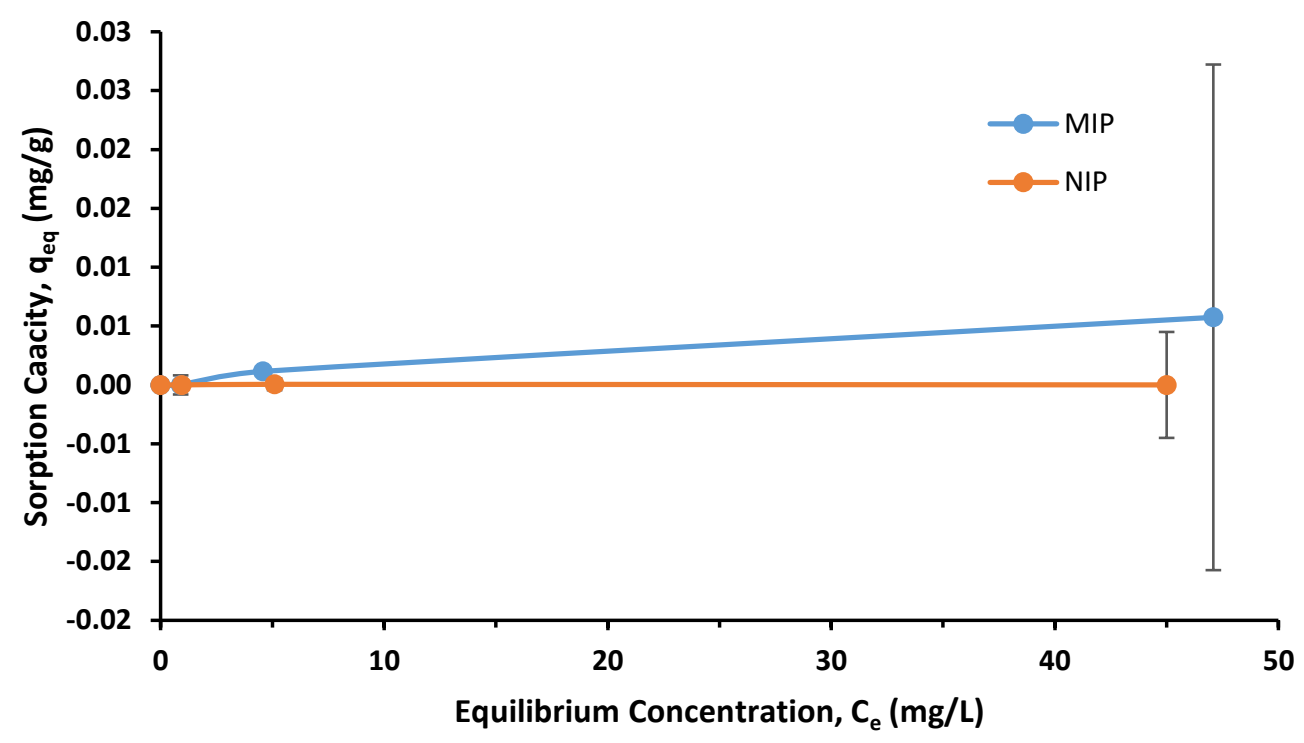

Figure 5. Sorption Capacities of TU NIP and MIP

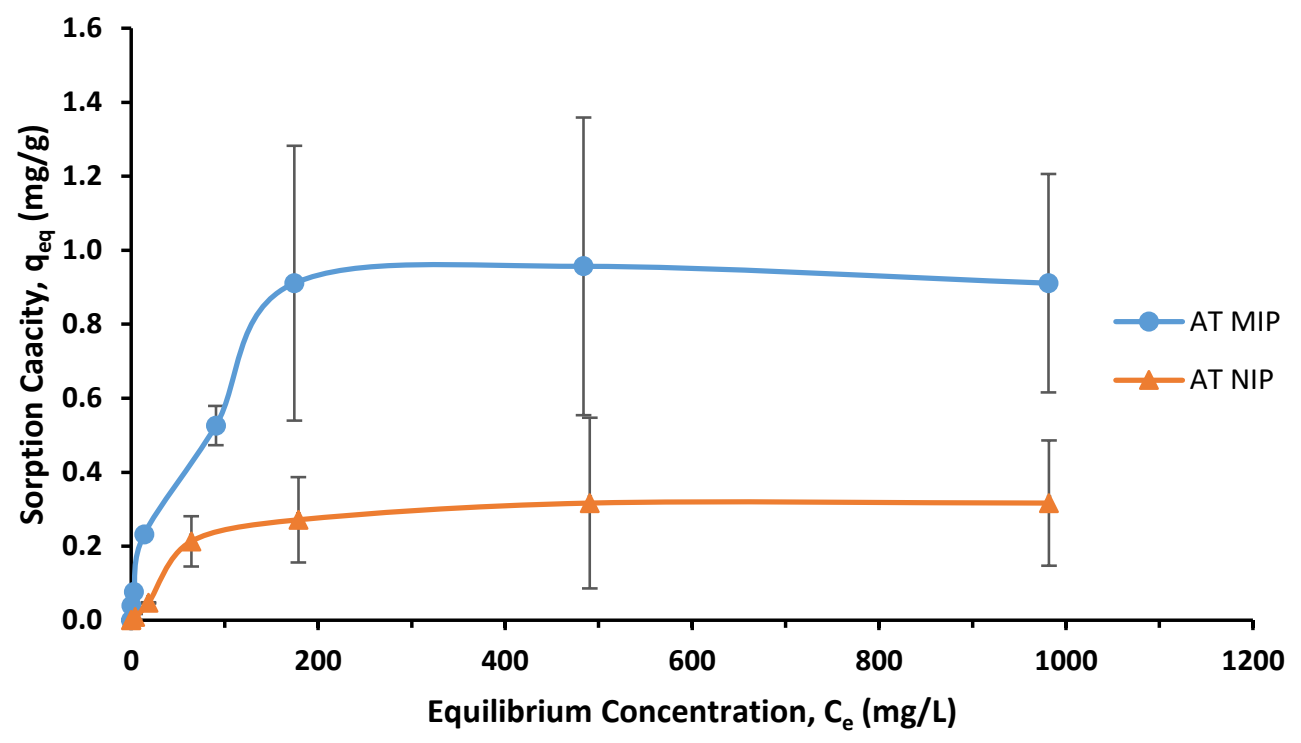

Figure 6. Sorption Capacities of AT NIP and MIP 


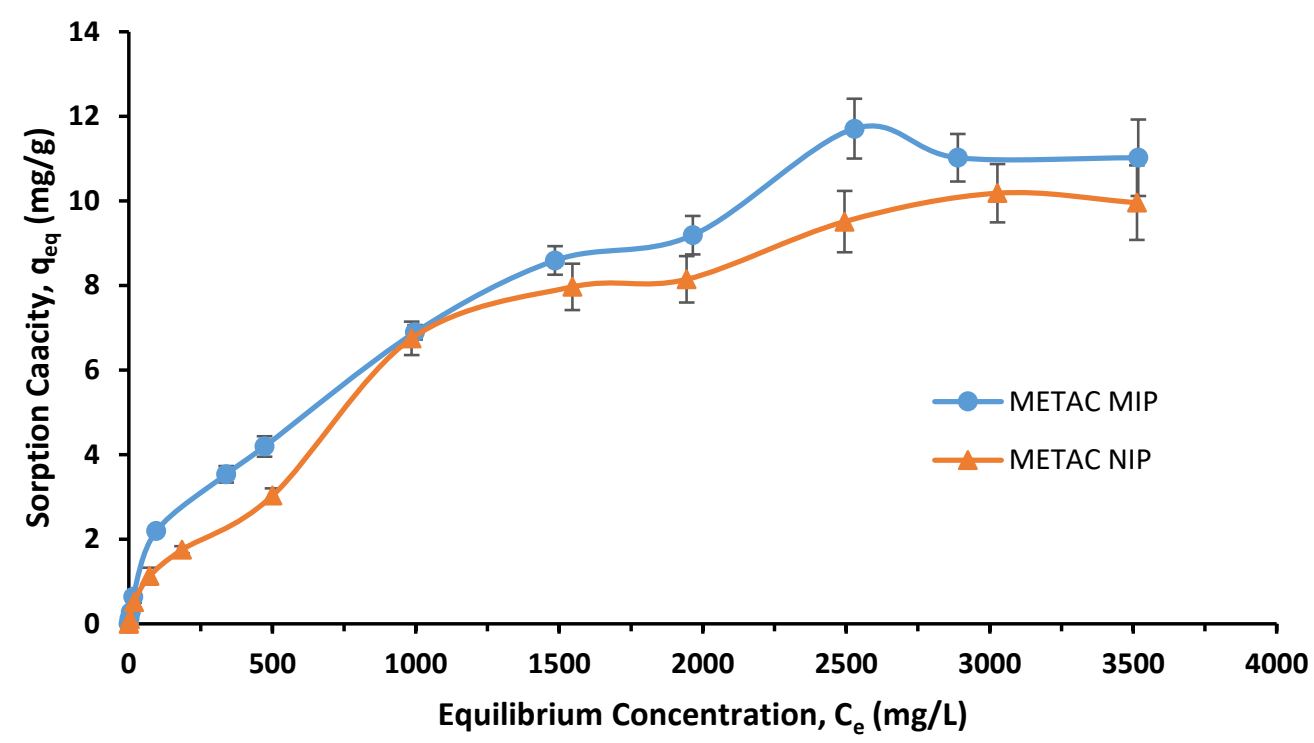

Figure 7. Sorption Capacities of METAC NIP and MIP

\subsubsection{Interference Studies}

It is necessary to determine the feasibility of applying these MIPs in actual lake water for P recovery, specifically the proficiency of the MIPs in the presence of coexisting anions and compounds which might compete for active binding sites. At this point in the study, the TU MIP was no longer considered for testing as it was unable to remove any significant amount of phosphate from solutions under varying $\mathrm{pH}$ and initial phosphate concentrations. The AT MIP also showed poor sorption capacity to be considered as a feasible sorbent for P recovery applications. However, Kugimiya et al. (2008) reported that their AT MIP had the ability to selectively remove phosphate from amongst coexisting ions. Kugimiya et al. (2008) did not provide any data from an interference study to support this claim. The AT MIP was included in this study in the hope that it may still provide potential as a low-efficiency selective sorbent. METAC MIPs worked well and were also considered for this study. 
The ions and their associated concentrations used in this interference study were selected due to their typical presence in surface waters. One-way ANOVA testing under a 95\% CI showed that the AT MIP experienced significant interference for binding sites from certain competing anions. The AT MIP experienced most of its significant reduction in phosphate removal from nitrate, chloride, and sulfate ( $\sim 55$ - 85\% reduction). Significant reduction was also seen with NOM at concentrations of $10 \mathrm{mg} / \mathrm{L}$ or higher $(\sim 18-22 \%$ reduction) (Figure 8). Minor interference was experienced from NOM while bicarbonate and humic acid showed no significant interference. The METAC MIP followed the same pattern of interference as one-way ANOVA testing under a 95\% CI showed that it only experienced significant reduction in phosphate removal from nitrate, chloride, and sulfate ( 15 - 85\% reduction) (Figure 9). Of those three interfering anions, interference from nitrate at a concentration of $10 \mathrm{mg} / \mathrm{L}$ did not show to significantly differ from the control's removal. These results indicate that the AT MIP is not selective toward phosphate even though indicated otherwise by Kugimiya et al. (2008). This was somewhat expected as the PZC value indicated the AT MIP as having a positive surface charge below a $\mathrm{pH}$ of 8.9, and a positively charged surface provides sites for non-specific binding with any negatively charged compound. The METAC MIP also showed poor selectivity toward phosphate in the presence of coexisting anions. The same explanation given for the AT MIP's failure to selectively remove phosphate can be given to the METAC MIP as it had a PZC at pH 10.9. 


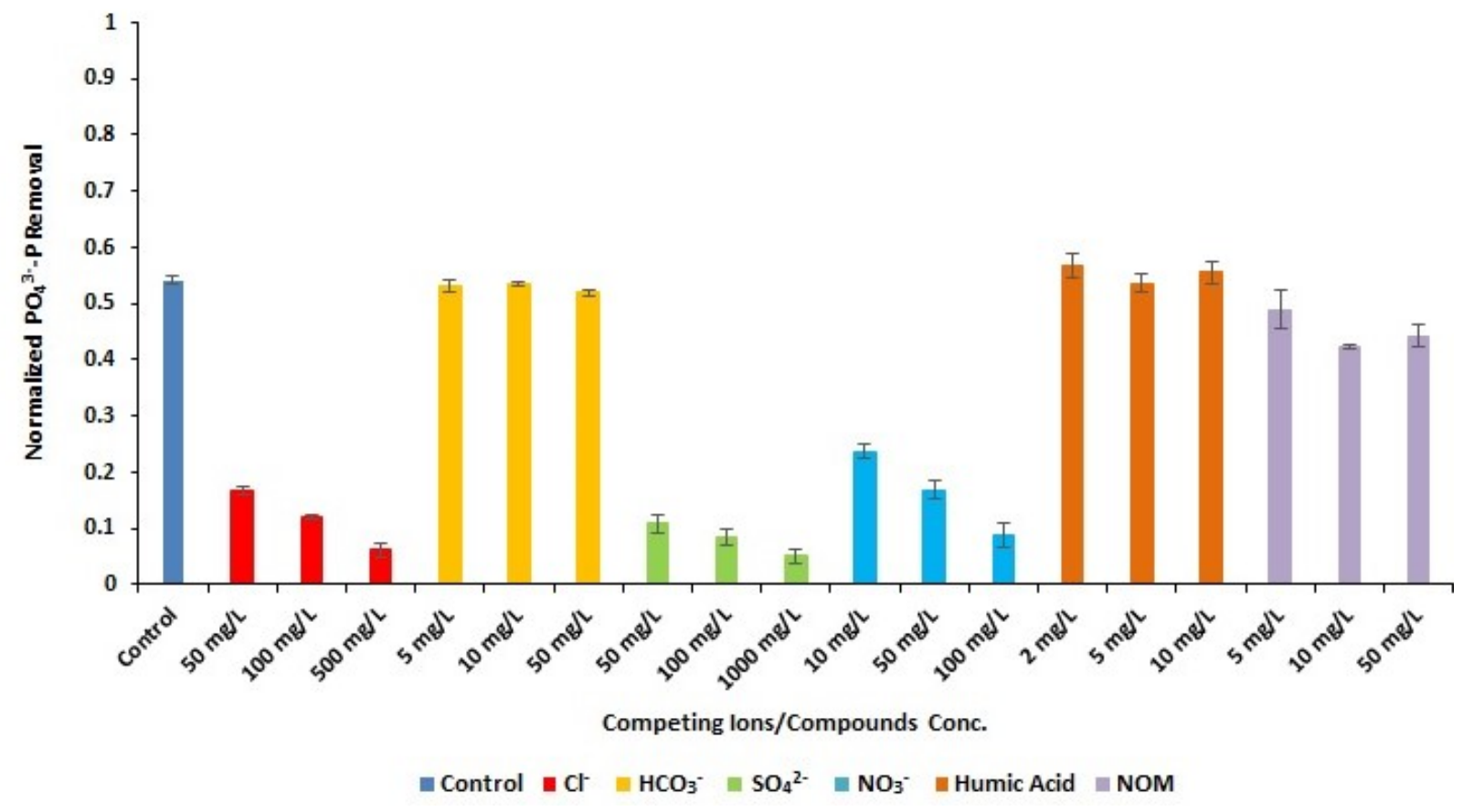

Figure 8. Competition of Common Coexisting Anions and Compounds for Binding Sites on AT $M I P\left(C_{0}=5 \mathrm{mg} \mathrm{PO}^{3--} \mathrm{P} / \mathrm{L}\right)$

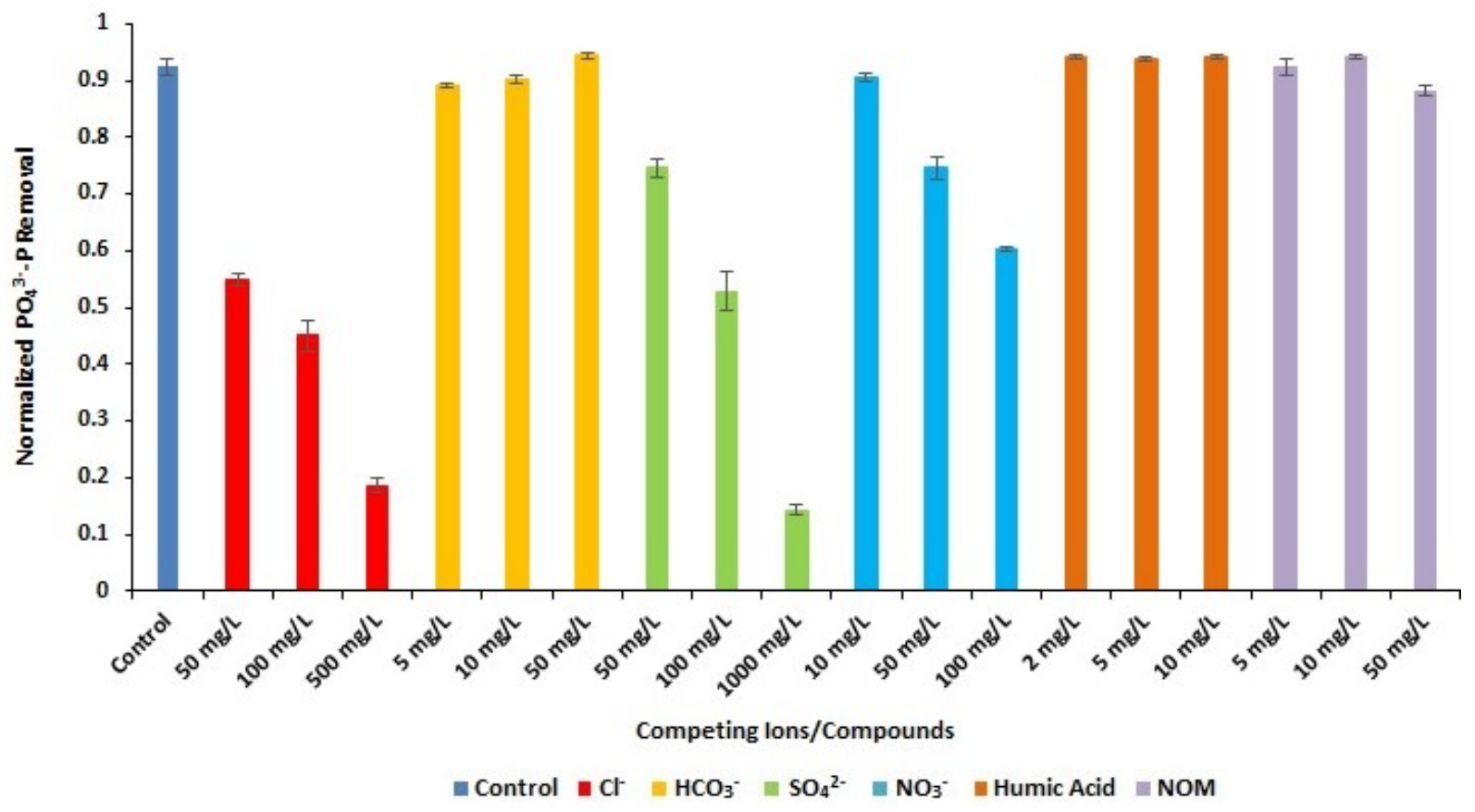

Figure 9. Competition of Common Coexisting Anions and Compounds for Binding Sites on METAC MIP $\left(C_{0}=5 \mathrm{mg} \mathrm{PO}^{3--} \mathrm{P} / \mathrm{L}\right)$ 
At first glance, it may appear that nitrate, chloride, and sulfate are the only ions to be concerned with for interference. This would make any surface water lacking significant quantities of those three anions remiss of interference toward MIP sorption of phosphate. While it is unrealistic to assume that surface waters will be lacking all three of these anions, it was also determined that the physicochemical compositions of those three anions were not the predominant reason for interference. The METAC MIP interference data collected were reorganized, only considering the normalized $\mathrm{PO}_{4}^{3-}-\mathrm{P}$ removal and the equivalent charge concentration (meq/L) of the anions applied (Figure 10). Fluoride (F-), Bromide $(B r-)$, and acetate $\left(\mathrm{C}_{2} \mathrm{H}_{3} \mathrm{O}_{2}^{-}\right)$were included in this reorganization to bolster confidence in the pattern shown. As the presence of negative charge in solution increased, the normalized phosphate removal decreased. It can also be seen that it did not matter as to which anion was used to provide competing negative charge; only the amount of negative charge present in solution impacted phosphate removal. This confirms that the specific anion size, shape, and chemical composition do not play inherently significant roles in the interference with phosphate removal. It also confirms that the METAC MIP is removing phosphate, at least to some degree, through non-selective electrostatic binding to positively charged surface sites. 


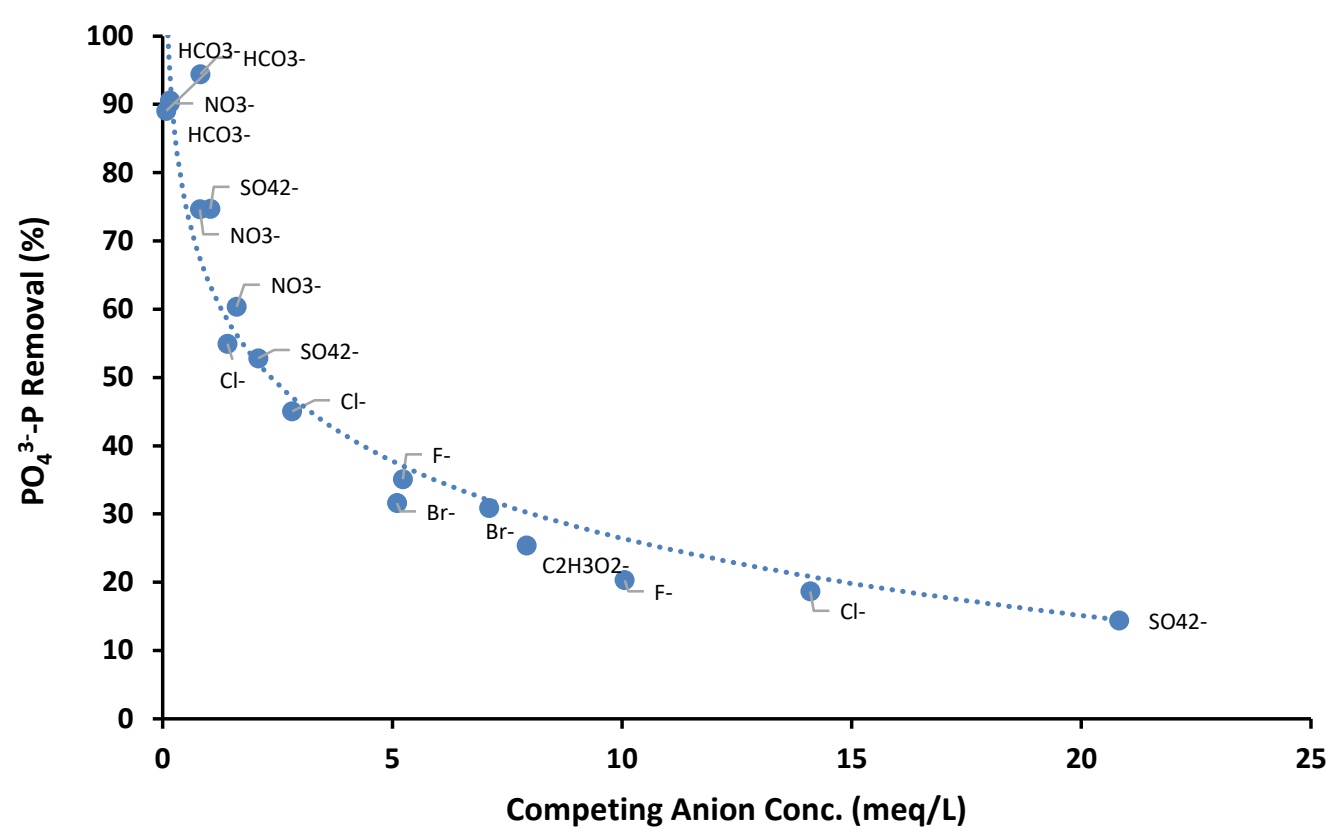

Figure 10. The Effect of Negative Charge Present in Solution on Phosphate Removal ( $C_{0}=5 \mathrm{mg}$ $\left.P O 4^{3-}-P / L\right)$

\subsubsection{Effect from Increasing Template:Monomer Ratio}

The original template:monomer ratio used for synthesis of all of the MIPs was 1:4. It was hypothesized that increasing this ratio will increase the amount of imprinted recognition sites. Under this assumption, it is also plausible that more imprinted recognition sites could lead to better selectivity toward phosphate.

At this point in the study, the AT MIP was eliminated from consideration for testing as it had already reached its maximum template:monomer ratio. This maximum ratio was reached due to solubility issues upon the addition of more template. Insoluble template does not affect the template:monomer ratio as it does not form complexes with the monomer. The decision to remove AT from the study was made due to poor sorption capacity and lack of selectivity at the maximum (1:4) and minimum (0:4) available template:monomer ratio for design. The METAC MIP was considered for further study 
because even though it did not show a resistance to interference from competing anions, it had a sorption capacity which can be considered competitive with many other technologies. There was potential to increase template:monomer ratio in METAC MIP, which could potentially solve the interference issue. Two more template:monomer ratios (4:4 and 12:4) were used to determine their impacts on interference reduction and sorption capacity (Table 4). A ratio of 12:4 was the highest ratio considered because that was the point where the template reached saturation.

Table 4. Components for METAC Reagent Mixtures with Various Template:Monomer Ratios

\begin{tabular}{|c|c|c|c|c|c|}
\hline $\begin{array}{c}\text { Template: } \\
\text { Monomer } \\
\text { Ratio }\end{array}$ & Notation & Monomer Qty. & Cross-linker & Solvent & Template \\
\hline $0: 4$ & MN & $\begin{array}{c}830 \mathrm{mg} \\
(4 \mathrm{mmol})\end{array}$ & $\begin{array}{c}3.8 \mathrm{~mL} \\
(20 \mathrm{mmol})\end{array}$ & $5 \mathrm{~mL}$ & $\begin{array}{c}0 \mathrm{mg} \\
(0 \mathrm{mmol})\end{array}$ \\
\hline $1: 4$ & MM & $\begin{array}{c}830 \mathrm{mg} \\
(4 \mathrm{mmol})\end{array}$ & $\begin{array}{c}3.8 \mathrm{~mL} \\
(20 \mathrm{mmol})\end{array}$ & $5 \mathrm{~mL}$ & $\begin{array}{c}158 \mathrm{mg} \\
(1 \mathrm{mmol})\end{array}$ \\
\hline $4: 4$ & MM4 & $\begin{array}{c}830 \mathrm{mg} \\
(4 \mathrm{mmol})\end{array}$ & $\begin{array}{c}3.8 \mathrm{~mL} \\
(20 \mathrm{mmol})\end{array}$ & $5 \mathrm{~mL}$ & $\begin{array}{c}632 \mathrm{mg} \\
(4 \mathrm{mmol})\end{array}$ \\
\hline $12: 4$ & MM12 & $\begin{array}{c}830 \mathrm{mg} \\
(4 \mathrm{mmol})\end{array}$ & $\begin{array}{c}3.8 \mathrm{~mL} \\
(20 \mathrm{mmol})\end{array}$ & $5 \mathrm{~mL}$ & $\begin{array}{c}1,896 \mathrm{mg} \\
(12 \mathrm{mmol})\end{array}$ \\
\hline
\end{tabular}

The impact of the template:monomer ratio on reduction of anion interference was analyzed under the same conditions as previously mentioned, where negative charge was introduced in varying amounts by several different anions. One-way ANOVA testing under a 95\% CI indicated that an increase in the template:monomer ratio made an insignificant difference on the METAC MIP's resistance to interference from competing anions (Figure 11). This confirms that increasing the template:monomer ratio does not reduce or overcome the presence of electrostatic interactions between anions and the METAC MIP. 


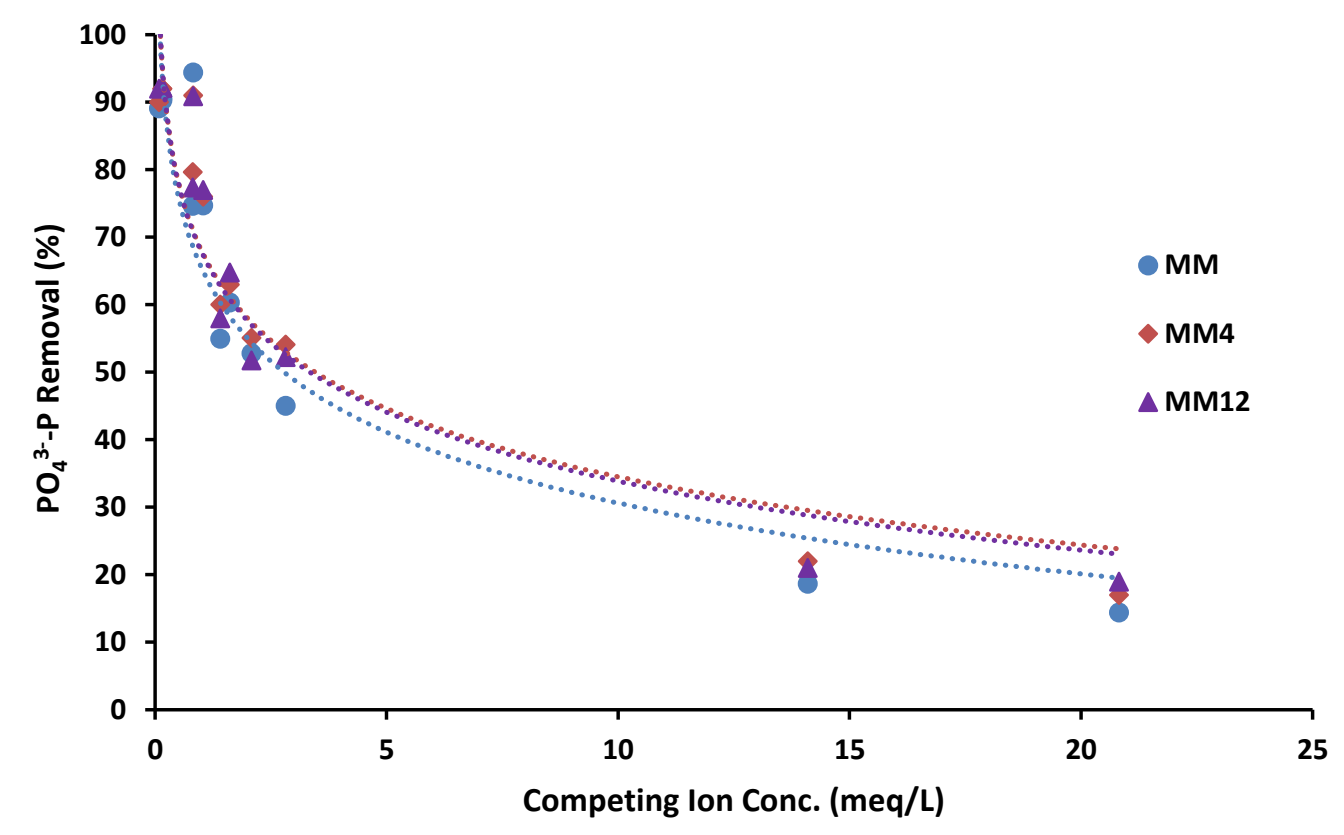

Figure 11. The Effect of Negative Charge Present in Solution on Phosphate Removal by METAC MIPs with Varying Template:Monomer Ratios ( $\left.C_{0}=5 \mathrm{mg} \mathrm{PO} 4^{3-}-\mathrm{P} / \mathrm{L}\right)$

Next, the impact of the template:monomer ratio on the sorption capacity was studied. The sorption capacities of all three METAC MIPs (MM, MM4, and MM12) along with the control, METAC NIP (MN), were compared. The data were fit to the Freundlich and Langmuir isotherm models (Figures 12 \& 13). The isotherm coefficients $\left(\mathrm{K}_{\mathrm{F}}, \mathrm{n}, \mathrm{K}_{\mathrm{L}}, \mathrm{q}_{\mathrm{m}}\right)$ and fit $\left(\mathrm{R}^{2}\right)$ were determined from the linearized forms of Eqs. 1 \& 2 and are summarized (Tables 5 \& 6).

Table 5. Coefficients and Fit of Freundlich Isotherm Model

\begin{tabular}{|c|c|c|c|}
\hline \multirow{2}{*}{ Polymer } & \multicolumn{2}{|c|}{ Freundlich Coefficients } & Fit \\
\cline { 2 - 4 } & $\mathrm{K}_{\mathrm{F}}$ & $\mathrm{n}$ & $\mathrm{R}^{2}$ \\
\hline MM12 & 0.223 & 1.682 & 0.9715 \\
MM4 & 0.230 & 1.776 & 0.9727 \\
MM & 0.310 & 2.180 & 0.9904 \\
MN & 0.061 & 1.504 & 0.9690 \\
\hline
\end{tabular}


Table 6. Coefficients and Fit of Langmuir Isotherm Model

\begin{tabular}{|c|c|c|c|}
\hline \multirow[b]{2}{*}{ Polymer } & \multicolumn{2}{|c|}{ Langmuir Coefficients } & Fit \\
\hline & $\mathrm{K}_{\mathrm{L}}$ & $\mathrm{q}_{\mathrm{m}}$ & $\mathrm{R}^{2}$ \\
\hline MM12 & 0.0012 & 30.960 & 0.7114 \\
\hline MM4 & 0.0024 & 19.608 & 0.9391 \\
\hline MM & 0.0037 & 11.669 & 0.9507 \\
\hline MN & 0.0019 & 11.403 & 0.9432 \\
\hline
\end{tabular}

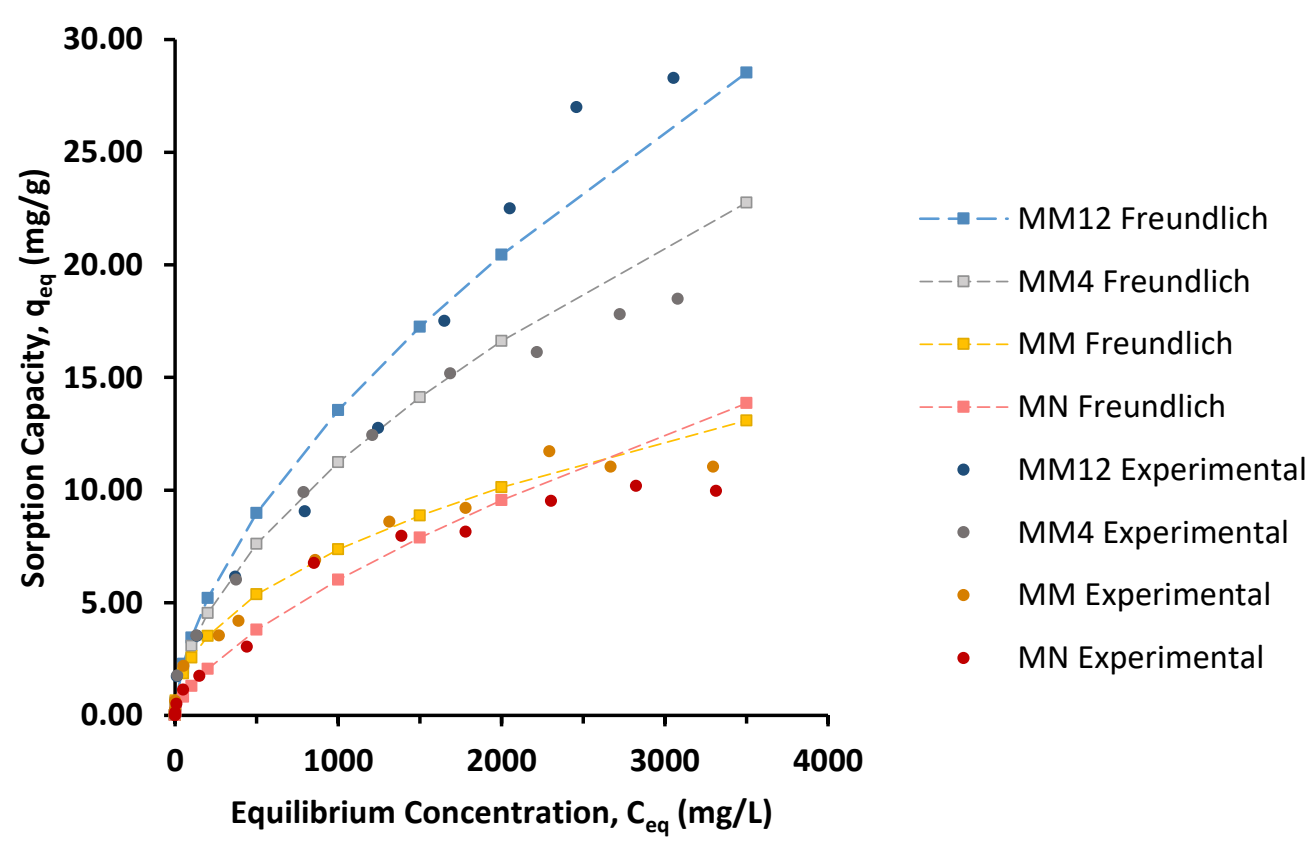

Figure 12. Comparison of METAC Freundlich Isotherm Model with Varying Template:Monomer Ratios 


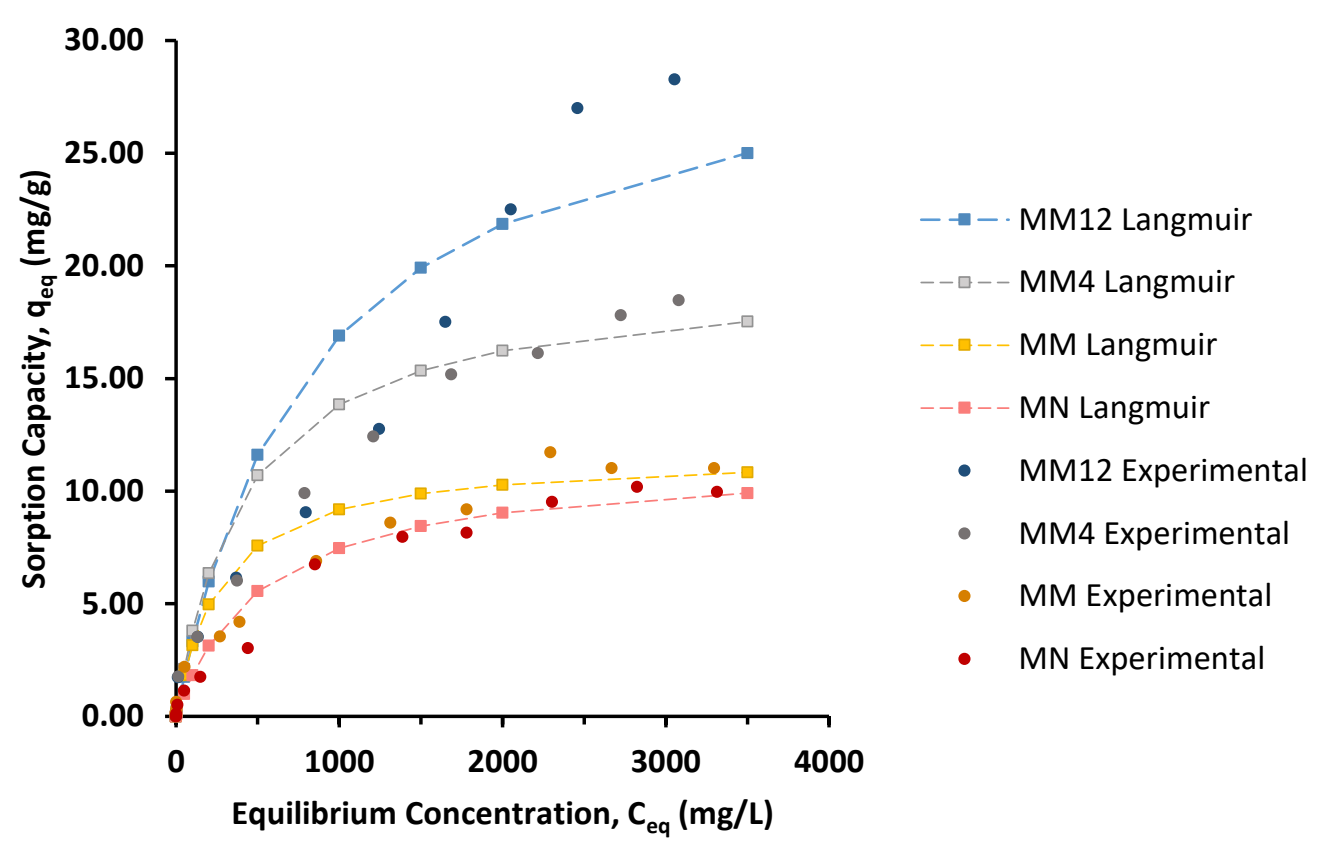

Figure 13. Comparison of METAC Langmuir Isotherm Model with Varying Template:Monomer Ratios

One-way ANOVA testing under a 95\% $\mathrm{CI}$ showed that with an increase in template:monomer ratio, the sorption capacity significantly increased as well. The increase in sorption capacity indicates that more active phosphate binding sites are becoming available on or within the polymer matrix. Due to the increase being a direct result of increasing the amount of template, it is assumed that these active binding sites are selective recognition sites. Based on this finding, it appears that MIPs could be designed for higher sorption capacities by increasing their template:monomer ratios. While this design parameter is significantly influenced by monomer and template saturation point within the solvent used, this finding could still help provide the framework for future development of MIPs. 


\subsubsection{Removal from Low Concentration Phosphate from Lake Water}

In order for a sorbent technology to be feasible for surface water application, it must be able to remove phosphate concentrations below environmentally relevant levels ( $50 \mu \mathrm{g}$ $\mathrm{PO}_{4}{ }^{3--\mathrm{P} / \mathrm{L})}$. Thus, the MM12 was tested in a low concentration phosphate solution $(\sim 150 \mu \mathrm{g}$ $\mathrm{PO}_{4}{ }^{3-}-\mathrm{P} / \mathrm{L}$ ). Even though interference studies were conducted on the METAC MIPs, it was still necessary to see how MM12 behaves in actual lake water. MM12 was selected for further study over the other METAC MIPs (MM and MM4) due its heightened sorption capacity, making it the sorbent with the most potential. After retrieving the samples and analyzing P content, it was found that concentrations of $\mathrm{P}$ were lower than $50 \mu \mathrm{g} \mathrm{PO} 4^{3--P / L}$. Therefore, the lake water samples were artificially spiked with $\mathrm{KH}_{2} \mathrm{PO}_{4}$ to bring their concentrations to a range of $100-200 \mu \mathrm{g} \mathrm{PO}_{4}^{3--P} / \mathrm{L}$. Lakes sampled and spiked are as follows: Lake Katrina (185 $\left.\mu \mathrm{g} \mathrm{PO} 4^{3--P / L}\right)$, Holy Name Lake $\left(180 \mu \mathrm{g} \mathrm{PO} 4^{3--P} / \mathrm{L}\right)$, Lake

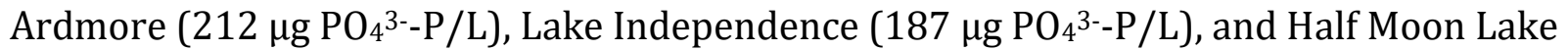
$\left(157 \mu \mathrm{g} \mathrm{PO} 4^{3--\mathrm{P} / \mathrm{L})}\right.$ (Figure 14). It was observed that MM12 was able to remove phosphate to levels lower than $50 \mu \mathrm{g} \mathrm{PO} 4^{3--P} / \mathrm{L}$ in synthetic water and lake waters. One-way ANOVA testing under a 95\% CI indicated that differences in removal between synthetic water and lake waters were insignificant for all except Lake Independence and Holy Name Lake. This difference is likely attributed to competing anions present in the lake waters. This study reinforces the concept of using MIPs to remove phosphate below environmentally relevant levels; a feat that several established technologies for phosphate removal cannot accomplish. 


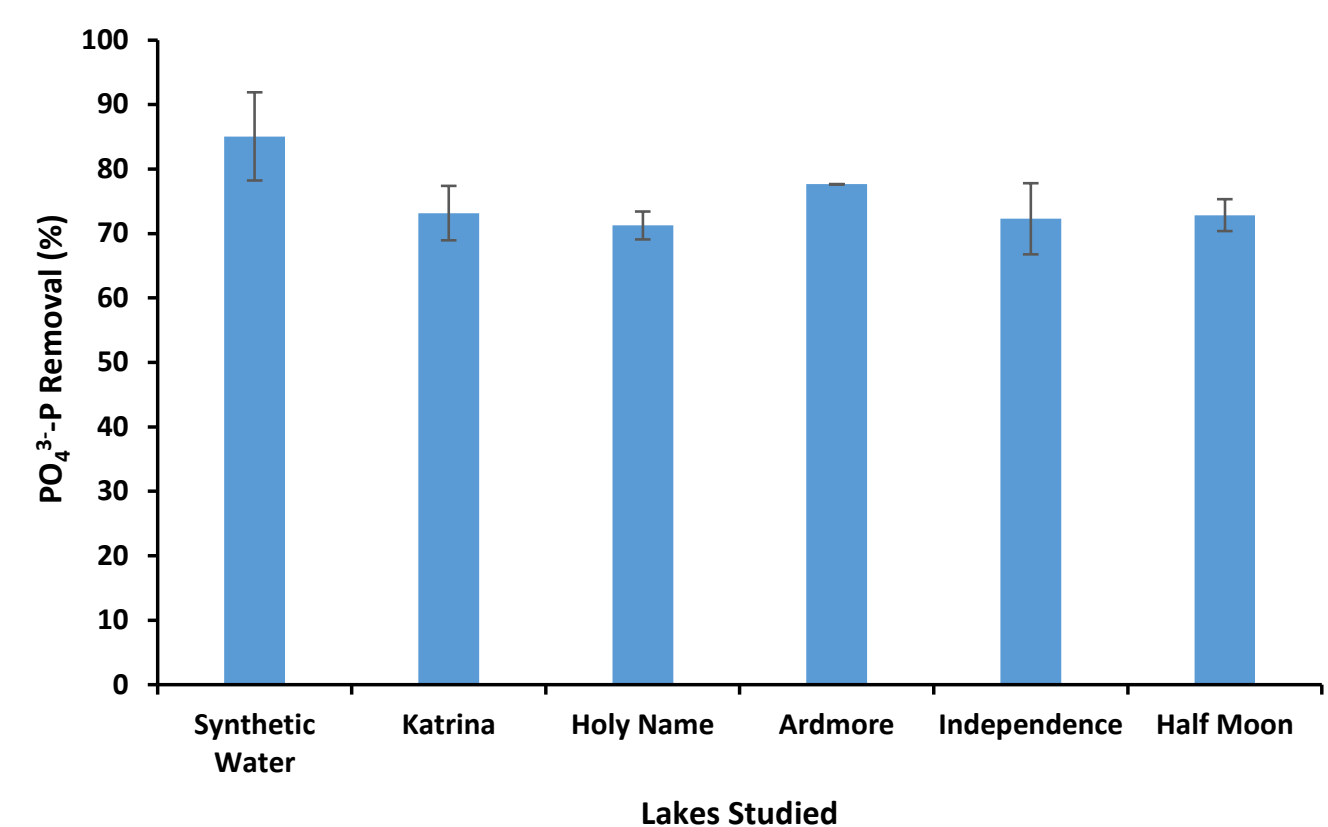

Figure 14. Phosphate Removal from Select Minnesota Lakes with MM12

\subsubsection{Influence from Temperature}

For MIPs to have any future as sorbents for eutrophic lake remediation, they must be able to handle seasonal variations in water temperatures. Lake water temperatures can reach as low as $4{ }^{\circ} \mathrm{C}$ (before freezing begins to occur) in the winter and can occasionally break $30^{\circ} \mathrm{C}$ in summer time conditions (http://www.gvsu.edu/videticp/stratification.htm, 2001). To assess the behavior of MM12 in a wide range of temperature conditions, the polymer and phosphate solution were studied in an environmental chamber where the temperature could be adjusted, monitored, and kept constant for extended periods of time (Figure 15). One-way ANOVA testing under a 95\% CI showed there was no significant variation in phosphate removal efficiencies observed between temperatures. This suggests that MM12, and potentially most other MIPs, can be used effectively during any season. 


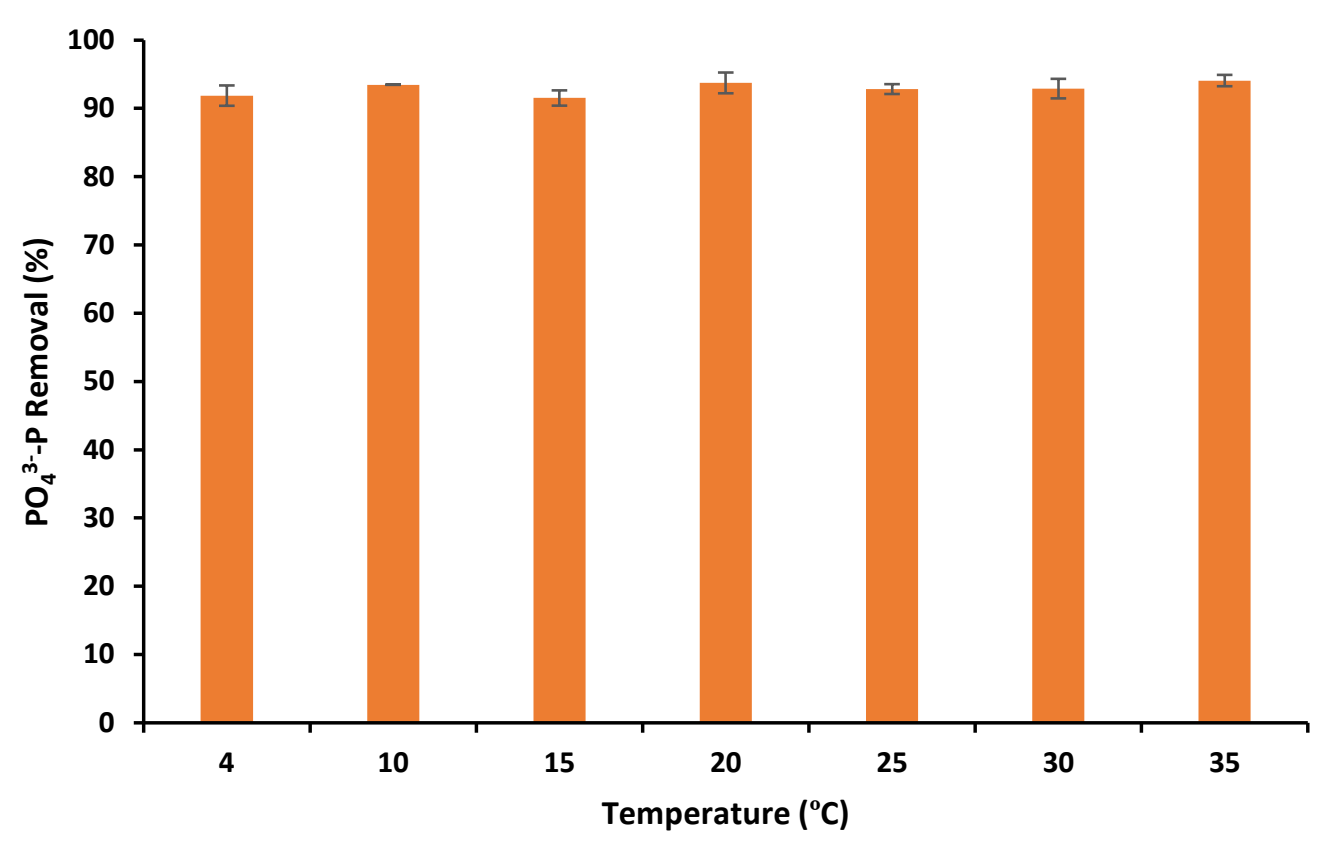

Figure 15. Influence of Temperature on Phosphate Removal Efficiency with MM12 ( $C_{0}=5 \mathrm{mg}$ $\left.\mathrm{PO}_{4}{ }^{3-}-\mathrm{P} / L\right)$

\subsubsection{Biochemical Availability and Potential for P Recovery}

\subsubsection{Biodegradability}

In order for used MM12 to be reused in agriculture, it must be biodegradable. Nonbiodegradable materials will reside in precious soil space for years on end without sorbed $\mathrm{P}$ being bioavailable to plants. Toxicity toward microorganisms and plants is one limiting factor that has prevented many wastewater P-recovery technology products from being feasible for reuse. Wastewater also contains heavy metals that are also removed by adsorbents. It is these heavy metals that cause toxicity toward microorganisms and plants, resulting in detrimental effects on croplands (Satorius et al., 2012). To assess MM12's potential for biodegradability, a respirometer experiment was conducted using the BODTrak (Hach, USA). Triplicate samples of the MM12 in a solution of bacteria and BOD nutrient were compared against triplicate samples of a control with only bacteria and BOD 
nutrient. After correcting the BOD reading for dilution and seeding factors (Appendix 3.6) the average readings were reported here (Figure 16). Samples with MM12 present showed higher levels of BOD when compared to the samples without them. This indicates that the MM12 served as a source of food for microorganism consumption, and that MM12 is biodegradable. This conclusion opens up the possibility that MM12 (with P sorbed) may be applicable for fertilizer use. Further studies would need to be conducted to ensure that MM12 biodegradation and its by-products do not result in toxicity in plants.

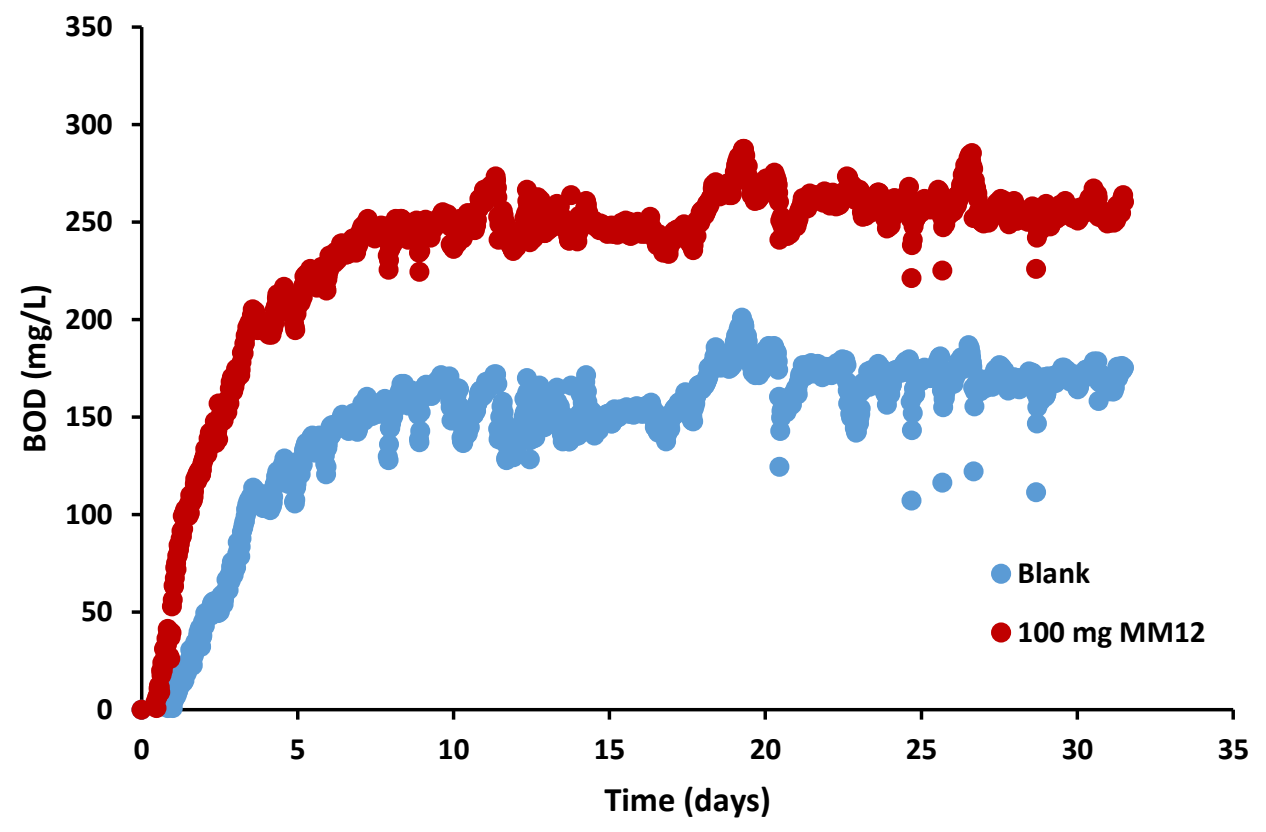

Figure 16. Respirometric Data of Biodegradability of MM12

\subsubsection{Desorption Study}

To understand how MM12 may behave as a soil amendment, the P-release mechanism needs to be understood. Fertilizer supplements that release P immediately are not as advantageous as slow P-release technologies. This is because plants cannot uptake all of the P that is supplied to them immediately. The current problem with fertilizer applications is that $40 \%$ of $\mathrm{P}$ applied results as surface runoff due to crops having the 
inability to uptake the P at high rates (Rittmann et al., 2011). Technologies that can release P in small amounts over a long period of time are more beneficial to plant growth as the slow release behavior more ideally matches with plant uptake kinetics.

A desorption study was conducted using spent (Figure 17) MM12. Fresh MM12 was initially placed in high phosphate concentration solution (2000 mg PO $4^{3--P / L) . ~ A n a l y s i s ~ o f ~}$ phosphate removal from bulk solution showed that the MM12 had $\sim 17 \mathrm{mg}$ of sorbed $\mathrm{PO}_{4}{ }^{3-}$ P available for release from MM12. After the six testing cycles (four total days), the desorption study indicates that MM12 released $29.3 \%\left(\sim 5 \mathrm{mg} \mathrm{PO} 4^{3-}-\mathrm{P}\right)$ of sorbed phosphate. The majority (19.2\%) of that $29.3 \%$ was released during the first cycle (6 hours). Each subsequent cycle released less $\mathrm{P}$ than the cycle before it. It is believed that this release of $\mathrm{P}$ is coming from the phosphate that is bound to the polymer electrostatically. This pattern of continuously decreasing P-release rates is expected to continue until the remaining majority of $\mathrm{P}$, which is assumed to be strongly bound to imprinted recognition sites within the polymer matrix, is released. To be able to access the $\mathrm{P}$ bound in this manner, the polymer would need to be degraded over a time. This mechanism of P-release would establish a slow release regiment that would be highly beneficial for plant growth. Studies in actual conditions (soil with growing plants) would need to be conducted in order to assess the P-release mechanism. 


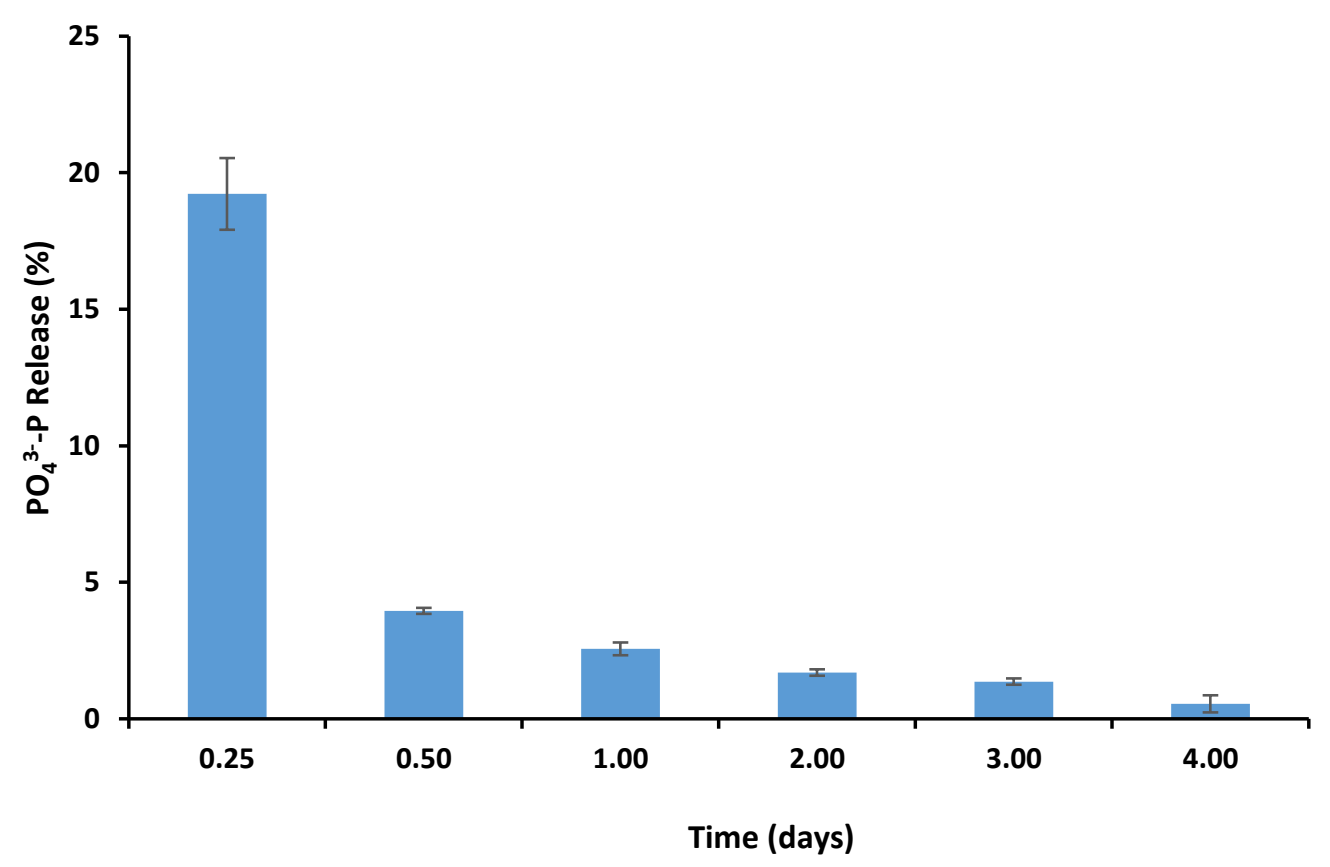

Figure 17. Phosphate Release from MM12 during Desorption Study

\subsubsection{MIP Characterization}

\subsubsection{SEM/EDS Analysis}

Characterization of the METAC MIP's surface via SEM/EDS analysis was done to gain an insight to the polymer's morphology. Additionally, the morphology of the polymer was studied under variable template:monomer ratios to see what affect the amount of templating could have on surface morphology. The first analysis was completed at the micron-scale using a low-resolution SEM (Figure 18(a-d)). An immediate trend can be found from the change in surface morphologies from one template:monomer ratio to the next. At the lowest ratio, MN (0:4), the surface appears extremely rough and heterogeneous in nature (Figure 18(a)). As the template:monomer ratio increases, the surface tends to become smoother and more homogenous than the previous until reaching the maximum ratio, MM12 (12:4), where the surface appears extremely smooth and flat (Figure 18(b- 
d)). (Wu, 2012) previously discussed how MIPs tend to have heterogeneous chemical structures at low template:monomer ratios. Surface characterization was never completed in tandem with that work. However from that work, it's reasonable to believe that increasing the template:monomer ratio will consequently increase homogeneous structure of MIPs. An increase in the overall homogeneity of the polymer matrix could explain the trend seen in surface morphology as homogeneous nature may generate more uniformity in surface structure.
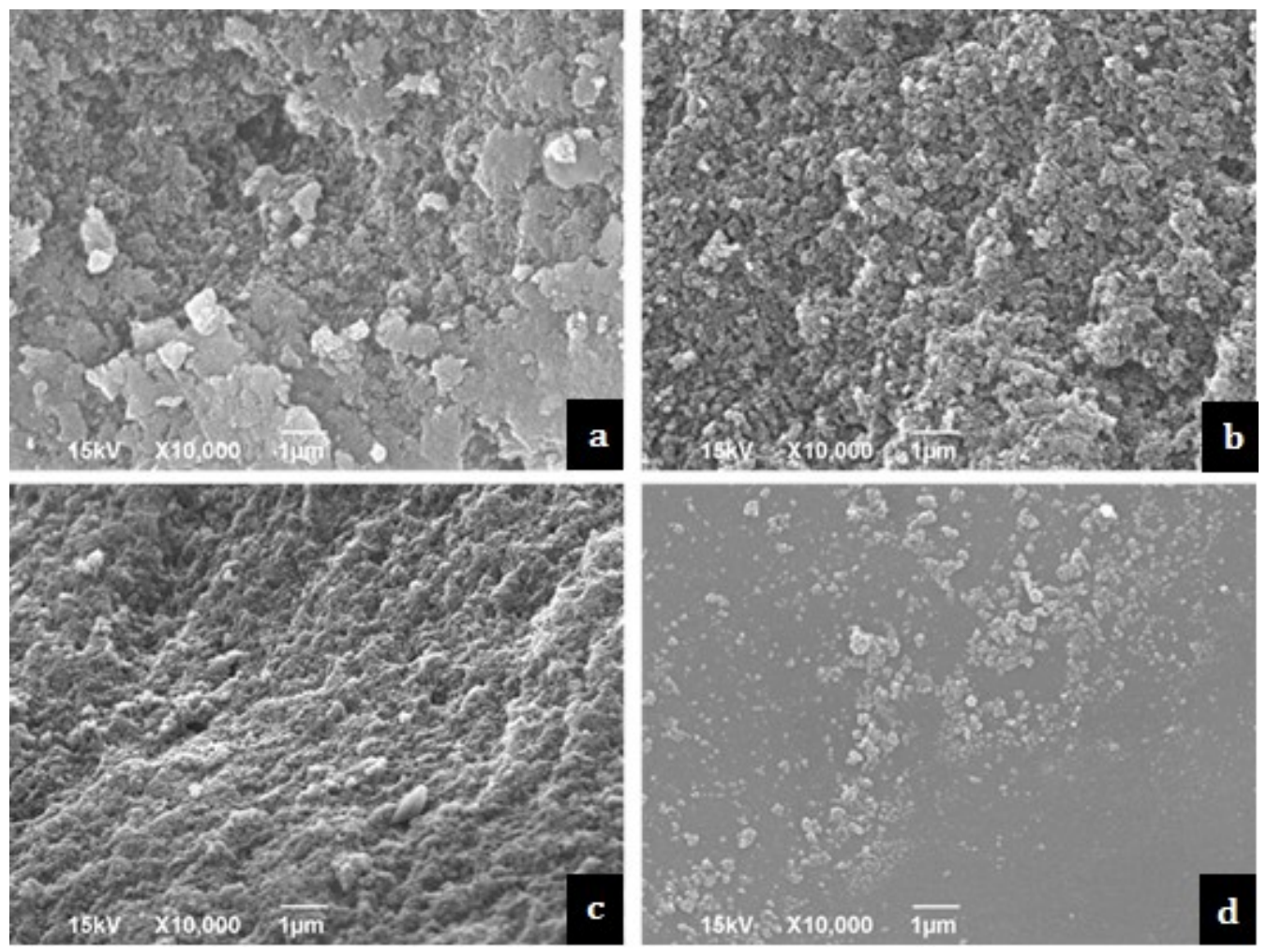

Figure 18. Low-resolution SEM Characterization of MN (a), MM (b), MM4 (c), and MM12 (d)

After seeing the changes to the surface on the micron-scale, it was deemed necessary to investigate what type of changes may have happened at the nano-scale. To view the polymer surface at this scale, high-resolution SEM was employed (Figure 19(ad)). One of the primary targets of this analysis was to characterize potential changes in the 
pore distribution or quantity. The high-resolution images are not of the highest quality as the polymers heated easily, resulting in image drift. The non-imprinted polymer (MN) was the only polymer void of explicit nanopores. While it was originally believed that the development of nanopores would be the result of template extraction from the polymer matrix, the nanopores are of larger size than the template molecules. Additionally, there was no distinguishable pattern change in nanopore distribution or quantity between the different template:monomer ratios at this scale. One general trend found was the localization of nanopores in clusters, which were scattered across the polymer particles. The template molecules may be bound into the polymer matrix in localized clusters, and the extraction of those clusters may be responsible for the development of the observed nanopores, however that remains to be unknown. It should be noted that even though MN did not show explicit nanopores, it still has a porous structure. The general porous structure of MN and the other MIPs is likely the result of the extraction of the porogen. During polymerization, the solvent (porogen) phase-separates and is trapped within the polymer matrix. The extraction process then pulls the porogen out, leaving behind a porous polymeric structure. Many of the nanopores were pointed out with white arrows to help distinguish them from the natural porous structure. 

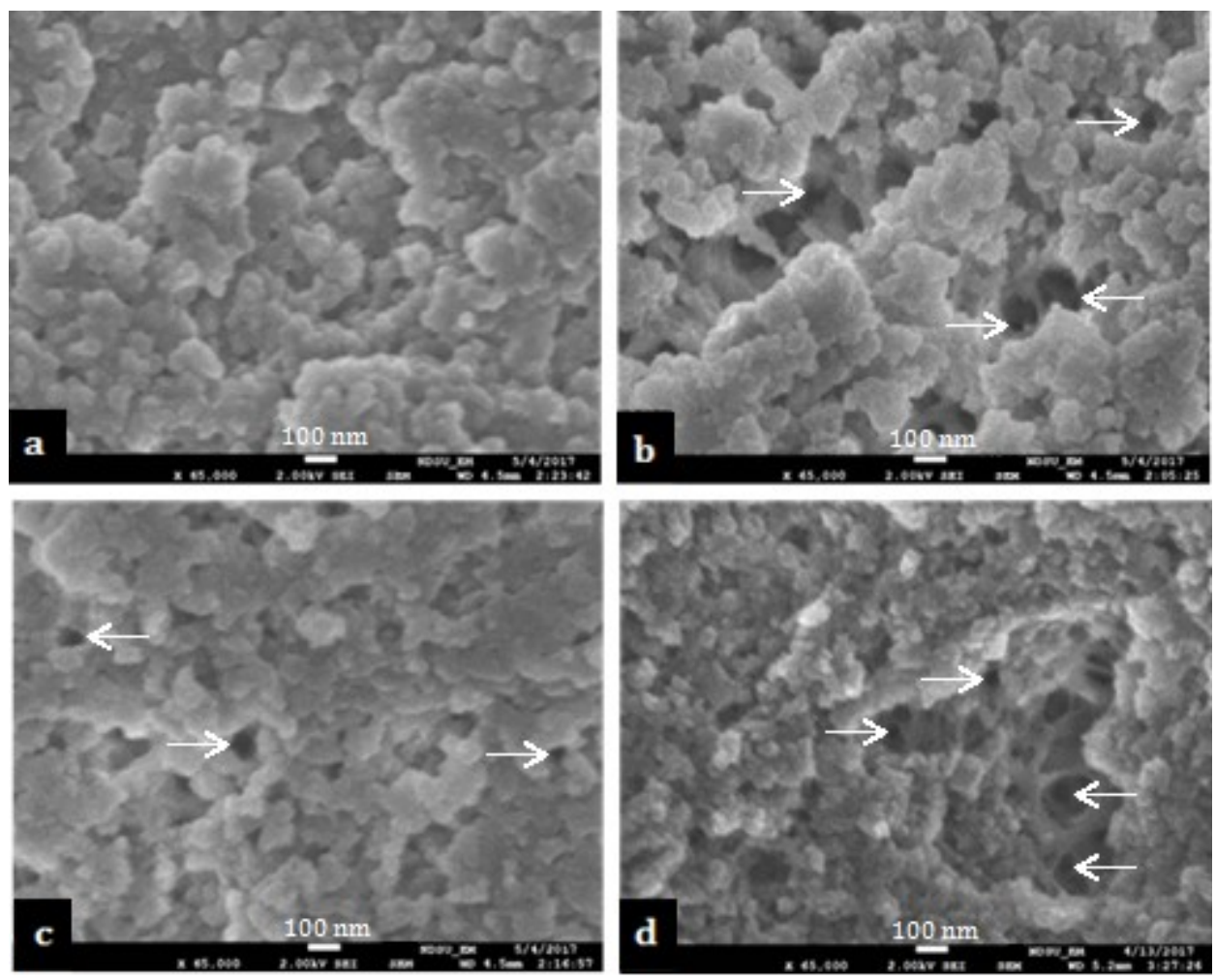

Figure 19. High-resolution SEM Characterization of $M N(a), M M(b), M M 4$ (c), and MM12 (d)

Lastly, EDS analysis was performed on MM12 (Figure 20). This analysis was performed to validate that the polymer is physically removing phosphate, as opposed to precipitating the phosphate from solution. For a control, EDS analysis was also performed on MM12 which had not been placed in a phosphate solution (Figure 21). On the blank MM12, EDS results showed the surface consisting of predominantly carbon and oxygen. Trace amounts of chloride were found, likely trapped in the polymer matrix after the dissociation and polymerization of the METAC monomer. Gold was found as well; however, the presence of gold is attributed to the coating that was used for sputtering on the polymer to provide conductivity to the sample. On the MM12 with sorbed phosphate, EDS results showed that the surface once again consisted of predominantly carbon and oxygen. Trace amounts of chloride was also found. Potassium was also detected in trace amounts 
on the surface, which is likely the result of some potassium dissociating from $\mathrm{KH}_{2} \mathrm{PO}_{4}$ and being adsorbed onto the surface of the polymer. Lastly, phosphorus was found on the surface of the polymer. The presence of phosphorus confirms that phosphorus was adsorbed as phosphate onto the surface of the polymer.

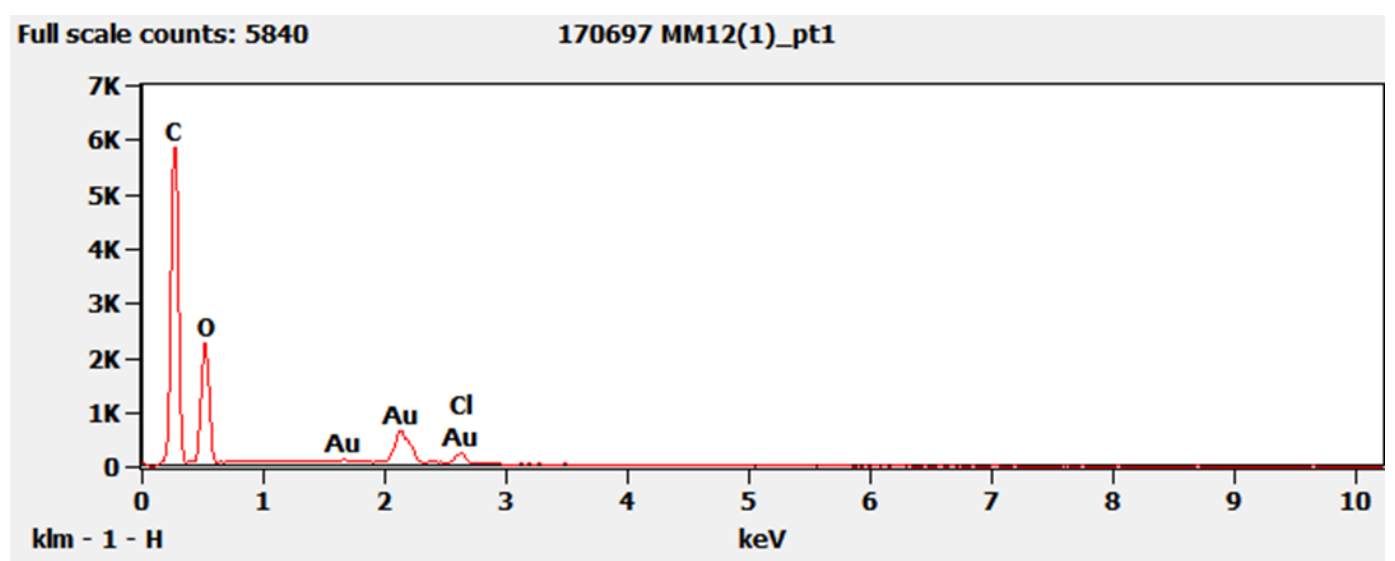

Figure 20. EDS Data from Analysis on Blank MM12

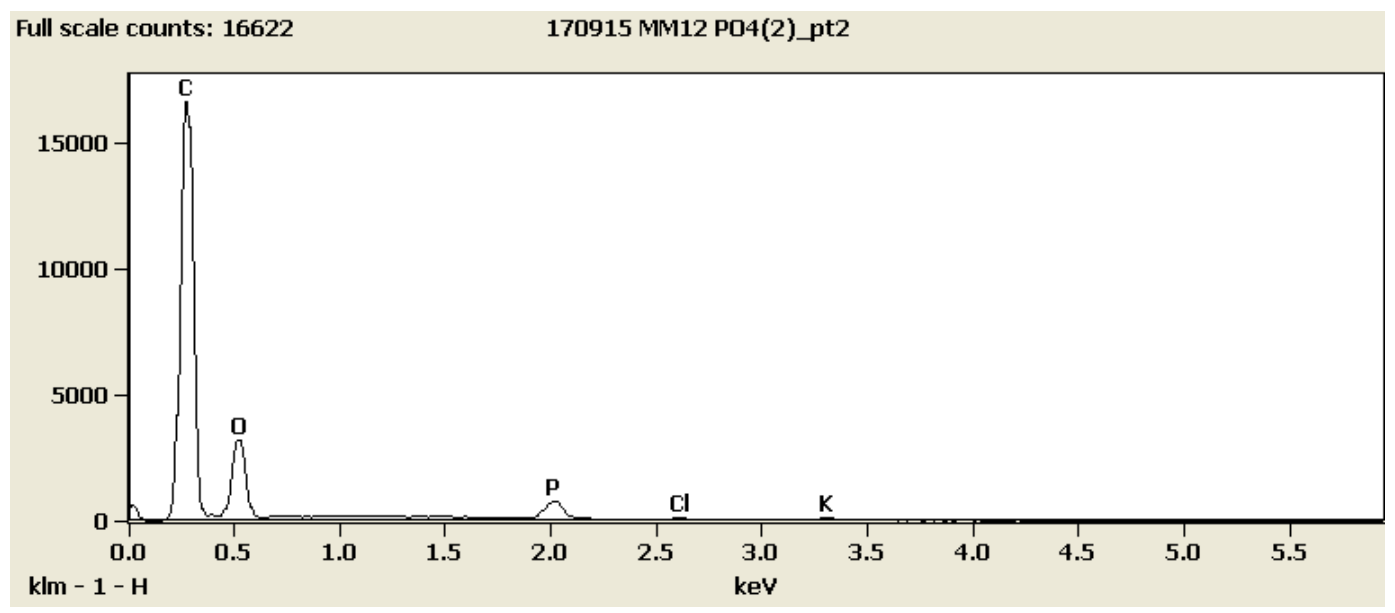

Figure 21. EDS Data from Analysis with Adsorbed Phosphate

\subsubsection{FTIR Spectroscopy}

FTIR spectroscopy can help determine what time of bonding is present within a material based on the unique rotational and vibrational resonances that result from bonds being gently excited by infrared radiation. FTIR analysis can help determine whether or not the template, phenylphosphonic acid, is being imprinted. To be imprinted, the template 
must first be bound in a complex with the monomer. Presence of the template bonds in the polymer matrix will confirm that the template is being imprinted. On top of that, loss of the template bonds after the extraction process will indicate effective template removal from the Soxhlet extraction. Lastly, if there is any selective recognition of phosphate in the MIP, it will be observed here. Phosphate, which is selectively removed by the recognition sites in the MM12, will be bound into the polymer matrix. Therefore, $\mathrm{P}$ binding should be seen. FTIR analysis was performed on unfinished MM12 just after synthesis without extraction (MM12 UNF), fresh MM12 after extraction (MM12), and spent MM12 after phosphate sorption (MM12 PF) (Figure 22).

In the MM12 sample before template extraction, there are several bands unique to the spectra as compared to after extraction. Weak bands at 1600 and $1500 \mathrm{~cm}^{-1}$ indicate the presence of $\mathrm{C}=\mathrm{C}$ stretching in a mono-alkyl arene ring structure $\left(\mathrm{R}-\mathrm{C}_{6} \mathrm{H}_{5}\right)$. The band at $990 \mathrm{~cm}^{-1}$ is indicative of a phosphorus ester functional group (P-OR). Lastly, strong band intensities at 700 and $680 \mathrm{~cm}^{-1}$ identify $=\mathrm{C}-\mathrm{H}$ bending in mono-alkyl arenes $\left(\mathrm{R}-\mathrm{C}_{6} \mathrm{H}_{5}\right)$. Phenylphosphonic is the only compound with a ring structure that was introduced into the reagent mixture for synthesis. Thus, it is clear that these bands are representative of phenylphosphonic acid's binding within the polymer matrix. Additionally, it can be seen in the spectra after extraction (MM12) that these bands disappear entirely. This suggests that phenylphosphonic acid is being effectively extracted from the polymer matrix, leaving imprinted recognition sites behind.

Signals from $\mathrm{P}=0$ stretching can generally be seen in the $1100-1200 \mathrm{~cm}^{-1}$ range. The $1130 \mathrm{~cm}^{-1}$ band is located right in that region. However, there are also intense signals coming from $\mathrm{C}-\mathrm{O}$ stretching in that region. The coexistence of these two signals in the same 
region makes it impossible to use that band region as an identifier for phosphate sorption. However, comparing the spectra of MM12 after phosphate sorption (MM12 PF) to the other spectra before phosphate sorption shows one unique difference. In the spectra before phosphate sorption, the relative intensities of the bands at $510 \mathrm{~cm}^{-1}$ and $490 \mathrm{~cm}^{-1}$ are equal. After phosphate sorption, the relative intensity of the band at $510 \mathrm{~cm}^{-1}$ significantly increases compared to that of the band at $490 \mathrm{~cm}^{-1}$, which remains constant. The increase in relative intensity is likely constituted by phosphate conjugation around nitrogen, forming $\left(\mathrm{PNCl}_{2}\right)_{3}$. From observation, it can be seen that the $510 \mathrm{~cm}^{-1}$ band was present before phosphate extraction. Before phosphate extraction, the appearance of this band was likely due to the presence of an alkyl halide with chlorine as its halogen component (C-Cl). Both of these explanations would justify the appearance of chlorine in the EDS analysis.

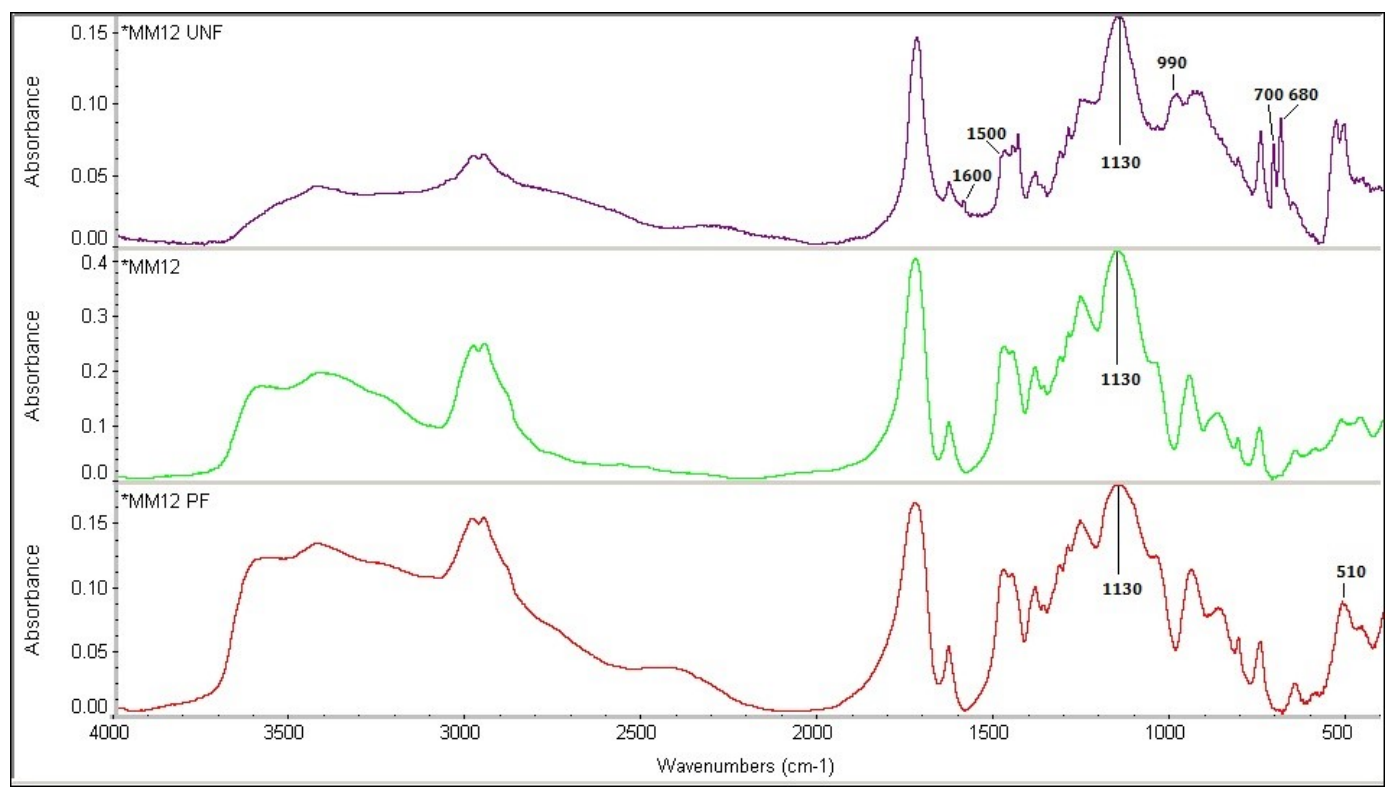

Figure 22. FTIR Spectra of MM12 during Different Phases of Life Cycle

While the analysis of the FTIR spectra does not prove selective binding of phosphate, it does validate the existence of bound phosphate. This suggests that the two 
primary mechanisms of phosphate removal with the MM12 are electrostatic attraction to the surface and phosphate-binding with nitrogen in the recognition sites.

\subsubsection{Swelling Studies, and Prediction of Porosity and Hydrated Diameter}

Upon immersion of MM12 particles in DI water for 30 minutes, it was found that the MM12 particles exhibited the following swelling capability (Table 7). From this information, the porosity of and hydrated diameter of the particle average was determined (Table 7). Such a high degree of swelling is indicative of the polymer likely having higher available surface area for anion interaction when immersed in water.

Table 7. Swelling, Predicted Porosity, and Predicted Hydrated Diameter of Hydrated MM12 particles

\begin{tabular}{|c|ccccc|}
\hline $\begin{array}{c}\text { MM12 } \\
\text { Samples }\end{array}$ & $\begin{array}{c}\text { Initial Dry } \\
\text { Weight } \\
\left(\mathrm{W}_{\mathrm{i}, \mathrm{g})}\right.\end{array}$ & $\begin{array}{c}\text { Hydrated } \\
\text { Weight } \\
\left(\mathrm{W}_{\mathrm{s}}, \mathrm{g}\right)\end{array}$ & $\begin{array}{c}\text { Swelling (\%) } \\
\text { eq. (4) }\end{array}$ & $\begin{array}{c}\text { Predicted Porosity } \\
\text { of Hydrated } \\
\text { Particles } \\
(\varepsilon, \%)\end{array}$ & $\begin{array}{c}\text { Predicted Diam. } \\
\text { of Hydrated } \\
\text { Particles } \\
(\mathrm{D}, \mathrm{mm})\end{array}$ \\
\hline 1 & 1.0236 & 2.5222 & 146.4 & 60.9 & 1.68 \\
2 & 1.1650 & 3.0674 & 163.3 & 63.5 & 1.79 \\
3 & 1.4737 & 3.6570 & 148.2 & 61.2 & 1.90 \\
Average & 1.2208 & 3.0822 & $152.6 \pm 7.6$ & $61.9 \pm 1.1$ & $1.79 \pm 0.09$ \\
\hline
\end{tabular}

\subsubsection{Mechanism of Phosphate Removal}

\subsubsection{Investigation of Partial-selectivity}

At this point, there has been little to no evidence of the synthesized MIPs having any form of selective phosphate recognition. The MM12 can be seen to have a significantly higher P sorption capacity than MM4, MM, and its non-imprinted counterpart, MN (Figure 23). This increased sorption capacity can be attributed to one of two situations. First, the increase in template:monomer ratio could result in greater porosity of the polymer, allowing for more anions to be trapped within the polymer pores by non-selective 
electrostatic attraction. The prospective alternative is that the increased template:monomer ratio generates a greater quantity of recognition sites within the polymer matrix which have the capability of selectively binding phosphate. To validate whether the increase in sorption capacity was from selective phosphate binding or nonspecific anion attraction, an experiment was designed. It has already been shown from interference studies that MM12 binds anions non-specifically due to having a positive surface charge. The underlying question is whether or not all of the phosphate removal observed was non-specific binding.

Mixing MM12 in extremely high anion concentration (110 meq/L) solution allows the non-specific binding surface sites to become saturated by the anion. If any of the recognition sites generated from imprinting are actually selective toward phosphate, their phosphate recognition capabilities will not be affected by the presence of anions. Then once introducing phosphate along with the competing anion in equal parts $(110 \mathrm{meq} / \mathrm{L})$, the removal of phosphate will be uninterrupted. For predictive capabilities, we can look at

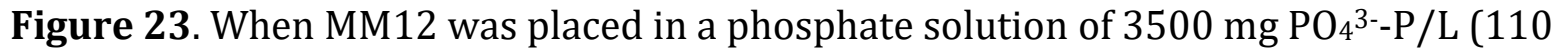
meq/L), its sorption capacity was $\sim 28 \mathrm{mg} \mathrm{PO} 4^{3--P}$. On the other hand when $\mathrm{MN}$ was placed in a phosphate solution of $3500 \mathrm{mg} \mathrm{PO} 4^{3-} \mathrm{P} / \mathrm{L}(110 \mathrm{meq} / \mathrm{L})$, its sorption capacity was $\sim 10$ mg PO4-3-P. If we consider MM12's removal to be the combination of electrostatic attraction and selective recognition and MN's removal to be the combination of purely electrostatic attraction, then the difference between the two polymers' sorption capacities will be the sorption capacity of the selective recognition sites ( $\left.18 \mathrm{mg} \mathrm{PO}_{4}^{3--P}\right)$. From this study, it can be seen that after the non-specific binding sites were saturated, approximately $17 \mathrm{mg}$ $\mathrm{PO}_{4}{ }^{3-}-\mathrm{P}$ was removed from solution (Figure 24). This level of removal is extremely similar 
to that of the $18 \mathrm{mg} \mathrm{PO}_{4}{ }^{3-}-\mathrm{P}$ sorption capacity predicted for the selective recognition sites. The ability for the MM12 to reach this P sorption capacity after continuous immersion in high concentrations of competing anions suggests that MM12 does in fact have imprinted recognition sites that selectively remove phosphate.

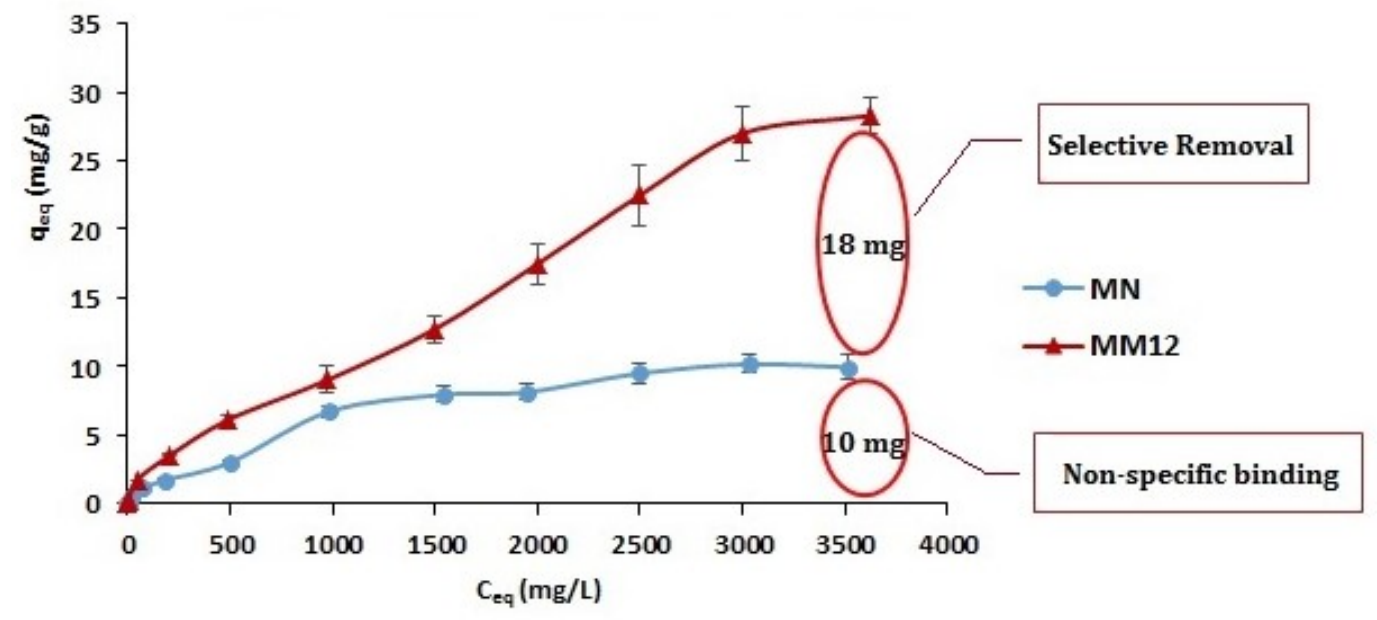

Figure 23. Comparison of Sorption Capacities between Non-specific Binding and Selective Removal 


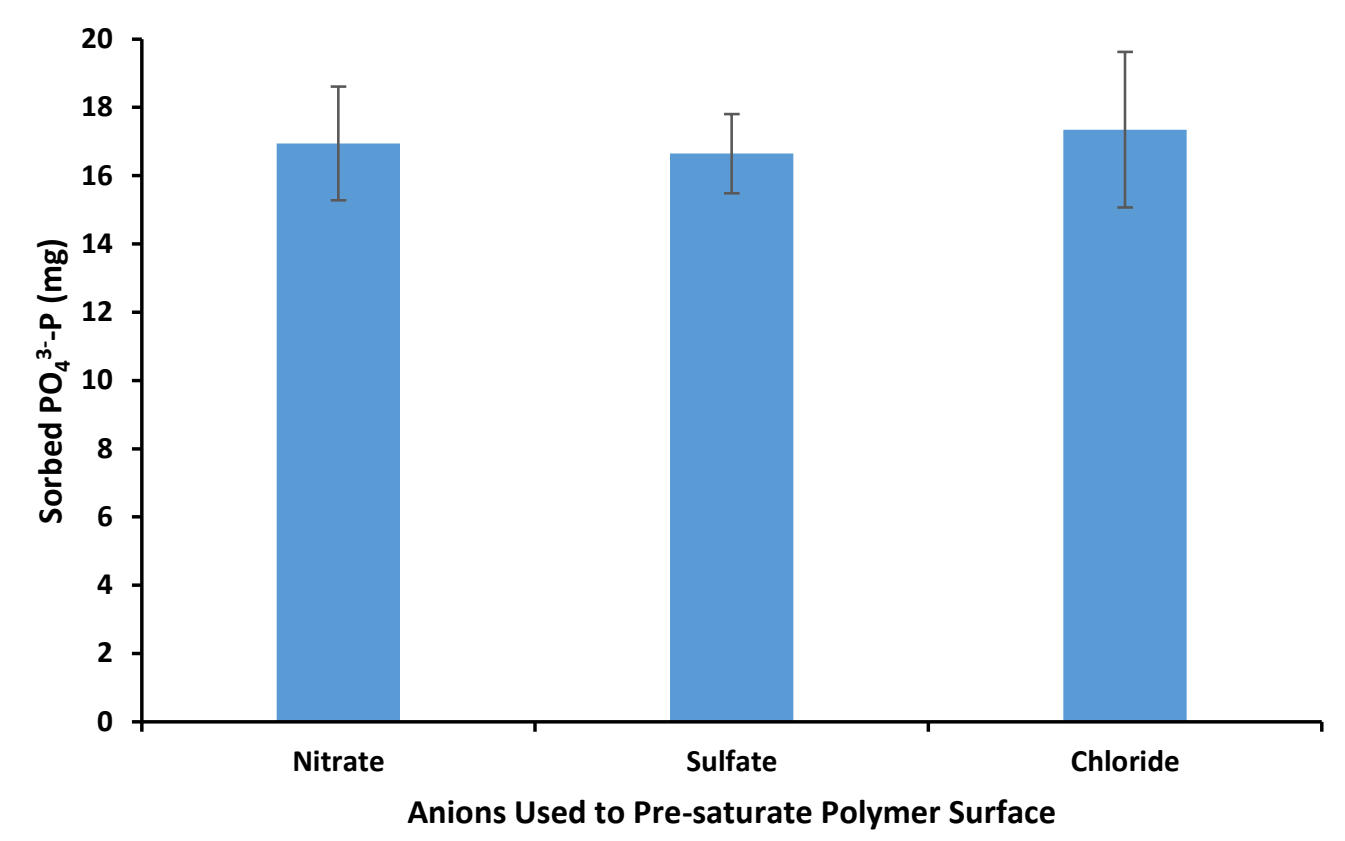

Figure 24. Phosphate Removal after Saturation of Electrostatic Attraction Sites

\subsubsection{Kinetic Study}

Understanding the rate at which the sorbent removes phosphate from solution can provide key insight into the removal mechanism. Therefore, kinetic studies were conducted to understand the phosphate removal mechanism of MM12. Removal behavior using several initial phosphate concentrations (0.1, 5, and $50 \mathrm{mg} / \mathrm{L}$ ) were recorded (Figure 25). Several pieces of information were discerned from the data shown. First, the reaction kinetics was identical with all initial concentrations of phosphate. Next, the removal of phosphate on the polymer surface occurred immediately. This immediate removal is likely the cause of electrostatic interactions taking place nearly instantaneously (Adamson and Gast, 1997). After the initial removal, a pseudo-equilibrium between sorption and desorption of phosphate onto the polymer surface was reached. Because of the unchanging nature of this pseudo-equilibrium, the data are reported up to 200 minutes (Figure 25) (although studies were conducted up to 1440 minutes). 
It is common to reach pseudo-equilibrium with electrostatic interactions.

Nevertheless, it was believed that the presence of selective binding (chemical binding) sites, this pseudo-equilibrium should be breached after adequate mechanical mixing of solution. The mechanical mixing provides means for phosphate ions to come in contact with the binding sites over time. Once the ions come in contact with these binding sites, desorption should not occur. Thus, the pseudo-equilibrium would be breached and the phosphate concentration would be slowly lowered until it reaches nearly zero or until the sorbent reaches its sorption capacity (Figure 26).

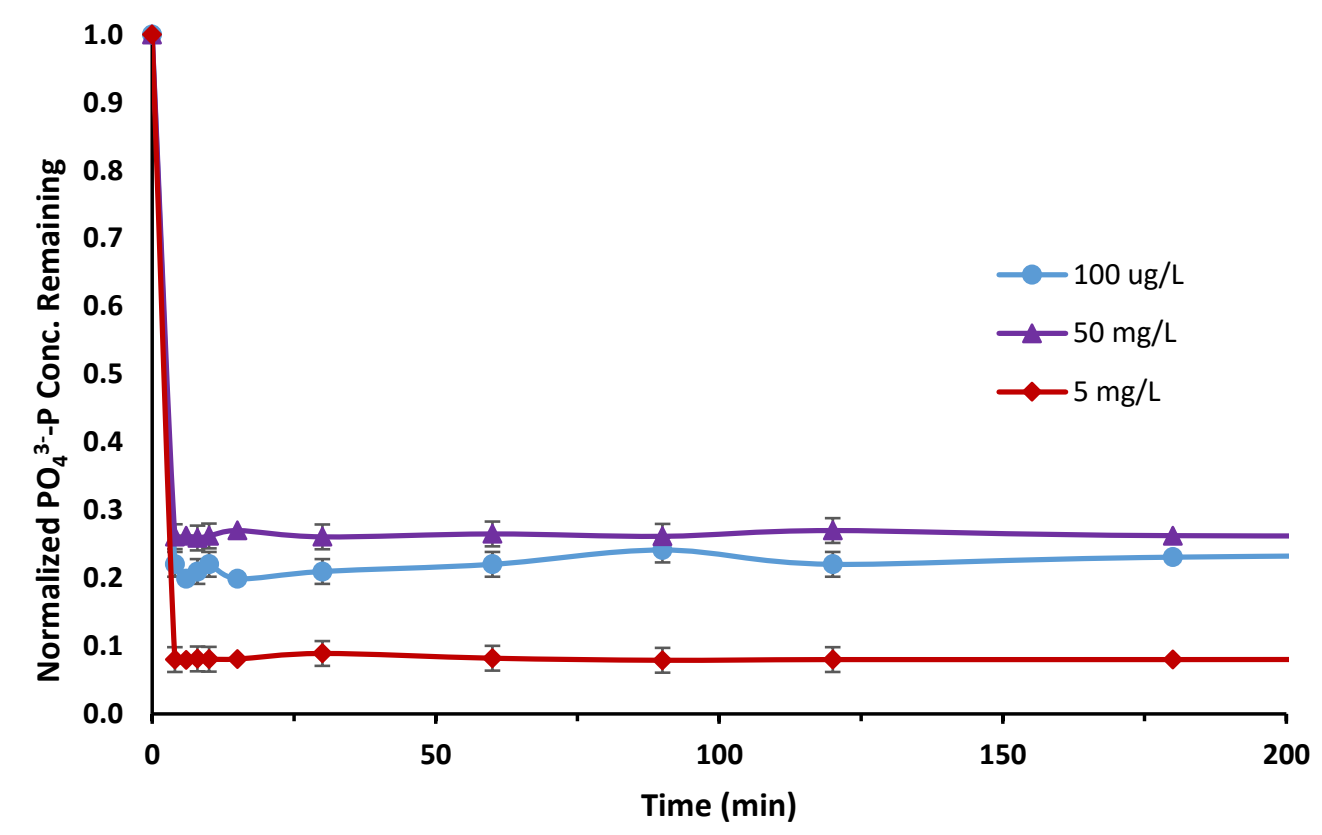

Figure 25. Assessment of MM12's Phosphate Removal Rate at Varying Initial Concentrations 


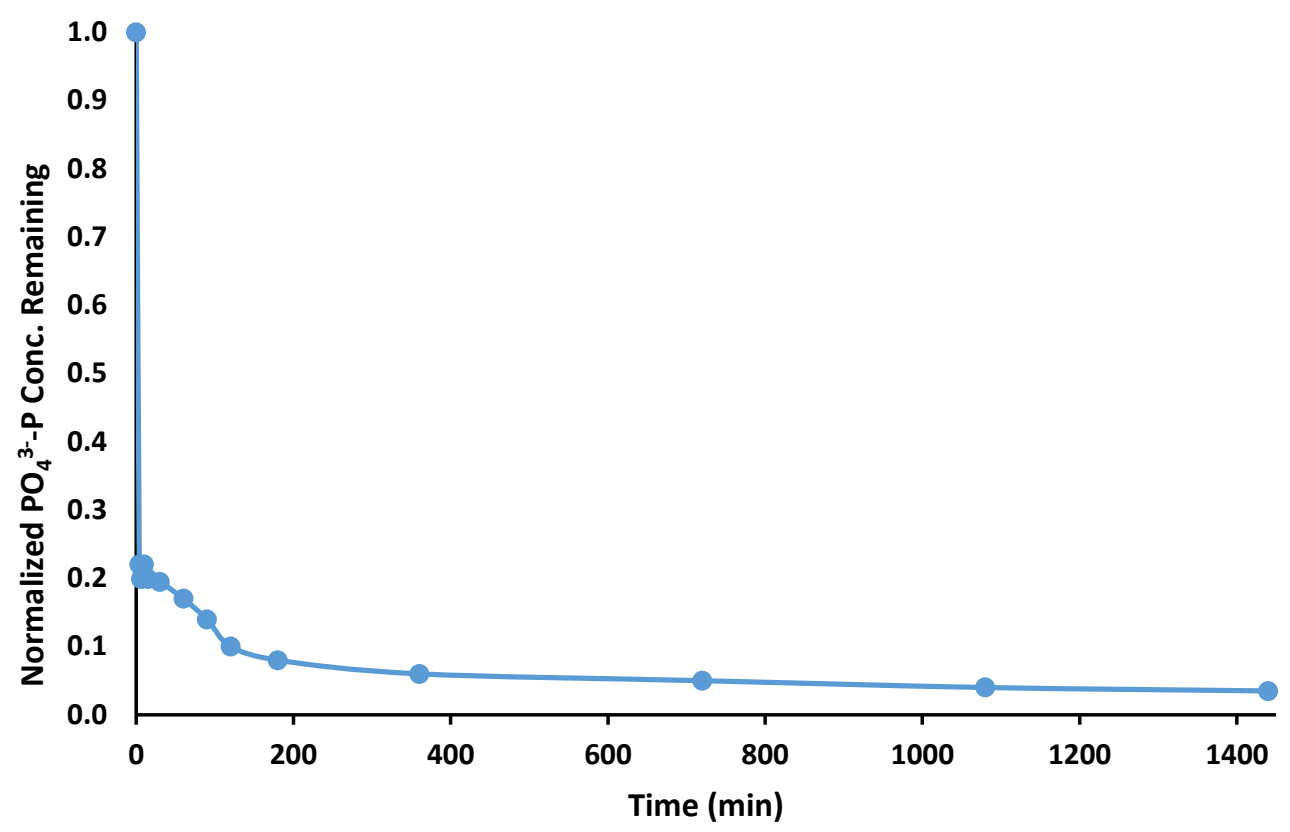

Figure 26. Expected Phosphate Removal Rate Behavior of MM12

With the observed kinetic behavior at hand, it appears that the recognition sites are not experiencing interactions with the phosphate ions. Further investigation on this behavior was thus conducted. The seemingly probable cause for this behavior was deemed to be that the phosphate ions were not reaching the imprinted recognition sites. The root of this issue is likely due to the formation of an electric double layer (Figure 27). When a charged surface is present in solution, ions of opposite charge will be attracted through electrostatic attraction. The attraction of anions to the surface of the positively charged polymer will generate a new charge on the surface of the polymer. This attraction of anions to the surface will continue to happen until the total net charge in the solution is balanced by the equal and opposite net charge on the surface. This then generates a double layer of charge, one localized on the surface of the plane and the other developed in the diffuse region extending into solution. The diffuse layer is the result of ions of one sign being held more strongly with those of the opposite sign. The pseudo-equilibrium that is developed 
over the diffuse layer is due to the osmotic pressure of solvent being reduced in the region between two planes. The two planes, in this case, are the surface of MM12 and the bulk solution. The equilibrium between these two "planes" can only be shifted by changing the external ionic strength in solution (Adamson and Gast, 1997). This helps to explain why imprinted recognition sites only appeared to take significant predominance at higher concentrations. As the phosphate concentration was increased, so was the ionic strength of the bulk solution. This increase in the ionic strength of the bulk solution likely grew so large that it diminished the equilibrium formed across the double layer and pushed phosphate anions past the surface of the polymer and into the polymer matrix. (Adamson and Gast, 1997) also reported that if specific chemical interactions are not dominant, the adsorption of an ionic species is largely determined by its charge (Adamson and Gast, 1997). Within that given charge type, the sequence of removal is likely that of increasing hydration enthalpy (Adamson and Gast, 1997). Based on MM12's removal kinetics witnessed at lower phosphate concentrations, it is believed that specific chemical interactions from the imprinted recognition sites are not the dominant mechanism for phosphate removal. In fact, it appears very likely that the dominant mechanism for phosphate removal is based on electrostatic attraction and is charge determinant. 


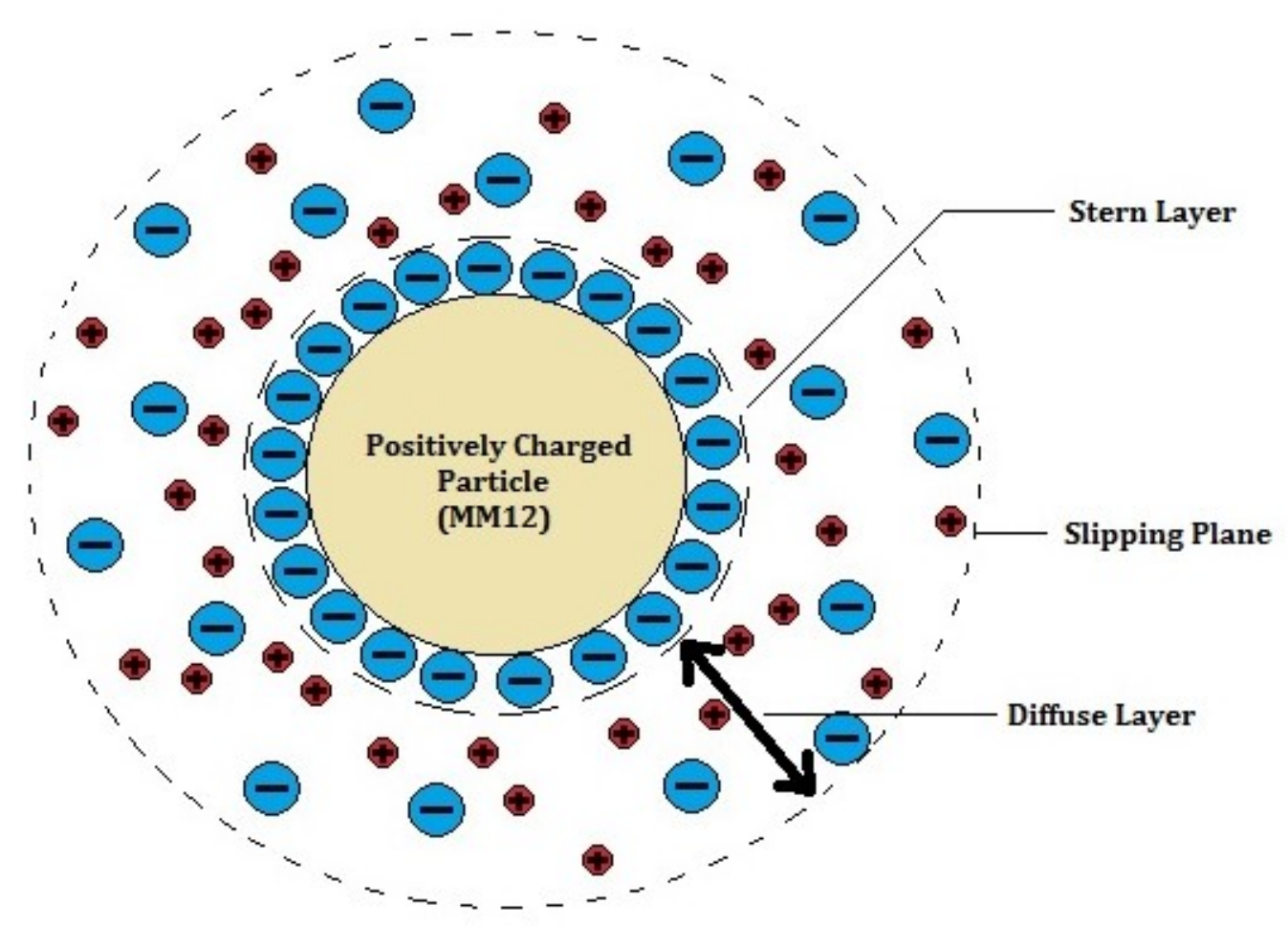

Figure 27. Hypothesized Electric Double Layer Phenomenon with MM12

\subsection{Conclusions}

Of the three MIPs initially selected for study, only one (METAC MIP) showed promise as a feasible P-sorbent. The METAC MIP's sorption capacity was found to be significantly increased by its template:monomer ratio; a ratio of 1:4 provided a sorption capacity of $\sim 11 \mathrm{mg} \mathrm{PO} 4^{3--} \mathrm{P}$ while a ratio of 12:4 provided a sorption capacity of $\sim 28 \mathrm{mg}$ $\mathrm{PO}_{4}{ }^{3-}-\mathrm{P}$ under the same conditions. The MM12 experienced significant interference from competing anions, as evidence collected throughout the study suggests that electrostatic attraction of anions is the predominant mechanism for P-removal. However, FTIR analysis and a partial-selectivity study confirmed that selective chemical binding of phosphate is occurring in the imprinted recognition sites. Nevertheless, this selective binding is inhibited at lower phosphate concentrations of relevance due to the development of an electric double layer from the polymer's positive surface charge. 


\subsection{Significance and Future Perspective}

The work completed herein is the first work done indicating that molecularly imprinted polymers can attain sorption capacities significant enough to be deemed as an effective P-removal technology. Additionally, this study provided evidence that the molecular recognition sites generated from imprinting can bind phosphate selectively in the presence of competing anions. While the MIP studied within this report (MM12) has limitations which currently bar it from being applicable to P-recovery and reuse, it shows that molecular imprinting technology has potential to produce sorbents which can selectively recover P for reuse. It should be noted that this study focused only on the ability of MIPs to remove orthophosphate. It is believed that the MIPs can also show successful removal of polyphosphates and organophosphates due to the shared functionalities of these different phosphate forms. Specifically, organophosphates are expected to be sorbed quite effectively as the MIPs were imprinted with phenylphosphonic acid, which is an organophosphate itself.

To best further the work in this area, several items of recommendation are provided. First, the available pool of functional monomers that can be used to synthesize MIPs for phosphate recognition is rather small. Screening of additional functional monomers, which can be completed through methods such as computational modeling, is necessary to find the optimal monomer. Another approach is to neutralize the surface charge on the MIP. As shown from the study, polymers with positive surface charge (high PZC) suffer from significant interference with other anions. Selecting functional monomers, which form complexes with phenylphosphonic acid while having a lower PZC, could help negate the effect from non-specific surface binding in MIPs. Additionally, copolymerization 
with monomers that have negatively charged surfaces could produce a polymer with a neutral net charge to negate this interference and electric double layer formation as well. Lastly, optimization of synthesis conditions is necessary for developing the best MIP for this application. In this study, only one design parameter (template:monomer ratio) was altered. Optimizing design parameters can require tedious effort and large dedications of time. High throughput well-plate testing as identified by (Vasapollo et al., 2011) can be a practical means to higher efficiency design for developing MIPs that may work for $\mathrm{P}$ removal. 


\section{CHAPTER 3. SUMMARY OF WORK, CONCLUSIONS, AND FUTURE PERSPECTIVES}

\subsection{Introduction}

Society is trending toward more sustainable methods for phosphorus (P) production and application in order to reduce pressure on natural and finite sources of phosphate rock. Recovery of $\mathrm{P}$ from new sources has been identified as a pivotal point in moving toward this direction. The majority of $\mathrm{P}$ harvested from phosphate rock is applied in agricultural applications. Of this $\mathrm{P}$ applied in agriculture, much of the $\mathrm{P}$ is transported through surface runoff into surface waters. As surface waters continue to be polluted with otherwise valuable $\mathrm{P}$, their viability as alternative sources to P-recovery continues to rise. In tandem to generating an alternative source for P-recovery, the health of socioeconomically important lakes could be restored. Restoring the quality of lakes (i.e. reducing and preventing eutrophication) across the United States could prevent an annual economic loss of $\$ 2.2$ billion. However, available technologies are not up to par to be implemented as effective vehicle for P-recovery and -reuse. Effective P-removal below environmentally relevant concentrations, selective removal of $\mathrm{P}$ in the presence of competing constituents, and the opportunity for recovery and reuse of $\mathrm{P}$ are critical attributes that many available technologies commonly lack. In the research presented in this thesis, molecularly imprinted polymers (MIPs) were identified as a potential vehicle for meeting all of the desired attributes for P-recovery and -reuse. Almost all works on MIP related to $\mathrm{P}$ have focused on phosphate recognition for sensing, not for targeted P recovery and reuse. 


\subsection{Evaluation of Several MIPs for P Removal}

Three candidate functional monomers for MIP formulations were selected for this work based on extensive literature survey. Thiourea (TU), 1-Allyl-2-thiourea (AT), and 2methacryloyloxyethyltrimethylammonium chloride (METAC) were the three functional monomers used here. TU showed no promise as a P-sorbent as it removed little to no phosphate across various $\mathrm{P}$ concentrations and $\mathrm{pH}$. The AT MIP was found to have a $\mathrm{P}$ sorption capacity of only $\sim 1 \mathrm{mg} \mathrm{PO} 4^{3--P / g}$. This polymer showed no promise as a competitive P-sorbent as it had a sorption capacity which was far lower than many other available technologies and did not resist interference from competing anions. The METAC MIP was the only polymer which showed potential as a P-sorbent with a competitive sorption capacity. The sorption capacity was largely affected by the template:monomer ratio. Ratios ranging from 0:4 to 12:4 lead to $\mathrm{P}$ sorption capacities of $10 \mathrm{mg} \mathrm{PO} 4^{3--} \mathrm{P} / \mathrm{g}$ to 28 mg PO $4^{3--P / g}$, respectively. However, it was found that phosphate removal was also significantly reduced by the presence of coexisting anions.

\subsection{Potential for P Recovery/Reuse with METAC MIPs}

The biodegradability and rate of phosphate desorption were the primary parameters tested to assess METAC MIP's (with template:monomer of 12:4, MM12) potential for recovery and reuse of P. Respirometer studies indicated that MM12 was an available food source for bacteria. MM12 can possibly be applied as a soil amendment as it will be biodegraded over time. Desorption studies indicated that MM12 releases a large bulk of loosely-bound phosphate immediately, but the majority of the bound phosphate is not released. It is believed that the phosphate not released immediately is strongly bound into the polymer matrix and cannot be accessed until those bonds are broken through 
(bio)degradation processes. This form of phosphate release indicates that MM12 could provide some phosphate to plants for immediate nourishment, and then work as a slowrelease fertilizer to provide subtle nourishment over time. Phosphate supplementation in this way can lead to more economically and environmentally favorable fertilizerapplication.

\subsection{P Removal Characteristics and Mechanism of Removal for METAC MIPs}

METAC MIPs were shown to have partial-selectivity toward P removal. Evidence suggests that the MIPs have non-selective removal of anions due to non-specific binding sites on the surface of the polymer. These non-specific binding sites are likely due to the polymer's high PZC, giving it a positive surface charge at the $\mathrm{pH}$ of interest $(7.5$ - 8.5). The positive surface charge therein contributes to electrostatic attraction of all negatively charged species in water. Once all non-specific binding sites are saturated, phosphate was selectively removed by the imprinted recognition sites. Kinetic studies indicated that electrostatic attraction is the predominant mechanism of P removal over chemical binding by the imprinted recognition sites. In fact, evidence suggests that chemical binding will not occur unless adequate ionic strength is present in solution. The formation of an electric double layer on the surface of the charged polymer surface is hypothesized. This electric double layer engenders pseudo-equilibrium between the charged surface and the bulk solution in a "diffuse layer," preventing the accumulation of additional ions on the polymer surface.

\subsection{Conclusions}

This work has found that, of the functional monomers previously investigated for phosphate recognition (sensors) can also act as phosphate sorbents for recovery and reuse. 
Of the three monomers tested, only METAC was shown to have potential viability as a selective P-sorbent when used in the synthesis of MIPs. The METAC MIPs showed partial selectivity as they also contained an abundance of non-specific binding sites due to their surface charge. METAC MIPs showed competitive sorption capacities when compared to available technologies. Also, METAC MIPs demonstrated characteristics which could lead to the successful implementation of recoverable/reusable sorbents. METAC MIPs are not feasible as selective P-sorbents from low ionic strength solutions like eutrophic surface waters and municipal wastewaters at this time due to their severe reduction in phosphate removal when in the presence of coexisting anions. However, they may be a feasible option as a selective P sorbent from high ionic strength solutions (i.e. powder coating industry and fertilizer plant effluents). Even without the presence of coexisting anions, their sorption capacities could be severely limited by the supposed formation of an electric double layer around the charged polymer surface. These results suggest that if better materials or design parameters are found, MIPs have promise to be implemented as sorbents for a more sustainable P-recovery and reuse cycle.

\subsection{Future Perspectives}

Currently, there are far too few functional monomers which have been screened for phosphate recognition. Screening more functional monomers to develop a larger selection pool for study is a crucial first step in advancing the area of MIPs for P-recovery and -reuse. Another approach is to strengthen or at least optimize the MIPs that are currently available for P recovery. In this study it was revealed that non-specific binding from electrostatic attraction of phosphate eventually led to detrimental effects that include interference by coexisting anions and possible sorption capacity limitations in low ionic strength solutions. 
The electrostatic attraction caused by the functional monomer's natural positive surface charge led to limitations in selective removal of P by MIPs. However, neutralizing this surface charge may be one of the options to negate the effect of electrostatic interactions. Selecting functional monomers which have a PZC below 7.5 (the lower pH range of typical eutrophic lakes) could result in MIPs which are void of non-specific electrostatic binding sites in the typical $\mathrm{pH}$ range. Another alternative is copolymerization with another monomer which can lead to neutrality on the MIP surface. Copolymerization with monomers of negative charge could result in charge-neutral polymers. The last option identified to advance this area is the optimization of MIPs through a better understanding of design parameters and their inherent influences. While template:monomer ratio was identified to be critical in influencing sorption capacity, there may be several other design parameters. High throughput well-plate testing can lead to a better understanding of design parameters and their influences in reasonable time and with reasonable efforts. 


\section{REFERENCES}

Ahn, Y.H. and Speece, R.E. (2006) Waste lime as a potential cation source in the phosphate crystallization process. Environmental Technology 27(11), 1225-1231.

Almeelbi, T. and Bezbaruah, A. (2012) Aqueous phosphate removal using nanoscale zerovalent iron. Journal of Nanoparticle Research 14(7).

Babatunde, A.O. and Zhao, Y.Q. (2010) Equilibrium and kinetic analysis of phosphorus adsorption from aqueous solution using waste alum sludge. Journal of Hazardous Materials 184(1-3), 746-752.

Basargin, N.N., Kosolapova, N.I., Anikin, V.Y. and Rozovskii, Y.G. (2007) Sorption of phosphorus $(\mathrm{V})$ by polymeric sorbents based on aminopolystyrene and 4-amino-Nazobenzenesulfamide. Russian Journal of Inorganic Chemistry 52(10), 1638-1642.

Beeton, A.M. (2002) Large freshwater lakes: present state, trends, and future. Environmental Conservation 29(1), 21-38.

Beltran, A., Borrull, F., Cormack, P.A.G. and Marce, R.M. (2010) Molecularly-imprinted polymers: useful sorbents for selective extractions. Trac-Trends in Analytical Chemistry 29(11), 1363-1375.

Blaney, L.M., Cinar, S. and SenGupta, A.K. (2007) Hybrid anion exchanger for trace phosphate removal from water and wastewater. Water Research 41(7), 1603-1613.

Boyer, T.H., Persaud, A., Banerjee, P. and Palomino, P. (2011) Comparison of low-cost and engineered materials for phosphorus removal from organic-rich surface water. Water Research 45(16), 4803-4814.

Bui, B.T.S. and Haupt, K. (2010) Molecularly imprinted polymers: synthetic receptors in bioanalysis. Analytical and Bioanalytical Chemistry 398(6), 2481-2492.

Caravelli, A.H., Contreras, E.M. and Zaritzky, N.E. (2010) Phosphorous removal in batch systems using ferric chloride in the presence of activated sludges. Journal of Hazardous Materials 177(1-3), 199-208.

Cheng, X., Huang, X., Wang, X., Zhao, B., Chen, A. and Sun, D. (2009) Phosphate adsorption from sewage sludge filtrate using zinc-aluminum layered double hydroxides. Journal of Hazardous Materials 169(1-3), 958-964.

Cheung, K.C. and Venkitachalam, T.H. (2000) Improving phosphate removal of sand infiltration system using alkaline fly ash. Chemosphere 41(1-2), 243-249. 
Chitrakar, R., Tezuka, S., Sonoda, A., Sakane, K., Ooi, K. and Hirotsu, T. (2006) Phosphate adsorption on synthetic goethite and akaganeite. Journal of Colloid and Interface Science 298(2), 602-608.

Choi, J.-W., Hong, S.-W., Kim, D.-J. and Lee, S.-H. (2012) Investigation of phosphate removal using sulphate-coated zeolite for ion exchange. Environmental Technology 33(20), 23292335.

Chouyyok, W., Wiacek, R.J., Pattamakomsan, K., Sangvanich, T., Grudzien, R.M., Fryxell, G.E. and Yantasee, W. (2010) Phosphate Removal by Anion Binding on Functionalized Nanoporous Sorbents. Environmental Science \& Technology 44(8), 3073-3078.

Copetti, D., Finsterle, K., Marziali, L., Stefani, F., Tartari, G., Douglas, G., Reitzel, K., Spears, B.M., Winfield, I.J., Crosa, G., D'Haese, P., Yasseri, S. and Lurling, M. (2016) Eutrophication management in surface waters using lanthanum modified bentonite: A review. Water Research 97, 162-174.

Cordell, D., Drangert, J.-O. and White, S. (2009) The story of phosphorus: Global food security and food for thought. Global Environmental Change-Human and Policy Dimensions 19(2), 292-305.

Cordell, D., Rosemarin, A., Schroder, J.J. and Smit, A.L. (2011) Towards global phosphorus security: A systems framework for phosphorus recovery and reuse options. Chemosphere 84(6), 747-758.

Cornel, P. and Schaum, C. (2009) Phosphorus recovery from wastewater: needs, technologies and costs. Water Science and Technology 59(6), 1069-1076.

Crini, G. (2005) Recent developments in polysaccharide-based materials used as adsorbents in wastewater treatment. Progress in Polymer Science 30(1), 38-70.

Das, J., Patra, B.S., Baliarsingh, N. and Parida, K.M. (2006) Adsorption of phosphate by layered double hydroxides in aqueous solutions. Applied Clay Science 32(3-4), 252-260.

de Vicente, I., Merino-Martos, A., Guerrero, F., Amores, V. and de Vicente, J. (2011) Chemical interferences when using high gradient magnetic separation for phosphate removal: Consequences for lake restoration. Journal of Hazardous Materials 192(3), 995-1001.

de-Bashan, L.E. and Bashan, Y. (2004) Recent advances in removing phosphorus from wastewater and its future use as fertilizer (1997-2003). Water Research 38(19), 42224246.

Dodds, W.K., Bouska, W.W., Eitzmann, J.L., Pilger, T.J., Pitts, K.L., Riley, A.J., Schloesser, J.T. and Thornbrugh, D.J. (2009) Eutrophication of US Freshwaters: Analysis of Potential Economic Damages. Environmental Science \& Technology 43(1), 12-19. 
Dolar, D., Kosutic, K. and Vucic, B. (2011) RO/NF treatment of wastewater from fertilizer factory - removal of fluoride and phosphate. Desalination 265(1-3), 237-241.

Dunets, C.S. and Zheng, Y. (2014) Removal of phosphate from greenhouse wastewater using hydrated lime. Environmental Technology 35(22), 2852-2862.

Ekama, G.A. (2015) Recent developments in biological nutrient removal. Water Sa 41(4), 515-524.

Ensing, K., Berggren, C. and Majors, R.E. (2001) Selective sorbents for solid-phase extraction based on molecularly imprinted polymers. Lc Gc North America 19(9), 942-+.

Freundlich, H. (1906) Concerning adsorption in solutions. Zeitschrift Fur Physikalische Chemie--Stochiometrie Und Verwandtschaftslehre 57(4), 385-470.

Goldyn, R., Podsiadlowski, S., Dondajewska, R. and Kozak, A. (2014) The sustainable restoration of lakes-towards the challenges of the Water Framework Directive. Ecohydrology \& Hydrobiology 14(1, Sp. Iss. SI), 68-74.

Guan, X.H., Shang, C. and Chen, G.H. (2006) Competitive adsorption of organic matter with phosphate on aluminum hydroxide. Journal of Colloid and Interface Science 296(1), 51-58.

Harrison, J.A., Bouwman, A.F., Mayorga, E. and Seitzinger, S. (2010) Magnitudes and sources of dissolved inorganic phosphorus inputs to surface fresh waters and the coastal zone: A new global model. Global Biogeochemical Cycles 24.

Huang, W., Wang, S., Zhu, Z., Li, L., Yao, X., Rudolph, V. and Haghseresht, F. (2008) Phosphate removal from wastewater using red mud. Journal of Hazardous Materials 158(1), 35-42.

Janos, P., Kormunda, M., Novak, F., Zivotsky, O., Fuitova, J. and Pilarova, V. (2013) Multifunctional humate-based magnetic sorbent: Preparation, properties and sorption of $\mathrm{Cu}$ (II), phosphates and selected pesticides. Reactive \& Functional Polymers 73(1), 46-52.

Jaradat, D.s.M.M., Ghrair, A.M., Alhesan, J.S.A., Ahmad, A.L., Ali, M.S.O. and Lafi, A.F. (2016) An efficient sorbent for phosphate removal from wastewater: a new application of phosphate mine wastes from Ruseifa City-Jordan. Desalination and Water Treatment 57(21), 9914-9924.

Jellali, S., Wahab, M.A., Anane, M., Riahi, K. and Bousselmi, L. (2010) Phosphate mine wastes reuse for phosphorus removal from aqueous solutions under dynamic conditions. Journal of Hazardous Materials 184(1-3), 226-233.

Jing, L., Liu, X., Bai, S., Wu, C., Ao, H. and Liu, J. (2015) Effects of sediment dredging on internal phosphorus: A comparative field study focused on iron and phosphorus forms in sediments. Ecological Engineering 82, 267-271. 
Jung, K.-W. and Ahn, K.-H. (2016) Fabrication of porosity-enhanced MgO/biochar for removal of phosphate from aqueous solution: Application of a novel combined electrochemical modification method. Bioresource Technology 200, 1029-1032.

Karthikeyan, K.G., Tshabalala, M.A., Wang, D. and Kalbasi, M. (2004) Solution chemistry effects on orthophosphate adsorption by cationized solid wood residues. Environmental Science \& Technology 38(3), 904-911.

Kioussis, D.R. and Kofinas, P. (2005a) Characterization of anion diffusion in polymer hydrogels used for wastewater remediation. Polymer 46(22), 9342-9347.

Kioussis, D.R. and Kofinas, P. (2005b) Characterization of network morphology in anion binding hydrogels used for wastewater remediation. Polymer 46(23), 10167-10172.

Kofinas, P. and Kioussis, D.R. (2003) Reactive phosphorus removal from aquaculture and poultry productions systems using polymeric hydrogels. Environmental Science \& Technology 37(2), 423-427.

Kugimiya, A. and Babe, F. (2011) Phosphate ion sensing using molecularly imprinted artificial polymer receptor. Polymer Bulletin 67(9), 2017-2024.

Kugimiya, A. and Takei, H. (2006) Preparation of molecularly imprinted polymers with thiourea group for phosphate. Analytica Chimica Acta 564(2), 179-183.

Kugimiya, A. and Takei, H. (2008a) Selective recovery of phosphate from river water using molecularly imprinted polymers. Analytical Letters 41(2), 302-311.

Kugimiya, A. and Takei, H. (2008b) Selectivity and recovery performance of phosphateselective molecularly imprinted polymer. Analytica Chimica Acta 606(2), 252-256.

Lai, L., Xie, Q., Chi, L., Gu, W. and Wu, D. (2016) Adsorption of phosphate from water by easily separable Fe304@SiO2 core/shell magnetic nanoparticles functionalized with hydrous lanthanum oxide. Journal of Colloid and Interface Science 465, 76-82.

Langmuir, I. (1918) THE ADSORPTION OF GASES ON PLANE SURFACES OF GLASS, MICA AND PLATINUM. Journal of the American Chemical Society 40, 1361-1403.

Lee, C.-G., Park, J.-A. and Kim, S.-B. (2012) Phosphate removal from aqueous solutions using slag microspheres. Desalination and Water Treatment 44(1-3), 229-236.

Lee, S.-h. and Doong, R.-a. (2012) Adsorption and selective recognition of 17 beta-estradiol by molecularly imprinted polymers. Journal of Polymer Research 19(8).

Li, R., Wang, J.J., Zhou, B., Awasthi, M.K., Ali, A., Zhang, Z., Lahori, A.H. and Mahar, A. (2016) Recovery of phosphate from aqueous solution by magnesium oxide decorated magnetic 
biochar and its potential as phosphate-based fertilizer substitute. Bioresource Technology 215, 209-214.

Liu, X. and Zhang, L. (2015) Removal of phosphate anions using the modified chitosan beads: Adsorption kinetic, isotherm and mechanism studies. Powder Technology 277, 112119.

Liu, Y.-T. and Hesterberg, D. (2011) Phosphate Bonding on Noncrystalline Al/Fe-Hydroxide Coprecipitates. Environmental Science \& Technology 45(15), 6283-6289.

Loganathan, P., Vigneswaran, S., Kandasamy, J. and Bolan, N.S. (2014) Removal and Recovery of Phosphate From Water Using Sorption. Critical Reviews in Environmental Science and Technology 44(8), 847-907.

Luo, W., Hai, F.I., Price, W.E., Guo, W., Ngo, H.H., Yamamoto, K. and Nghiem, L.D. (2016) Phosphorus and water recovery by a novel osmotic membrane bioreactor-reverse osmosis system. Bioresource Technology 200, 297-304.

McDowell, R.W., Dils, R.M., Collins, A.L., Flahive, K.A., Sharpley, A.N. and Quinn, J. (2016) A review of the policies and implementation of practices to decrease water quality impairment by phosphorus in New Zealand, the UK, and the US. Nutrient Cycling in Agroecosystems 104(3), 289-305.

Mezenner, N.Y. and Bensmaili, A. (2009) Kinetics and thermodynamic study of phosphate adsorption on iron hydroxide-eggshell waste. Chemical Engineering Journal 147(2-3), 8796.

Mishra, S.P., Das, M. and Dash, U.N. (2010) Review on adverse effects of water contaminants like arsenic, fluoride and phosphate and their remediation. Journal of Scientific \& Industrial Research 69(4), 249-253.

Morse, G.K., Brett, S.W., Guy, J.A. and Lester, J.N. (1998) Review: Phosphorus removal and recovery technologies. Science of the Total Environment 212(1), 69-81.

Oehmen, A., Lemos, P.C., Carvalho, G., Yuan, Z., Keller, J., Blackall, L.L. and Reis, M.A.M. (2007) Advances in enhanced biological phosphorus removal: From micro to macro scale. Water Research 41(11), 2271-2300.

Ogata, T., Morisada, S., Oinuma, Y., Seida, Y. and Nakano, Y. (2011) Preparation of adsorbent for phosphate recovery from aqueous solutions based on condensed tannin gel. Journal of Hazardous Materials 192(2), 698-703.

Oguz, E. (2004) Removal of phosphate from aqueous solution with blast furnace slag. Journal of Hazardous Materials 114(1-3), 131-137. 
Ozkutuk, E.B., Ersoz, A., Denizli, A. and Say, R. (2008) Preconcentration of phosphate ion onto ion-imprinted polymer. Journal of Hazardous Materials 157(1), 130-136.

Pan, B., Wu, J., Pan, B., Lv, L., Zhang, W., Xiao, L., Wang, X., Tao, X. and Zheng, S. (2009) Development of polymer-based nanosized hydrated ferric oxides (HFOs) for enhanced phosphate removal from waste effluents. Water Research 43(17), 4421-4429.

Park, H.-S., Kwak, S.-H., Mahardika, D., Mameda, N. and Choo, K.-H. (2017) Mixed metal oxide coated polymer beads for enhanced phosphorus removal from membrane bioreactor effluents. Chemical Engineering Journal 319, 240-247.

Pasparakis, G. and Bouropoulos, N. (2006) Swelling studies and in vitro release of verapamil from calcium alginate and calcium alginate-chitosan beads. International Journal of Pharmaceutics 323(1-2), 34-42.

Peleka, E.N. and Deliyanni, E.A. (2009) Adsorptive removal of phosphates from aqueous solutions. Desalination 245(1-3), 357-371.

Reddy, K.R., Fisher, M.M., Wang, Y., White, J.R. and James, R.T. (2007) Potential effects of sediment dredging on internal phosphorus loading in a shallow, subtropical lake. Lake and Reservoir Management 23(1), 27-38.

Reitzel, K., Andersen, F.O., Egemose, S. and Jensen, H.S. (2013) Phosphate adsorption by lanthanum modified bentonite clay in fresh and brackish water. Water Research 47(8), 2787-2796.

Rittmann, B.E., Mayer, B., Westerhoff, P. and Edwards, M. (2011) Capturing the lost phosphorus. Chemosphere 84(6), 846-853.

Robalds, A., Dreijalte, L., Bikovens, O. and Klavins, M. (2016) A novel peat-based biosorbent for the removal of phosphate from synthetic and real wastewater and possible utilization of spent sorbent in land application. Desalination and Water Treatment 57(28), 13285-13294.

Roques, H., Nugrohojeudy, L. and Lebugle, A. (1991) PHOSPHORUS REMOVAL FROM WASTE-WATER BY HALF-BURNED DOLOMITE. Water Research 25(8), 959-965.

Sarkar, S., Chatterjee, P.K., Cumbal, L.H. and SenGupta, A.K. (2011) Hybrid ion exchanger supported nanocomposites: Sorption and sensing for environmental applications. Chemical Engineering Journal 166(3), 923-931.

Sengupta, S. and Pandit, A. (2011) Selective removal of phosphorus from wastewater combined with its recovery as a solid-phase fertilizer. Water Research 45(11), 3318-3330.

Sharpley, A.N., Chapra, S.C., Wedepohl, R., Sims, J.T., Daniel, T.C. and Reddy, K.R. (1994) MANAGING AGRICULTURAL PHOSPHORUS FOR PROTECTION OF SURFACE WATERS ISSUES AND OPTIONS. Journal of Environmental Quality 23(3), 437-451. 
Smith, V.H. (2003) Eutrophication of freshwater and coastal marine ecosystems - A global problem. Environmental Science and Pollution Research 10(2), 126-139.

Soliemanzadeh, A., Fekri, M., Bakhtiary, S. and Mehrizi, M.H. (2016) Biosynthesis of iron nanoparticles and their application in removing phosphorus from aqueous solutions. Chemistry and Ecology 32(3), 286-300.

Song, X., Pan, Y., Wu, Q., Cheng, Z. and Ma, W. (2011) Phosphate removal from aqueous solutions by adsorption using ferric sludge. Desalination 280(1-3), 384-390.

Survey, U.S.G. (2012) Mineral commodity summaries January 2012, Phosphorus. Tom, L.A., Schneck, N.A. and Walter, C. (2012) Improving the imprinting effect by optimizing template:monomer:cross-linker ratios in a molecularly imprinted polymer for sulfadimethoxine. Journal of Chromatography B-Analytical Technologies in the Biomedical and Life Sciences 909, 61-64.

Tshabalala, M.A., Karthikeyan, K.G. and Wang, D. (2004) Cationized milled pine bark as an adsorbent for orthophosphate anions. Journal of Applied Polymer Science 93(4), 15771583.

U.N. (2000) Millennium Development Goals, Millennium Assembly.

U.N. (2005) Millennium Development Goals Report, Department of

Economic and Social Affairs of the United Nations Secretariat New York.

Unnithan, M.R., Vinod, V.P. and Anirudhan, T.S. (2002) Ability of iron(III)-loaded carboxylated polyacrylamide-grafted sawdust to remove phosphate ions from aqueous solution and fertilizer industry wastewater: Adsorption kinetics and isotherm studies. Journal of Applied Polymer Science 84(13), 2541-2553.

Vakros, J., Kordulis, C. and Lycourghiotis, A. (2002) Potentiometric mass titrations: a quick scan for determining the point of zero charge. Chemical Communications (17), 1980-1981.

Vasapollo, G., Del Sole, R., Mergola, L., Lazzoi, M.R., Scardino, A., Scorrano, S. and Mele, G. (2011) Molecularly Imprinted Polymers: Present and Future Prospective. International Journal of Molecular Sciences 12(9), 5908-5945.

Wang, C.-H., Gao, S.-J., Wang, T.-X., Tian, B.-H. and Pei, Y.-S. (2011) Effectiveness of sequential thermal and acid activation on phosphorus removal by ferric and alum water treatment residuals. Chemical Engineering Journal 172(2-3), 885-891.

Warwick, C., Guerreiro, A., Gomez-Caballero, A., Wood, E., Kitson, J., Robinson, J. and Soares, A. (2014a) Conductance based sensing and analysis of soluble phosphates in wastewater. Biosensors \& Bioelectronics 52, 173-179. 
Warwick, C., Guerreiro, A., Wood, E., Kitson, J., Robinson, J. and Soares, A. (2014b) A molecular imprinted polymer based sensor for measuring phosphate in wastewater samples. Water Science and Technology 69(1), 48-54.

Wen, Z., Zhang, Y. and Dai, C. (2014) Removal of phosphate from aqueous solution using nanoscale zerovalent iron (nZVI). Colloids and Surfaces a-Physicochemical and Engineering Aspects 457, 433-440.

$\mathrm{Wu}, \mathrm{X}$. (2012) Molecular imprinting for anion recognition in aqueous media. Microchimica Acta 176(1-2), 23-47.

Wu, X., Goswami, K. and Shimizu, K.D. (2008) Comparison of monofunctional and multifunctional monomers in phosphate binding molecularly imprinted polymers. Journal of Molecular Recognition 21(6), 410-418.

Xie, J., Lin, Y., Li, C., Wu, D. and Kong, H. (2015) Removal and recovery of phosphate from water by activated aluminum oxide and lanthanum oxide. Powder Technology 269, 351357.

Yan, L.-g., Yang, K., Shan, R.-r., Yan, T., Wei, J., Yu, S.-j., Yu, H.-q. and Du, B. (2015) Kinetic, isotherm and thermodynamic investigations of phosphate adsorption onto core-shell Fe304@LDHs composites with easy magnetic separation assistance. Journal of Colloid and Interface Science 448, 508-516.

Yin, H. and Kong, M. (2015) Reduction of sediment internal P-loading from eutrophic lakes using thermally modified calcium-rich attapulgite-based thin-layer cap. Journal of Environmental Management 151, 178-185.

You, X., Farran, A., Guaya, D., Valderrama, C., Soldatov, V. and Luis Cortina, J. (2016a) Phosphate removal from aqueous solutions using a hybrid fibrous exchanger containing hydrated ferric oxide nanoparticles. Journal of Environmental Chemical Engineering 4(1), 388-397.

You, X., Guay, D., Farran, A., Valderrama, C. and Luis Cortina, J. (2016b) Phosphate removal from aqueous solution using a hybrid impregnated polymeric sorbent containing hydrated ferric oxide (HFO). Journal of Chemical Technology and Biotechnology 91(3), 693-704.

Zeng, L., Li, X.M. and Liu, J.D. (2004) Adsorptive removal of phosphate from aqueous solutions using iron oxide tailings. Water Research 38(5), 1318-1326.

Zhu, X.P. and Jyo, A. (2005) Column-mode phosphate removal by a novel highly selective adsorbent. Water Research 39(11), 2301-2308. 


\section{APPENDIX}

\section{A.1. Thiourea (TU)}

\section{A.1.1. TU PZC}

Table A.1. PZC Data for TU MIP

\begin{tabular}{|c|c|c|c|c|c|}
\hline \multicolumn{2}{|c|}{$0.5 \mathrm{~g} / 100 \mathrm{~mL}$} & \multicolumn{2}{|c|}{$1.0 \mathrm{~g} / 100 \mathrm{~mL}$} & \multicolumn{2}{|c|}{$1.5 \mathrm{~g} / 100 \mathrm{~mL}$} \\
\hline $\begin{array}{c}\text { Volume } \\
\text { Titrant } \\
(\mathrm{mL})\end{array}$ & $\mathrm{pH}$ & $\begin{array}{c}\text { Volume } \\
\text { Titrant } \\
(\mathrm{mL})\end{array}$ & $\mathrm{pH}$ & $\begin{array}{c}\text { Volume } \\
\text { Titrant } \\
(\mathrm{mL})\end{array}$ & $\mathrm{pH}$ \\
\hline 0 & 11.32 & 0 & 11.6 & 0 & 11.65 \\
\hline 0.2 & 11.24 & 0.25 & 11.51 & 0.5 & 11.49 \\
\hline 0.4 & 11.16 & 0.5 & 11.41 & 0.75 & 11.4 \\
\hline 0.6 & 11.05 & 0.75 & 11.28 & 1 & 11.27 \\
\hline 0.8 & 10.91 & 1 & 11.09 & 1.25 & 11.1 \\
\hline 1 & 10.73 & 1.25 & 10.81 & 1.5 & 10.86 \\
\hline 1.2 & 10.47 & 1.5 & 10.23 & 1.75 & 10.41 \\
\hline 1.4 & 10.05 & 1.75 & 6.1 & 1.85 & 10.04 \\
\hline 1.5 & 9.59 & 2 & 3.94 & 1.95 & 9.08 \\
\hline 1.6 & 7.34 & 2.25 & 3.47 & 2.05 & 6.46 \\
\hline 1.7 & 6.19 & 2.5 & 3.25 & 2.15 & 5.28 \\
\hline 1.8 & 5.02 & 2.75 & 3.1 & 2.25 & 4.58 \\
\hline 1.9 & 4.06 & 3 & 2.99 & 2.35 & 4.17 \\
\hline 2 & 3.75 & 3.25 & 2.9 & 2.45 & 3.89 \\
\hline 2.1 & 3.57 & 3.5 & 2.84 & 2.7 & 3.5 \\
\hline 2.2 & 3.44 & 3.75 & 2.8 & 2.95 & 3.29 \\
\hline 2.3 & 3.35 & 4 & 2.76 & 3.2 & 3.14 \\
\hline 2.5 & 3.2 & 4.25 & 2.72 & 3.45 & 3.04 \\
\hline 2.7 & 3.09 & 4.5 & 2.69 & 3.7 & 2.95 \\
\hline 2.9 & 3.01 & 4.75 & 2.66 & 3.95 & 2.88 \\
\hline 3.1 & 2.94 & 5 & 2.64 & 4.2 & 2.84 \\
\hline 3.3 & 2.89 & 5.25 & 2.61 & 4.45 & 2.8 \\
\hline 3.5 & 2.84 & 5.5 & 2.59 & 4.7 & 2.76 \\
\hline 3.7 & 2.8 & 5.75 & 2.57 & 4.95 & 2.72 \\
\hline 3.9 & 2.76 & 6 & 2.55 & 5.2 & 2.69 \\
\hline 4.1 & 2.72 & 6.25 & 2.53 & 5.45 & 2.66 \\
\hline 4.3 & 2.69 & 6.5 & 2.51 & 5.7 & 2.64 \\
\hline 4.5 & 2.66 & 6.75 & 2.5 & 5.95 & 2.61 \\
\hline
\end{tabular}


Table A.1. PZC Data for TU MIP (Continued)

\begin{tabular}{|c|c|c|c|c|c|}
\hline $\begin{array}{c}\text { Volume } \\
\text { Titrant } \\
(\mathrm{mL})\end{array}$ & $\mathrm{pH}$ & $\begin{array}{c}\text { Volume } \\
\text { Titrant } \\
(\mathrm{mL})\end{array}$ & $\mathrm{pH}$ & $\begin{array}{c}\text { Volume } \\
\text { Titrant } \\
(\mathrm{mL})\end{array}$ & $\mathrm{pH}$ \\
\hline 4.9 & 2.61 & 7.25 & 2.47 & 6.45 & 2.57 \\
5.1 & 2.59 & - & - & 6.7 & 2.55 \\
5.3 & 2.57 & - & - & 6.95 & 2.53 \\
5.5 & 2.55 & - & - & 7.2 & 2.51 \\
5.7 & 2.53 & - & - & 7.45 & 2.5 \\
5.9 & 2.51 & - & - & 7.7 & 2.48 \\
6.1 & 2.5 & - & - & 7.95 & 2.47 \\
6.3 & 2.48 & - & - & - & - \\
6.5 & 2.47 & - & - & - & - \\
\hline
\end{tabular}

\section{A.1.2. TU pH}

Table A.2. P Removal for TU MIP over Varying $\mathrm{pH}\left(\mathrm{C}_{0}=5 \mathrm{mg} \mathrm{PO} 4^{3-}-\mathrm{P} / \mathrm{L}\right)$

\begin{tabular}{|c|r|r|}
\hline \multicolumn{2}{|c|}{$\mathrm{pH}$} & \multicolumn{2}{c|}{ Normalized } \\
\hline 3 & 0.000 & 0.017 \\
4 & 0.000 & 0.019 \\
5 & 0.008 & 0.020 \\
6 & 0.000 & 0.005 \\
7 & 0.000 & 0.012 \\
8 & 0.005 & 0.008 \\
9 & 0.000 & 0.008 \\
10 & 0.008 & 0.005 \\
11 & 0.005 & 0.012 \\
12 & 0.000 & 0.016 \\
\hline
\end{tabular}




\section{A1.3. TU Sorption Capacity}

Table A.3. TU NIP Sorption Capacity Data

\begin{tabular}{|c|c|ccccc|}
\hline $\begin{array}{c}\text { Experiment } \\
\text { Title }\end{array}$ & $\begin{array}{c}\text { Actual } \\
\text { Initial } \\
\text { Conc. } \\
\text { (mg/L) }\end{array}$ & $\begin{array}{c}\text { Sorbed } \\
\text { Phosphate } \\
(\mathrm{mg} / \mathrm{L})\end{array}$ & $\begin{array}{c}\text { Standard } \\
\text { Deviation }\end{array}$ & $\begin{array}{c}\text { Remaining } \\
\text { P } \\
(\mathrm{mg} / \mathrm{L})\end{array}$ & $\begin{array}{c}\text { Sorbed } \\
\text { (mg/g) }\end{array}$ & $\begin{array}{c}\text { StdDev } \\
(\mathrm{mg} / \mathrm{g})\end{array}$ \\
\hline 0 & 0.00 & 0.00 & 0.00 & 0.00 & 0.00 & 0.00 \\
$1 \mathrm{mg} / \mathrm{L}$ & 0.95 & 0.00 & 0.00 & 0.95 & 0.00 & 0.00 \\
$5 \mathrm{mg} / \mathrm{L}$ & 5.10 & 0.00 & 0.01 & 5.10 & 0.00 & 0.00 \\
$50 \mathrm{mg} / \mathrm{L}$ & 45.00 & 0.00 & 0.09 & 45.00 & 0.00 & 0.00 \\
\hline
\end{tabular}

Table A.4. TU MIP Sorption Capacity Data

\begin{tabular}{|c|c|cc|cc|c|}
\hline $\begin{array}{c}\text { Experiment } \\
\text { Title }\end{array}$ & $\begin{array}{c}\text { Actual } \\
\text { Initial } \\
\text { Conc. } \\
\text { (mg/L) }\end{array}$ & $\begin{array}{c}\text { Sorbed } \\
\text { Phosphate } \\
(\mathrm{mg} / \mathrm{L})\end{array}$ & $\begin{array}{c}\text { Standard } \\
\text { Deviation }\end{array}$ & $\begin{array}{c}\text { Remaining } \\
\text { (mg/L) }\end{array}$ & \multicolumn{1}{c|}{$\begin{array}{c}\text { Sorbed } \\
\text { (mg/g) }\end{array}$} & $\begin{array}{c}\text { StdDev } \\
\text { (mg/g) }\end{array}$ \\
\hline 0 & 0.00 & 0.00 & 0.00 & 0.00 & 0.00 & 0.00 \\
$1 \mathrm{mg} / \mathrm{L}$ & 0.90 & 0.00 & 0.02 & 0.90 & 0.00 & 0.00 \\
$5 \mathrm{mg} / \mathrm{L}$ & 4.60 & 0.02 & 0.00 & 4.57 & 0.00 & 0.00 \\
$50 \mathrm{mg} / \mathrm{L}$ & 47.21 & 0.11 & 0.43 & 47.09 & 0.01 & 0.02 \\
\hline
\end{tabular}

\section{A.2. 1-Allyl-2-thiourea (AT)}

\section{A.2.1. AT PZC}

Table A.5. PZC Data for AT MIP

\begin{tabular}{|c|c|c|c|c|c|}
\hline \multicolumn{2}{|c|}{$0.5 \mathrm{~g} / 100 \mathrm{~mL}$} & \multicolumn{2}{|c|}{$1.0 \mathrm{~g} / 100 \mathrm{~mL}$} & \multicolumn{2}{c|}{$1.5 \mathrm{~g} / 100 \mathrm{~mL}$} \\
\hline $\begin{array}{c}\text { Volume } \\
\begin{array}{c}\text { Titrant } \\
(\mathrm{mL})\end{array}\end{array}$ & $\mathrm{pH}$ & $\begin{array}{c}\text { Volume } \\
\text { Titrant } \\
(\mathrm{mL})\end{array}$ & $\mathrm{pH}$ & $\begin{array}{c}\text { Volume } \\
\text { Titrant } \\
(\mathrm{mL})\end{array}$ & $\mathrm{pH}$ \\
\hline 0 & 11.63 & 0 & 11.58 & 0 & 11.49 \\
0.25 & 11.53 & 0.25 & 11.42 & 0.25 & 11.22 \\
0.5 & 11.32 & 0.5 & 11.2 & 0.5 & 10.89 \\
0.75 & 10.94 & 0.75 & 10.8 & 0.75 & 10.2 \\
1 & 8.87 & 1 & 8.85 & 1 & 8.9 \\
1.1 & 6.85 & 1.1 & 6.64 & 1.1 & 6.22 \\
1.2 & 4.61 & 1.2 & 4.88 & 1.2 & 4.65 \\
\hline
\end{tabular}


Table A.5. PZC Data for AT MIP (Continued)

\begin{tabular}{|c|c|c|c|c|c|}
\hline $\begin{array}{c}\text { Volume } \\
\text { Titrant } \\
(\mathrm{mL})\end{array}$ & $\mathrm{pH}$ & $\begin{array}{c}\text { Volume } \\
\text { Titrant } \\
(\mathrm{mL})\end{array}$ & $\mathrm{pH}$ & $\begin{array}{c}\text { Volume } \\
\text { Titrant } \\
(\mathrm{mL})\end{array}$ & $\mathrm{pH}$ \\
\hline 1.3 & 3.99 & 1.3 & 4.1 & 1.3 & 4.06 \\
1.55 & 3.5 & 1.55 & 3.57 & 1.55 & 3.56 \\
1.8 & 3.27 & 1.8 & 3.33 & 1.8 & 3.32 \\
2.05 & 3.13 & 2.05 & 3.18 & 2.05 & 3.17 \\
2.3 & 3.02 & 2.3 & 3.07 & 2.3 & 3.06 \\
2.55 & 2.94 & 2.55 & 2.98 & 2.55 & 2.97 \\
3.05 & 2.81 & 3.05 & 2.85 & 3.05 & 2.84 \\
3.55 & 2.71 & 3.55 & 2.75 & 3.55 & 2.74 \\
4.05 & 2.64 & 4.05 & 2.68 & 4.05 & 2.67 \\
\hline
\end{tabular}

\section{A.2.2. AT pH Study}

Table A.6. P Removal for AT MIP over Varying $\mathrm{pH}\left(\mathrm{C}_{0}=5 \mathrm{mg} \mathrm{PO} 4^{3-}-\mathrm{P} / \mathrm{L}\right)$

\begin{tabular}{|c|r|r|}
\hline \multicolumn{4}{|c|}{ pH } & Normalized & \multicolumn{1}{r|}{ Sormalized } \\
\hline 3 & 0.213 & 0.088 \\
4 & 0.190 & 0.055 \\
5 & 0.244 & 0.037 \\
6 & 0.358 & 0.013 \\
7 & 0.366 & 0.020 \\
8 & 0.357 & 0.020 \\
9 & 0.292 & 0.018 \\
10 & 0.293 & 0.019 \\
11 & 0.274 & 0.011 \\
12 & 0.277 & 0.024 \\
\hline
\end{tabular}




\section{A.2.3. AT Sorption Capacity}

Table A.7. AT MIP Sorption Capacity Data

\begin{tabular}{|ccccccc|c|}
\hline Experiment & \multicolumn{1}{c}{$\begin{array}{c}\text { Actual } \\
\text { Initial } \\
\text { Title }\end{array}$} & $\begin{array}{c}\text { Conc. } \\
\text { Corbed } \\
\text { (mg/L) }\end{array}$ & $\begin{array}{c}\text { Phosphate } \\
\text { (mg/L) }\end{array}$ & $\begin{array}{c}\text { Standard } \\
\text { Deviation }\end{array}$ & $\begin{array}{c}\text { Remaining } \\
\text { P } \\
(\mathrm{mg} / \mathrm{L})\end{array}$ & $\begin{array}{c}\text { Sorbed } \\
\text { P } \\
(\mathrm{mg} / \mathrm{g})\end{array}$ & $\begin{array}{c}\text { StdDev } \\
\text { (mg/g) }\end{array}$ \\
\hline 0 & 0.00 & 0.00 & 0.00 & 0.00 & 0.00 & 0.00 \\
$1 \mathrm{mg} / \mathrm{L}$ & 1.21 & 0.77 & 0.05 & 0.44 & 0.04 & 0.00 \\
$5 \mathrm{mg} / \mathrm{L}$ & 4.48 & 1.53 & 0.09 & 2.95 & 0.08 & 0.00 \\
$20 \mathrm{mg} / \mathrm{L}$ & 18.48 & 4.64 & 0.11 & 13.83 & 0.23 & 0.01 \\
$100 \mathrm{mg} / \mathrm{L}$ & 101.08 & 10.52 & 1.06 & 90.56 & 0.53 & 0.05 \\
$200 \mathrm{mg} / \mathrm{L}$ & 192.79 & 18.22 & 7.43 & 174.57 & 0.91 & 0.37 \\
$500 \mathrm{mg} / \mathrm{L}$ & 503.07 & 19.13 & 8.04 & 483.95 & 0.96 & 0.4 \\
$1000 \mathrm{mg} / \mathrm{L}$ & 999.5 & 18.22 & 5.9 & 981.28 & 0.91 & 0.3 \\
\hline
\end{tabular}

Table A.8. AT NIP Sorption Capacity Data

\begin{tabular}{|c|c|cc|c|c|c|}
\hline $\begin{array}{c}\text { Experiment } \\
\text { Title }\end{array}$ & $\begin{array}{c}\text { Actual } \\
\text { Initial } \\
\text { Conc. } \\
\text { (mg/L) }\end{array}$ & $\begin{array}{c}\text { corbed } \\
\text { Phosphate } \\
\text { (mg/L) }\end{array}$ & $\begin{array}{c}\text { Standard } \\
\text { Deviation }\end{array}$ & $\begin{array}{c}\text { Remaining } \\
\text { P } \\
(\mathrm{mg} / \mathrm{L})\end{array}$ & $\begin{array}{c}\text { Sorbed } \\
\text { P } \\
(\mathrm{mg} / \mathrm{g})\end{array}$ & $\begin{array}{c}\text { StdDev } \\
(\mathrm{mg} / \mathrm{g})\end{array}$ \\
\hline 0 & 0.00 & 0.00 & 0.00 & 0.00 & 0.00 & 0.00 \\
$1 \mathrm{mg} / \mathrm{L}$ & 0.42 & 0.01 & 0.02 & 0.41 & 0.00 & 0.00 \\
$5 \mathrm{mg} / \mathrm{L}$ & 4.38 & 0.16 & 0.17 & 4.21 & 0.01 & 0.01 \\
$20 \mathrm{mg} / \mathrm{L}$ & 19.39 & 0.94 & 0.03 & 18.45 & 0.05 & 0.00 \\
$100 \mathrm{mg} / \mathrm{L}$ & 68.46 & 4.26 & 1.36 & 64.19 & 0.21 & 0.07 \\
$200 \mathrm{mg} / \mathrm{L}$ & 184.24 & 5.43 & 2.31 & 178.81 & 0.27 & 0.12 \\
$500 \mathrm{mg} / \mathrm{L}$ & 496.95 & 6.33 & 4.61 & 490.61 & 0.32 & 0.23 \\
$1000 \mathrm{mg} / \mathrm{L}$ & 988.19 & 6.33 & 3.39 & 981.86 & 0.32 & 0.17 \\
\hline
\end{tabular}




\section{A.2.4. AT Interference Study}

Table A.9. P Removal by AT MIP amongst Competing Anions ( $\left.\mathrm{C}_{0}=5 \mathrm{mg} \mathrm{PO} 4^{3--} \mathrm{P} / \mathrm{L}\right)$

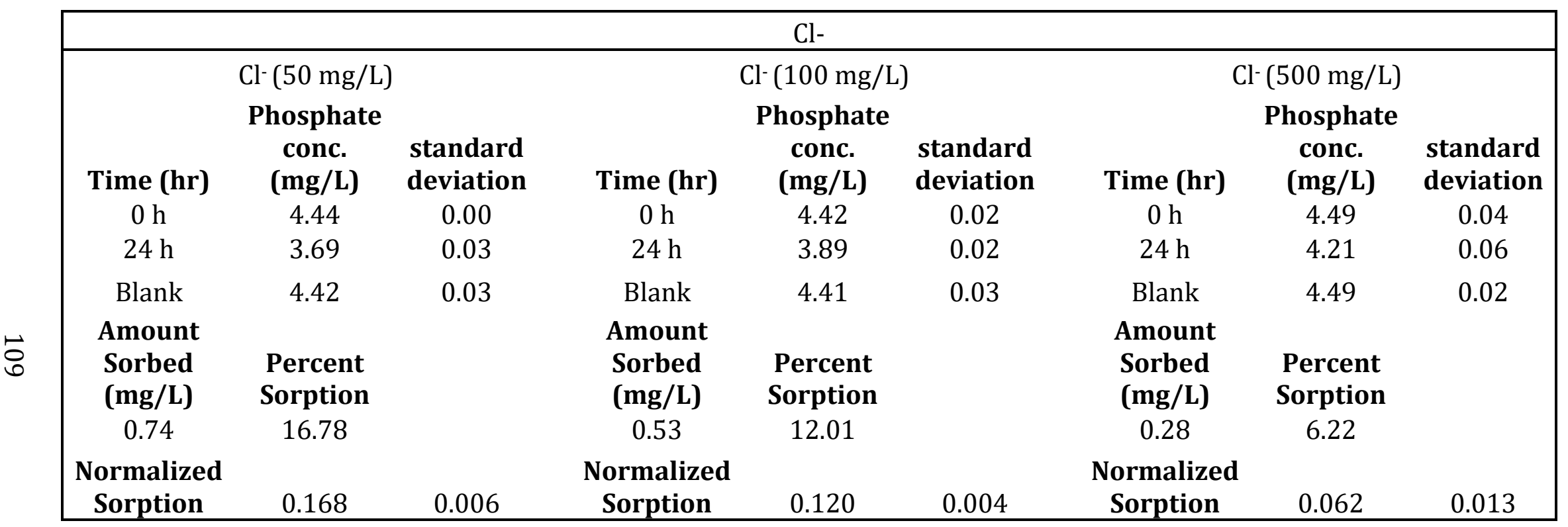


Table A.9. P Removal by AT MIP amongst Competing Anions ( $C_{0}=5 \mathrm{mg} \mathrm{PO} 4^{3-} \mathrm{P} / \mathrm{L}$ ) (Continued)

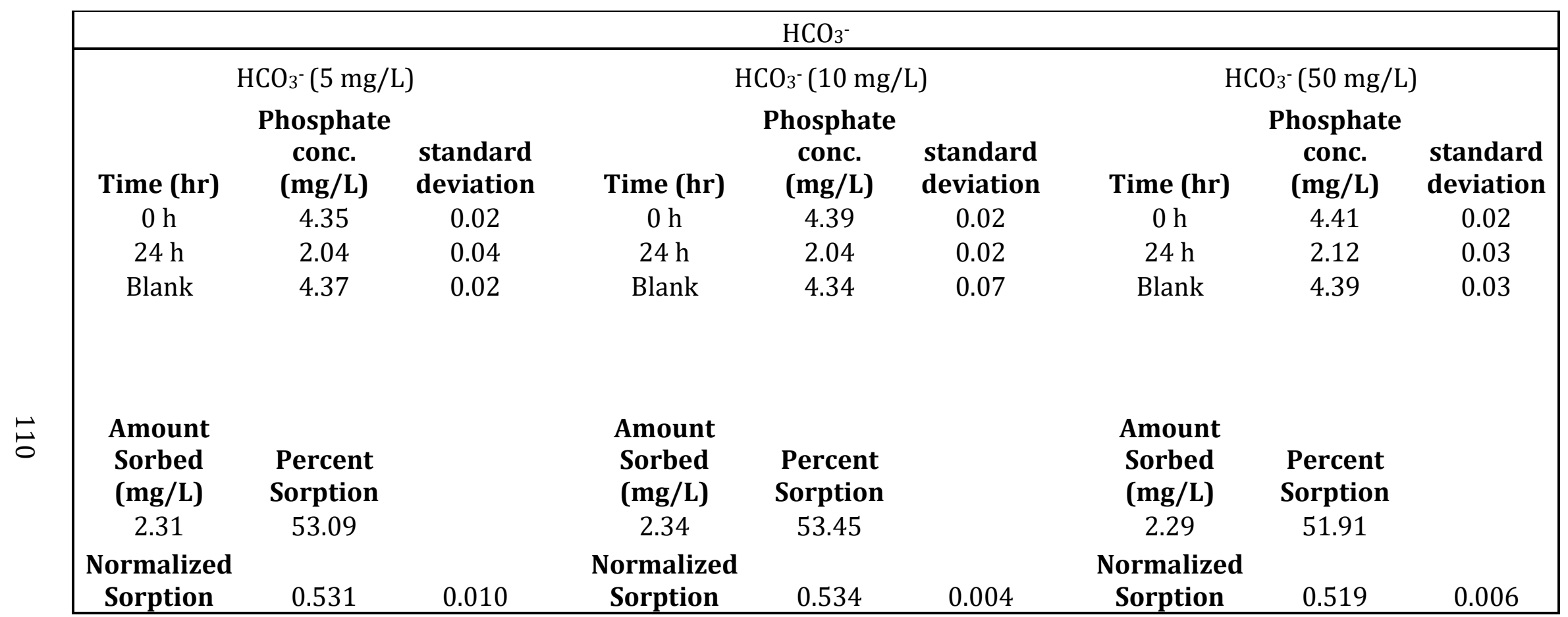


Table A.9. P Removal by AT MIP amongst Competing Anions ( $C_{0}=5 \mathrm{mg} \mathrm{PO} 4^{3-}-\mathrm{P} / \mathrm{L}$ ) (Continued)

\begin{tabular}{|c|c|c|c|c|c|c|c|c|}
\hline \multicolumn{9}{|c|}{$\mathrm{SO}_{4}^{2-}$} \\
\hline \multicolumn{3}{|c|}{$\mathrm{SO}_{4}{ }^{2-}(50 \mathrm{mg} / \mathrm{L})$} & \multicolumn{3}{|c|}{$\mathrm{SO}_{4}^{2-}(100 \mathrm{mg} / \mathrm{L})$} & \multicolumn{3}{|c|}{$\mathrm{SO}_{4}^{2-}(1000 \mathrm{mg} / \mathrm{L})$} \\
\hline Time (hr) & $\begin{array}{c}\text { Phosphate } \\
\text { conc. } \\
\text { (mg/L) }\end{array}$ & $\begin{array}{l}\text { standard } \\
\text { deviation }\end{array}$ & Time (hr) & $\begin{array}{c}\text { Phosphate } \\
\text { conc. } \\
\text { (mg/L) }\end{array}$ & $\begin{array}{l}\text { standard } \\
\text { deviation }\end{array}$ & Time (hr) & $\begin{array}{c}\text { Phosphate } \\
\text { conc. } \\
\text { (mg/L) }\end{array}$ & $\begin{array}{l}\text { standard } \\
\text { deviation }\end{array}$ \\
\hline $0 \mathrm{~h}$ & 4.45 & 0.02 & $0 \mathrm{~h}$ & 4.53 & 0.02 & $0 \mathrm{~h}$ & 4.45 & 0.04 \\
\hline $24 \mathrm{~h}$ & 3.97 & 0.07 & $24 \mathrm{~h}$ & 4.15 & 0.07 & $24 \mathrm{~h}$ & 4.22 & 0.06 \\
\hline Blank & 4.39 & 0.04 & Blank & 4.52 & 0.03 & Blank & 4.42 & 0.03 \\
\hline $\begin{array}{l}\text { Amount } \\
\text { Sorbed } \\
(\mathrm{mg} / \mathrm{L})\end{array}$ & $\begin{array}{l}\text { Percent } \\
\text { Sorption }\end{array}$ & & $\begin{array}{l}\text { Amount } \\
\text { Sorbed } \\
(\mathrm{mg} / \mathrm{L})\end{array}$ & $\begin{array}{l}\text { Percent } \\
\text { Sorption }\end{array}$ & & $\begin{array}{l}\text { Amount } \\
\text { Sorbed } \\
(\mathrm{mg} / \mathrm{L})\end{array}$ & $\begin{array}{l}\text { Percent } \\
\text { Sorption }\end{array}$ & \\
\hline 0.49 & 10.91 & & 0.38 & 8.47 & & 0.23 & 5.07 & \\
\hline $\begin{array}{c}\text { Normalized } \\
\text { Sorption } \\
\end{array}$ & 0.109 & 0.016 & $\begin{array}{c}\text { Normalized } \\
\text { Sorption } \\
\end{array}$ & 0.085 & 0.015 & $\begin{array}{c}\text { Normalized } \\
\text { Sorption } \\
\end{array}$ & 0.051 & 0.013 \\
\hline \multicolumn{9}{|c|}{ Humic Acid } \\
\hline \multicolumn{3}{|c|}{ Humic Acid (2 mg/L) } & \multicolumn{3}{|c|}{ Humic Acid (5 mg/L) } & \multicolumn{3}{|c|}{ Humic Acid (10 mg/L) } \\
\hline Time (hr) & $\begin{array}{c}\text { Phosphate } \\
\text { conc. } \\
\text { (mg/L) }\end{array}$ & $\begin{array}{l}\text { standard } \\
\text { deviation }\end{array}$ & Time (hr) & $\begin{array}{c}\text { Phosphate } \\
\text { conc. } \\
\text { (mg/L) }\end{array}$ & $\begin{array}{l}\text { standard } \\
\text { deviation }\end{array}$ & Time (hr) & $\begin{array}{c}\text { Phosphate } \\
\text { conc. } \\
(\mathrm{mg} / \mathrm{L})\end{array}$ & $\begin{array}{l}\text { standard } \\
\text { deviation }\end{array}$ \\
\hline $0 \mathrm{~h}$ & 4.70 & 0.04 & $0 \mathrm{~h}$ & 4.76 & 0.02 & $0 \mathrm{~h}$ & 4.76 & 0.07 \\
\hline $24 \mathrm{~h}$ & 2.04 & 0.10 & $24 \mathrm{~h}$ & 2.20 & 0.07 & $24 \mathrm{~h}$ & 2.11 & 0.09 \\
\hline Blank & 4.70 & 0.02 & Blank & 4.77 & 0.07 & Blank & 4.73 & 0.02 \\
\hline $\begin{array}{l}\text { Amount } \\
\text { Sorbed } \\
(\mathrm{mg} / \mathrm{L})\end{array}$ & $\begin{array}{l}\text { Percent } \\
\text { Sorption }\end{array}$ & & $\begin{array}{l}\text { Amount } \\
\text { Sorbed } \\
(\mathrm{mg} / \mathrm{L})\end{array}$ & $\begin{array}{l}\text { Percent } \\
\text { Sorption }\end{array}$ & & $\begin{array}{l}\text { Amount } \\
\text { Sorbed } \\
(\mathrm{mg} / \mathrm{L})\end{array}$ & $\begin{array}{l}\text { Percent } \\
\text { Sorption }\end{array}$ & \\
\hline 2.66 & 56.69 & & 2.55 & 53.64 & & 2.64 & 55.54 & \\
\hline $\begin{array}{c}\text { Normalized } \\
\text { Sorption }\end{array}$ & 0.567 & 0.021 & $\begin{array}{c}\text { Normalized } \\
\text { Sorption } \\
\end{array}$ & 0.536 & 0.015 & $\begin{array}{c}\text { Normalized } \\
\text { Sorption } \\
\end{array}$ & 0.555 & 0.019 \\
\hline
\end{tabular}


Table A.9. P Removal by AT MIP amongst Competing Anions ( $\left.C_{0}=5 \mathrm{mg} \mathrm{PO} 4^{3-P} / L\right)$ (Continued)

\begin{tabular}{|c|c|c|c|c|c|c|c|c|}
\hline \multicolumn{9}{|c|}{ NOM } \\
\hline & NOM $(5 \mathrm{mg} / \mathrm{L})$ & & & $\mathrm{OM}(10 \mathrm{mg} /$ & & & $\mathrm{M}(50 \mathrm{mg} / \mathrm{L}$ & \\
\hline & Phosphate & & & Phosphate & & & Phosphate & \\
\hline Time (hr) & $\begin{array}{c}\text { conc. } \\
(\mathrm{mg} / \mathrm{L})\end{array}$ & $\begin{array}{l}\text { standard } \\
\text { deviation }\end{array}$ & Time (hr) & $\begin{array}{l}\text { conc. } \\
\text { (mg/L) }\end{array}$ & $\begin{array}{l}\text { standard } \\
\text { deviation }\end{array}$ & Time (hr) & $\begin{array}{c}\text { conc. } \\
(\mathrm{mg} / \mathrm{L})\end{array}$ & $\begin{array}{l}\text { standard } \\
\text { deviation }\end{array}$ \\
\hline $0 \mathrm{~h}$ & 4.99 & 0.02 & $0 \mathrm{~h}$ & 4.89 & 0.04 & $0 \mathrm{~h}$ & 4.84 & 0.03 \\
\hline $24 \mathrm{~h}$ & 2.55 & 0.18 & $24 \mathrm{~h}$ & 2.82 & 0.02 & $24 \mathrm{~h}$ & 2.69 & 0.09 \\
\hline Blank & 4.86 & 0.06 & Blank & 4.94 & 0.06 & Blank & 4.85 & 0.04 \\
\hline Amount & & & Amount & & & Amount & & \\
\hline Sorbed & Percent & & Sorbed & Percent & & Sorbed & Percent & \\
\hline$(\mathrm{mg} / \mathrm{L})$ & Sorption & & $(\mathrm{mg} / \mathrm{L})$ & Sorption & & $(\mathrm{mg} / \mathrm{L})$ & Sorption & \\
\hline 2.45 & 48.98 & & 2.07 & 42.40 & & 2.14 & 44.29 & \\
\hline Normalized & & & Normalized & & & Normalized & & \\
\hline Sorption & 0.490 & 0.036 & Sorption & 0.424 & 0.003 & Sorption & 0.443 & 0.018 \\
\hline & & & & Control & & & & \\
\hline & & & & trol $(5 \mathrm{mg} / \mathrm{L}$ & & & & \\
\hline & & & & Phosphate & & & & \\
\hline & & & & conc. & standard & & & \\
\hline & & & Time (hr) & (mg/L) & deviation & & & \\
\hline & & & $0 \mathrm{~h}$ & 4.48 & 0.23 & & & \\
\hline & & & $24 \mathrm{~h}$ & 2.05 & 0.03 & & & \\
\hline & & & Blank & 4.55 & 0.09 & & & \\
\hline & & & Amount & & & & & \\
\hline & & & Sorbed & Percent & & & & \\
\hline & & & (mg/L) & Sorption & & & & \\
\hline & & & 2.42 & 54.14 & & & & \\
\hline & & & Normalized & & & & & \\
\hline & & & Sorption & 0.541 & 0.007 & & & \\
\hline
\end{tabular}




\section{A.2.5. AT Statistical Analysis}

\section{7/4/2017 9:01:02 AM}

Welcome to Minitab, press F1 for help.

\section{One-way ANOVA: \% Removal versus pH}

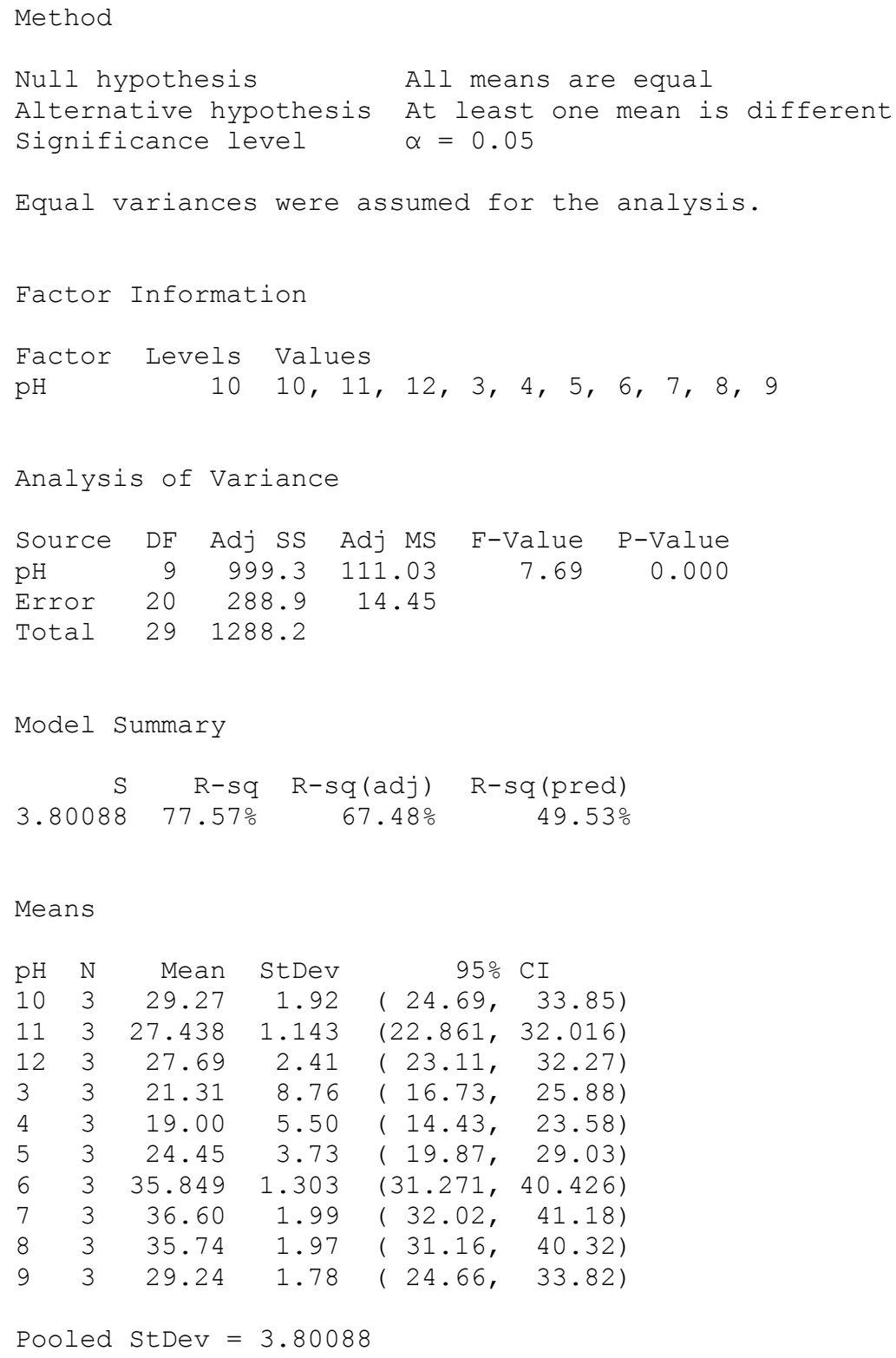

\section{Tukey Pairwise Comparisons}




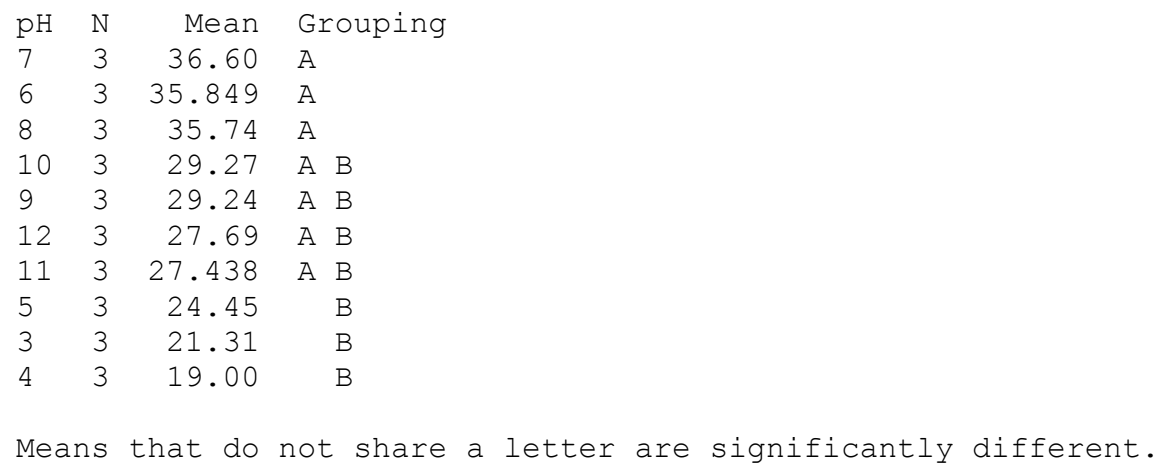

Tukey Simultaneous 95\% Cls

Interval Plot of \% Removal vs pH

\section{7/4/2017 10:01:11 AM}

Welcome to Minitab, press F1 for help.

Retrieving project from file: 'E: $\backslash$ Research $\backslash M S \backslash A T \backslash S t a t i s t i c a l$ Analysis.MPJ'

\section{One-way ANOVA: Sorption (mg) versus Polymer}

Method

Null hypothesis All means are equal

Alternative hypothesis At least one mean is different

Significance level $\quad \alpha=0.05$

Equal variances were assumed for the analysis.

Factor Information

Factor Levels Values

Polymer $8100 \mathrm{MIP}, 100 \mathrm{NIP}, 20 \mathrm{MIP}, 20 \mathrm{NIP}, 200 \mathrm{MIP}, 200 \mathrm{NIP}, 5 \mathrm{MIP}, 5 \mathrm{NIP}$

Analysis of Variance

Source DF Adj SS Adj MS F-Value P-Value

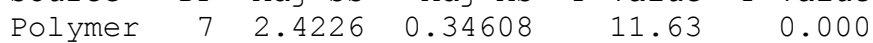

Error $\quad \begin{array}{llll}16 & 0.4763 & 0.02977\end{array}$

Total $23 \quad 2.8989$

Model Summary
0.172539
$R-s q$
$3.57 \%$
$R-s q(a d j)$
$76.38 \%$
R-sq (pred)
(pred)
$63.03 \%$ 
Means

\begin{tabular}{|c|c|c|c|c|c|}
\hline Polymer & $\mathrm{N}$ & Mean & StDev & $95 \%$ & CI \\
\hline $100 \mathrm{MIP}$ & 3 & 0.4861 & 0.0650 & 0.2749 , & $0.6973)$ \\
\hline 100 NIP & 3 & 0.2319 & 0.0832 & 0.0207 , & $0.4430)$ \\
\hline 20 MIP & 3 & 0.23218 & 0.00686 & $(0.02101$, & $0.44336)$ \\
\hline $20 \mathrm{NIP}$ & 3 & 0.04450 & 0.00203 & $(-0.16667$, & $0.25568)$ \\
\hline $200 \mathrm{MIP}$ & 3 & 0.934 & 0.455 & ( 0.722 , & $1.145)$ \\
\hline $200 \mathrm{NIP}$ & 3 & 0.7215 & 0.1412 & ( 0.5103 , & $0.9326)$ \\
\hline 5 MIP & 3 & 0.08006 & 0.00524 & $(-0.13111$, & $0.29124)$ \\
\hline $5 \mathrm{NIP}$ & 3 & 0.00820 & 0.00884 & $(-0.20298$, & $0.21937)$ \\
\hline
\end{tabular}

\section{Tukey Pairwise Comparisons}

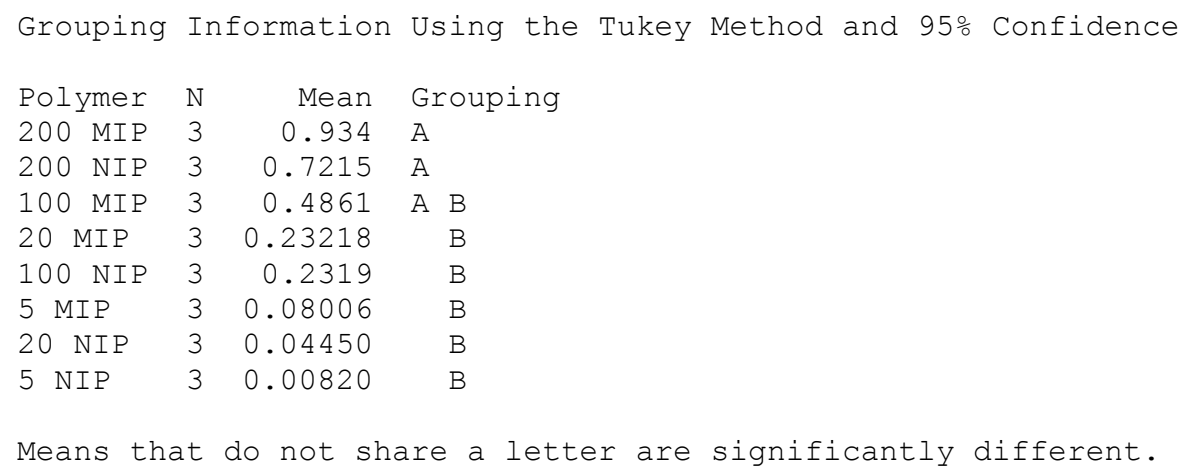

\section{Tukey Simultaneous $\mathbf{9 5 \%}$ Cls}

\section{Interval Plot of Sorption (mg) vs Polymer}

\section{One-way ANOVA: Sorption (mg) versus Polymer}

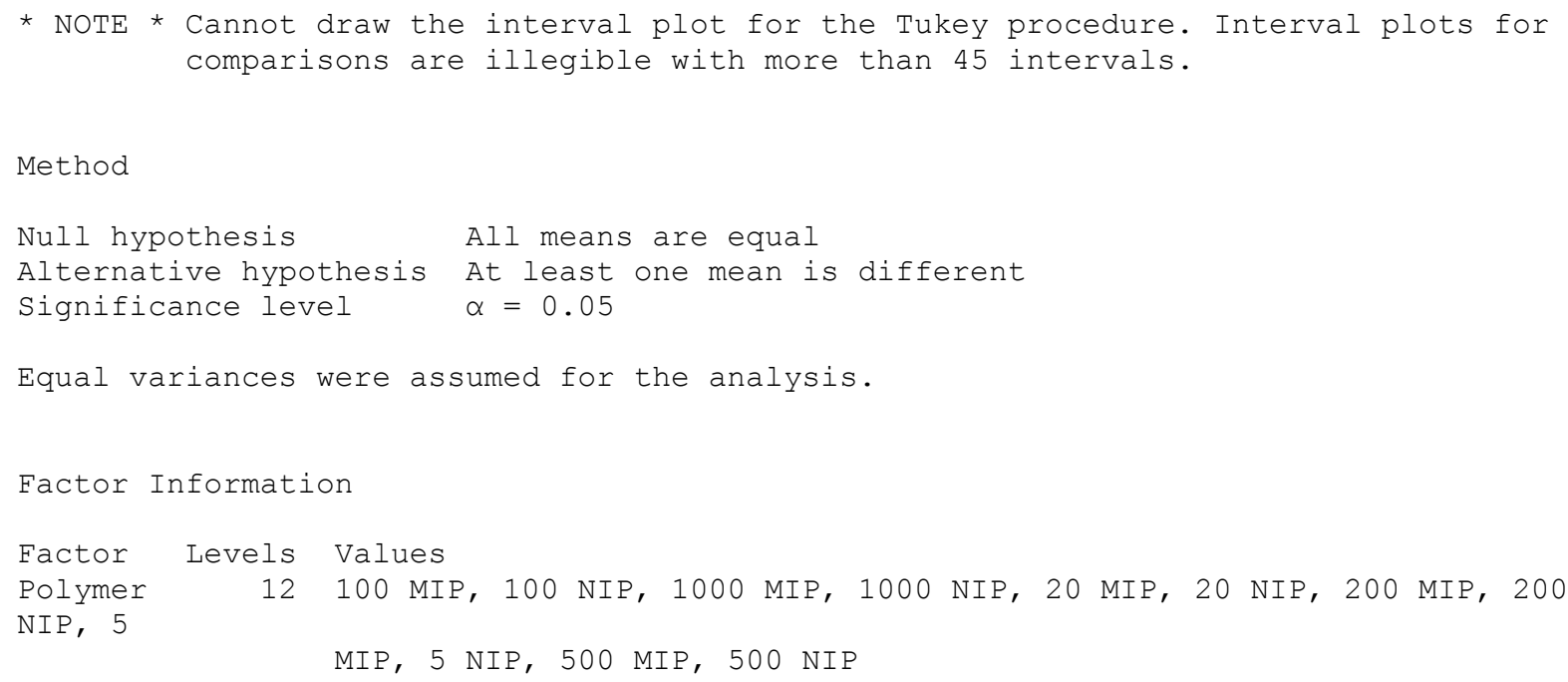




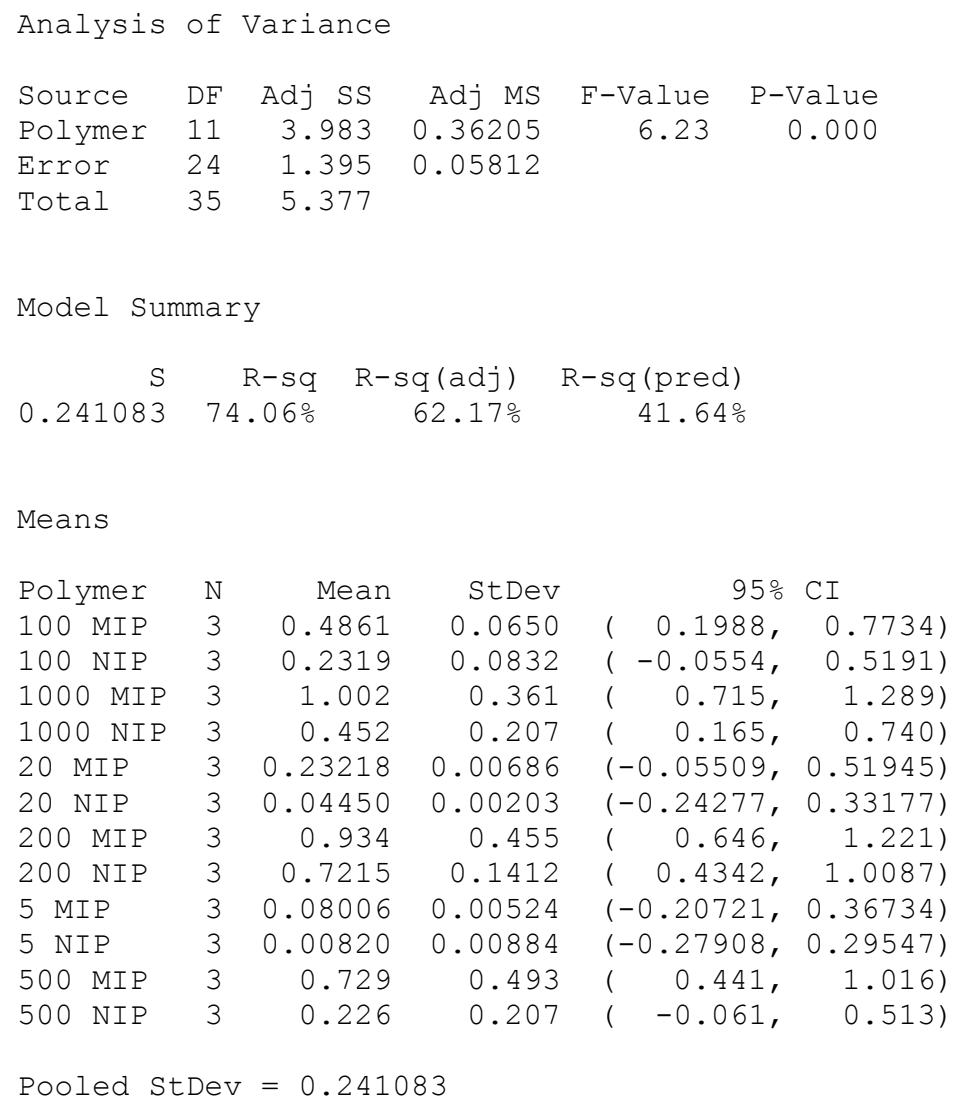

\section{Tukey Pairwise Comparisons}

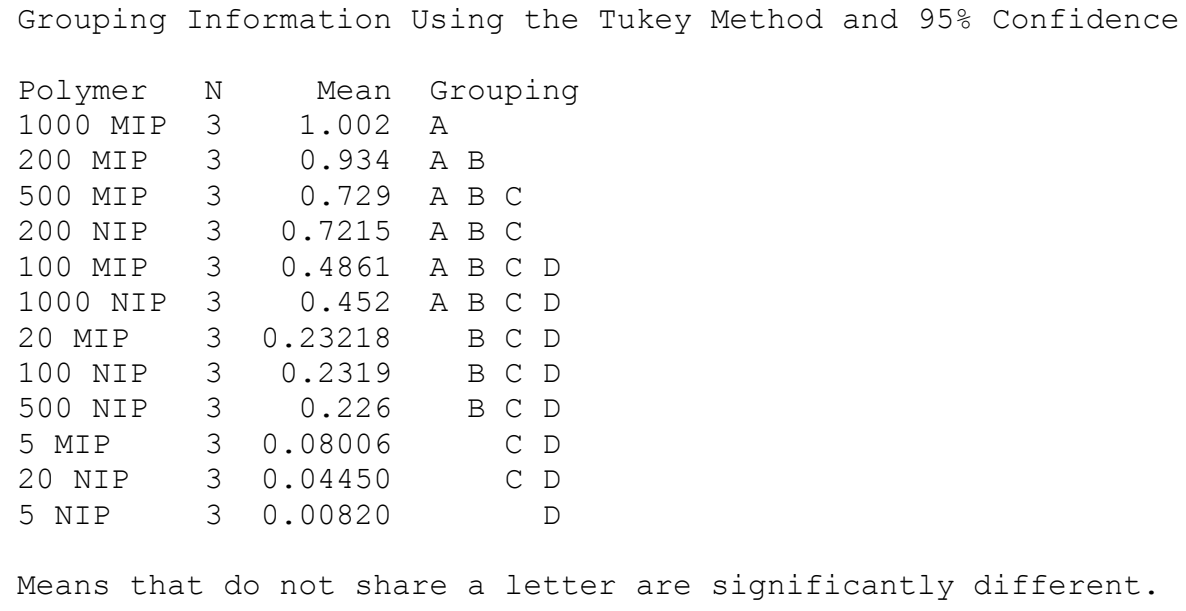

\section{Interval Plot of Sorption (mg) vs Polymer}


Welcome to Minitab, press F1 for help.

Retrieving project from file: 'E: \Research \MS $\backslash \mathrm{AT} \backslash$ Statistical Analysis.MPJ'

\section{One-way ANOVA: Normalized Removal versus Interference}

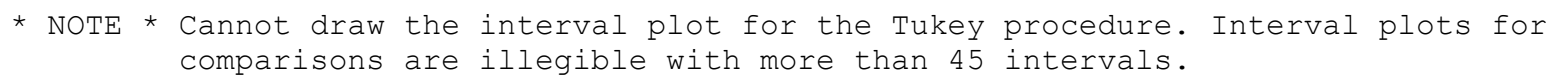

Method

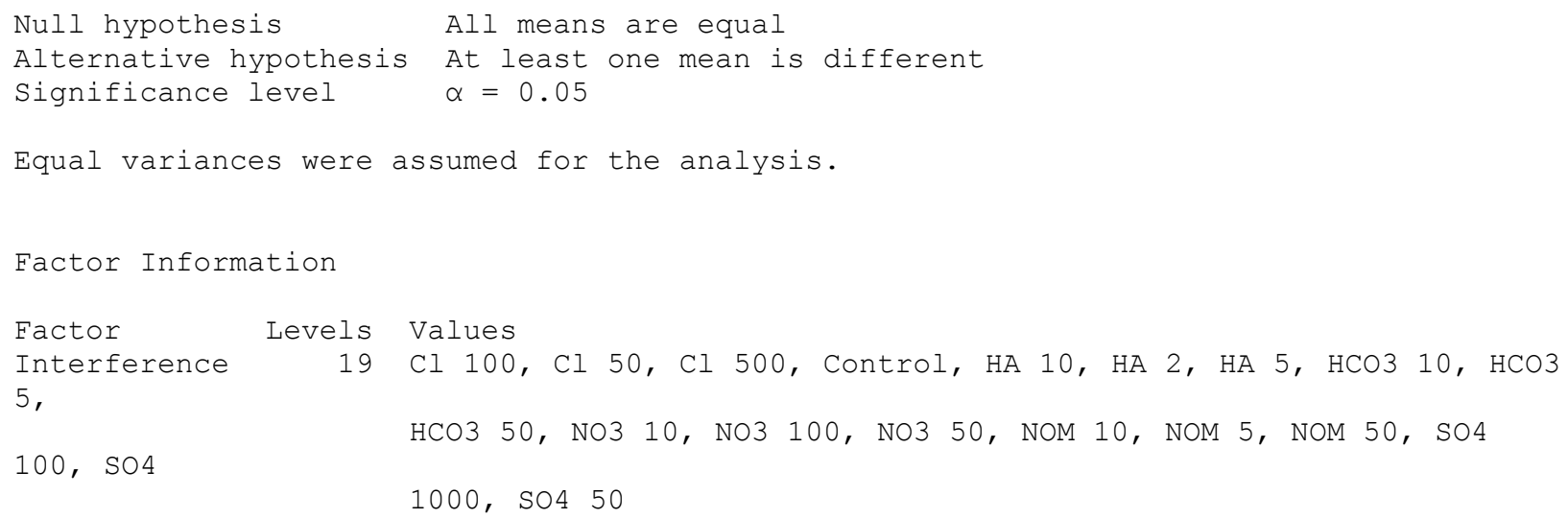




$\begin{array}{llrrrr}\text { NOM } 50 & 3 & 0.4429 & 0.0225 & (0.4205, & 0.4653) \\ \text { SO4 } 100 & 3 & 0.0847 & 0.0188 & (0.0624, & 0.1071) \\ \text { SO4 } 1000 & 3 & 0.05072 & 0.01584 & (0.02836, & 0.07309) \\ \text { SO4 } 50 & 3 & 0.1091 & 0.0201 & (0.0867, & 0.1314) \\ \text { Pooled StDev }= & 0.0191377 & & & \end{array}$

\section{Tukey Pairwise Comparisons}

\begin{tabular}{|c|c|c|c|c|c|c|c|}
\hline Interference & $\mathrm{N}$ & Mean & Group & uping & & & \\
\hline $\mathrm{HA} 2$ & 3 & 0.5669 & A & & & & \\
\hline HA 10 & 3 & 0.5554 & A & & & & \\
\hline Control & 3 & 0.54137 & A B & & & & \\
\hline $\mathrm{HA} 5$ & 3 & 0.5364 & A B & & & & \\
\hline HCO3 10 & 3 & 0.53449 & A B & & & & \\
\hline $\mathrm{HCO} 35$ & 3 & 0.53091 & A B & & & & \\
\hline $\mathrm{HCO} 350$ & 3 & 0.51912 & A B & & & & \\
\hline NOM 5 & 3 & 0.4898 & $\mathrm{BC}$ & $\mathrm{C}$ & & & \\
\hline NOM 50 & 3 & 0.4429 & C & $C D$ & & & \\
\hline NOM 10 & 3 & 0.42396 & & D & & & \\
\hline NO3 10 & 3 & 0.23754 & & $\mathrm{E}$ & & & \\
\hline NO3 50 & 3 & 0.1687 & & & $F$ & & \\
\hline Cl 50 & 3 & 0.16781 & & & $\mathrm{~F}$ & G & \\
\hline Cl 100 & 3 & 0.12011 & & & $\mathrm{~F}$ & $\mathrm{G} \mathrm{H}$ & \\
\hline $\mathrm{SO} 450$ & 3 & 0.1091 & & & & $\mathrm{G} \mathrm{H}$ & I \\
\hline NO3 100 & 3 & 0.0867 & & & & $\mathrm{H}$ & I \\
\hline SO4 100 & 3 & 0.0847 & & & & $\mathrm{H}$ & I \\
\hline Cl 500 & 3 & 0.06220 & & & & $\mathrm{H}$ & I \\
\hline SO4 1000 & 3 & 0.05072 & & & & & I \\
\hline
\end{tabular}

Interval Plot of Normalized Removal vs Interference 


\section{A.3. 2-Methacryloyloxyethyltrimethylammonium Chloride (METAC)}

\section{A.3.1. METAC MIP PZC}

Table A.10. PZC Data for METAC MIP

\begin{tabular}{|c|c|c|c|c|c|}
\hline \multicolumn{2}{|c|}{$0.5 \mathrm{~g} / 100 \mathrm{~mL}$} & \multicolumn{2}{|c|}{$1.0 \mathrm{~g} / 100 \mathrm{~mL}$} & \multicolumn{2}{c|}{$1.5 \mathrm{~g} / 100 \mathrm{~mL}$} \\
\hline $\begin{array}{c}\text { Volume } \\
\text { Titrant } \\
(\mathrm{mL})\end{array}$ & $\mathrm{pH}$ & $\begin{array}{c}\text { Volume } \\
\text { Titrant } \\
(\mathrm{mL})\end{array}$ & $\mathrm{pH}$ & $\begin{array}{c}\text { Volume } \\
\text { Titrant } \\
(\mathrm{mL})\end{array}$ & $\mathrm{pH}$ \\
\hline 0 & 11.49 & 0 & 11.29 & 0 & 11.32 \\
0.5 & 11.27 & 0.5 & 10.99 & 0.2 & 11.24 \\
1 & 10.89 & 1 & 10.88 & 0.4 & 11.16 \\
1.1 & 8.69 & 1.25 & 7.81 & 0.6 & 11.05 \\
1.2 & 6.48 & 1.5 & 5.59 & 0.8 & 10.91 \\
1.3 & 5.75 & 1.6 & 5.29 & 1 & 10.73 \\
1.4 & 5.21 & 1.7 & 5.06 & 1.2 & 10.47 \\
1.5 & 4.81 & 1.8 & 4.88 & 1.4 & 10.05 \\
1.75 & 4.21 & 1.9 & 4.7 & 1.5 & 9.59 \\
2 & 3.79 & 2 & 4.55 & 1.6 & 7.34 \\
2.25 & 3.5 & 2.1 & 4.42 & 1.7 & 6.19 \\
2.75 & 3.16 & 2.2 & 4.3 & 1.8 & 5.02 \\
3.25 & 2.97 & 2.3 & 4.18 & 1.9 & 4.06 \\
3.75 & 2.84 & 2.4 & 4.06 & 2 & 3.75 \\
- & - & 2.5 & 3.95 & 2.1 & 3.57 \\
- & - & 2.6 & 3.58 & 2.2 & 3.44 \\
- & - & 2.7 & 3.5 & 2.3 & 3.35 \\
- & - & 2.8 & 3.48 & 2.5 & 3.2 \\
- & - & 2.9 & 3.45 & 2.7 & 3.09 \\
- & - & 3 & 3.41 & 2.9 & 3.01 \\
- & - & 3.5 & 2.95 & 3.1 & 2.94 \\
- & - & - & - & 3.3 & 2.89 \\
- & - & - & - & 3.5 & 2.84 \\
- & - & - & - & 3.7 & 2.8 \\
\hline & & & & & \\
\hline
\end{tabular}




\section{A.3.2. METAC pH Study}

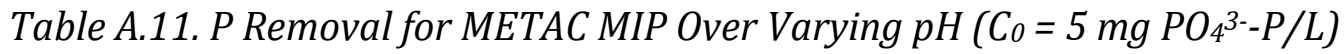

\begin{tabular}{|c|c|c|}
\hline \multicolumn{2}{|c|}{} & \multicolumn{1}{c|}{ Normalized } \\
$\mathrm{pH}$ & Normalized & StdDev \\
\hline 3 & 0.813 & 0.008 \\
4 & 0.919 & 0.008 \\
5 & 0.935 & 0.009 \\
6 & 0.932 & 0.005 \\
7 & 0.924 & 0.009 \\
8 & 0.919 & 0.005 \\
9 & 0.923 & 0.005 \\
10 & 0.945 & 0.008 \\
11 & 0.951 & 0.004 \\
12 & 0.951 & 0.009 \\
\hline
\end{tabular}

\section{A.3.3. METAC Sorption Capacities (MN, MM, MM4, and MM12)}

Table A.12. MN Sorption Capacity Data

\begin{tabular}{|c|c|c|c|c|c|c|}
\hline \multicolumn{1}{|c}{$\begin{array}{c}\text { Actual } \\
\begin{array}{c}\text { Experiment } \\
\text { Title }\end{array}\end{array}$} & $\begin{array}{c}\text { Initial } \\
\text { Conc. } \\
\text { (mg/L) }\end{array}$ & $\begin{array}{c}\text { Sorbed } \\
\text { Phosphate } \\
\text { (mg/L) }\end{array}$ & $\begin{array}{c}\text { Standard } \\
\text { Deviation }\end{array}$ & $\begin{array}{c}\text { Remaining } \\
\text { P } \\
\text { (mg/L) }\end{array}$ & $\begin{array}{c}\text { Sorbed } \\
\text { P } \\
\text { (mg/g) }\end{array}$ & $\begin{array}{c}\text { StdDev } \\
\text { (mg/g) }\end{array}$ \\
\hline 0 & 0.00 & 0.00 & 0.00 & 0.00 & 0.00 & 0.00 \\
$0.5 \mathrm{mg} / \mathrm{L}$ & 0.57 & 0.26 & 0.02 & 0.31 & 0.01 & 0.00 \\
$5 \mathrm{mg} / \mathrm{L}$ & 4.00 & 2.18 & 0.15 & 1.82 & 0.11 & 0.01 \\
$20 \mathrm{mg} / \mathrm{L}$ & 18.22 & 10.28 & 0.29 & 7.94 & 0.51 & 0.01 \\
$100 \mathrm{mg} / \mathrm{L}$ & 72.42 & 22.58 & 3.95 & 49.84 & 1.13 & 0.20 \\
$200 \mathrm{mg} / \mathrm{L}$ & 185.15 & 35.00 & 1.72 & 150.15 & 1.75 & 0.09 \\
$500 \mathrm{mg} / \mathrm{L}$ & 500.71 & 60.61 & 3.44 & 440.10 & 3.03 & 0.17 \\
$1000 \mathrm{mg} / \mathrm{L}$ & 985.63 & 135.00 & 7.90 & 850.62 & 6.75 & 0.40 \\
$1500 \mathrm{mg} / \mathrm{L}$ & 1545.68 & 159.35 & 10.96 & 1386.33 & 7.97 & 0.55 \\
$2000 \mathrm{mg} / \mathrm{L}$ & 1944.05 & 162.93 & 10.96 & 1781.12 & 8.15 & 0.55 \\
$2500 \mathrm{mg} / \mathrm{L}$ & 2494.52 & 190.23 & 14.50 & 2304.28 & 9.51 & 0.73 \\
$3000 \mathrm{mg} / \mathrm{L}$ & 3027.17 & 203.66 & 13.80 & 2823.51 & 10.18 & 0.69 \\
$3500 \mathrm{mg} / \mathrm{L}$ & 3512.82 & 199.19 & 17.62 & 3313.64 & 9.96 & 0.88 \\
\hline
\end{tabular}


Table A.13. MM Sorption Capacity Data

\begin{tabular}{|c|c|c|c|c|c|c|}
\hline \multicolumn{1}{|c}{$\begin{array}{c}\text { Actual } \\
\text { Experiment } \\
\text { Initial } \\
\text { Title }\end{array}$} & $\begin{array}{c}\text { Conc. } \\
\text { (mg/L) }\end{array}$ & $\begin{array}{c}\text { Sorbed } \\
\text { Phosphate } \\
(\mathrm{mg} / \mathrm{L})\end{array}$ & $\begin{array}{c}\text { Standard } \\
\text { Deviation }\end{array}$ & $\begin{array}{c}\text { Remaining } \\
\text { P } \\
(\mathrm{mg} / \mathrm{L})\end{array}$ & $\begin{array}{c}\text { Sorbed } \\
\text { P } \\
(\mathrm{mg} / \mathrm{g})\end{array}$ & $\begin{array}{c}\text { StdDev } \\
(\mathrm{mg} / \mathrm{g})\end{array}$ \\
\hline 0 & 0.00 & 0.00 & 0.00 & 0.00 & 0.00 & 0.00 \\
$0.5 \mathrm{mg} / \mathrm{L}$ & 0.51 & 0.50 & 0.01 & 0.01 & 0.03 & 0.00 \\
$2.5 \mathrm{mg} / \mathrm{L}$ & 2.62 & 2.47 & 0.09 & 0.14 & 0.12 & 0.00 \\
$5 \mathrm{mg} / \mathrm{L}$ & 5.99 & 5.46 & 0.17 & 0.54 & 0.27 & 0.01 \\
$15 \mathrm{mg} / \mathrm{L}$ & 14.62 & 12.83 & 0.12 & 1.78 & 0.64 & 0.01 \\
$100 \mathrm{mg} / \mathrm{L}$ & 95.46 & 43.86 & 1.58 & 51.60 & 2.19 & 0.08 \\
$300 \mathrm{mg} / \mathrm{L}$ & 339.23 & 70.72 & 3.90 & 268.51 & 3.54 & 0.19 \\
$500 \mathrm{mg} / \mathrm{L}$ & 472.96 & 83.87 & 4.84 & 389.09 & 4.19 & 0.24 \\
$1000 \mathrm{mg} / \mathrm{L}$ & 997.33 & 137.85 & 3.44 & 859.48 & 6.89 & 0.17 \\
$1500 \mathrm{mg} / \mathrm{L}$ & 1485.34 & 171.86 & 6.75 & 1313.48 & 8.59 & 0.34 \\
$2000 \mathrm{mg} / \mathrm{L}$ & 1965.08 & 183.81 & 9.10 & 1781.27 & 9.19 & 0.45 \\
$2500 \mathrm{mg} / \mathrm{L}$ & 2528.36 & 234.19 & 14.15 & 2294.16 & 11.71 & 0.71 \\
$3000 \mathrm{mg} / \mathrm{L}$ & 2888.83 & 220.42 & 11.25 & 2668.41 & 11.02 & 0.56 \\
$3500 \mathrm{mg} / \mathrm{L}$ & 3517.93 & 220.42 & 18.08 & 3297.52 & 11.02 & 0.90 \\
\hline
\end{tabular}

Table A.14. MM4 Sorption Capacity Data

\begin{tabular}{|c|c|c|c|c|c|c|}
\hline $\begin{array}{c}\text { Experiment } \\
\text { Title }\end{array}$ & $\begin{array}{c}\text { Actual } \\
\text { Initial } \\
\text { Conc. } \\
\text { (mg/L) }\end{array}$ & $\begin{array}{c}\text { Sorbed } \\
\text { Phosphate } \\
\text { (mg/L) }\end{array}$ & $\begin{array}{l}\text { Standard } \\
\text { Deviation }\end{array}$ & $\begin{array}{c}\text { Remaining } \\
\mathrm{P} \\
(\mathrm{mg} / \mathrm{L}) \\
\end{array}$ & $\begin{array}{c}\text { Sorbed } \\
\mathrm{P} \\
(\mathrm{mg} / \mathrm{g})\end{array}$ & $\begin{array}{l}\text { StdDev } \\
(\mathrm{mg} / \mathrm{g})\end{array}$ \\
\hline 0 & 0.00 & 0.00 & 0.00 & 0.00 & 0.00 & 0.00 \\
\hline $0.5 \mathrm{mg} / \mathrm{L}$ & 0.42 & 0.37 & 0.01 & 0.05 & 0.02 & 0.00 \\
\hline $5 \mathrm{mg} / \mathrm{L}$ & 4.40 & 4.13 & 0.03 & 0.27 & 0.21 & 0.00 \\
\hline $50 \mathrm{mg} / \mathrm{L}$ & 49.47 & 35.43 & 0.16 & 14.04 & 1.77 & 0.01 \\
\hline $200 \mathrm{mg} / \mathrm{L}$ & 201.58 & 70.63 & 1.45 & 130.95 & 3.53 & 0.07 \\
\hline $500 \mathrm{mg} / \mathrm{L}$ & 494.25 & 120.48 & 4.52 & 373.77 & 6.02 & 0.23 \\
\hline $1000 \mathrm{mg} / \mathrm{L}$ & 984.49 & 198.03 & 9.05 & 786.46 & 9.90 & 0.45 \\
\hline $1500 \mathrm{mg} / \mathrm{L}$ & 1458.31 & 248.56 & 10.80 & 1209.75 & 12.43 & 0.54 \\
\hline $2000 \mathrm{mg} / \mathrm{L}$ & 1990.12 & 303.42 & 44.60 & 1686.71 & 15.17 & 2.23 \\
\hline $2500 \mathrm{mg} / \mathrm{L}$ & 2540.42 & 322.45 & 44.73 & 2217.97 & 16.12 & 2.24 \\
\hline $3000 \mathrm{mg} / \mathrm{L}$ & 3080.08 & 356.04 & 38.78 & 2724.04 & 17.80 & 1.94 \\
\hline $3500 \mathrm{mg} / \mathrm{L}$ & 3449.55 & 369.47 & 26.87 & 3080.08 & 18.47 & 1.34 \\
\hline
\end{tabular}


Table A.15. MM12 Sorption Capacity Data

\begin{tabular}{|c|c|c|c|c|c|c|}
\hline $\begin{array}{c}\text { Experiment } \\
\text { Title }\end{array}$ & $\begin{array}{l}\text { Actual } \\
\text { Initial } \\
\text { Conc. } \\
\text { (mg/L) }\end{array}$ & $\begin{array}{c}\text { Sorbed } \\
\text { Phosphate } \\
(\mathrm{mg} / \mathrm{L})\end{array}$ & $\begin{array}{l}\text { Standard } \\
\text { Deviation } \\
\end{array}$ & $\begin{array}{c}\text { Remaining } \\
\mathrm{P} \\
(\mathrm{mg} / \mathrm{L}) \\
\end{array}$ & $\begin{array}{c}\text { Sorbed } \\
\text { P } \\
(\mathrm{mg} / \mathrm{g})\end{array}$ & $\begin{array}{l}\text { StdDev } \\
(\mathrm{mg} / \mathrm{g})\end{array}$ \\
\hline 0.00 & 0.00 & 0.00 & 0.00 & 0.00 & 0.00 & 0.00 \\
\hline $0.5 \mathrm{mg} / \mathrm{L}$ & 0.33 & 0.30 & 0.03 & 0.04 & 0.01 & 0.00 \\
\hline $5 \mathrm{mg} / \mathrm{L}$ & 4.28 & 4.02 & 0.00 & 0.26 & 0.20 & 0.00 \\
\hline $50 \mathrm{mg} / \mathrm{L}$ & 46.21 & 34.58 & 0.92 & 11.63 & 1.73 & 0.05 \\
\hline $200 \mathrm{mg} / \mathrm{L}$ & 203.99 & 70.33 & 1.47 & 133.66 & 3.52 & 0.07 \\
\hline $500 \mathrm{mg} / \mathrm{L}$ & 491.96 & 122.85 & 6.99 & 369.11 & 6.14 & 0.35 \\
\hline $1000 \mathrm{mg} / \mathrm{L}$ & 976.41 & 180.99 & 19.80 & 795.42 & 9.05 & 0.99 \\
\hline $1500 \mathrm{mg} / \mathrm{L}$ & 1514.36 & 255.26 & 21.20 & 1259.10 & 12.76 & 1.06 \\
\hline $2000 \mathrm{mg} / \mathrm{L}$ & 2079.72 & 351.30 & 29.80 & 1728.42 & 17.57 & 1.49 \\
\hline $2500 \mathrm{mg} / \mathrm{L}$ & 2416.33 & 457.04 & 45.07 & 1959.29 & 22.85 & 2.25 \\
\hline $3000 \mathrm{mg} / \mathrm{L}$ & 3099.18 & 539.89 & 38.21 & 2559.29 & 26.99 & 1.91 \\
\hline $3500 \mathrm{mg} / \mathrm{L}$ & 3619.34 & 565.56 & 26.72 & 3053.79 & 28.28 & 1.34 \\
\hline
\end{tabular}




\section{A.3.4. METAC Interference Study (MM, MM4, and MM12)}

Table A.16. P Removal by MM Amongst Competing Anions ( $\left.C_{0}=5 \mathrm{mg} P \mathrm{P}_{4}^{3-}-\mathrm{P} / \mathrm{L}\right)$

\begin{tabular}{|c|c|c|c|c|c|c|c|c|}
\hline \multicolumn{9}{|c|}{$\mathrm{Cl}-$} \\
\hline & $\mathrm{Cl}^{-}(50 \mathrm{mg} / \mathrm{L})$ & & & $\mathrm{Cl}^{-}(100 \mathrm{mg} / \mathrm{L})$ & & & $-(500 \mathrm{mg} / \mathrm{L})$ & \\
\hline Time (hr) & $\begin{array}{c}\text { Phosphate } \\
\text { conc. } \\
\text { (mg/L) }\end{array}$ & $\begin{array}{l}\text { standard } \\
\text { deviation }\end{array}$ & Time (hr) & $\begin{array}{c}\text { Phosphate } \\
\text { conc. } \\
\text { (mg/L) }\end{array}$ & $\begin{array}{l}\text { standard } \\
\text { deviation }\end{array}$ & Time (hr) & $\begin{array}{c}\text { Phosphate } \\
\text { conc. } \\
\text { (mg/L) }\end{array}$ & $\begin{array}{l}\text { standard } \\
\text { deviation }\end{array}$ \\
\hline $0 \mathrm{~h}$ & 4.46 & 0.04 & $0 \mathrm{~h}$ & 4.47 & 0.03 & $0 \mathrm{~h}$ & 4.13 & 0.05 \\
\hline $24 \mathrm{~h}$ & 2.01 & 0.04 & $24 \mathrm{~h}$ & 2.46 & 0.12 & $24 \mathrm{~h}$ & 3.36 & 0.05 \\
\hline Blank & 4.49 & 0.02 & Blank & 4.45 & 0.03 & Blank & 4.08 & 0.08 \\
\hline $\begin{array}{l}\text { Amount } \\
\text { Sorbed } \\
(\mathrm{mg} / \mathrm{L})\end{array}$ & $\begin{array}{l}\text { Percent } \\
\text { Sorption }\end{array}$ & & $\begin{array}{c}\text { Amount } \\
\text { Sorbed } \\
(\mathrm{mg} / \mathrm{L})\end{array}$ & $\begin{array}{l}\text { Percent } \\
\text { Sorption }\end{array}$ & & $\begin{array}{l}\text { Amount } \\
\text { Sorbed } \\
(\mathrm{mg} / \mathrm{L})\end{array}$ & $\begin{array}{l}\text { Percent } \\
\text { Sorption }\end{array}$ & \\
\hline 2.45 & 54.94 & & 2.01 & 45.05 & & 0.77 & 18.65 & \\
\hline $\begin{array}{c}\text { Normalized } \\
\text { Sorption }\end{array}$ & 0.549 & 0.009 & $\begin{array}{c}\text { Normalized } \\
\text { Sorption } \\
\end{array}$ & 0.450 & 0.027 & $\begin{array}{c}\text { Normalized } \\
\text { Sorption } \\
\end{array}$ & 0.187 & 0.013 \\
\hline
\end{tabular}


Table A.16. P Removal by MM Amongst Competing Anions ( $C_{0}=5 \mathrm{mg} \mathrm{PO} 4^{3-}-\mathrm{P} / \mathrm{L}$ ) (Continued)

\begin{tabular}{|c|c|c|c|c|c|c|c|c|}
\hline \multicolumn{9}{|c|}{$\mathrm{SO}_{4}^{2-}$} \\
\hline \multicolumn{3}{|c|}{$\mathrm{SO}_{4}{ }^{2-}(50 \mathrm{mg} / \mathrm{L})$} & \multicolumn{3}{|c|}{$\mathrm{SO}_{4}^{2-}(100 \mathrm{mg} / \mathrm{L})$} & \multicolumn{3}{|c|}{$\mathrm{SO}_{4}{ }^{2-}(1000 \mathrm{mg} / \mathrm{L})$} \\
\hline & Phosphate & & & Phosphate & & & Phosphate & \\
\hline Time (hr) & $\begin{array}{c}\text { conc. } \\
\text { (mg/L) }\end{array}$ & $\begin{array}{l}\text { standard } \\
\text { deviation }\end{array}$ & Time (hr) & $\begin{array}{c}\text { conc. } \\
\text { (mg/L) }\end{array}$ & $\begin{array}{l}\text { standard } \\
\text { deviation }\end{array}$ & Time (hr) & $\begin{array}{c}\text { conc. } \\
\text { (mg/L) }\end{array}$ & $\begin{array}{l}\text { standard } \\
\text { deviation }\end{array}$ \\
\hline $0 \mathrm{~h}$ & 4.32 & 0.02 & $0 \mathrm{~h}$ & 4.29 & 0.04 & $0 \mathrm{~h}$ & 4.35 & 0.02 \\
\hline $24 \mathrm{~h}$ & 1.09 & 0.07 & $24 \mathrm{~h}$ & 2.03 & 0.15 & $24 \mathrm{~h}$ & 3.73 & 0.04 \\
\hline Blank & 4.30 & 0.00 & Blank & 4.33 & 0.02 & Blank & 4.35 & 0.04 \\
\hline $\begin{array}{c}\text { Amount } \\
\text { Sorbed } \\
(\mathrm{mg} / \mathrm{L})\end{array}$ & $\begin{array}{l}\text { Percent } \\
\text { Sorption }\end{array}$ & & $\begin{array}{c}\text { Amount } \\
\text { Sorbed } \\
(\mathrm{mg} / \mathrm{L})\end{array}$ & $\begin{array}{l}\text { Percent } \\
\text { Sorption }\end{array}$ & & $\begin{array}{l}\text { Amount } \\
\text { Sorbed } \\
(\mathrm{mg} / \mathrm{L})\end{array}$ & $\begin{array}{l}\text { Percent } \\
\text { Sorption }\end{array}$ & \\
\hline 3.22 & 74.69 & & 2.27 & 52.82 & & 0.63 & 14.38 & \\
\hline $\begin{array}{c}\text { Normalized } \\
\text { Sorption }\end{array}$ & 0.747 & 0.017 & $\begin{array}{l}\text { Normalized } \\
\text { Sorption }\end{array}$ & 0.528 & 0.035 & $\begin{array}{l}\text { Normalized } \\
\text { Sorption }\end{array}$ & 0.144 & 0.010 \\
\hline
\end{tabular}


Table A.16. P Removal by MM Amongst Competing Anions ( $C_{0}=5 \mathrm{mg} \mathrm{PO} 4^{3-}-\mathrm{P} / \mathrm{L}$ ) (Continued)

\begin{tabular}{|c|c|c|c|c|c|c|c|c|}
\hline \multicolumn{9}{|c|}{$\mathrm{NO}_{3}^{-}$} \\
\hline \multicolumn{3}{|c|}{$\mathrm{NO}_{3}{ }^{-}(10 \mathrm{mg} / \mathrm{L})$} & \multicolumn{3}{|c|}{$\mathrm{NO}_{3}{ }^{-}(50 \mathrm{mg} / \mathrm{L})$} & \multicolumn{3}{|c|}{$\mathrm{NO}_{3}-(100 \mathrm{mg} / \mathrm{L})$} \\
\hline & Phosphate & & & Phosphate & & & Phosphate & \\
\hline Time (hr) & $\begin{array}{c}\text { conc. } \\
\text { (mg/L) }\end{array}$ & $\begin{array}{l}\text { standard } \\
\text { deviation }\end{array}$ & Time (hr) & $\begin{array}{c}\text { conc. } \\
\text { (mg/L) }\end{array}$ & $\begin{array}{l}\text { standard } \\
\text { deviation }\end{array}$ & Time (hr) & $\begin{array}{c}\text { conc. } \\
(\mathrm{mg} / \mathrm{L})\end{array}$ & $\begin{array}{l}\text { standard } \\
\text { deviation }\end{array}$ \\
\hline $0 \mathrm{~h}$ & 4.32 & 0.02 & $0 \mathrm{~h}$ & 4.35 & 0.03 & $0 \mathrm{~h}$ & 4.36 & 0.02 \\
\hline $24 \mathrm{~h}$ & 0.41 & 0.03 & $24 \mathrm{~h}$ & 1.10 & 0.09 & $24 \mathrm{~h}$ & 1.73 & 0.02 \\
\hline Blank & 4.30 & 0.03 & Blank & 4.36 & 0.02 & Blank & 4.36 & 0.02 \\
\hline $\begin{array}{c}\text { Amount } \\
\text { Sorbed } \\
(\mathrm{mg} / \mathrm{L})\end{array}$ & $\begin{array}{l}\text { Percent } \\
\text { Sorption }\end{array}$ & & $\begin{array}{c}\text { Amount } \\
\text { Sorbed } \\
(\mathrm{mg} / \mathrm{L})\end{array}$ & $\begin{array}{l}\text { Percent } \\
\text { Sorption }\end{array}$ & & $\begin{array}{l}\text { Amount } \\
\text { Sorbed } \\
(\mathrm{mg} / \mathrm{L})\end{array}$ & $\begin{array}{l}\text { Percent } \\
\text { Sorption }\end{array}$ & \\
\hline 3.91 & 90.56 & & 3.25 & 74.63 & & 2.63 & 60.35 & \\
\hline $\begin{array}{c}\text { Normalized } \\
\text { Sorption } \\
\end{array}$ & 0.906 & 0.007 & $\begin{array}{c}\text { Normalized } \\
\text { Sorption } \\
\end{array}$ & 0.746 & 0.020 & $\begin{array}{l}\text { Normalized } \\
\text { Sorption }\end{array}$ & 0.604 & 0.004 \\
\hline
\end{tabular}


Table A.16. P Removal by MM Amongst Competing Anions ( $\left.C_{0}=5 \mathrm{mg} \mathrm{PO} 4^{3-}-\mathrm{P} / \mathrm{L}\right)$ (Continued)

\begin{tabular}{|c|c|c|c|c|c|c|c|c|}
\hline \multicolumn{9}{|c|}{ Humic Acid } \\
\hline \multicolumn{3}{|c|}{ Humic Acid (2 mg/L) } & \multicolumn{3}{|c|}{ Humic Acid (5 mg/L) } & \multicolumn{3}{|c|}{ Humic Acid (10 mg/L) } \\
\hline \multicolumn{3}{|c|}{ Phosphate } & \multicolumn{3}{|c|}{ Phosphate } & \multicolumn{3}{|c|}{ Phosphate } \\
\hline Time (hr) & $\begin{array}{c}\text { conc. } \\
\text { (mg/L) }\end{array}$ & $\begin{array}{l}\text { standard } \\
\text { deviation }\end{array}$ & Time (hr) & $\begin{array}{l}\text { conc. } \\
\text { (mg/L) }\end{array}$ & $\begin{array}{l}\text { standard } \\
\text { deviation }\end{array}$ & Time (hr) & $\begin{array}{c}\text { conc. } \\
(\mathrm{mg} / \mathrm{L})\end{array}$ & $\begin{array}{l}\text { standard } \\
\text { deviation }\end{array}$ \\
\hline $0 \mathrm{~h}$ & 4.88 & 0.02 & $0 \mathrm{~h}$ & 4.81 & 0.03 & $0 \mathrm{~h}$ & 4.86 & 0.02 \\
\hline $24 \mathrm{~h}$ & 0.28 & 0.02 & $24 \mathrm{~h}$ & 0.29 & 0.02 & $24 \mathrm{~h}$ & 0.28 & 0.02 \\
\hline Blank & 4.74 & 0.15 & Blank & 4.78 & 0.11 & Blank & 4.85 & 0.03 \\
\hline $\begin{array}{l}\text { Amount } \\
\text { Sorbed } \\
(\mathrm{mg} / \mathrm{L})\end{array}$ & $\begin{array}{l}\text { Percent } \\
\text { Sorption }\end{array}$ & & $\begin{array}{l}\text { Amount } \\
\text { Sorbed } \\
(\mathrm{mg} / \mathrm{L})\end{array}$ & $\begin{array}{l}\text { Percent } \\
\text { Sorption }\end{array}$ & & $\begin{array}{l}\text { Amount } \\
\text { Sorbed } \\
(\mathrm{mg} / \mathrm{L})\end{array}$ & $\begin{array}{l}\text { Percent } \\
\text { Sorption }\end{array}$ & \\
\hline 4.60 & 94.23 & & 4.52 & 93.91 & & 4.58 & 94.20 & \\
\hline $\begin{array}{c}\text { Normalized } \\
\text { Sorption } \\
\end{array}$ & 0.942 & 0.003 & $\begin{array}{c}\text { Normalized } \\
\text { Sorption } \\
\end{array}$ & 0.939 & 0.003 & $\begin{array}{c}\text { Normalized } \\
\text { Sorption } \\
\end{array}$ & 0.942 & 0.003 \\
\hline \multicolumn{9}{|c|}{ NOM } \\
\hline \multicolumn{3}{|c|}{ NOM (5 mg/L) } & \multicolumn{3}{|c|}{ NOM (10 mg/L) } & \multicolumn{3}{|c|}{ NOM (50 mg/L) } \\
\hline Time (hr) & $\begin{array}{c}\text { Phosphate } \\
\text { conc. } \\
\text { (mg/L) }\end{array}$ & $\begin{array}{l}\text { standard } \\
\text { deviation }\end{array}$ & Time (hr) & $\begin{array}{c}\text { Phosphate } \\
\text { conc. } \\
(\mathrm{mg} / \mathrm{L})\end{array}$ & $\begin{array}{l}\text { standard } \\
\text { deviation }\end{array}$ & Time (hr) & $\begin{array}{c}\text { Phosphate } \\
\text { conc. } \\
\text { (mg/L) }\end{array}$ & $\begin{array}{l}\text { standard } \\
\text { deviation }\end{array}$ \\
\hline $0 \mathrm{~h}$ & 4.98 & 0.02 & $0 \mathrm{~h}$ & 4.88 & 0.03 & $0 \mathrm{~h}$ & 4.77 & 0.07 \\
\hline $24 \mathrm{~h}$ & 0.37 & 0.07 & $24 \mathrm{~h}$ & 0.28 & 0.02 & $24 \mathrm{~h}$ & 0.56 & 0.04 \\
\hline Blank & 4.81 & 0.18 & Blank & 4.81 & 0.10 & Blank & 4.79 & 0.03 \\
\hline $\begin{array}{l}\text { Amount } \\
\text { Sorbed } \\
(\mathrm{mg} / \mathrm{L})\end{array}$ & $\begin{array}{l}\text { Percent } \\
\text { Sorption }\end{array}$ & & $\begin{array}{l}\text { Amount } \\
\text { Sorbed } \\
(\mathrm{mg} / \mathrm{L})\end{array}$ & $\begin{array}{l}\text { Percent } \\
\text { Sorption }\end{array}$ & & $\begin{array}{l}\text { Amount } \\
\text { Sorbed } \\
(\mathrm{mg} / \mathrm{L})\end{array}$ & $\begin{array}{l}\text { Percent } \\
\text { Sorption }\end{array}$ & \\
\hline 4.61 & 92.53 & & 4.60 & 94.23 & & 4.20 & 88.18 & \\
\hline $\begin{array}{l}\text { Normalized } \\
\text { Sorption }\end{array}$ & 0.925 & 0.015 & $\begin{array}{l}\text { Normalized } \\
\text { Sorption }\end{array}$ & 0.942 & 0.003 & $\begin{array}{l}\text { Normalized } \\
\text { Sorption }\end{array}$ & 0.882 & 0.009 \\
\hline
\end{tabular}




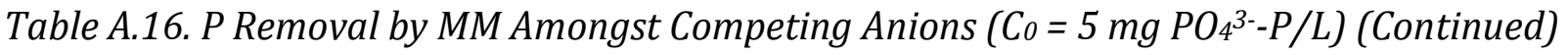

\begin{tabular}{|ccc|}
\hline & Control & Standard deviation \\
\hline Time (hr) & Control (5 mg/L) & 0.03 \\
0 & Phosphate Conc. (mg/L) & 0.07 \\
24 & 4.95 & 0.06 \\
Blank & 0.37 & \\
Amount Sorbed (mg/L) & 4.91 & 0.015 \\
N.58 & Percent Sorption & \\
\hline
\end{tabular}




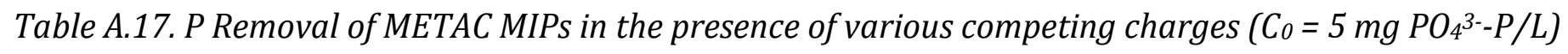

\begin{tabular}{|c|c|c|c|c|c|c|}
\hline \multirow[b]{2}{*}{$\begin{array}{c}\text { Anion } \\
\text { Species }\end{array}$} & \multicolumn{2}{|c|}{$\mathbf{M M}$} & \multicolumn{2}{|c|}{ MM4 } & \multicolumn{2}{|c|}{ MM12 } \\
\hline & $\begin{array}{c}\text { Anion Charge } \\
(\mathrm{meq} / \mathrm{L})\end{array}$ & $\begin{array}{c}\text { Normalized } \\
\text { P Removal }\end{array}$ & $\begin{array}{c}\text { Anion Charge } \\
(\mathrm{meq} / \mathrm{L})\end{array}$ & $\begin{array}{c}\text { Normalized } \\
\text { P Removal } \\
\end{array}$ & $\begin{array}{c}\text { Anion Charge } \\
(\mathrm{meq} / \mathrm{L})\end{array}$ & $\begin{array}{c}\text { Normalized } \\
\text { P Removal }\end{array}$ \\
\hline Control & 0.00 & 0.92 & 0.00 & 0.92 & 0.00 & 0.92 \\
\hline $\mathrm{Cl}^{-}$ & 1.41 & 0.55 & 1.41 & 0.60 & 1.41 & 0.58 \\
\hline $\mathrm{Cl}^{-}$ & 2.82 & 0.45 & 2.82 & 0.54 & 2.82 & 0.52 \\
\hline $\mathrm{Cl}^{-}$ & 14.10 & 0.19 & 14.10 & 0.22 & 14.10 & 0.21 \\
\hline $\mathrm{HCO}_{3}^{-}$ & 0.08 & 0.89 & 0.08 & 0.90 & 0.08 & 0.92 \\
\hline $\mathrm{HCO}_{3}^{-}$ & 0.16 & 0.90 & 0.16 & 0.92 & 0.16 & 0.92 \\
\hline $\mathrm{HCO}_{3}^{-}$ & 0.82 & 0.94 & 0.82 & 0.91 & 0.82 & 0.91 \\
\hline $\mathrm{SO}_{4}{ }^{2-}$ & 1.04 & 0.75 & 1.04 & 0.76 & 1.04 & 0.77 \\
\hline $\mathrm{SO}_{4}{ }^{2-}$ & 2.08 & 0.53 & 2.08 & 0.55 & 2.08 & 0.52 \\
\hline $\mathrm{SO}_{4}{ }^{2-}$ & 20.82 & 0.14 & 20.82 & 0.17 & 20.82 & 0.19 \\
\hline $\mathrm{NO}_{3}^{-}$ & 0.16 & 0.91 & 0.16 & 0.92 & 0.16 & 0.92 \\
\hline $\mathrm{NO}_{3}^{-}$ & 0.81 & 0.75 & 0.81 & 0.80 & 0.81 & 0.77 \\
\hline $\mathrm{NO}_{3}^{-}$ & 1.61 & 0.60 & 1.61 & 0.63 & 1.61 & 0.65 \\
\hline $\mathbf{F}^{-}$ & 10.06 & 0.20 & - & - & - & - \\
\hline $\mathrm{Br}^{-}$ & 7.11 & 0.31 & - & - & - & - \\
\hline $\mathbf{F}^{-}$ & 5.23 & 0.35 & - & - & - & - \\
\hline $\mathrm{Br}^{-}$ & 5.10 & 0.32 & - & - & - & - \\
\hline $\mathrm{C}_{2} \mathrm{H}_{3} \mathrm{O}_{2}^{-}$ & 7.92 & 0.25 & - & - & - & - \\
\hline
\end{tabular}




\section{A.3.5. METAC Desorption Study}

Table A.18. Desorption of P from MM12 Over Six Time-Variable Cycles

\begin{tabular}{|c|c|c|c|}
\hline $\begin{array}{c}\text { Cumulative } \\
\text { Days }\end{array}$ & Cycles & $\begin{array}{c}\text { Normalized } \\
\text { P Removal }\end{array}$ & $\begin{array}{c}\text { Normalized } \\
\text { StdDev }\end{array}$ \\
\hline 0 & 0 & 0.00 & 0.00 \\
\hline 0.25 & $\begin{array}{c}\text { Cycle } 1 \\
\text { (6 hr) }\end{array}$ & 3.27 & 0.22 \\
\hline 0.5 & $\begin{array}{c}\text { Cycle } 2 \\
\text { (6 hr) }\end{array}$ & 0.67 & 0.02 \\
\hline 1 & $\begin{array}{l}\text { Cycle } 3 \\
\text { (12 hr) }\end{array}$ & 0.44 & 0.04 \\
\hline 2 & $\begin{array}{l}\text { Cycle } 4 \\
\text { (24 hr) }\end{array}$ & 0.29 & 0.02 \\
\hline 3 & $\begin{array}{l}\text { Cycle } 5 \\
\text { (24 hr) }\end{array}$ & 0.23 & 0.02 \\
\hline 4 & $\begin{array}{l}\text { Cycle } 6 \\
(24 \mathrm{hr})\end{array}$ & 0.09 & 0.05 \\
\hline
\end{tabular}

\section{A.3.6. METAC Biodegradability Respirometer Data}

Table A.19. BOD of Blank and Sample with $100 \mathrm{mg}$ MM12

\begin{tabular}{|l|cc|c|c|}
\hline & \multicolumn{2}{|c|}{ Blank } & \multicolumn{2}{c|}{ Sample } \\
\cline { 2 - 5 } Days & $\begin{array}{c}\text { Corrected } \\
\text { Reading }\end{array}$ & $\begin{array}{c}\text { Corrected } \\
\text { StdDev }\end{array}$ & $\begin{array}{c}\text { Corrected } \\
\text { Reading }\end{array}$ & $\begin{array}{c}\text { Corrected } \\
\text { StdDev }\end{array}$ \\
\hline 0.00 & 0.00 & 0.00 & 0.00 & 0.00 \\
0.02 & -21.82 & 3.62 & -21.82 & 6.26 \\
0.04 & -34.38 & 4.74 & -27.62 & 2.46 \\
0.06 & -36.32 & 5.34 & -30.03 & 2.46 \\
0.08 & -39.70 & 6.26 & -36.80 & 4.27 \\
0.10 & -37.77 & 4.10 & -37.77 & 1.81 \\
0.12 & -36.32 & 9.40 & -36.80 & 2.46 \\
0.14 & -34.87 & 7.20 & -37.28 & 4.16 \\
0.16 & -33.42 & 10.34 & -31.48 & 6.73 \\
0.18 & -34.38 & 9.86 & -29.55 & 2.98 \\
0.20 & -31.00 & 13.34 & -26.65 & 3.62 \\
0.22 & -33.42 & 10.07 & -28.10 & 1.37 \\
0.25 & -27.13 & 14.71 & -21.33 & 2.98 \\
0.27 & -26.65 & 17.17 & -21.33 & 1.81 \\
\hline
\end{tabular}


Table A.19. BOD of Blank and Sample with $100 \mathrm{mg}$ MM12 (Continued)

\begin{tabular}{|c|c|c|c|c|}
\hline Days & $\begin{array}{c}\text { Blank } \\
\text { Corrected } \\
\text { Reading } \\
\end{array}$ & $\begin{array}{c}\text { Corrected } \\
\text { StdDev }\end{array}$ & $\begin{array}{c}\text { Sample } \\
\text { Corrected } \\
\text { Reading }\end{array}$ & $\begin{array}{c}\text { Corrected } \\
\text { StdDev }\end{array}$ \\
\hline 0.31 & -25.20 & 15.99 & -17.95 & 2.46 \\
\hline 0.33 & -28.10 & 16.80 & -14.08 & 2.37 \\
\hline 0.35 & -28.10 & 14.80 & -17.47 & 2.98 \\
\hline 0.37 & -22.78 & 15.41 & -11.18 & 4.93 \\
\hline 0.39 & -23.75 & 17.44 & -10.70 & 8.89 \\
\hline 0.41 & -21.82 & 18.08 & -2.00 & 7.76 \\
\hline 0.43 & -21.33 & 18.43 & -4.42 & 10.12 \\
\hline 0.45 & -20.85 & 19.68 & 4.28 & 11.92 \\
\hline 0.47 & -22.78 & 19.38 & 0.90 & 8.89 \\
\hline 0.50 & -18.92 & 20.41 & 6.70 & 10.85 \\
\hline 0.52 & -14.08 & 17.57 & 7.18 & 12.44 \\
\hline 0.54 & -15.05 & 19.03 & 11.05 & 14.32 \\
\hline 0.56 & -13.60 & 23.51 & 12.50 & 17.68 \\
\hline 0.58 & -16.50 & 21.34 & 11.53 & 17.01 \\
\hline 0.60 & -11.67 & 21.52 & 9.12 & 18.79 \\
\hline 0.62 & -4.90 & 26.93 & 20.23 & 17.57 \\
\hline 0.64 & -10.70 & 23.29 & 17.82 & 20.59 \\
\hline 0.66 & -5.87 & 24.39 & 24.10 & 19.92 \\
\hline 0.68 & -7.80 & 29.34 & 20.23 & 21.34 \\
\hline 0.70 & -9.73 & 20.38 & 23.13 & 25.40 \\
\hline 0.72 & -2.48 & 23.51 & 31.35 & 20.38 \\
\hline 0.75 & -4.90 & 22.38 & 27.00 & 20.17 \\
\hline 0.77 & -3.45 & 20.95 & 32.80 & 23.27 \\
\hline 0.79 & -1.52 & 23.94 & 36.67 & 19.70 \\
\hline 0.81 & -2.97 & 20.14 & 33.28 & 23.24 \\
\hline 0.83 & 0.90 & 25.12 & 41.50 & 23.27 \\
\hline 0.85 & -3.93 & 22.18 & 40.05 & 25.54 \\
\hline 0.87 & 1.38 & 39.16 & 37.15 & 27.31 \\
\hline 0.89 & -22.30 & 43.41 & 27.48 & 20.54 \\
\hline 0.91 & -30.03 & 29.74 & 26.03 & 21.32 \\
\hline 0.93 & -8.77 & 31.11 & 37.15 & 20.86 \\
\hline 0.95 & -7.80 & 22.49 & 39.57 & 25.54 \\
\hline 0.97 & 4.28 & 28.42 & 53.10 & 25.64 \\
\hline 1.00 & 0.90 & 24.19 & 56.48 & 29.74 \\
\hline 1.02 & 8.15 & 27.97 & 63.73 & 28.42 \\
\hline 1.04 & 4.77 & 20.86 & 63.25 & 35.56 \\
\hline 1.06 & 6.22 & 22.35 & 67.60 & 35.33 \\
\hline 1.10 & 12.98 & 25.06 & 75.33 & 29.98 \\
\hline
\end{tabular}


Table A.19. BOD of Blank and Sample with $100 \mathrm{mg}$ MM12 (Continued)

\begin{tabular}{|c|c|c|c|c|}
\hline Days & $\begin{array}{c}\text { Blank } \\
\text { Corrected } \\
\text { Reading }\end{array}$ & $\begin{array}{c}\text { Corrected } \\
\text { StdDev }\end{array}$ & $\begin{array}{c}\text { Sample } \\
\text { Corrected } \\
\text { Reading }\end{array}$ & $\begin{array}{c}\text { Corrected } \\
\text { StdDev }\end{array}$ \\
\hline 1.16 & 9.12 & 23.05 & 79.20 & 37.45 \\
1.18 & 17.33 & 28.42 & 84.52 & 37.11 \\
1.20 & 11.05 & 25.51 & 82.10 & 38.50 \\
1.22 & 12.50 & 25.06 & 85.00 & 36.78 \\
1.25 & 21.68 & 28.25 & 87.90 & 36.17 \\
1.27 & 19.27 & 28.42 & 91.77 & 33.49 \\
1.29 & 19.75 & 31.79 & 88.87 & 29.10 \\
1.31 & 15.88 & 29.22 & 99.50 & 36.12 \\
1.33 & 13.95 & 29.88 & 92.73 & 32.86 \\
1.35 & 15.88 & 31.26 & 100.95 & 32.43 \\
1.37 & 14.92 & 31.26 & 98.05 & 30.62 \\
1.39 & 19.27 & 33.49 & 102.88 & 32.69 \\
1.41 & 18.30 & 33.49 & 99.02 & 32.96 \\
1.43 & 21.20 & 33.00 & 102.88 & 33.66 \\
1.45 & 18.78 & 34.03 & 102.40 & 32.34 \\
1.47 & 24.10 & 34.98 & 103.37 & 31.69 \\
1.50 & 21.68 & 34.69 & 99.50 & 35.30 \\
1.52 & 22.65 & 34.15 & 105.78 & 34.77 \\
1.54 & 26.03 & 32.52 & 100.95 & 35.30 \\
1.56 & 30.87 & 33.18 & 110.13 & 31.39 \\
1.58 & 27.00 & 33.84 & 105.78 & 33.66 \\
1.60 & 26.03 & 36.61 & 106.75 & 34.15 \\
1.62 & 24.10 & 35.80 & 107.23 & 33.72 \\
1.64 & 22.65 & 34.70 & 107.23 & 32.34 \\
1.66 & 27.48 & 36.03 & 109.17 & 34.65 \\
1.68 & 28.45 & 32.90 & 112.07 & 36.45 \\
1.70 & 32.80 & 31.32 & 115.93 & 38.26 \\
1.72 & 34.73 & 36.70 & 118.35 & 38.59 \\
1.75 & 34.73 & 37.83 & 117.87 & 36.82 \\
1.77 & 34.73 & 34.03 & 120.28 & 38.42 \\
1.79 & 34.25 & 34.93 & 117.38 & 37.27 \\
1.81 & 38.12 & 38.73 & 121.73 & 35.21 \\
1.83 & 40.05 & 36.50 & 119.80 & 38.26 \\
1.85 & 38.12 & 38.31 & 122.70 & 35.30 \\
1.87 & 41.98 & 42.56 & 123.18 & 36.82 \\
1.89 & 32.80 & 43.89 & 120.28 & 32.77 \\
1.91 & 32.32 & 41.70 & 120.77 & 32.18 \\
1.95 & 38.12 & 37.89 & 126.08 & 38.11 \\
\hline
\end{tabular}


Table A.19. BOD of Blank and Sample with $100 \mathrm{mg}$ MM12 (Continued)

\begin{tabular}{|c|c|c|c|c|}
\hline Days & $\begin{array}{c}\text { Blank } \\
\text { Corrected } \\
\text { Reading } \\
\end{array}$ & $\begin{array}{c}\text { Corrected } \\
\text { StdDev }\end{array}$ & $\begin{array}{c}\text { Sample } \\
\text { Corrected } \\
\text { Reading }\end{array}$ & $\begin{array}{c}\text { Corrected } \\
\text { StdDev }\end{array}$ \\
\hline 2.02 & 42.95 & 38.26 & 130.43 & 38.91 \\
\hline 2.04 & 49.72 & 38.93 & 133.82 & 38.11 \\
\hline 2.06 & 47.30 & 38.59 & 130.92 & 38.77 \\
\hline 2.08 & 47.30 & 39.41 & 132.85 & 39.27 \\
\hline 2.10 & 47.78 & 38.93 & 130.92 & 40.19 \\
\hline 2.12 & 48.75 & 37.14 & 132.85 & 40.10 \\
\hline 2.14 & 48.27 & 42.30 & 139.13 & 38.26 \\
\hline 2.16 & 48.27 & 38.04 & 138.65 & 41.87 \\
\hline 2.18 & 51.65 & 41.39 & 142.03 & 39.22 \\
\hline 2.20 & 51.17 & 39.93 & 138.65 & 41.05 \\
\hline 2.22 & 48.27 & 39.16 & 138.65 & 40.57 \\
\hline 2.25 & 54.07 & 40.10 & 140.10 & 41.54 \\
\hline 2.27 & 55.03 & 41.19 & 139.13 & 39.08 \\
\hline 2.29 & 54.07 & 39.38 & 141.55 & 41.54 \\
\hline 2.31 & 55.52 & 43.21 & 142.03 & 41.22 \\
\hline 2.33 & 55.52 & 42.37 & 143.97 & 43.40 \\
\hline 2.35 & 55.03 & 41.02 & 147.83 & 43.54 \\
\hline 2.37 & 52.62 & 40.08 & 136.72 & 42.76 \\
\hline 2.39 & 52.62 & 40.57 & 142.52 & 40.95 \\
\hline 2.41 & 51.65 & 42.56 & 141.55 & 40.96 \\
\hline 2.43 & 54.55 & 42.51 & 143.48 & 40.19 \\
\hline 2.45 & 49.72 & 46.30 & 138.65 & 43.60 \\
\hline 2.47 & 53.10 & 43.70 & 157.02 & 47.80 \\
\hline 2.50 & 50.20 & 47.30 & 146.87 & 42.11 \\
\hline 2.52 & 55.03 & 46.64 & 147.35 & 42.11 \\
\hline 2.54 & 57.93 & 44.08 & 151.70 & 44.23 \\
\hline 2.56 & 58.90 & 45.32 & 149.28 & 43.06 \\
\hline 2.58 & 58.42 & 45.32 & 156.53 & 44.87 \\
\hline 2.60 & 54.07 & 46.16 & 154.60 & 44.34 \\
\hline 2.62 & 54.07 & 44.36 & 148.32 & 43.54 \\
\hline 2.64 & 56.48 & 44.56 & 155.57 & 44.70 \\
\hline 2.66 & 60.35 & 47.96 & 151.22 & 46.00 \\
\hline 2.68 & 60.35 & 43.23 & 154.60 & 44.97 \\
\hline 2.70 & 60.83 & 47.22 & 153.63 & 44.84 \\
\hline 2.72 & 66.63 & 46.54 & 154.12 & 45.49 \\
\hline 2.75 & 62.77 & 43.42 & 152.67 & 44.36 \\
\hline 2.77 & 67.60 & 48.37 & 159.43 & 44.49 \\
\hline 2.81 & 66.15 & 48.35 & 157.02 & 44.05 \\
\hline
\end{tabular}


Table A.19. BOD of Blank and Sample with $100 \mathrm{mg}$ MM12 (Continued)

\begin{tabular}{|c|c|c|c|c|}
\hline Days & $\begin{array}{c}\text { Blank } \\
\text { Corrected } \\
\text { Reading } \\
\end{array}$ & $\begin{array}{c}\text { Corrected } \\
\text { StdDev }\end{array}$ & $\begin{array}{c}\text { Sample } \\
\text { Corrected } \\
\text { Reading }\end{array}$ & $\begin{array}{c}\text { Corrected } \\
\text { StdDev }\end{array}$ \\
\hline 2.87 & 73.40 & 45.03 & 162.82 & 44.49 \\
\hline 2.89 & 75.82 & 47.78 & 170.55 & 44.70 \\
\hline 2.91 & 72.43 & 51.02 & 167.17 & 45.32 \\
\hline 2.93 & 72.43 & 50.91 & 163.30 & 43.70 \\
\hline 2.95 & 69.05 & 49.29 & 170.07 & 39.66 \\
\hline 2.97 & 71.47 & 45.81 & 165.72 & 41.87 \\
\hline 3.00 & 75.33 & 51.06 & 168.13 & 44.05 \\
\hline 3.02 & 72.92 & 50.91 & 174.90 & 44.97 \\
\hline 3.04 & 77.75 & 50.43 & 169.58 & 44.56 \\
\hline 3.06 & 80.17 & 48.78 & 171.52 & 44.99 \\
\hline 3.08 & 85.97 & 47.96 & 171.03 & 47.31 \\
\hline 3.10 & 82.10 & 50.91 & 172.48 & 41.47 \\
\hline 3.12 & 82.58 & 51.69 & 173.93 & 45.81 \\
\hline 3.14 & 84.52 & 52.71 & 173.93 & 43.92 \\
\hline 3.16 & 78.72 & 48.33 & 171.52 & 47.69 \\
\hline 3.18 & 83.55 & 50.57 & 174.42 & 49.77 \\
\hline 3.20 & 87.90 & 48.11 & 178.28 & 50.91 \\
\hline 3.22 & 91.28 & 49.90 & 183.12 & 46.47 \\
\hline 3.25 & 93.22 & 51.28 & 183.60 & 47.49 \\
\hline 3.27 & 94.67 & 52.18 & 182.63 & 49.29 \\
\hline 3.29 & 96.60 & 49.69 & 187.95 & 49.91 \\
\hline 3.31 & 96.60 & 51.09 & 187.95 & 47.45 \\
\hline 3.33 & 99.50 & 53.04 & 191.82 & 51.39 \\
\hline 3.35 & 102.88 & 55.49 & 191.82 & 50.51 \\
\hline 3.37 & 101.43 & 55.71 & 193.27 & 49.35 \\
\hline 3.39 & 105.30 & 53.53 & 196.17 & 47.67 \\
\hline 3.41 & 104.82 & 50.83 & 195.68 & 48.45 \\
\hline 3.43 & 107.23 & 53.03 & 195.68 & 50.91 \\
\hline 3.45 & 106.27 & 51.09 & 198.58 & 52.07 \\
\hline 3.47 & 106.75 & 49.90 & 196.17 & 49.59 \\
\hline 3.50 & 109.17 & 55.28 & 198.10 & 50.26 \\
\hline 3.52 & 107.72 & 52.13 & 199.55 & 51.88 \\
\hline 3.54 & 108.68 & 53.28 & 202.45 & 52.22 \\
\hline 3.56 & 107.72 & 52.58 & 205.35 & 50.41 \\
\hline 3.58 & 114.00 & 54.61 & 198.58 & 52.89 \\
\hline 3.60 & 111.58 & 52.18 & 198.58 & 45.95 \\
\hline 3.62 & 112.55 & 52.37 & 200.52 & 50.08 \\
\hline 3.66 & 110.62 & 52.54 & 199.55 & 50.73 \\
\hline
\end{tabular}


Table A.19. BOD of Blank and Sample with $100 \mathrm{mg}$ MM12 (Continued)

\begin{tabular}{|c|c|c|c|c|}
\hline Days & $\begin{array}{c}\text { Blank } \\
\text { Corrected } \\
\text { Reading }\end{array}$ & $\begin{array}{c}\text { Corrected } \\
\text { StdDev }\end{array}$ & $\begin{array}{c}\text { Sample } \\
\text { Corrected } \\
\text { Reading }\end{array}$ & $\begin{array}{c}\text { Corrected } \\
\text { StdDev }\end{array}$ \\
\hline 3.72 & 105.78 & 56.61 & 194.72 & 50.41 \\
3.75 & 109.65 & 57.09 & 200.03 & 51.68 \\
3.77 & 108.68 & 54.63 & 199.07 & 52.72 \\
3.79 & 109.17 & 53.71 & 195.68 & 51.42 \\
3.81 & 109.17 & 53.92 & 196.65 & 53.37 \\
3.83 & 109.17 & 56.61 & 199.55 & 53.03 \\
3.85 & 108.20 & 55.98 & 196.65 & 49.42 \\
3.87 & 105.78 & 53.86 & 197.62 & 50.57 \\
3.89 & 103.37 & 55.94 & 196.17 & 49.91 \\
3.91 & 107.72 & 55.04 & 198.10 & 48.70 \\
3.93 & 110.62 & 57.52 & 196.65 & 51.42 \\
3.95 & 105.30 & 55.71 & 196.65 & 52.72 \\
3.97 & 108.20 & 54.15 & 194.23 & 51.80 \\
4.00 & 108.68 & 57.28 & 196.65 & 52.71 \\
4.02 & 108.68 & 51.50 & 195.20 & 53.88 \\
4.04 & 107.72 & 56.38 & 198.58 & 51.22 \\
4.06 & 105.78 & 55.27 & 192.78 & 51.42 \\
4.08 & 105.78 & 56.98 & 192.30 & 52.87 \\
4.10 & 104.82 & 57.34 & 193.27 & 51.09 \\
4.12 & 102.40 & 55.27 & 193.27 & 53.74 \\
4.14 & 108.68 & 60.48 & 193.75 & 54.13 \\
4.16 & 106.75 & 55.98 & 192.30 & 56.81 \\
4.18 & 104.33 & 58.87 & 194.72 & 53.74 \\
4.20 & 106.27 & 59.07 & 195.20 & 53.49 \\
4.22 & 109.17 & 56.88 & 195.68 & 52.58 \\
4.25 & 114.48 & 60.63 & 198.10 & 51.42 \\
4.27 & 115.93 & 58.88 & 205.35 & 54.53 \\
4.29 & 115.93 & 57.35 & 202.45 & 51.22 \\
4.31 & 119.80 & 56.68 & 207.28 & 51.04 \\
4.33 & 117.87 & 58.41 & 211.15 & 51.57 \\
4.35 & 122.22 & 58.17 & 213.08 & 52.87 \\
4.37 & 120.77 & 55.49 & 209.22 & 56.81 \\
4.39 & 120.28 & 55.49 & 209.22 & 51.80 \\
4.41 & 118.83 & 57.73 & 206.80 & 55.00 \\
4.43 & 119.80 & 57.35 & 205.35 & 53.37 \\
4.45 & 116.90 & 59.15 & 203.90 & 56.84 \\
4.47 & 118.83 & 57.82 & 208.25 & 53.53 \\
4.52 & 125.60 & 57.29 & 211.15 & 51.93 \\
\hline
\end{tabular}


Table A.19. BOD of Blank and Sample with $100 \mathrm{mg}$ MM12 (Continued)

\begin{tabular}{|c|c|c|c|c|}
\hline Days & $\begin{array}{c}\text { Blank } \\
\text { Corrected } \\
\text { Reading }\end{array}$ & $\begin{array}{c}\text { Corrected } \\
\text { StdDev }\end{array}$ & $\begin{array}{c}\text { Sample } \\
\text { Corrected } \\
\text { Reading }\end{array}$ & $\begin{array}{c}\text { Corrected } \\
\text { StdDev }\end{array}$ \\
\hline 4.58 & 128.98 & 59.29 & 213.57 & 55.04 \\
4.60 & 122.22 & 60.67 & 211.63 & 54.53 \\
4.62 & 119.32 & 59.51 & 209.70 & 54.13 \\
4.64 & 118.83 & 58.88 & 208.25 & 53.88 \\
4.66 & 123.18 & 59.62 & 207.28 & 54.53 \\
4.68 & 121.25 & 57.09 & 208.25 & 52.23 \\
4.70 & 115.93 & 62.01 & 206.32 & 53.69 \\
4.72 & 121.73 & 60.21 & 206.32 & 53.37 \\
4.75 & 118.35 & 60.48 & 206.80 & 53.37 \\
4.77 & 119.80 & 59.96 & 206.80 & 54.88 \\
4.79 & 121.25 & 59.98 & 208.73 & 49.91 \\
4.81 & 117.87 & 60.29 & 205.35 & 53.69 \\
4.83 & 123.18 & 58.88 & 209.22 & 53.49 \\
4.85 & 124.63 & 62.67 & 211.63 & 55.69 \\
4.87 & 120.77 & 68.72 & 206.80 & 59.16 \\
4.89 & 106.75 & 67.09 & 198.10 & 51.28 \\
4.91 & 105.78 & 64.52 & 196.17 & 49.11 \\
4.93 & 107.72 & 61.76 & 194.72 & 51.72 \\
4.95 & 114.00 & 61.32 & 203.42 & 52.37 \\
4.97 & 115.93 & 62.21 & 202.93 & 53.37 \\
5.00 & 121.25 & 64.27 & 206.80 & 57.36 \\
5.02 & 121.73 & 63.71 & 210.18 & 55.49 \\
5.04 & 127.53 & 61.34 & 210.18 & 56.64 \\
5.06 & 121.25 & 64.47 & 210.18 & 54.68 \\
5.08 & 124.15 & 64.08 & 210.18 & 58.14 \\
5.10 & 120.77 & 60.01 & 208.73 & 57.14 \\
5.12 & 124.63 & 61.14 & 210.67 & 58.65 \\
5.14 & 127.53 & 61.09 & 212.12 & 58.52 \\
5.16 & 125.60 & 57.54 & 211.63 & 58.30 \\
5.18 & 129.47 & 64.47 & 217.43 & 52.87 \\
5.20 & 132.85 & 62.09 & 217.92 & 55.99 \\
5.22 & 133.82 & 61.31 & 222.27 & 54.34 \\
5.25 & 135.27 & 62.67 & 221.78 & 55.49 \\
5.27 & 136.72 & 62.65 & 223.23 & 55.33 \\
5.29 & 134.78 & 59.34 & 221.30 & 57.47 \\
5.31 & 131.40 & 63.14 & 218.88 & 56.98 \\
5.33 & 131.88 & 63.71 & 222.75 & 54.88 \\
5.37 & 134.30 & 59.81 & 222.27 & 53.37 \\
\hline
\end{tabular}


Table A.19. BOD of Blank and Sample with $100 \mathrm{mg}$ MM12 (Continued)

\begin{tabular}{|c|c|c|c|c|}
\hline Days & $\begin{array}{c}\text { Blank } \\
\text { Corrected } \\
\text { Reading }\end{array}$ & $\begin{array}{c}\text { Corrected } \\
\text { StdDev }\end{array}$ & $\begin{array}{c}\text { Sample } \\
\text { Corrected } \\
\text { Reading }\end{array}$ & $\begin{array}{c}\text { Corrected } \\
\text { StdDev }\end{array}$ \\
\hline 5.43 & 139.62 & 60.29 & 223.72 & 56.21 \\
5.45 & 139.13 & 62.01 & 225.17 & 55.55 \\
5.47 & 140.58 & 63.77 & 222.75 & 53.69 \\
5.50 & 136.23 & 65.41 & 220.82 & 53.69 \\
5.52 & 133.33 & 62.88 & 219.37 & 56.21 \\
5.54 & 137.68 & 67.14 & 220.82 & 50.91 \\
5.56 & 131.88 & 66.47 & 219.37 & 51.57 \\
5.58 & 134.30 & 65.60 & 218.40 & 52.89 \\
5.60 & 134.30 & 65.56 & 218.88 & 53.37 \\
5.62 & 132.37 & 62.72 & 216.47 & 54.70 \\
5.64 & 132.37 & 67.21 & 219.85 & 53.08 \\
5.66 & 132.37 & 64.94 & 219.37 & 56.21 \\
5.68 & 139.62 & 60.29 & 222.27 & 57.64 \\
5.70 & 140.58 & 63.32 & 223.72 & 55.74 \\
5.72 & 139.62 & 62.47 & 224.68 & 54.41 \\
5.75 & 140.10 & 66.07 & 225.65 & 53.03 \\
5.77 & 135.27 & 64.47 & 227.10 & 53.75 \\
5.79 & 140.10 & 63.55 & 224.68 & 55.84 \\
5.81 & 138.17 & 62.43 & 224.20 & 57.05 \\
5.83 & 140.58 & 60.63 & 227.10 & 55.66 \\
5.85 & 140.58 & 63.14 & 225.17 & 57.35 \\
5.87 & 130.43 & 68.70 & 225.17 & 63.61 \\
5.89 & 126.08 & 70.70 & 216.47 & 53.49 \\
5.91 & 120.77 & 71.05 & 215.98 & 54.21 \\
5.93 & 124.63 & 63.99 & 215.02 & 55.95 \\
5.95 & 134.30 & 62.65 & 220.82 & 59.81 \\
5.97 & 136.23 & 64.47 & 222.75 & 59.74 \\
6.00 & 141.55 & 62.24 & 225.17 & 60.19 \\
6.02 & 140.58 & 63.99 & 232.90 & 59.98 \\
6.04 & 140.10 & 59.60 & 230.00 & 60.86 \\
6.06 & 145.42 & 60.95 & 228.07 & 58.63 \\
6.08 & 141.07 & 58.63 & 230.97 & 62.20 \\
6.10 & 145.90 & 62.01 & 231.45 & 59.30 \\
6.12 & 143.48 & 60.88 & 230.48 & 58.17 \\
6.14 & 143.48 & 60.88 & 231.45 & 58.78 \\
6.16 & 143.48 & 61.98 & 232.42 & 57.28 \\
6.18 & 144.45 & 64.89 & 229.03 & 56.83 \\
6.22 & 146.38 & 63.14 & 234.83 & 58.63 \\
\hline
\end{tabular}


Table A.19. BOD of Blank and Sample with $100 \mathrm{mg}$ MM12 (Continued)

\begin{tabular}{|c|c|c|c|c|}
\hline Days & $\begin{array}{c}\text { Blank } \\
\text { Corrected } \\
\text { Reading }\end{array}$ & $\begin{array}{c}\text { Corrected } \\
\text { StdDev }\end{array}$ & $\begin{array}{c}\text { Sample } \\
\text { Corrected } \\
\text { Reading }\end{array}$ & $\begin{array}{c}\text { Corrected } \\
\text { StdDev }\end{array}$ \\
\hline 6.29 & 144.93 & 60.42 & 231.45 & 56.61 \\
6.31 & 146.87 & 61.54 & 233.87 & 62.21 \\
6.33 & 146.87 & 62.75 & 233.87 & 59.51 \\
6.35 & 147.35 & 58.41 & 233.38 & 61.31 \\
6.37 & 148.32 & 62.47 & 235.80 & 59.51 \\
6.39 & 148.80 & 59.98 & 239.18 & 62.43 \\
6.41 & 149.77 & 61.31 & 236.28 & 62.28 \\
6.43 & 151.22 & 59.93 & 239.18 & 64.01 \\
6.45 & 145.90 & 62.87 & 237.73 & 60.19 \\
6.47 & 150.25 & 64.37 & 237.25 & 55.27 \\
6.50 & 144.45 & 64.66 & 237.73 & 58.17 \\
6.52 & 146.38 & 62.94 & 235.80 & 58.41 \\
6.54 & 145.42 & 65.78 & 235.80 & 54.34 \\
6.56 & 146.38 & 63.34 & 233.38 & 53.56 \\
6.58 & 144.45 & 65.88 & 235.80 & 55.28 \\
6.60 & 143.97 & 68.27 & 235.80 & 56.21 \\
6.62 & 147.83 & 66.56 & 233.87 & 54.18 \\
6.64 & 143.00 & 64.70 & 234.35 & 55.33 \\
6.66 & 145.90 & 68.26 & 237.25 & 55.00 \\
6.68 & 148.32 & 67.35 & 237.25 & 55.99 \\
6.70 & 147.35 & 65.62 & 236.77 & 53.95 \\
6.72 & 148.80 & 67.23 & 236.77 & 55.49 \\
6.75 & 146.38 & 66.01 & 237.73 & 53.03 \\
6.77 & 148.80 & 62.43 & 241.60 & 54.70 \\
6.79 & 152.18 & 64.70 & 241.60 & 57.16 \\
6.81 & 150.25 & 66.05 & 240.63 & 57.64 \\
6.83 & 149.77 & 67.79 & 239.67 & 56.64 \\
6.85 & 144.93 & 66.47 & 237.73 & 56.68 \\
6.87 & 144.45 & 66.56 & 234.35 & 56.81 \\
6.89 & 147.35 & 68.69 & 239.67 & 59.27 \\
6.91 & 142.52 & 66.90 & 237.25 & 56.49 \\
6.93 & 143.48 & 65.78 & 240.15 & 56.49 \\
6.95 & 144.93 & 64.01 & 238.70 & 56.99 \\
6.97 & 146.38 & 65.11 & 240.63 & 57.64 \\
7.00 & 147.35 & 63.99 & 241.60 & 57.49 \\
7.02 & 148.80 & 64.94 & 245.47 & 59.81 \\
7.04 & 152.67 & 60.86 & 244.50 & 64.55 \\
7.08 & 157.02 & 65.34 & 247.88 & 60.91 \\
\hline
\end{tabular}


Table A.19. BOD of Blank and Sample with $100 \mathrm{mg}$ MM12 (Continued)

\begin{tabular}{|c|c|c|c|c|}
\hline Days & $\begin{array}{c}\text { Blank } \\
\text { Corrected } \\
\text { Reading } \\
\end{array}$ & $\begin{array}{c}\text { Corrected } \\
\text { StdDev }\end{array}$ & $\begin{array}{c}\text { Sample } \\
\text { Corrected } \\
\text { Reading }\end{array}$ & $\begin{array}{c}\text { Corrected } \\
\text { StdDev }\end{array}$ \\
\hline 7.14 & 148.32 & 64.47 & 244.50 & 63.81 \\
\hline 7.16 & 151.70 & 61.53 & 245.95 & 61.08 \\
\hline 7.18 & 156.53 & 68.26 & 246.92 & 61.76 \\
\hline 7.20 & 155.57 & 62.75 & 249.82 & 63.06 \\
\hline 7.22 & 160.40 & 62.87 & 248.85 & 58.80 \\
\hline 7.25 & 157.50 & 63.77 & 251.75 & 60.75 \\
\hline 7.27 & 157.98 & 67.57 & 247.40 & 59.03 \\
\hline 7.29 & 154.12 & 69.37 & 248.37 & 60.91 \\
\hline 7.31 & 155.57 & 68.91 & 244.98 & 56.84 \\
\hline 7.33 & 157.98 & 67.79 & 244.50 & 60.46 \\
\hline 7.35 & 153.63 & 66.68 & 243.53 & 54.25 \\
\hline 7.37 & 151.22 & 67.40 & 243.53 & 56.06 \\
\hline 7.39 & 150.73 & 69.61 & 243.05 & 55.33 \\
\hline 7.41 & 155.08 & 71.21 & 244.50 & 54.84 \\
\hline 7.43 & 154.12 & 70.36 & 244.02 & 52.87 \\
\hline 7.45 & 152.18 & 70.03 & 244.02 & 57.64 \\
\hline 7.47 & 155.08 & 72.31 & 241.60 & 55.94 \\
\hline 7.50 & 154.12 & 70.62 & 244.02 & 55.66 \\
\hline 7.52 & 154.60 & 69.43 & 244.02 & 56.46 \\
\hline 7.54 & 153.63 & 71.30 & 244.50 & 54.39 \\
\hline 7.56 & 153.63 & 71.57 & 242.57 & 53.88 \\
\hline 7.58 & 154.60 & 72.27 & 243.53 & 54.39 \\
\hline 7.60 & 151.70 & 70.62 & 246.92 & 52.87 \\
\hline 7.62 & 154.60 & 69.61 & 244.02 & 55.84 \\
\hline 7.64 & 155.08 & 71.30 & 244.50 & 53.53 \\
\hline 7.66 & 155.08 & 68.85 & 243.53 & 53.23 \\
\hline 7.68 & 155.57 & 71.63 & 248.37 & 52.54 \\
\hline 7.70 & 157.98 & 71.39 & 245.47 & 54.18 \\
\hline 7.72 & 155.57 & 71.60 & 243.05 & 53.03 \\
\hline 7.75 & 157.02 & 70.96 & 244.50 & 52.54 \\
\hline 7.77 & 157.50 & 71.30 & 245.47 & 53.09 \\
\hline 7.79 & 159.43 & 70.78 & 247.88 & 55.69 \\
\hline 7.81 & 156.05 & 73.75 & 245.95 & 54.01 \\
\hline 7.83 & 157.50 & 72.13 & 246.92 & 51.28 \\
\hline 7.85 & 152.67 & 73.61 & 245.47 & 52.37 \\
\hline 7.87 & 151.70 & 78.48 & 240.63 & 58.39 \\
\hline 7.89 & 129.95 & 79.90 & 232.90 & 49.11 \\
\hline 7.93 & 136.23 & 74.35 & 230.48 & 50.64 \\
\hline
\end{tabular}


Table A.19. BOD of Blank and Sample with $100 \mathrm{mg}$ MM12 (Continued)

\begin{tabular}{|c|c|c|c|c|}
\hline Days & $\begin{array}{c}\text { Blank } \\
\text { Corrected } \\
\text { Reading }\end{array}$ & $\begin{array}{c}\text { Corrected } \\
\text { StdDev }\end{array}$ & $\begin{array}{c}\text { Sample } \\
\text { Corrected } \\
\text { Reading }\end{array}$ & $\begin{array}{c}\text { Corrected } \\
\text { StdDev }\end{array}$ \\
\hline 8.00 & 146.87 & 71.63 & 237.25 & 57.23 \\
8.02 & 155.08 & 71.37 & 238.70 & 56.84 \\
8.04 & 153.15 & 72.81 & 240.15 & 59.33 \\
8.06 & 150.25 & 68.02 & 239.18 & 61.08 \\
8.08 & 156.05 & 67.12 & 245.47 & 62.27 \\
8.10 & 157.50 & 68.70 & 243.05 & 60.42 \\
8.12 & 159.43 & 70.04 & 248.85 & 58.45 \\
8.14 & 154.60 & 69.85 & 251.75 & 59.03 \\
8.16 & 157.50 & 73.40 & 246.92 & 57.36 \\
8.18 & 157.98 & 72.50 & 249.33 & 59.68 \\
8.20 & 157.02 & 70.96 & 247.88 & 58.80 \\
8.22 & 158.95 & 72.07 & 248.85 & 61.41 \\
8.25 & 160.40 & 70.89 & 249.82 & 64.46 \\
8.27 & 162.82 & 71.04 & 248.37 & 62.56 \\
8.29 & 159.92 & 70.76 & 245.47 & 61.91 \\
8.31 & 164.27 & 70.48 & 251.75 & 63.54 \\
8.33 & 167.17 & 70.48 & 251.75 & 65.10 \\
8.35 & 163.30 & 69.01 & 250.78 & 63.17 \\
8.37 & 164.27 & 71.16 & 250.78 & 63.57 \\
8.39 & 161.85 & 72.31 & 250.78 & 64.98 \\
8.41 & 167.17 & 72.66 & 250.30 & 60.46 \\
8.43 & 161.85 & 67.79 & 246.43 & 57.87 \\
8.45 & 162.33 & 71.16 & 245.47 & 59.81 \\
8.47 & 161.85 & 70.93 & 245.47 & 57.30 \\
8.50 & 162.33 & 72.74 & 245.95 & 57.49 \\
8.52 & 157.98 & 74.09 & 244.02 & 59.45 \\
8.54 & 156.05 & 72.50 & 241.12 & 59.60 \\
8.56 & 157.02 & 74.59 & 243.05 & 56.15 \\
8.58 & 159.43 & 75.37 & 245.95 & 62.06 \\
8.60 & 160.88 & 75.69 & 244.98 & 62.39 \\
8.62 & 160.88 & 72.07 & 248.85 & 59.30 \\
8.64 & 158.95 & 75.52 & 243.53 & 58.95 \\
8.66 & 163.78 & 73.23 & 247.88 & 60.10 \\
8.68 & 161.37 & 79.49 & 244.98 & 58.29 \\
8.70 & 158.47 & 77.20 & 246.92 & 56.84 \\
8.72 & 158.47 & 74.43 & 245.95 & 57.52 \\
8.75 & 155.08 & 77.42 & 242.57 & 58.69 \\
8.79 & 162.33 & 75.64 & 244.98 & 60.84 \\
\hline
\end{tabular}


Table A.19. BOD of Blank and Sample with $100 \mathrm{mg}$ MM12 (Continued)

\begin{tabular}{|c|c|c|c|c|}
\hline Days & $\begin{array}{c}\text { Blank } \\
\text { Corrected } \\
\text { Reading }\end{array}$ & $\begin{array}{c}\text { Corrected } \\
\text { StdDev }\end{array}$ & $\begin{array}{c}\text { Sample } \\
\text { Corrected } \\
\text { Reading }\end{array}$ & $\begin{array}{c}\text { Corrected } \\
\text { StdDev }\end{array}$ \\
\hline 8.85 & 160.40 & 75.44 & 247.88 & 59.81 \\
8.87 & 151.22 & 81.80 & 244.02 & 69.24 \\
8.89 & 138.65 & 80.42 & 234.35 & 48.93 \\
8.91 & 137.20 & 81.38 & 224.68 & 53.69 \\
8.93 & 143.00 & 78.23 & 235.32 & 60.75 \\
8.95 & 152.67 & 76.73 & 240.15 & 56.58 \\
8.97 & 158.95 & 73.49 & 243.53 & 64.20 \\
9.00 & 163.78 & 74.84 & 242.57 & 62.27 \\
9.02 & 160.40 & 76.73 & 245.95 & 62.22 \\
9.04 & 163.30 & 75.13 & 249.82 & 60.10 \\
9.06 & 163.78 & 74.01 & 250.78 & 65.84 \\
9.08 & 165.72 & 75.94 & 248.85 & 59.81 \\
9.10 & 166.20 & 75.69 & 251.27 & 62.41 \\
9.12 & 166.68 & 74.96 & 247.88 & 63.43 \\
9.14 & 162.82 & 74.69 & 247.40 & 65.50 \\
9.16 & 163.30 & 76.08 & 246.43 & 64.87 \\
9.18 & 163.78 & 75.94 & 248.37 & 61.49 \\
9.20 & 161.85 & 79.04 & 248.85 & 62.84 \\
9.22 & 162.82 & 76.88 & 247.88 & 61.41 \\
9.25 & 164.27 & 76.62 & 245.47 & 62.78 \\
9.27 & 165.23 & 77.41 & 242.08 & 60.60 \\
9.29 & 160.88 & 77.72 & 248.37 & 58.80 \\
9.31 & 163.78 & 79.18 & 247.40 & 59.95 \\
9.33 & 164.27 & 80.00 & 247.40 & 58.91 \\
9.35 & 164.75 & 77.55 & 246.43 & 64.34 \\
9.37 & 166.68 & 77.82 & 249.33 & 60.97 \\
9.39 & 164.75 & 82.44 & 248.37 & 60.46 \\
9.41 & 163.78 & 78.91 & 250.78 & 61.57 \\
9.43 & 166.20 & 78.36 & 248.85 & 61.67 \\
9.45 & 165.23 & 77.29 & 249.33 & 64.08 \\
9.47 & 168.62 & 77.82 & 249.82 & 60.97 \\
9.50 & 164.75 & 79.25 & 249.82 & 62.27 \\
9.52 & 167.65 & 80.00 & 248.85 & 62.41 \\
9.54 & 169.10 & 75.44 & 250.78 & 62.78 \\
9.56 & 168.62 & 75.11 & 249.33 & 61.62 \\
9.58 & 168.62 & 77.29 & 252.23 & 64.08 \\
9.60 & 171.52 & 80.00 & 252.72 & 60.08 \\
9.64 & 170.55 & 79.85 & 254.65 & 60.10 \\
\hline & & & & \\
\hline
\end{tabular}


Table A.19. BOD of Blank and Sample with $100 \mathrm{mg}$ MM12 (Continued)

\begin{tabular}{|c|c|c|c|c|}
\hline Days & $\begin{array}{c}\text { Blank } \\
\text { Corrected } \\
\text { Reading }\end{array}$ & $\begin{array}{c}\text { Corrected } \\
\text { StdDev }\end{array}$ & $\begin{array}{c}\text { Sample } \\
\text { Corrected } \\
\text { Reading }\end{array}$ & $\begin{array}{c}\text { Corrected } \\
\text { StdDev }\end{array}$ \\
\hline 9.70 & 170.07 & 75.24 & 251.75 & 60.97 \\
9.72 & 169.58 & 80.00 & 252.72 & 56.99 \\
9.75 & 169.10 & 78.91 & 252.23 & 60.60 \\
9.77 & 169.10 & 78.14 & 252.72 & 62.30 \\
9.79 & 170.55 & 79.75 & 253.20 & 59.03 \\
9.81 & 168.13 & 82.33 & 254.17 & 61.11 \\
9.83 & 166.68 & 78.93 & 253.20 & 61.26 \\
9.85 & 167.17 & 79.59 & 250.78 & 62.92 \\
9.87 & 171.03 & 83.23 & 249.82 & 66.67 \\
9.89 & 158.47 & 85.35 & 247.88 & 54.18 \\
9.91 & 155.08 & 89.89 & 238.70 & 55.07 \\
9.93 & 148.32 & 85.45 & 237.73 & 56.99 \\
9.95 & 155.08 & 82.04 & 247.88 & 62.78 \\
9.97 & 159.92 & 83.80 & 239.18 & 60.46 \\
10.00 & 157.50 & 83.81 & 236.28 & 63.43 \\
10.02 & 159.43 & 84.28 & 237.25 & 65.24 \\
10.04 & 159.43 & 81.08 & 239.67 & 61.67 \\
10.06 & 161.37 & 79.85 & 240.63 & 65.89 \\
10.08 & 160.40 & 80.27 & 243.53 & 64.59 \\
10.10 & 161.37 & 82.44 & 243.05 & 65.10 \\
10.12 & 163.78 & 80.94 & 239.18 & 61.77 \\
10.14 & 164.75 & 83.60 & 244.02 & 64.01 \\
10.16 & 164.75 & 80.60 & 244.98 & 64.46 \\
10.18 & 164.27 & 83.39 & 244.02 & 61.11 \\
10.20 & 155.57 & 85.58 & 251.75 & 66.45 \\
10.22 & 146.87 & 84.49 & 242.57 & 63.94 \\
10.25 & 139.62 & 84.36 & 243.53 & 61.11 \\
10.27 & 137.68 & 83.55 & 241.60 & 67.69 \\
10.29 & 141.07 & 83.55 & 241.60 & 63.81 \\
10.31 & 136.72 & 82.62 & 243.05 & 65.38 \\
10.33 & 139.62 & 78.98 & 248.85 & 65.88 \\
10.35 & 141.07 & 79.65 & 248.37 & 63.87 \\
10.37 & 140.10 & 81.00 & 251.75 & 66.83 \\
10.39 & 141.55 & 81.00 & 251.27 & 65.89 \\
10.41 & 141.07 & 80.10 & 253.68 & 68.47 \\
10.43 & 145.42 & 81.27 & 252.72 & 67.50 \\
10.45 & 141.55 & 80.32 & 254.65 & 67.32 \\
10.50 & 144.45 & 79.21 & 249.82 & 65.62 \\
\hline & & & & \\
\hline
\end{tabular}


Table A.19. BOD of Blank and Sample with $100 \mathrm{mg}$ MM12 (Continued)

\begin{tabular}{|c|c|c|c|c|}
\hline Days & $\begin{array}{c}\text { Blank } \\
\text { Corrected } \\
\text { Reading }\end{array}$ & $\begin{array}{c}\text { Corrected } \\
\text { StdDev }\end{array}$ & $\begin{array}{c}\text { Sample } \\
\text { Corrected } \\
\text { Reading }\end{array}$ & $\begin{array}{c}\text { Corrected } \\
\text { StdDev }\end{array}$ \\
\hline 10.54 & 150.25 & 78.09 & 247.40 & 65.75 \\
10.56 & 152.67 & 80.59 & 248.85 & 62.27 \\
10.58 & 152.67 & 78.54 & 247.40 & 65.10 \\
10.60 & 151.70 & 80.10 & 249.33 & 65.75 \\
10.62 & 152.67 & 80.79 & 253.20 & 67.69 \\
10.64 & 151.22 & 81.70 & 248.85 & 64.34 \\
10.66 & 151.22 & 82.14 & 252.23 & 67.33 \\
10.68 & 153.63 & 80.35 & 245.95 & 67.19 \\
10.70 & 153.15 & 78.76 & 249.82 & 64.86 \\
10.72 & 153.15 & 81.44 & 248.37 & 66.40 \\
10.75 & 156.53 & 79.21 & 251.27 & 67.84 \\
10.77 & 157.98 & 80.32 & 256.58 & 69.50 \\
10.79 & 157.98 & 81.23 & 257.07 & 69.12 \\
10.81 & 162.33 & 82.81 & 257.07 & 70.01 \\
10.83 & 161.37 & 80.55 & 261.90 & 68.85 \\
10.85 & 163.78 & 83.68 & 261.90 & 69.29 \\
10.87 & 163.78 & 79.43 & 261.90 & 69.88 \\
10.89 & 163.78 & 80.32 & 259.97 & 71.69 \\
10.91 & 163.78 & 80.55 & 262.38 & 68.70 \\
10.93 & 163.30 & 80.55 & 262.38 & 68.89 \\
10.95 & 160.88 & 81.95 & 263.35 & 68.21 \\
10.97 & 162.33 & 79.21 & 266.73 & 70.29 \\
11.00 & 164.27 & 80.10 & 259.97 & 68.34 \\
11.02 & 162.82 & 78.09 & 264.32 & 69.88 \\
11.04 & 168.13 & 81.00 & 265.77 & 72.98 \\
11.06 & 163.30 & 76.75 & 265.77 & 71.31 \\
11.08 & 166.20 & 80.10 & 266.73 & 71.69 \\
11.10 & 165.72 & 83.68 & 263.83 & 70.40 \\
11.12 & 166.68 & 83.68 & 264.80 & 68.85 \\
11.14 & 165.23 & 78.09 & 263.35 & 68.60 \\
11.16 & 165.72 & 78.33 & 263.83 & 72.21 \\
11.18 & 167.17 & 77.22 & 268.67 & 69.45 \\
11.20 & 169.10 & 77.42 & 266.73 & 70.29 \\
11.22 & 169.10 & 79.88 & 268.67 & 70.01 \\
11.25 & 167.17 & 80.13 & 267.70 & 69.76 \\
11.27 & 167.65 & 81.67 & 269.63 & 71.18 \\
11.29 & 169.10 & 80.77 & 266.25 & 70.15 \\
11.33 & 171.52 & 83.72 & 270.60 & 71.26 \\
\hline
\end{tabular}


Table A.19. BOD of Blank and Sample with $100 \mathrm{mg}$ MM12 (Continued)

\begin{tabular}{|c|c|c|c|c|}
\hline Days & $\begin{array}{c}\text { Blank } \\
\text { Corrected } \\
\text { Reading }\end{array}$ & $\begin{array}{c}\text { Corrected } \\
\text { StdDev }\end{array}$ & $\begin{array}{c}\text { Sample } \\
\text { Corrected } \\
\text { Reading }\end{array}$ & $\begin{array}{c}\text { Corrected } \\
\text { StdDev }\end{array}$ \\
\hline 11.39 & 167.17 & 79.49 & 267.70 & 66.40 \\
11.41 & 167.17 & 84.40 & 262.87 & 71.82 \\
11.43 & 143.97 & 93.04 & 252.72 & 57.64 \\
11.45 & 138.65 & 90.04 & 241.12 & 62.39 \\
11.47 & 141.07 & 81.89 & 248.85 & 61.08 \\
11.50 & 150.25 & 80.32 & 251.27 & 66.18 \\
11.52 & 150.73 & 81.00 & 249.82 & 65.75 \\
11.54 & 155.57 & 77.86 & 251.75 & 68.14 \\
11.56 & 155.57 & 79.67 & 251.75 & 65.38 \\
11.58 & 157.98 & 81.52 & 256.10 & 65.52 \\
11.60 & 152.67 & 82.14 & 253.68 & 65.62 \\
11.62 & 147.83 & 85.03 & 249.82 & 68.48 \\
11.64 & 141.07 & 81.72 & 250.30 & 68.72 \\
11.66 & 136.72 & 82.47 & 249.82 & 69.37 \\
11.68 & 128.98 & 82.85 & 247.88 & 69.64 \\
11.70 & 128.02 & 81.52 & 245.95 & 73.79 \\
11.72 & 129.95 & 81.00 & 242.57 & 69.43 \\
11.75 & 129.95 & 81.44 & 242.08 & 68.26 \\
11.77 & 133.82 & 79.67 & 243.53 & 72.62 \\
11.79 & 131.88 & 82.94 & 241.12 & 70.44 \\
11.81 & 134.30 & 82.76 & 238.70 & 69.08 \\
11.83 & 134.78 & 83.32 & 238.70 & 70.28 \\
11.85 & 134.78 & 81.99 & 239.67 & 68.72 \\
11.87 & 138.17 & 85.02 & 236.77 & 68.70 \\
11.89 & 134.30 & 83.73 & 236.28 & 67.95 \\
11.91 & 136.72 & 82.85 & 235.32 & 69.53 \\
11.93 & 129.47 & 83.05 & 238.22 & 72.61 \\
11.95 & 130.43 & 81.80 & 239.67 & 68.60 \\
11.97 & 131.40 & 82.80 & 239.18 & 71.24 \\
12.00 & 133.33 & 82.78 & 237.25 & 70.40 \\
12.02 & 137.20 & 83.79 & 237.25 & 67.84 \\
12.04 & 140.10 & 83.47 & 240.63 & 70.81 \\
12.06 & 139.62 & 85.72 & 241.60 & 67.43 \\
12.08 & 139.62 & 83.32 & 243.53 & 67.98 \\
12.10 & 142.03 & 79.06 & 242.57 & 68.79 \\
12.12 & 143.48 & 80.67 & 241.12 & 69.29 \\
12.14 & 141.55 & 81.33 & 245.95 & 68.48 \\
12.18 & 146.38 & 80.67 & 242.57 & 67.20 \\
\hline
\end{tabular}


Table A.19. BOD of Blank and Sample with $100 \mathrm{mg}$ MM12 (Continued)

\begin{tabular}{|c|c|c|c|c|}
\hline Days & $\begin{array}{c}\text { Blank } \\
\text { Corrected } \\
\text { Reading }\end{array}$ & $\begin{array}{c}\text { Corrected } \\
\text { StdDev }\end{array}$ & $\begin{array}{c}\text { Sample } \\
\text { Corrected } \\
\text { Reading }\end{array}$ & $\begin{array}{c}\text { Corrected } \\
\text { StdDev }\end{array}$ \\
\hline 12.25 & 150.25 & 80.55 & 242.08 & 69.79 \\
12.27 & 159.43 & 81.22 & 252.23 & 67.62 \\
12.29 & 152.67 & 84.35 & 246.92 & 67.84 \\
12.31 & 158.47 & 79.88 & 252.23 & 73.50 \\
12.33 & 160.40 & 82.11 & 254.65 & 69.16 \\
12.35 & 170.07 & 79.21 & 266.73 & 72.22 \\
12.37 & 162.82 & 85.26 & 260.93 & 71.45 \\
12.39 & 154.60 & 83.25 & 258.52 & 66.79 \\
12.41 & 152.18 & 87.52 & 249.82 & 75.83 \\
12.43 & 138.17 & 95.70 & 241.60 & 64.20 \\
12.45 & 128.50 & 88.46 & 239.67 & 65.38 \\
12.47 & 142.03 & 86.94 & 245.95 & 65.38 \\
12.50 & 139.13 & 84.36 & 244.50 & 68.48 \\
12.52 & 139.13 & 81.92 & 245.95 & 72.21 \\
12.54 & 140.58 & 79.67 & 242.57 & 70.06 \\
12.56 & 139.13 & 83.79 & 241.60 & 70.60 \\
12.58 & 145.90 & 83.68 & 244.98 & 65.62 \\
12.60 & 140.58 & 81.00 & 244.02 & 70.81 \\
12.62 & 139.62 & 81.46 & 243.05 & 70.50 \\
12.64 & 150.25 & 81.89 & 245.95 & 74.02 \\
12.66 & 154.60 & 80.13 & 252.23 & 70.40 \\
12.68 & 160.40 & 82.80 & 259.00 & 71.82 \\
12.70 & 160.88 & 83.55 & 262.87 & 69.96 \\
12.72 & 157.02 & 76.12 & 254.17 & 75.71 \\
12.75 & 166.20 & 79.68 & 261.42 & 71.77 \\
12.77 & 162.82 & 81.90 & 259.48 & 78.64 \\
12.79 & 162.82 & 80.39 & 261.42 & 77.64 \\
12.81 & 161.85 & 80.10 & 258.52 & 73.38 \\
12.83 & 152.67 & 85.02 & 258.52 & 71.68 \\
12.85 & 151.70 & 82.19 & 256.10 & 73.15 \\
12.87 & 147.83 & 83.52 & 247.40 & 70.81 \\
12.89 & 147.35 & 83.92 & 250.30 & 71.96 \\
12.91 & 144.93 & 81.44 & 244.50 & 68.08 \\
12.93 & 145.42 & 82.59 & 244.50 & 70.80 \\
12.95 & 152.67 & 83.46 & 248.85 & 68.60 \\
12.97 & 150.73 & 81.44 & 247.88 & 70.93 \\
13.00 & 153.63 & 83.47 & 252.23 & 71.05 \\
13.04 & 146.87 & 83.01 & 245.95 & 67.95 \\
\hline
\end{tabular}


Table A.19. BOD of Blank and Sample with $100 \mathrm{mg}$ MM12 (Continued)

\begin{tabular}{|c|c|c|c|c|}
\hline Days & $\begin{array}{c}\text { Blank } \\
\text { Corrected } \\
\text { Reading }\end{array}$ & $\begin{array}{c}\text { Corrected } \\
\text { StdDev }\end{array}$ & $\begin{array}{c}\text { Sample } \\
\text { Corrected } \\
\text { Reading }\end{array}$ & $\begin{array}{c}\text { Corrected } \\
\text { StdDev }\end{array}$ \\
\hline 13.10 & 149.28 & 83.47 & 246.92 & 70.28 \\
13.12 & 161.37 & 82.78 & 251.27 & 72.94 \\
13.14 & 160.40 & 81.46 & 255.13 & 70.17 \\
13.16 & 149.77 & 84.39 & 249.33 & 70.28 \\
13.18 & 153.15 & 81.72 & 251.27 & 73.63 \\
13.20 & 155.57 & 84.81 & 253.68 & 71.77 \\
13.22 & 156.53 & 87.27 & 250.78 & 70.28 \\
13.25 & 153.15 & 84.35 & 248.37 & 69.64 \\
13.27 & 151.22 & 80.59 & 248.85 & 71.57 \\
13.29 & 157.02 & 78.79 & 253.20 & 73.63 \\
13.31 & 165.23 & 83.68 & 259.48 & 73.04 \\
13.33 & 157.98 & 84.14 & 257.07 & 72.09 \\
13.35 & 153.15 & 83.46 & 250.78 & 69.70 \\
13.37 & 147.83 & 82.85 & 252.72 & 70.40 \\
13.39 & 146.87 & 82.85 & 254.65 & 72.94 \\
13.41 & 155.57 & 80.86 & 258.03 & 70.28 \\
13.43 & 152.67 & 82.59 & 251.27 & 70.50 \\
13.45 & 143.97 & 84.13 & 250.30 & 70.53 \\
13.47 & 141.07 & 85.89 & 250.78 & 74.02 \\
13.50 & 137.68 & 80.34 & 247.40 & 68.79 \\
13.52 & 146.87 & 82.85 & 248.37 & 69.24 \\
13.54 & 138.17 & 82.11 & 251.75 & 71.05 \\
13.56 & 143.97 & 81.52 & 249.82 & 71.14 \\
13.58 & 150.25 & 81.72 & 249.82 & 68.08 \\
13.60 & 143.97 & 83.13 & 247.40 & 68.07 \\
13.62 & 141.07 & 80.13 & 246.92 & 70.93 \\
13.64 & 144.45 & 83.05 & 247.88 & 70.80 \\
13.66 & 140.58 & 83.92 & 245.95 & 72.34 \\
13.68 & 143.97 & 83.46 & 243.05 & 72.86 \\
13.70 & 137.68 & 84.18 & 240.63 & 72.51 \\
13.72 & 137.68 & 83.72 & 240.63 & 70.50 \\
13.75 & 141.07 & 79.82 & 247.40 & 75.59 \\
13.77 & 166.20 & 83.47 & 263.83 & 74.28 \\
13.79 & 145.42 & 83.23 & 245.95 & 71.69 \\
13.81 & 141.07 & 84.57 & 246.43 & 72.86 \\
13.83 & 143.48 & 83.47 & 243.53 & 70.15 \\
13.85 & 142.52 & 86.39 & 246.43 & 68.89 \\
13.89 & 144.45 & 83.32 & 246.43 & 71.57 \\
\hline
\end{tabular}


Table A.19. BOD of Blank and Sample with $100 \mathrm{mg}$ MM12 (Continued)

\begin{tabular}{|c|c|c|c|c|}
\hline Days & $\begin{array}{c}\text { Blank } \\
\text { Corrected } \\
\text { Reading } \\
\end{array}$ & $\begin{array}{c}\text { Corrected } \\
\text { StdDev }\end{array}$ & $\begin{array}{c}\text { Sample } \\
\text { Corrected } \\
\text { Reading } \\
\end{array}$ & $\begin{array}{c}\text { Corrected } \\
\text { StdDev }\end{array}$ \\
\hline 13.95 & 142.52 & 84.18 & 248.85 & 66.56 \\
\hline 13.97 & 140.58 & 83.68 & 240.15 & 69.24 \\
\hline 14.00 & 140.58 & 82.59 & 244.50 & 71.24 \\
\hline 14.02 & 151.22 & 85.52 & 253.20 & 69.76 \\
\hline 14.04 & 145.90 & 83.61 & 249.33 & 69.64 \\
\hline 14.06 & 152.18 & 79.00 & 251.75 & 72.41 \\
\hline 14.08 & 161.85 & 84.75 & 253.20 & 68.16 \\
\hline 14.10 & 152.18 & 83.13 & 247.40 & 67.52 \\
\hline 14.12 & 151.22 & 83.69 & 247.88 & 71.05 \\
\hline 14.14 & 157.50 & 85.70 & 251.27 & 70.28 \\
\hline 14.16 & 157.50 & 83.25 & 249.82 & 70.28 \\
\hline 14.18 & 153.63 & 87.05 & 252.72 & 69.24 \\
\hline 14.20 & 155.57 & 81.23 & 248.85 & 74.67 \\
\hline 14.22 & 168.13 & 83.47 & 257.55 & 72.86 \\
\hline 14.25 & 171.52 & 88.16 & 260.93 & 71.57 \\
\hline 14.27 & 163.30 & 85.47 & 259.00 & 70.93 \\
\hline 14.29 & 157.98 & 87.27 & 253.68 & 68.60 \\
\hline 14.31 & 153.15 & 84.59 & 255.13 & 70.28 \\
\hline 14.33 & 154.12 & 86.18 & 249.82 & 68.08 \\
\hline 14.35 & 149.28 & 88.84 & 250.30 & 68.48 \\
\hline 14.37 & 147.35 & 84.57 & 250.30 & 67.95 \\
\hline 14.39 & 146.38 & 82.66 & 251.27 & 68.16 \\
\hline 14.41 & 143.00 & 83.52 & 248.85 & 71.18 \\
\hline 14.43 & 153.15 & 85.72 & 248.85 & 67.20 \\
\hline 14.45 & 148.32 & 85.98 & 249.82 & 67.09 \\
\hline 14.47 & 146.87 & 84.93 & 249.33 & 68.26 \\
\hline 14.50 & 144.45 & 84.18 & 250.78 & 68.16 \\
\hline 14.52 & 140.58 & 85.47 & 248.85 & 68.72 \\
\hline 14.54 & 143.97 & 86.45 & 248.37 & 67.84 \\
\hline 14.56 & 144.93 & 85.79 & 247.88 & 67.73 \\
\hline 14.58 & 148.80 & 89.01 & 247.40 & 69.78 \\
\hline 14.60 & 147.83 & 86.45 & 247.40 & 65.92 \\
\hline 14.62 & 149.28 & 88.83 & 247.88 & 70.01 \\
\hline 14.64 & 147.83 & 87.94 & 248.85 & 69.12 \\
\hline 14.66 & 143.48 & 86.45 & 248.37 & 68.48 \\
\hline 14.68 & 147.83 & 86.36 & 245.95 & 69.64 \\
\hline 14.70 & 148.32 & 85.26 & 247.40 & 69.43 \\
\hline 14.75 & 147.83 & 88.25 & 246.43 & 69.76 \\
\hline
\end{tabular}


Table A.19. BOD of Blank and Sample with $100 \mathrm{mg}$ MM12 (Continued)

\begin{tabular}{|c|c|c|c|c|}
\hline Days & $\begin{array}{c}\text { Blank } \\
\text { Corrected } \\
\text { Reading }\end{array}$ & $\begin{array}{c}\text { Corrected } \\
\text { StdDev }\end{array}$ & $\begin{array}{c}\text { Sample } \\
\text { Corrected } \\
\text { Reading }\end{array}$ & $\begin{array}{c}\text { Corrected } \\
\text { StdDev }\end{array}$ \\
\hline 14.81 & 148.80 & 86.81 & 247.40 & 66.27 \\
14.83 & 149.28 & 87.06 & 247.88 & 68.34 \\
14.85 & 147.83 & 89.52 & 248.37 & 66.79 \\
14.87 & 147.35 & 88.61 & 245.47 & 64.22 \\
14.89 & 148.32 & 86.39 & 247.40 & 65.62 \\
14.91 & 148.80 & 87.27 & 246.92 & 68.79 \\
14.93 & 151.70 & 88.84 & 244.02 & 67.84 \\
14.95 & 151.70 & 90.52 & 244.98 & 67.43 \\
14.97 & 151.22 & 87.87 & 246.43 & 64.22 \\
15.00 & 150.73 & 87.31 & 247.40 & 65.75 \\
15.02 & 150.73 & 87.72 & 245.95 & 70.53 \\
15.04 & 151.22 & 88.85 & 246.43 & 68.34 \\
15.06 & 146.87 & 87.48 & 248.37 & 68.99 \\
15.08 & 146.87 & 89.72 & 246.43 & 66.89 \\
15.10 & 149.28 & 89.50 & 244.02 & 67.05 \\
15.12 & 149.77 & 85.69 & 246.43 & 65.52 \\
15.14 & 150.73 & 86.85 & 244.98 & 67.09 \\
15.16 & 154.12 & 91.58 & 247.88 & 70.80 \\
15.18 & 149.28 & 89.78 & 244.50 & 64.86 \\
15.20 & 150.25 & 85.94 & 244.02 & 65.28 \\
15.22 & 149.77 & 88.38 & 246.92 & 69.37 \\
15.25 & 149.77 & 89.95 & 243.53 & 67.43 \\
15.27 & 150.73 & 88.61 & 244.98 & 68.26 \\
15.29 & 152.67 & 90.65 & 244.98 & 69.37 \\
15.31 & 150.25 & 86.14 & 246.43 & 66.91 \\
15.33 & 151.70 & 89.98 & 248.85 & 67.95 \\
15.35 & 154.12 & 88.91 & 248.37 & 69.24 \\
15.37 & 153.15 & 89.72 & 248.85 & 69.12 \\
15.39 & 152.18 & 87.49 & 249.82 & 67.69 \\
15.41 & 153.63 & 87.71 & 247.40 & 68.60 \\
15.43 & 153.63 & 89.05 & 249.33 & 66.40 \\
15.45 & 153.15 & 87.52 & 249.82 & 68.21 \\
15.47 & 153.15 & 88.61 & 247.88 & 62.74 \\
15.50 & 154.12 & 89.81 & 247.40 & 68.21 \\
15.52 & 152.67 & 85.93 & 250.78 & 67.09 \\
15.54 & 155.08 & 87.48 & 246.43 & 67.56 \\
15.56 & 154.12 & 89.72 & 245.47 & 64.34 \\
15.60 & 154.12 & 88.45 & 243.53 & 67.33 \\
\hline
\end{tabular}


Table A.19. BOD of Blank and Sample with $100 \mathrm{mg}$ MM12 (Continued)

\begin{tabular}{|c|c|c|c|c|}
\hline Days & $\begin{array}{c}\text { Blank } \\
\text { Corrected } \\
\text { Reading }\end{array}$ & $\begin{array}{c}\text { Corrected } \\
\text { StdDev }\end{array}$ & $\begin{array}{c}\text { Sample } \\
\text { Corrected } \\
\text { Reading }\end{array}$ & $\begin{array}{c}\text { Corrected } \\
\text { StdDev }\end{array}$ \\
\hline 15.66 & 154.12 & 86.39 & 247.88 & 66.56 \\
15.68 & 153.15 & 89.31 & 243.05 & 67.56 \\
15.70 & 152.18 & 86.14 & 249.82 & 66.99 \\
15.72 & 154.12 & 89.78 & 245.95 & 66.14 \\
15.75 & 151.70 & 87.05 & 248.85 & 63.43 \\
15.77 & 151.22 & 90.19 & 247.40 & 66.54 \\
15.79 & 153.63 & 89.28 & 245.95 & 64.87 \\
15.81 & 151.70 & 89.39 & 244.02 & 66.89 \\
15.83 & 152.67 & 86.14 & 248.37 & 66.79 \\
15.85 & 155.57 & 88.45 & 245.47 & 66.14 \\
15.87 & 152.18 & 84.85 & 247.40 & 67.19 \\
15.89 & 155.57 & 87.27 & 245.47 & 64.59 \\
15.91 & 153.15 & 87.49 & 250.30 & 67.05 \\
15.93 & 152.18 & 88.39 & 249.33 & 64.08 \\
15.95 & 154.60 & 89.58 & 246.92 & 65.38 \\
15.97 & 152.18 & 85.69 & 248.85 & 63.87 \\
16.00 & 153.63 & 85.92 & 245.95 & 66.99 \\
16.02 & 153.15 & 89.20 & 248.85 & 62.53 \\
16.04 & 153.15 & 89.52 & 244.02 & 67.73 \\
16.06 & 151.70 & 85.69 & 248.85 & 65.38 \\
16.08 & 155.08 & 89.73 & 248.85 & 65.18 \\
16.10 & 152.67 & 91.32 & 249.33 & 62.78 \\
16.12 & 153.63 & 92.63 & 247.88 & 67.84 \\
16.14 & 152.67 & 87.06 & 246.43 & 66.27 \\
16.16 & 153.63 & 87.26 & 249.33 & 69.50 \\
16.18 & 154.12 & 87.03 & 244.02 & 67.73 \\
16.20 & 156.05 & 88.84 & 247.40 & 66.40 \\
16.22 & 156.05 & 88.39 & 249.82 & 67.52 \\
16.25 & 156.05 & 90.39 & 246.43 & 64.11 \\
16.27 & 155.57 & 89.95 & 246.92 & 64.11 \\
16.29 & 156.05 & 89.28 & 251.27 & 68.34 \\
16.31 & 156.05 & 87.52 & 252.72 & 67.31 \\
16.33 & 157.50 & 87.48 & 247.40 & 66.99 \\
16.35 & 152.67 & 89.28 & 245.95 & 69.50 \\
16.37 & 152.67 & 86.39 & 246.92 & 66.79 \\
16.39 & 154.60 & 88.18 & 245.47 & 64.46 \\
16.41 & 149.28 & 88.18 & 243.53 & 66.40 \\
16.45 & 144.93 & 89.28 & 242.57 & 67.95 \\
\hline
\end{tabular}


Table A.19. BOD of Blank and Sample with $100 \mathrm{mg}$ MM12 (Continued)

\begin{tabular}{|c|c|c|c|c|}
\hline Days & $\begin{array}{c}\text { Blank } \\
\text { Corrected } \\
\text { Reading }\end{array}$ & $\begin{array}{c}\text { Corrected } \\
\text { StdDev }\end{array}$ & $\begin{array}{c}\text { Sample } \\
\text { Corrected } \\
\text { Reading }\end{array}$ & $\begin{array}{c}\text { Corrected } \\
\text { StdDev }\end{array}$ \\
\hline 16.52 & 151.70 & 89.28 & 238.22 & 68.21 \\
16.54 & 143.00 & 87.06 & 240.63 & 66.03 \\
16.56 & 142.03 & 88.61 & 244.02 & 64.46 \\
16.58 & 145.42 & 89.50 & 241.12 & 67.20 \\
16.60 & 146.87 & 88.38 & 242.57 & 66.45 \\
16.62 & 146.87 & 87.78 & 241.12 & 65.62 \\
16.64 & 145.90 & 88.85 & 238.22 & 68.26 \\
16.66 & 146.87 & 91.32 & 242.08 & 65.39 \\
16.68 & 146.38 & 89.05 & 238.70 & 67.62 \\
16.70 & 144.45 & 88.54 & 238.22 & 68.49 \\
16.72 & 141.07 & 86.14 & 234.35 & 66.45 \\
16.75 & 143.00 & 89.39 & 236.77 & 66.56 \\
16.77 & 141.07 & 86.65 & 235.80 & 69.12 \\
16.79 & 140.10 & 90.19 & 238.22 & 66.26 \\
16.81 & 137.68 & 88.38 & 235.80 & 65.10 \\
16.83 & 145.42 & 91.53 & 236.28 & 66.67 \\
16.85 & 141.55 & 89.73 & 236.28 & 66.03 \\
16.87 & 145.42 & 89.95 & 235.32 & 66.40 \\
16.89 & 144.93 & 89.95 & 233.87 & 68.36 \\
16.91 & 144.93 & 90.44 & 236.77 & 65.50 \\
16.93 & 146.38 & 87.98 & 240.63 & 66.18 \\
16.95 & 143.97 & 88.16 & 241.12 & 64.55 \\
16.97 & 151.70 & 90.24 & 241.12 & 66.45 \\
17.00 & 149.77 & 91.96 & 244.02 & 66.56 \\
17.02 & 150.73 & 90.19 & 243.05 & 67.09 \\
17.04 & 150.73 & 91.96 & 242.08 & 65.50 \\
17.06 & 153.63 & 89.28 & 240.63 & 65.28 \\
17.08 & 154.60 & 88.85 & 245.47 & 66.03 \\
17.10 & 154.12 & 89.06 & 244.02 & 62.01 \\
17.12 & 155.08 & 89.52 & 244.98 & 63.58 \\
17.14 & 151.70 & 92.20 & 243.53 & 66.03 \\
17.16 & 155.57 & 90.86 & 245.47 & 63.75 \\
17.18 & 155.57 & 89.28 & 246.43 & 67.43 \\
17.20 & 156.05 & 89.05 & 246.43 & 65.55 \\
17.22 & 157.50 & 90.18 & 244.50 & 64.01 \\
17.25 & 155.57 & 91.53 & 246.43 & 63.43 \\
17.27 & 155.08 & 87.48 & 245.95 & 64.22 \\
17.31 & 157.98 & 90.17 & 246.92 & 66.91 \\
\hline
\end{tabular}


Table A.19. BOD of Blank and Sample with $100 \mathrm{mg}$ MM12 (Continued)

\begin{tabular}{|c|c|c|c|c|}
\hline Days & $\begin{array}{c}\text { Blank } \\
\text { Corrected } \\
\text { Reading }\end{array}$ & $\begin{array}{c}\text { Corrected } \\
\text { StdDev }\end{array}$ & $\begin{array}{c}\text { Sample } \\
\text { Corrected } \\
\text { Reading }\end{array}$ & $\begin{array}{c}\text { Corrected } \\
\text { StdDev }\end{array}$ \\
\hline 17.37 & 158.47 & 89.75 & 247.40 & 63.47 \\
17.39 & 158.95 & 86.18 & 248.85 & 64.22 \\
17.41 & 159.43 & 89.99 & 244.50 & 66.18 \\
17.43 & 162.82 & 89.39 & 246.92 & 67.31 \\
17.45 & 154.60 & 87.71 & 243.05 & 62.65 \\
17.47 & 157.98 & 87.96 & 243.05 & 63.69 \\
17.50 & 154.12 & 88.38 & 241.12 & 66.56 \\
17.52 & 154.12 & 85.47 & 241.60 & 66.45 \\
17.54 & 151.22 & 89.72 & 242.57 & 65.62 \\
17.56 & 152.18 & 88.38 & 239.67 & 63.37 \\
17.58 & 152.67 & 88.18 & 239.67 & 63.91 \\
17.60 & 150.73 & 89.72 & 238.70 & 62.53 \\
17.62 & 152.18 & 89.07 & 242.57 & 64.22 \\
17.64 & 148.32 & 88.16 & 238.70 & 64.64 \\
17.66 & 150.25 & 89.06 & 237.25 & 65.39 \\
17.68 & 147.83 & 84.85 & 235.80 & 66.03 \\
17.70 & 154.12 & 86.86 & 238.22 & 63.58 \\
17.72 & 155.57 & 91.10 & 243.53 & 64.37 \\
17.75 & 157.02 & 86.68 & 245.95 & 66.99 \\
17.77 & 159.92 & 88.16 & 247.40 & 64.64 \\
17.79 & 161.37 & 90.18 & 243.05 & 65.50 \\
17.81 & 161.85 & 88.03 & 250.78 & 61.67 \\
17.83 & 165.23 & 87.36 & 249.33 & 62.27 \\
17.85 & 166.20 & 88.29 & 250.30 & 65.62 \\
17.87 & 166.20 & 88.60 & 249.82 & 65.38 \\
17.89 & 166.68 & 89.13 & 251.75 & 64.87 \\
17.91 & 166.68 & 86.43 & 249.82 & 66.68 \\
17.93 & 164.75 & 88.71 & 255.13 & 65.34 \\
17.95 & 165.72 & 89.28 & 254.17 & 59.95 \\
17.97 & 164.27 & 88.88 & 256.10 & 65.24 \\
18.00 & 165.72 & 87.93 & 254.17 & 64.87 \\
18.02 & 167.65 & 89.13 & 254.17 & 64.73 \\
18.04 & 166.68 & 89.95 & 256.58 & 65.92 \\
18.06 & 166.20 & 87.78 & 253.68 & 64.11 \\
18.08 & 168.62 & 88.14 & 255.62 & 64.34 \\
18.10 & 167.65 & 86.86 & 255.13 & 64.73 \\
18.12 & 168.62 & 84.16 & 259.48 & 64.34 \\
18.16 & 170.07 & 86.59 & 258.52 & 64.22 \\
\hline & & & & \\
\hline
\end{tabular}


Table A.19. BOD of Blank and Sample with $100 \mathrm{mg}$ MM12 (Continued)

\begin{tabular}{|c|c|c|c|c|}
\hline Days & $\begin{array}{c}\text { Blank } \\
\text { Corrected } \\
\text { Reading }\end{array}$ & $\begin{array}{c}\text { Corrected } \\
\text { StdDev }\end{array}$ & $\begin{array}{c}\text { Sample } \\
\text { Corrected } \\
\text { Reading }\end{array}$ & $\begin{array}{c}\text { Corrected } \\
\text { StdDev }\end{array}$ \\
\hline 18.22 & 174.42 & 87.53 & 260.45 & 65.50 \\
18.25 & 174.90 & 86.86 & 262.38 & 66.40 \\
18.27 & 175.87 & 87.96 & 262.87 & 63.69 \\
18.29 & 174.42 & 85.33 & 262.87 & 64.87 \\
18.31 & 177.80 & 87.10 & 267.22 & 64.64 \\
18.33 & 176.83 & 87.61 & 269.15 & 63.37 \\
18.35 & 177.32 & 83.81 & 265.77 & 62.92 \\
18.37 & 181.18 & 84.83 & 268.67 & 66.18 \\
18.39 & 181.67 & 86.86 & 269.15 & 64.98 \\
18.41 & 186.02 & 85.08 & 270.60 & 63.72 \\
18.43 & 184.08 & 85.43 & 268.67 & 64.73 \\
18.45 & 177.32 & 88.14 & 269.63 & 66.18 \\
18.47 & 182.15 & 87.20 & 269.15 & 65.68 \\
18.50 & 177.80 & 83.13 & 267.22 & 63.81 \\
18.52 & 177.80 & 86.86 & 267.70 & 65.02 \\
18.54 & 175.87 & 86.94 & 263.35 & 62.27 \\
18.56 & 175.38 & 86.18 & 266.25 & 64.37 \\
18.58 & 179.73 & 84.65 & 266.73 & 65.02 \\
18.60 & 177.32 & 83.92 & 267.70 & 65.52 \\
18.62 & 180.22 & 84.23 & 266.73 & 66.00 \\
18.64 & 177.80 & 86.43 & 265.28 & 62.41 \\
18.66 & 179.25 & 87.73 & 265.28 & 63.94 \\
18.68 & 178.28 & 87.49 & 268.18 & 65.52 \\
18.70 & 176.83 & 86.38 & 266.73 & 66.33 \\
18.72 & 179.73 & 86.18 & 268.18 & 66.27 \\
18.75 & 178.28 & 85.70 & 269.63 & 66.27 \\
18.77 & 177.80 & 85.69 & 269.63 & 65.10 \\
18.79 & 179.73 & 86.82 & 268.18 & 68.08 \\
18.81 & 179.25 & 90.05 & 264.80 & 68.49 \\
18.83 & 174.90 & 85.08 & 266.25 & 63.57 \\
18.85 & 176.83 & 86.86 & 263.83 & 66.40 \\
18.87 & 175.87 & 85.27 & 267.22 & 64.86 \\
18.89 & 175.38 & 86.62 & 265.77 & 66.67 \\
18.91 & 176.35 & 87.05 & 263.83 & 66.14 \\
18.93 & 177.32 & 87.71 & 264.80 & 64.98 \\
18.95 & 176.83 & 86.18 & 269.15 & 64.98 \\
18.97 & 181.18 & 84.59 & 272.05 & 64.73 \\
19.02 & 188.92 & 86.36 & 275.92 & 66.79 \\
\hline
\end{tabular}


Table A.19. BOD of Blank and Sample with $100 \mathrm{mg}$ MM12 (Continued)

\begin{tabular}{|c|c|c|c|c|}
\hline Days & $\begin{array}{c}\text { Blank } \\
\text { Corrected } \\
\text { Reading }\end{array}$ & $\begin{array}{c}\text { Corrected } \\
\text { StdDev }\end{array}$ & $\begin{array}{c}\text { Sample } \\
\text { Corrected } \\
\text { Reading }\end{array}$ & $\begin{array}{c}\text { Corrected } \\
\text { StdDev }\end{array}$ \\
\hline 19.08 & 188.43 & 84.83 & 280.27 & 65.62 \\
19.10 & 190.37 & 86.81 & 281.72 & 68.34 \\
19.12 & 191.33 & 82.78 & 280.27 & 68.08 \\
19.14 & 195.20 & 84.59 & 283.65 & 66.27 \\
19.16 & 196.65 & 83.39 & 282.68 & 66.91 \\
19.18 & 194.72 & 84.80 & 282.20 & 66.03 \\
19.20 & 193.75 & 86.26 & 283.17 & 68.34 \\
19.22 & 195.20 & 84.80 & 284.62 & 67.05 \\
19.25 & 201.00 & 86.14 & 284.13 & 65.89 \\
19.27 & 198.10 & 86.82 & 287.03 & 67.20 \\
19.29 & 198.10 & 85.92 & 287.52 & 66.03 \\
19.31 & 198.10 & 85.52 & 287.52 & 67.84 \\
19.33 & 196.65 & 85.47 & 285.58 & 67.09 \\
19.35 & 192.78 & 85.27 & 284.13 & 68.36 \\
19.37 & 191.33 & 83.46 & 277.37 & 68.72 \\
19.39 & 191.33 & 89.28 & 278.82 & 69.50 \\
19.41 & 191.82 & 85.03 & 278.82 & 68.34 \\
19.43 & 188.92 & 87.26 & 278.82 & 66.91 \\
19.45 & 184.57 & 81.95 & 273.50 & 67.33 \\
19.47 & 184.08 & 84.65 & 270.60 & 65.34 \\
19.50 & 178.77 & 86.85 & 270.12 & 67.56 \\
19.52 & 180.22 & 84.35 & 271.57 & 68.26 \\
19.54 & 180.22 & 84.80 & 268.18 & 68.60 \\
19.56 & 176.35 & 83.68 & 263.83 & 69.64 \\
19.58 & 175.38 & 84.83 & 266.25 & 67.43 \\
19.60 & 172.97 & 83.73 & 266.73 & 66.68 \\
19.62 & 177.32 & 83.30 & 265.28 & 65.52 \\
19.64 & 173.45 & 86.43 & 262.38 & 67.43 \\
19.66 & 172.00 & 85.47 & 260.93 & 67.05 \\
19.68 & 171.52 & 86.18 & 263.83 & 65.38 \\
19.70 & 172.48 & 88.65 & 263.35 & 65.52 \\
19.72 & 176.35 & 87.05 & 263.83 & 66.79 \\
19.75 & 172.97 & 83.81 & 261.42 & 65.92 \\
19.77 & 173.93 & 83.23 & 265.28 & 68.60 \\
19.79 & 171.52 & 82.34 & 262.38 & 65.10 \\
19.81 & 172.97 & 84.36 & 263.83 & 68.72 \\
19.83 & 178.28 & 84.13 & 265.77 & 68.48 \\
19.87 & 173.45 & 81.92 & 267.22 & 67.05 \\
\hline
\end{tabular}


Table A.19. BOD of Blank and Sample with $100 \mathrm{mg}$ MM12 (Continued)

\begin{tabular}{|c|c|c|c|c|}
\hline Days & $\begin{array}{c}\text { Blank } \\
\text { Corrected } \\
\text { Reading }\end{array}$ & $\begin{array}{c}\text { Corrected } \\
\text { StdDev }\end{array}$ & $\begin{array}{c}\text { Sample } \\
\text { Corrected } \\
\text { Reading }\end{array}$ & $\begin{array}{c}\text { Corrected } \\
\text { StdDev }\end{array}$ \\
\hline 19.93 & 180.22 & 83.55 & 269.63 & 67.84 \\
19.95 & 181.67 & 81.44 & 269.63 & 65.38 \\
19.97 & 184.08 & 83.25 & 267.70 & 68.72 \\
20.00 & 179.73 & 81.52 & 270.12 & 67.05 \\
20.02 & 183.12 & 82.34 & 272.53 & 71.75 \\
20.04 & 181.67 & 82.56 & 271.08 & 68.49 \\
20.06 & 181.18 & 82.78 & 270.60 & 68.21 \\
20.08 & 182.15 & 82.57 & 268.18 & 65.38 \\
20.10 & 186.50 & 84.13 & 272.05 & 69.29 \\
20.12 & 181.67 & 81.44 & 269.15 & 66.99 \\
20.14 & 181.18 & 85.05 & 272.05 & 65.68 \\
20.16 & 182.63 & 83.97 & 271.57 & 71.05 \\
20.18 & 182.63 & 85.70 & 273.02 & 66.83 \\
20.20 & 183.60 & 79.43 & 271.57 & 67.33 \\
20.22 & 179.73 & 83.39 & 273.50 & 70.60 \\
20.25 & 181.67 & 82.38 & 272.53 & 66.54 \\
20.27 & 186.50 & 85.33 & 272.05 & 67.43 \\
20.29 & 185.05 & 82.59 & 275.43 & 66.40 \\
20.31 & 184.57 & 84.57 & 271.57 & 66.54 \\
20.33 & 184.08 & 83.23 & 273.50 & 68.49 \\
20.35 & 181.67 & 82.81 & 270.60 & 70.66 \\
20.37 & 183.12 & 83.92 & 271.57 & 69.64 \\
20.39 & 178.77 & 83.01 & 269.15 & 68.26 \\
20.41 & 174.42 & 87.21 & 265.28 & 69.24 \\
20.43 & 160.40 & 107.74 & 260.45 & 55.55 \\
20.45 & 124.63 & 92.52 & 241.12 & 62.78 \\
20.47 & 143.00 & 90.39 & 250.78 & 67.43 \\
20.50 & 149.77 & 85.02 & 250.78 & 66.45 \\
20.52 & 153.15 & 88.65 & 252.72 & 68.72 \\
20.54 & 154.60 & 85.72 & 248.37 & 67.62 \\
20.56 & 152.67 & 87.12 & 248.37 & 65.39 \\
20.58 & 154.12 & 84.35 & 244.50 & 67.43 \\
20.60 & 157.02 & 83.01 & 247.88 & 68.21 \\
20.62 & 158.95 & 84.35 & 244.98 & 64.34 \\
20.64 & 157.02 & 82.11 & 247.88 & 67.20 \\
20.66 & 157.02 & 83.47 & 244.02 & 65.82 \\
20.68 & 152.67 & 85.98 & 244.50 & 66.18 \\
20.72 & 155.57 & 84.93 & 244.02 & 67.33 \\
\hline
\end{tabular}


Table A.19. BOD of Blank and Sample with $100 \mathrm{mg}$ MM12 (Continued)

\begin{tabular}{|c|c|c|c|c|}
\hline Days & $\begin{array}{c}\text { Blank } \\
\text { Corrected } \\
\text { Reading }\end{array}$ & $\begin{array}{c}\text { Corrected } \\
\text { StdDev }\end{array}$ & $\begin{array}{c}\text { Sample } \\
\text { Corrected } \\
\text { Reading }\end{array}$ & $\begin{array}{c}\text { Corrected } \\
\text { StdDev }\end{array}$ \\
\hline 20.79 & 160.40 & 85.12 & 244.02 & 66.56 \\
20.81 & 158.47 & 84.16 & 247.40 & 65.39 \\
20.83 & 160.88 & 82.80 & 248.85 & 67.05 \\
20.85 & 156.53 & 83.05 & 249.33 & 62.41 \\
20.87 & 159.43 & 83.68 & 249.33 & 67.56 \\
20.89 & 160.88 & 85.69 & 251.27 & 65.89 \\
20.91 & 162.33 & 82.13 & 247.88 & 63.37 \\
20.93 & 161.85 & 84.81 & 248.37 & 66.27 \\
20.95 & 162.33 & 84.39 & 247.88 & 64.59 \\
20.97 & 164.75 & 87.98 & 248.85 & 67.43 \\
21.00 & 162.82 & 82.85 & 247.88 & 67.95 \\
21.00 & 164.27 & 82.85 & 249.82 & 67.95 \\
21.02 & 164.27 & 79.82 & 249.82 & 67.43 \\
21.04 & 161.85 & 81.00 & 250.78 & 68.48 \\
21.06 & 167.65 & 79.67 & 251.75 & 66.03 \\
21.08 & 168.13 & 80.55 & 255.62 & 67.20 \\
21.10 & 170.55 & 81.52 & 255.62 & 66.83 \\
21.12 & 172.00 & 82.14 & 257.07 & 66.79 \\
21.14 & 171.03 & 85.03 & 257.07 & 66.45 \\
21.16 & 171.52 & 79.88 & 258.52 & 66.14 \\
21.18 & 173.45 & 79.67 & 260.45 & 68.21 \\
21.20 & 176.83 & 80.10 & 262.38 & 67.98 \\
21.22 & 171.52 & 78.31 & 258.03 & 67.73 \\
21.25 & 175.38 & 78.79 & 261.90 & 64.11 \\
21.27 & 171.03 & 82.56 & 261.42 & 66.27 \\
21.29 & 176.83 & 82.38 & 260.93 & 71.24 \\
21.31 & 172.00 & 79.21 & 261.90 & 69.37 \\
21.33 & 175.38 & 80.79 & 260.93 & 67.95 \\
21.35 & 176.83 & 81.25 & 257.07 & 66.91 \\
21.37 & 172.00 & 82.38 & 260.45 & 68.08 \\
21.39 & 174.90 & 78.77 & 261.90 & 67.52 \\
21.41 & 174.42 & 83.25 & 259.48 & 65.39 \\
21.43 & 173.93 & 79.25 & 264.80 & 67.43 \\
21.45 & 174.90 & 78.76 & 260.93 & 64.64 \\
21.47 & 177.80 & 80.34 & 260.45 & 68.34 \\
21.50 & 172.97 & 80.55 & 261.42 & 63.69 \\
21.52 & 173.93 & 84.81 & 262.87 & 65.63 \\
21.56 & 172.97 & 79.43 & 261.90 & 65.82 \\
\hline
\end{tabular}


Table A.19. BOD of Blank and Sample with $100 \mathrm{mg}$ MM12 (Continued)

\begin{tabular}{|c|c|c|c|c|}
\hline Days & $\begin{array}{c}\text { Blank } \\
\text { Corrected } \\
\text { Reading }\end{array}$ & $\begin{array}{c}\text { Corrected } \\
\text { StdDev }\end{array}$ & $\begin{array}{c}\text { Sample } \\
\text { Corrected } \\
\text { Reading }\end{array}$ & $\begin{array}{c}\text { Corrected } \\
\text { StdDev }\end{array}$ \\
\hline 21.62 & 174.90 & 82.34 & 263.83 & 67.56 \\
21.64 & 175.87 & 77.64 & 261.42 & 69.64 \\
21.66 & 174.90 & 80.79 & 261.90 & 66.14 \\
21.68 & 177.32 & 82.34 & 263.35 & 68.16 \\
21.70 & 176.83 & 81.67 & 261.90 & 66.45 \\
21.72 & 175.38 & 76.79 & 262.87 & 67.56 \\
21.75 & 173.93 & 79.46 & 262.87 & 66.35 \\
21.77 & 172.97 & 81.89 & 262.38 & 64.75 \\
21.79 & 174.90 & 83.46 & 260.93 & 68.08 \\
21.81 & 175.38 & 81.89 & 261.90 & 66.14 \\
21.83 & 170.55 & 82.59 & 263.35 & 64.86 \\
21.85 & 174.42 & 80.34 & 259.97 & 66.40 \\
21.87 & 175.87 & 82.13 & 261.42 & 66.03 \\
21.89 & 173.45 & 80.86 & 265.77 & 65.39 \\
21.91 & 175.87 & 77.54 & 260.45 & 66.45 \\
21.93 & 173.45 & 82.13 & 261.42 & 66.56 \\
21.95 & 174.90 & 78.79 & 260.45 & 65.10 \\
21.97 & 175.38 & 78.09 & 265.28 & 62.13 \\
22.00 & 175.38 & 80.32 & 261.42 & 67.31 \\
22.02 & 175.38 & 81.05 & 264.80 & 62.78 \\
22.04 & 175.38 & 82.85 & 262.38 & 64.86 \\
22.06 & 175.87 & 76.75 & 258.52 & 67.05 \\
22.08 & 174.90 & 83.01 & 262.38 & 67.43 \\
22.10 & 175.87 & 81.00 & 263.83 & 65.89 \\
22.12 & 171.52 & 82.14 & 260.93 & 66.67 \\
22.14 & 175.38 & 80.55 & 260.93 & 69.00 \\
22.16 & 174.90 & 79.65 & 265.28 & 64.73 \\
22.18 & 173.45 & 81.00 & 260.93 & 66.40 \\
22.20 & 174.90 & 82.14 & 262.87 & 66.56 \\
22.22 & 173.93 & 78.54 & 263.35 & 70.28 \\
22.25 & 175.38 & 80.10 & 259.97 & 65.18 \\
22.27 & 175.87 & 83.01 & 258.03 & 66.45 \\
22.29 & 177.80 & 81.00 & 261.42 & 65.28 \\
22.31 & 173.45 & 80.55 & 262.87 & 69.24 \\
22.33 & 173.93 & 77.86 & 258.52 & 64.01 \\
22.35 & 174.42 & 79.21 & 260.93 & 64.98 \\
22.37 & 177.32 & 81.89 & 261.90 & 65.39 \\
22.41 & 174.42 & 80.77 & 262.87 & 67.31 \\
\hline
\end{tabular}


Table A.19. BOD of Blank and Sample with $100 \mathrm{mg}$ MM12 (Continued)

\begin{tabular}{|c|c|c|c|c|}
\hline Days & $\begin{array}{c}\text { Blank } \\
\text { Corrected } \\
\text { Reading }\end{array}$ & $\begin{array}{c}\text { Corrected } \\
\text { StdDev }\end{array}$ & $\begin{array}{c}\text { Sample } \\
\text { Corrected } \\
\text { Reading }\end{array}$ & $\begin{array}{c}\text { Corrected } \\
\text { StdDev }\end{array}$ \\
\hline 22.47 & 179.73 & 81.00 & 263.83 & 65.09 \\
22.50 & 174.90 & 82.34 & 263.35 & 67.95 \\
22.52 & 177.32 & 81.05 & 264.32 & 69.24 \\
22.54 & 176.83 & 81.00 & 263.35 & 66.14 \\
22.56 & 179.25 & 81.80 & 266.25 & 69.24 \\
22.58 & 177.80 & 78.79 & 263.35 & 65.62 \\
22.60 & 176.83 & 81.33 & 265.77 & 67.43 \\
22.62 & 168.13 & 77.35 & 273.50 & 69.37 \\
22.64 & 163.78 & 77.02 & 265.28 & 75.38 \\
22.66 & 157.02 & 75.37 & 273.02 & 76.35 \\
22.68 & 157.50 & 75.37 & 271.08 & 74.96 \\
22.70 & 157.50 & 74.71 & 270.12 & 73.50 \\
22.72 & 151.70 & 75.52 & 263.35 & 74.32 \\
22.75 & 149.77 & 74.15 & 267.70 & 76.37 \\
22.77 & 154.60 & 74.54 & 269.15 & 76.56 \\
22.79 & 153.15 & 72.34 & 268.67 & 75.58 \\
22.81 & 152.67 & 74.54 & 268.18 & 73.90 \\
22.83 & 150.25 & 75.87 & 267.70 & 75.44 \\
22.85 & 148.32 & 78.15 & 267.70 & 69.88 \\
22.87 & 144.45 & 76.02 & 265.77 & 71.45 \\
22.89 & 143.48 & 74.42 & 261.42 & 71.69 \\
22.91 & 142.03 & 75.52 & 263.83 & 73.50 \\
22.93 & 142.52 & 72.31 & 266.25 & 72.98 \\
22.95 & 145.90 & 74.85 & 262.87 & 73.15 \\
22.97 & 147.83 & 73.58 & 266.25 & 75.71 \\
23.00 & 146.87 & 73.15 & 262.87 & 76.02 \\
23.02 & 149.77 & 69.12 & 266.73 & 78.04 \\
23.04 & 151.70 & 76.18 & 265.77 & 70.06 \\
23.06 & 154.60 & 76.40 & 260.45 & 68.36 \\
23.08 & 163.30 & 79.43 & 259.97 & 65.92 \\
23.10 & 165.23 & 77.42 & 255.13 & 67.64 \\
23.12 & 167.65 & 79.65 & 252.72 & 61.89 \\
23.14 & 166.20 & 80.79 & 254.65 & 64.59 \\
23.16 & 167.17 & 81.10 & 253.20 & 64.34 \\
23.18 & 166.20 & 81.33 & 256.58 & 62.13 \\
23.20 & 168.13 & 79.43 & 258.52 & 65.39 \\
23.22 & 166.68 & 80.10 & 253.20 & 66.14 \\
23.27 & 169.10 & 80.13 & 258.03 & 66.27 \\
\hline
\end{tabular}


Table A.19. BOD of Blank and Sample with $100 \mathrm{mg}$ MM12 (Continued)

\begin{tabular}{|c|c|c|c|c|}
\hline Days & $\begin{array}{c}\text { Blank } \\
\text { Corrected } \\
\text { Reading }\end{array}$ & $\begin{array}{c}\text { Corrected } \\
\text { StdDev }\end{array}$ & $\begin{array}{c}\text { Sample } \\
\text { Corrected } \\
\text { Reading }\end{array}$ & $\begin{array}{c}\text { Corrected } \\
\text { StdDev }\end{array}$ \\
\hline 23.33 & 165.72 & 77.86 & 257.07 & 66.26 \\
23.35 & 171.52 & 79.82 & 254.65 & 66.56 \\
23.37 & 170.55 & 79.46 & 259.00 & 66.14 \\
23.39 & 170.07 & 82.11 & 260.45 & 67.95 \\
23.41 & 174.42 & 79.92 & 259.97 & 68.36 \\
23.43 & 171.03 & 79.21 & 259.97 & 68.07 \\
23.45 & 171.52 & 82.39 & 262.87 & 66.14 \\
23.47 & 173.45 & 79.67 & 261.90 & 65.62 \\
23.50 & 173.93 & 78.50 & 259.97 & 66.03 \\
23.52 & 173.93 & 80.79 & 262.87 & 66.79 \\
23.54 & 172.48 & 76.59 & 262.87 & 68.72 \\
23.56 & 172.97 & 76.30 & 261.42 & 70.01 \\
23.58 & 175.38 & 79.72 & 261.90 & 66.67 \\
23.60 & 175.87 & 78.33 & 265.28 & 67.05 \\
23.62 & 177.32 & 78.33 & 265.28 & 66.27 \\
23.64 & 174.42 & 77.46 & 265.28 & 65.75 \\
23.66 & 175.87 & 77.46 & 264.80 & 66.03 \\
23.68 & 175.87 & 79.65 & 261.42 & 67.05 \\
23.70 & 172.00 & 81.44 & 260.93 & 67.43 \\
23.72 & 171.03 & 80.13 & 259.48 & 66.45 \\
23.75 & 170.55 & 78.76 & 257.07 & 65.39 \\
23.77 & 172.00 & 76.08 & 257.55 & 64.87 \\
23.79 & 171.52 & 80.17 & 258.52 & 67.52 \\
23.81 & 167.65 & 78.59 & 255.13 & 67.09 \\
23.83 & 162.82 & 80.13 & 252.23 & 65.82 \\
23.85 & 161.85 & 80.34 & 256.10 & 63.58 \\
23.87 & 165.72 & 82.34 & 253.68 & 64.08 \\
23.89 & 156.53 & 77.97 & 246.92 & 65.50 \\
23.91 & 161.85 & 79.67 & 249.33 & 62.01 \\
23.93 & 165.23 & 79.68 & 250.78 & 64.64 \\
23.95 & 162.82 & 78.14 & 247.40 & 65.39 \\
23.97 & 164.75 & 77.64 & 248.85 & 67.19 \\
24.00 & 161.85 & 75.87 & 249.82 & 65.28 \\
24.02 & 165.23 & 79.44 & 248.37 & 64.22 \\
24.04 & 166.20 & 79.43 & 253.20 & 63.69 \\
24.06 & 166.68 & 78.09 & 252.72 & 64.86 \\
24.08 & 169.58 & 77.64 & 254.17 & 65.62 \\
24.12 & 172.00 & 79.67 & 259.00 & 65.10 \\
\hline
\end{tabular}


Table A.19. BOD of Blank and Sample with $100 \mathrm{mg}$ MM12 (Continued)

\begin{tabular}{|c|c|c|c|c|}
\hline Days & $\begin{array}{c}\text { Blank } \\
\text { Corrected } \\
\text { Reading }\end{array}$ & $\begin{array}{c}\text { Corrected } \\
\text { StdDev }\end{array}$ & $\begin{array}{c}\text { Sample } \\
\text { Corrected } \\
\text { Reading }\end{array}$ & $\begin{array}{c}\text { Corrected } \\
\text { StdDev }\end{array}$ \\
\hline 24.18 & 172.48 & 77.20 & 258.52 & 71.05 \\
24.20 & 174.42 & 78.20 & 258.03 & 65.50 \\
24.22 & 173.93 & 75.87 & 259.48 & 68.89 \\
24.25 & 172.48 & 77.73 & 260.45 & 67.09 \\
24.27 & 174.42 & 79.88 & 260.93 & 67.43 \\
24.29 & 172.97 & 79.68 & 260.93 & 65.09 \\
24.31 & 174.42 & 79.44 & 261.90 & 66.27 \\
24.33 & 174.90 & 81.44 & 259.48 & 64.01 \\
24.35 & 173.93 & 79.46 & 260.93 & 65.92 \\
24.37 & 172.97 & 76.08 & 262.38 & 64.98 \\
24.39 & 175.87 & 78.54 & 259.00 & 64.86 \\
24.41 & 175.38 & 78.09 & 261.42 & 65.92 \\
24.43 & 176.83 & 78.09 & 259.48 & 65.92 \\
24.45 & 177.32 & 77.87 & 260.93 & 63.69 \\
24.47 & 177.80 & 77.86 & 258.52 & 65.39 \\
24.50 & 178.77 & 79.21 & 263.35 & 67.20 \\
24.52 & 175.87 & 76.98 & 262.87 & 67.31 \\
24.54 & 175.38 & 77.42 & 263.35 & 63.58 \\
24.56 & 178.28 & 80.59 & 260.93 & 66.80 \\
24.58 & 177.32 & 77.42 & 262.38 & 65.10 \\
24.60 & 179.73 & 78.77 & 268.18 & 67.43 \\
24.62 & 172.97 & 78.77 & 262.38 & 65.24 \\
24.64 & 172.97 & 80.19 & 257.07 & 65.38 \\
24.66 & 157.98 & 110.70 & 251.75 & 44.84 \\
24.68 & 107.23 & 88.37 & 221.30 & 57.87 \\
24.70 & 143.48 & 82.71 & 238.22 & 56.35 \\
24.72 & 152.18 & 81.48 & 241.12 & 60.08 \\
24.75 & 160.88 & 79.65 & 247.88 & 58.39 \\
24.77 & 164.75 & 76.75 & 251.75 & 60.08 \\
24.79 & 161.85 & 77.87 & 250.78 & 64.01 \\
24.81 & 161.85 & 80.55 & 252.23 & 60.84 \\
24.83 & 166.20 & 78.54 & 252.23 & 66.35 \\
24.85 & 169.10 & 77.66 & 253.68 & 64.22 \\
24.87 & 168.13 & 76.88 & 253.20 & 64.30 \\
24.89 & 170.07 & 77.86 & 255.62 & 64.75 \\
24.91 & 170.07 & 77.19 & 255.13 & 64.87 \\
24.93 & 168.13 & 76.97 & 259.97 & 65.24 \\
24.97 & 171.03 & 79.21 & 259.97 & 63.58 \\
\hline & & & & \\
\hline
\end{tabular}


Table A.19. BOD of Blank and Sample with $100 \mathrm{mg}$ MM12 (Continued)

\begin{tabular}{|c|c|c|c|c|}
\hline Days & $\begin{array}{c}\text { Blank } \\
\text { Corrected } \\
\text { Reading } \\
\end{array}$ & $\begin{array}{c}\text { Corrected } \\
\text { StdDev }\end{array}$ & $\begin{array}{c}\text { Sample } \\
\text { Corrected } \\
\text { Reading } \\
\end{array}$ & $\begin{array}{c}\text { Corrected } \\
\text { StdDev }\end{array}$ \\
\hline 25.04 & 170.07 & 77.64 & 256.58 & 65.39 \\
\hline 25.06 & 173.45 & 77.18 & 260.45 & 66.79 \\
\hline 25.08 & 172.97 & 76.79 & 258.52 & 66.56 \\
\hline 25.10 & 175.38 & 76.79 & 261.90 & 67.98 \\
\hline 25.12 & 173.93 & 76.79 & 259.97 & 67.20 \\
\hline 25.14 & 173.93 & 76.75 & 259.97 & 63.28 \\
\hline 25.16 & 173.45 & 80.34 & 259.48 & 67.69 \\
\hline 25.18 & 171.52 & 79.88 & 260.45 & 66.14 \\
\hline 25.20 & 170.55 & 77.87 & 259.00 & 65.28 \\
\hline 25.22 & 170.55 & 78.59 & 259.97 & 65.75 \\
\hline 25.25 & 172.97 & 79.21 & 259.00 & 62.41 \\
\hline 25.27 & 170.07 & 78.33 & 256.58 & 68.48 \\
\hline 25.29 & 170.07 & 79.72 & 257.55 & 65.92 \\
\hline 25.31 & 171.52 & 79.53 & 256.58 & 67.95 \\
\hline 25.33 & 172.00 & 76.21 & 257.07 & 68.07 \\
\hline 25.35 & 173.93 & 79.06 & 257.07 & 66.56 \\
\hline 25.37 & 175.38 & 78.39 & 260.45 & 68.26 \\
\hline 25.39 & 172.00 & 77.54 & 258.03 & 63.47 \\
\hline 25.41 & 172.00 & 81.25 & 259.00 & 63.20 \\
\hline 25.43 & 172.00 & 75.26 & 263.35 & 66.14 \\
\hline 25.45 & 174.90 & 79.21 & 259.00 & 68.26 \\
\hline 25.47 & 172.97 & 83.10 & 259.48 & 68.16 \\
\hline 25.50 & 173.45 & 75.20 & 261.90 & 67.09 \\
\hline 25.52 & 178.77 & 77.42 & 262.38 & 66.35 \\
\hline 25.54 & 176.83 & 78.54 & 266.73 & 65.82 \\
\hline 25.56 & 176.83 & 78.12 & 261.90 & 67.20 \\
\hline 25.58 & 180.70 & 74.79 & 265.77 & 65.63 \\
\hline 25.60 & 181.18 & 79.46 & 260.93 & 64.86 \\
\hline 25.62 & 172.97 & 79.44 & 262.87 & 64.22 \\
\hline 25.64 & 170.55 & 82.47 & 259.00 & 69.12 \\
\hline 25.66 & 163.78 & 103.46 & 252.72 & 53.00 \\
\hline 25.68 & 116.42 & 83.52 & 225.17 & 58.45 \\
\hline 25.70 & 155.08 & 81.03 & 247.40 & 61.89 \\
\hline 25.72 & 159.43 & 78.77 & 248.85 & 62.20 \\
\hline 25.75 & 159.92 & 78.79 & 249.82 & 62.74 \\
\hline 25.77 & 162.33 & 80.32 & 248.85 & 64.01 \\
\hline 25.79 & 165.23 & 76.33 & 252.23 & 64.98 \\
\hline 25.83 & 171.03 & 74.53 & 255.62 & 65.28 \\
\hline
\end{tabular}


Table A.19. BOD of Blank and Sample with $100 \mathrm{mg}$ MM12 (Continued)

\begin{tabular}{|c|c|c|c|c|}
\hline Days & $\begin{array}{c}\text { Blank } \\
\text { Corrected } \\
\text { Reading }\end{array}$ & $\begin{array}{c}\text { Corrected } \\
\text { StdDev }\end{array}$ & $\begin{array}{c}\text { Sample } \\
\text { Corrected } \\
\text { Reading }\end{array}$ & $\begin{array}{c}\text { Corrected } \\
\text { StdDev }\end{array}$ \\
\hline 25.89 & 171.52 & 73.39 & 260.93 & 62.92 \\
25.91 & 167.65 & 78.09 & 254.17 & 60.20 \\
25.93 & 170.07 & 76.99 & 255.62 & 61.36 \\
25.95 & 170.55 & 77.42 & 257.07 & 62.01 \\
25.97 & 170.55 & 78.77 & 258.03 & 63.69 \\
26.00 & 170.07 & 76.75 & 259.97 & 61.77 \\
26.02 & 168.62 & 75.85 & 255.62 & 62.20 \\
26.04 & 167.17 & 74.96 & 255.62 & 66.40 \\
26.06 & 174.42 & 78.20 & 259.97 & 65.82 \\
26.08 & 171.03 & 75.66 & 257.55 & 65.63 \\
26.10 & 171.03 & 78.54 & 260.93 & 66.72 \\
26.12 & 172.48 & 77.87 & 263.35 & 64.11 \\
26.14 & 173.45 & 76.12 & 258.52 & 66.72 \\
26.16 & 173.45 & 80.10 & 263.35 & 63.94 \\
26.18 & 175.87 & 78.09 & 260.93 & 64.59 \\
26.20 & 178.77 & 77.46 & 261.90 & 66.99 \\
26.22 & 174.42 & 78.98 & 264.80 & 66.03 \\
26.25 & 179.25 & 77.92 & 265.77 & 67.90 \\
26.27 & 178.28 & 77.67 & 269.15 & 71.20 \\
26.29 & 180.70 & 75.86 & 268.67 & 72.76 \\
26.31 & 176.35 & 75.21 & 270.12 & 73.04 \\
26.33 & 175.38 & 72.25 & 274.47 & 73.61 \\
26.35 & 174.90 & 72.47 & 274.95 & 77.73 \\
26.37 & 178.28 & 72.47 & 273.02 & 77.76 \\
26.39 & 176.83 & 72.86 & 275.92 & 74.28 \\
26.41 & 176.83 & 72.10 & 279.30 & 77.82 \\
26.43 & 181.18 & 70.95 & 277.85 & 79.62 \\
26.45 & 179.73 & 70.28 & 278.82 & 78.72 \\
26.47 & 180.70 & 72.73 & 279.30 & 78.09 \\
26.50 & 181.67 & 71.69 & 279.78 & 78.94 \\
26.52 & 186.98 & 72.34 & 283.17 & 80.24 \\
26.54 & 183.12 & 73.26 & 281.23 & 74.09 \\
26.56 & 185.53 & 67.33 & 284.62 & 78.64 \\
26.58 & 183.12 & 70.66 & 283.17 & 78.36 \\
26.60 & 180.70 & 71.31 & 281.23 & 76.02 \\
26.62 & 178.28 & 70.80 & 285.58 & 76.08 \\
26.64 & 175.87 & 70.60 & 278.82 & 76.88 \\
26.68 & 122.22 & 75.20 & 252.23 & 74.02 \\
\hline & & & & \\
\hline
\end{tabular}


Table A.19. BOD of Blank and Sample with $100 \mathrm{mg}$ MM12 (Continued)

\begin{tabular}{|c|c|c|c|c|}
\hline Days & $\begin{array}{c}\text { Blank } \\
\text { Corrected } \\
\text { Reading } \\
\end{array}$ & $\begin{array}{c}\text { Corrected } \\
\text { StdDev }\end{array}$ & $\begin{array}{c}\text { Sample } \\
\text { Corrected } \\
\text { Reading } \\
\end{array}$ & $\begin{array}{c}\text { Corrected } \\
\text { StdDev }\end{array}$ \\
\hline 26.75 & 167.17 & 74.60 & 267.70 & 73.04 \\
\hline 26.77 & 162.82 & 76.40 & 265.77 & 70.81 \\
\hline 26.79 & 167.65 & 74.05 & 264.80 & 69.33 \\
\hline 26.81 & 168.62 & 73.57 & 261.90 & 68.36 \\
\hline 26.83 & 169.10 & 72.95 & 255.62 & 64.37 \\
\hline 26.85 & 167.17 & 74.06 & 254.65 & 65.10 \\
\hline 26.87 & 169.58 & 75.87 & 252.23 & 65.18 \\
\hline 26.89 & 163.30 & 76.08 & 250.78 & 64.01 \\
\hline 26.91 & 166.68 & 74.96 & 252.23 & 64.98 \\
\hline 26.93 & 165.23 & 75.41 & 250.30 & 63.30 \\
\hline 26.95 & 165.23 & 76.31 & 251.27 & 62.94 \\
\hline 26.97 & 166.20 & 75.41 & 249.82 & 64.75 \\
\hline 27.00 & 165.23 & 77.66 & 249.33 & 62.84 \\
\hline 27.02 & 167.17 & 74.74 & 253.68 & 63.37 \\
\hline 27.04 & 164.75 & 74.74 & 251.27 & 64.22 \\
\hline 27.06 & 169.10 & 74.52 & 254.65 & 63.58 \\
\hline 27.08 & 168.62 & 74.06 & 253.68 & 64.22 \\
\hline 27.10 & 168.13 & 77.66 & 253.20 & 64.55 \\
\hline 27.12 & 168.13 & 75.85 & 252.72 & 64.01 \\
\hline 27.14 & 168.62 & 74.79 & 252.23 & 65.72 \\
\hline 27.16 & 166.68 & 74.96 & 249.82 & 67.09 \\
\hline 27.18 & 168.62 & 77.20 & 250.78 & 66.80 \\
\hline 27.20 & 170.07 & 76.40 & 252.23 & 66.99 \\
\hline 27.22 & 169.10 & 77.18 & 254.65 & 65.41 \\
\hline 27.25 & 168.62 & 78.59 & 253.68 & 66.56 \\
\hline 27.27 & 165.72 & 75.46 & 254.65 & 66.79 \\
\hline 27.29 & 168.62 & 74.60 & 255.62 & 64.01 \\
\hline 27.31 & 168.62 & 75.26 & 255.13 & 62.65 \\
\hline 27.33 & 170.55 & 74.79 & 255.62 & 64.46 \\
\hline 27.35 & 172.48 & 73.75 & 258.03 & 64.55 \\
\hline 27.37 & 174.42 & 76.97 & 257.07 & 66.26 \\
\hline 27.39 & 174.42 & 75.26 & 256.10 & 62.88 \\
\hline 27.41 & 170.55 & 75.07 & 258.03 & 62.93 \\
\hline 27.43 & 173.93 & 77.66 & 259.97 & 63.83 \\
\hline 27.45 & 175.38 & 75.93 & 255.62 & 60.69 \\
\hline 27.47 & 173.93 & 78.20 & 256.58 & 63.83 \\
\hline 27.50 & 176.83 & 78.50 & 259.97 & 67.35 \\
\hline 27.54 & 176.35 & 75.93 & 261.90 & 66.26 \\
\hline
\end{tabular}


Table A.19. BOD of Blank and Sample with $100 \mathrm{mg}$ MM12 (Continued)

\begin{tabular}{|c|c|c|c|c|}
\hline Days & $\begin{array}{c}\text { Blank } \\
\text { Corrected } \\
\text { Reading }\end{array}$ & $\begin{array}{c}\text { Corrected } \\
\text { StdDev }\end{array}$ & $\begin{array}{c}\text { Sample } \\
\text { Corrected } \\
\text { Reading }\end{array}$ & $\begin{array}{c}\text { Corrected } \\
\text { StdDev }\end{array}$ \\
\hline 27.60 & 174.90 & 79.06 & 259.48 & 62.94 \\
27.62 & 173.93 & 78.76 & 261.42 & 60.50 \\
27.64 & 170.55 & 76.21 & 258.03 & 62.49 \\
27.66 & 173.93 & 75.46 & 257.55 & 63.28 \\
27.68 & 171.52 & 77.42 & 258.03 & 61.77 \\
27.70 & 169.58 & 75.87 & 254.17 & 63.47 \\
27.72 & 170.55 & 77.66 & 254.65 & 61.48 \\
27.75 & 165.23 & 74.33 & 251.27 & 66.26 \\
27.77 & 167.17 & 76.08 & 251.75 & 64.98 \\
27.79 & 163.78 & 73.09 & 251.75 & 65.82 \\
27.81 & 166.68 & 75.74 & 248.85 & 63.47 \\
27.83 & 164.27 & 75.66 & 250.30 & 63.12 \\
27.85 & 165.23 & 75.40 & 249.82 & 64.01 \\
27.87 & 164.75 & 76.53 & 252.23 & 65.50 \\
27.89 & 166.68 & 76.99 & 253.68 & 65.63 \\
27.91 & 167.65 & 76.97 & 255.13 & 65.50 \\
27.93 & 170.07 & 74.89 & 255.13 & 64.64 \\
27.95 & 170.07 & 77.54 & 259.00 & 62.41 \\
27.97 & 170.55 & 74.53 & 260.93 & 57.96 \\
28.00 & 165.23 & 77.26 & 258.52 & 61.87 \\
28.02 & 169.10 & 73.16 & 256.58 & 62.65 \\
28.04 & 169.58 & 72.99 & 254.65 & 60.93 \\
28.06 & 164.75 & 73.83 & 250.78 & 60.69 \\
28.08 & 170.07 & 77.87 & 250.78 & 62.65 \\
28.10 & 166.20 & 76.12 & 254.17 & 62.41 \\
28.12 & 166.20 & 74.89 & 256.58 & 64.46 \\
28.14 & 164.27 & 76.99 & 254.17 & 63.37 \\
28.16 & 167.65 & 74.53 & 254.17 & 65.10 \\
28.18 & 168.13 & 75.26 & 253.68 & 66.56 \\
28.20 & 169.10 & 73.94 & 253.20 & 67.69 \\
28.22 & 169.58 & 73.39 & 256.10 & 64.64 \\
28.25 & 169.10 & 76.03 & 251.75 & 67.52 \\
28.27 & 170.07 & 74.96 & 252.23 & 64.46 \\
28.29 & 169.58 & 77.84 & 252.72 & 65.00 \\
28.31 & 170.55 & 75.26 & 251.27 & 64.55 \\
28.33 & 169.10 & 77.73 & 252.72 & 66.56 \\
28.35 & 168.62 & 80.78 & 254.65 & 67.95 \\
28.39 & 170.55 & 75.26 & 256.10 & 67.43 \\
\hline
\end{tabular}


Table A.19. BOD of Blank and Sample with $100 \mathrm{mg}$ MM12 (Continued)

\begin{tabular}{|c|c|c|c|c|}
\hline Days & $\begin{array}{c}\text { Blank } \\
\text { Corrected } \\
\text { Reading }\end{array}$ & $\begin{array}{c}\text { Corrected } \\
\text { StdDev }\end{array}$ & $\begin{array}{c}\text { Sample } \\
\text { Corrected } \\
\text { Reading }\end{array}$ & $\begin{array}{c}\text { Corrected } \\
\text { StdDev }\end{array}$ \\
\hline 28.45 & 173.45 & 77.35 & 256.10 & 65.09 \\
28.47 & 169.58 & 76.52 & 254.65 & 63.67 \\
28.50 & 172.48 & 77.73 & 256.10 & 65.00 \\
28.52 & 172.97 & 78.50 & 254.17 & 63.05 \\
28.54 & 172.48 & 74.33 & 257.55 & 62.84 \\
28.56 & 172.97 & 77.35 & 258.03 & 67.43 \\
28.58 & 172.48 & 77.87 & 256.10 & 64.11 \\
28.60 & 172.00 & 75.26 & 257.07 & 67.09 \\
28.62 & 167.65 & 74.60 & 253.68 & 63.05 \\
28.64 & 164.27 & 73.72 & 252.23 & 63.12 \\
28.66 & 162.33 & 103.57 & 252.72 & 55.14 \\
28.68 & 111.58 & 82.81 & 226.13 & 57.75 \\
28.70 & 146.87 & 80.79 & 242.08 & 61.81 \\
28.72 & 155.08 & 79.67 & 247.40 & 59.76 \\
28.75 & 159.43 & 76.79 & 244.98 & 61.03 \\
28.77 & 163.78 & 77.46 & 248.37 & 61.13 \\
28.79 & 159.92 & 74.41 & 248.85 & 61.36 \\
28.81 & 160.40 & 77.20 & 246.92 & 60.85 \\
28.83 & 158.47 & 75.93 & 245.95 & 60.77 \\
28.85 & 163.78 & 78.59 & 246.92 & 62.84 \\
28.87 & 165.72 & 78.32 & 250.78 & 63.05 \\
28.89 & 167.17 & 74.53 & 253.20 & 61.13 \\
28.91 & 166.68 & 76.40 & 251.75 & 64.64 \\
28.93 & 170.55 & 75.87 & 256.10 & 63.37 \\
28.95 & 164.75 & 71.00 & 254.17 & 62.65 \\
28.97 & 160.40 & 72.33 & 252.72 & 63.17 \\
29.00 & 161.37 & 72.28 & 259.48 & 61.76 \\
29.02 & 162.33 & 72.73 & 254.17 & 61.36 \\
29.04 & 164.75 & 74.29 & 255.62 & 63.28 \\
29.06 & 171.03 & 72.33 & 249.33 & 63.12 \\
29.08 & 165.72 & 74.33 & 249.82 & 64.46 \\
29.10 & 168.62 & 73.20 & 255.13 & 65.00 \\
29.12 & 168.62 & 75.46 & 251.27 & 61.24 \\
29.14 & 167.17 & 74.60 & 247.88 & 66.56 \\
29.16 & 170.07 & 75.74 & 248.85 & 63.37 \\
29.18 & 168.62 & 75.07 & 249.82 & 60.85 \\
29.20 & 171.03 & 73.57 & 253.20 & 63.58 \\
29.25 & 171.03 & 72.95 & 254.17 & 66.80 \\
\hline
\end{tabular}


Table A.19. BOD of Blank and Sample with $100 \mathrm{mg}$ MM12 (Continued)

\begin{tabular}{|c|c|c|c|c|}
\hline Days & $\begin{array}{c}\text { Blank } \\
\text { Corrected } \\
\text { Reading } \\
\end{array}$ & $\begin{array}{c}\text { Corrected } \\
\text { StdDev }\end{array}$ & $\begin{array}{c}\text { Sample } \\
\text { Corrected } \\
\text { Reading } \\
\end{array}$ & $\begin{array}{c}\text { Corrected } \\
\text { StdDev }\end{array}$ \\
\hline 29.31 & 167.65 & 75.93 & 253.20 & 63.91 \\
\hline 29.33 & 169.58 & 77.66 & 251.75 & 65.82 \\
\hline 29.35 & 171.03 & 74.07 & 254.65 & 62.99 \\
\hline 29.37 & 171.52 & 76.12 & 253.20 & 64.86 \\
\hline 29.39 & 172.00 & 75.26 & 255.62 & 64.86 \\
\hline 29.41 & 169.10 & 75.46 & 255.62 & 62.43 \\
\hline 29.43 & 170.07 & 76.59 & 252.72 & 63.50 \\
\hline 29.45 & 170.07 & 76.59 & 259.00 & 63.12 \\
\hline 29.47 & 170.07 & 77.66 & 255.62 & 62.65 \\
\hline 29.50 & 173.93 & 75.41 & 257.07 & 63.91 \\
\hline 29.52 & 175.38 & 76.08 & 259.00 & 65.28 \\
\hline 29.54 & 172.97 & 77.66 & 257.07 & 65.82 \\
\hline 29.56 & 172.48 & 76.79 & 257.55 & 63.05 \\
\hline 29.58 & 175.38 & 74.89 & 259.48 & 62.37 \\
\hline 29.60 & 174.42 & 76.59 & 255.13 & 62.01 \\
\hline 29.62 & 171.52 & 74.23 & 260.93 & 59.76 \\
\hline 29.64 & 173.93 & 77.26 & 256.58 & 64.11 \\
\hline 29.66 & 173.45 & 75.07 & 255.62 & 61.48 \\
\hline 29.68 & 173.93 & 77.26 & 257.07 & 63.67 \\
\hline 29.70 & 173.45 & 74.13 & 257.55 & 61.39 \\
\hline 29.72 & 169.10 & 75.69 & 253.68 & 60.57 \\
\hline 29.75 & 169.58 & 76.59 & 254.17 & 61.77 \\
\hline 29.77 & 171.52 & 75.66 & 257.07 & 65.28 \\
\hline 29.79 & 168.13 & 74.79 & 255.62 & 61.32 \\
\hline 29.81 & 169.58 & 74.74 & 253.20 & 61.57 \\
\hline 29.83 & 170.55 & 76.79 & 256.10 & 68.70 \\
\hline 29.85 & 168.13 & 76.12 & 252.23 & 65.28 \\
\hline 29.87 & 169.10 & 73.62 & 255.62 & 65.18 \\
\hline 29.89 & 172.00 & 74.96 & 253.68 & 63.37 \\
\hline 29.91 & 168.62 & 73.66 & 257.07 & 61.39 \\
\hline 29.93 & 169.58 & 72.72 & 255.13 & 66.35 \\
\hline 29.95 & 168.62 & 74.41 & 253.68 & 63.94 \\
\hline 29.97 & 167.65 & 75.26 & 256.58 & 62.74 \\
\hline 30.00 & 164.75 & 76.33 & 254.65 & 64.75 \\
\hline 30.02 & 164.27 & 74.60 & 250.78 & 64.22 \\
\hline 30.04 & 165.72 & 74.29 & 253.20 & 64.64 \\
\hline 30.06 & 165.23 & 72.61 & 251.75 & 63.05 \\
\hline 30.10 & 168.62 & 74.41 & 255.13 & 65.89 \\
\hline
\end{tabular}


Table A.19. BOD of Blank and Sample with $100 \mathrm{mg}$ MM12 (Continued)

\begin{tabular}{|c|c|c|c|c|}
\hline Days & $\begin{array}{c}\text { Blank } \\
\text { Corrected } \\
\text { Reading }\end{array}$ & $\begin{array}{c}\text { Corrected } \\
\text { StdDev }\end{array}$ & $\begin{array}{c}\text { Sample } \\
\text { Corrected } \\
\text { Reading }\end{array}$ & $\begin{array}{c}\text { Corrected } \\
\text { StdDev }\end{array}$ \\
\hline 30.16 & 170.07 & 72.08 & 257.07 & 65.50 \\
\hline 30.18 & 171.52 & 71.47 & 256.58 & 65.09 \\
\hline 30.20 & 171.52 & 76.03 & 256.10 & 63.05 \\
\hline 30.22 & 170.07 & 75.93 & 257.55 & 66.56 \\
\hline 30.25 & 172.48 & 72.08 & 256.10 & 64.22 \\
\hline 30.27 & 174.42 & 71.76 & 259.00 & 64.34 \\
\hline 30.29 & 174.42 & 75.07 & 255.13 & 65.50 \\
\hline 30.31 & 172.48 & 74.33 & 256.58 & 67.05 \\
\hline 30.33 & 174.42 & 72.33 & 256.58 & 66.14 \\
\hline 30.35 & 174.42 & 73.83 & 259.00 & 62.78 \\
\hline 30.37 & 174.42 & 71.86 & 260.93 & 65.52 \\
\hline 30.39 & 174.90 & 73.57 & 262.38 & 66.14 \\
\hline 30.41 & 172.00 & 76.69 & 259.00 & 63.81 \\
\hline 30.43 & 174.90 & 74.23 & 261.90 & 65.82 \\
\hline 30.45 & 175.38 & 74.74 & 257.55 & 64.46 \\
\hline 30.47 & 176.35 & 74.79 & 260.93 & 62.74 \\
\hline 30.50 & 173.93 & 74.53 & 257.55 & 64.86 \\
\hline 30.52 & 175.38 & 76.33 & 267.22 & 64.08 \\
\hline 30.54 & 178.77 & 73.94 & 264.32 & 61.89 \\
\hline 30.56 & 175.38 & 74.54 & 264.80 & 61.77 \\
\hline 30.58 & 173.93 & 73.57 & 261.42 & 65.24 \\
\hline 30.60 & 176.35 & 74.37 & 264.32 & 64.75 \\
\hline 30.62 & 174.42 & 73.22 & 260.93 & 64.08 \\
\hline 30.64 & 178.77 & 75.20 & 264.32 & 61.87 \\
\hline 30.66 & 172.97 & 83.55 & 262.38 & 58.69 \\
\hline 30.68 & 158.47 & 76.53 & 252.72 & 63.37 \\
\hline 30.70 & 168.13 & 75.87 & 255.62 & 60.60 \\
\hline 30.72 & 169.10 & 76.40 & 255.62 & 63.47 \\
\hline 30.75 & 167.65 & 74.41 & 256.10 & 64.55 \\
\hline 30.77 & 172.00 & 73.86 & 254.17 & 63.83 \\
\hline 30.79 & 170.55 & 71.47 & 252.72 & 63.69 \\
\hline 30.81 & 170.07 & 72.07 & 255.62 & 62.41 \\
\hline 30.83 & 170.07 & 72.61 & 255.13 & 63.58 \\
\hline 30.85 & 168.62 & 74.23 & 255.13 & 64.55 \\
\hline 30.87 & 168.13 & 74.96 & 251.27 & 64.01 \\
\hline 30.89 & 165.72 & 72.07 & 253.68 & 64.55 \\
\hline 30.91 & 168.62 & 73.66 & 251.27 & 62.11 \\
\hline 30.95 & 166.20 & 71.66 & 254.17 & 60.22 \\
\hline
\end{tabular}


Table A.19. BOD of Blank and Sample with $100 \mathrm{mg}$ MM12 (Continued)

\begin{tabular}{|c|c|c|c|c|}
\hline Days & $\begin{array}{c}\text { Blank } \\
\text { Corrected } \\
\text { Reading }\end{array}$ & $\begin{array}{c}\text { Corrected } \\
\text { StdDev }\end{array}$ & $\begin{array}{c}\text { Sample } \\
\text { Corrected } \\
\text { Reading }\end{array}$ & $\begin{array}{c}\text { Corrected } \\
\text { StdDev }\end{array}$ \\
\hline 31.02 & 169.10 & 73.20 & 250.30 & 63.83 \\
31.04 & 164.27 & 72.33 & 249.82 & 61.77 \\
31.06 & 168.62 & 74.99 & 254.17 & 65.09 \\
31.08 & 164.75 & 72.95 & 251.75 & 63.20 \\
31.10 & 165.72 & 73.20 & 251.75 & 61.62 \\
31.12 & 164.27 & 70.73 & 255.13 & 62.30 \\
31.14 & 163.30 & 71.91 & 251.75 & 61.36 \\
31.16 & 163.30 & 72.61 & 254.17 & 64.30 \\
31.18 & 167.17 & 74.23 & 249.82 & 62.94 \\
31.20 & 165.23 & 73.75 & 254.17 & 65.24 \\
31.22 & 171.52 & 75.20 & 257.07 & 59.51 \\
31.25 & 170.07 & 73.27 & 250.78 & 62.20 \\
31.27 & 170.55 & 74.89 & 258.52 & 64.64 \\
31.29 & 175.87 & 73.75 & 256.10 & 66.14 \\
31.31 & 170.07 & 71.47 & 256.10 & 64.22 \\
31.33 & 175.87 & 75.26 & 256.10 & 62.30 \\
31.35 & 172.00 & 71.76 & 257.55 & 62.84 \\
31.37 & 175.87 & 74.23 & 255.13 & 61.57 \\
31.39 & 175.38 & 72.07 & 259.00 & 64.22 \\
31.41 & 174.42 & 73.86 & 254.65 & 60.77 \\
31.43 & 176.35 & 74.23 & 259.97 & 62.11 \\
31.45 & 173.93 & 73.57 & 262.38 & 60.50 \\
31.47 & 174.90 & 74.23 & 263.83 & 59.95 \\
31.50 & 175.38 & 76.79 & 260.45 & 60.85 \\
\hline
\end{tabular}




\section{A.3.7. METAC Kinetics}

Table A.20. P Removal by MM12 over Varying Times of Exposure

\begin{tabular}{|c|cc|cc|cc|}
\hline \multirow{2}{*}{$\begin{array}{c}\text { Time } \\
\text { (min) }\end{array}$} & \multicolumn{2}{|c|}{$\mathrm{C}_{0}=0.1 \mathrm{mg} / \mathrm{L}$} & \multicolumn{2}{c|}{$\mathrm{C}_{0}=50 \mathrm{mg} / \mathrm{L}$} & \multicolumn{2}{c|}{$\mathrm{C}_{0}=5 \mathrm{mg} / \mathrm{L}$} \\
\cline { 2 - 7 } & $\begin{array}{c}\text { Normalized } \\
\text { Conc. }\end{array}$ & $\begin{array}{c}\text { Standard } \\
\text { Deviation }\end{array}$ & $\begin{array}{c}\text { Normalized } \\
\text { Conc. }\end{array}$ & $\begin{array}{c}\text { Standard } \\
\text { Deviation }\end{array}$ & $\begin{array}{c}\text { Normalized } \\
\text { Conc. }\end{array}$ & $\begin{array}{c}\text { Standard } \\
\text { Deviation }\end{array}$ \\
\hline 1440 & 0.28 & 0.02 & 0.27 & 0.03 & 0.08 & 0.00 \\
1080 & 0.28 & 0.02 & 0.26 & 0.01 & 0.08 & 0.00 \\
720 & 0.26 & 0.03 & 0.26 & 0.00 & 0.08 & 0.02 \\
360 & 0.24 & 0.02 & 0.26 & 0.00 & 0.08 & 0.02 \\
180 & 0.23 & 0.00 & 0.26 & 0.00 & 0.08 & 0.00 \\
120 & 0.22 & 0.02 & 0.27 & 0.02 & 0.08 & 0.00 \\
60 & 0.22 & 0.02 & 0.27 & 0.01 & 0.08 & 0.02 \\
30 & 0.21 & 0.02 & 0.26 & 0.01 & 0.09 & 0.02 \\
15 & 0.20 & 0.00 & 0.27 & 0.00 & 0.08 & 0.00 \\
10 & 0.22 & 0.02 & 0.26 & 0.00 & 0.08 & 0.01 \\
8 & 0.21 & 0.02 & 0.26 & 0.00 & 0.08 & 0.01 \\
6 & 0.20 & 0.00 & 0.26 & 0.00 & 0.08 & 0.00 \\
4 & 0.22 & 0.02 & 0.26 & 0.02 & 0.08 & 0.01 \\
0 & 1.00 & 0.00 & 1.00 & 0.00 & 1.00 & 0.00 \\
\hline
\end{tabular}




\section{A.3.8. METAC Behavior in Eutrophic Lake Samples}

Table A.21. P Removal by MM12 from Eutrophic Lakes and Low Conc. Synthetic Lab Water

\begin{tabular}{|c|c|c|c|c|c|c|c|c|c|c|}
\hline Source & Sample & $\begin{array}{c}\text { Absorbance } \\
\text { (nm) }\end{array}$ & Conc. & $\begin{array}{l}\text { Dilution } \\
\text { Factor }\end{array}$ & $\begin{array}{l}\text { Adj. Conc } \\
\text { ug/L }\end{array}$ & Average & StdDev & $\begin{array}{c}\text { Sorbed Phosphate } \\
(\mathrm{mg} / \mathrm{L})\end{array}$ & Normalized & $\begin{array}{c}\text { Normalized } \\
\text { StdDev }\end{array}$ \\
\hline \multirow[b]{6}{*}{ Synthetic } & 1 & 0.002 & 0.00 & 5.00 & 13.52 & 22.53 & 10.32 & \multirow[t]{6}{*}{128.41} & \multirow[t]{6}{*}{0.85} & \multirow[t]{6}{*}{0.07} \\
\hline & 2 & 0.005 & 0.01 & 5.00 & 33.79 & & & & & \\
\hline & 3 & 0.003 & 0.00 & 5.00 & 20.28 & & & & & \\
\hline & $\mathrm{C}$ & 0.022 & 0.03 & 5.00 & 148.69 & 150.94 & 17.01 & & & \\
\hline & $\mathrm{C}$ & 0.02 & 0.03 & 5.00 & 135.17 & & & & & \\
\hline & \multirow{2}{*}{ C } & 0.025 & 0.03 & 5.00 & 168.96 & & & & & \\
\hline \multirow[b]{6}{*}{ Katrina } & & 0.008 & 0.01 & 5.00 & 54.07 & 49.56 & 7.80 & \multirow[t]{6}{*}{135.17} & \multirow[t]{6}{*}{0.73} & \multirow[t]{6}{*}{0.04} \\
\hline & \multirow{5}{*}{$\begin{array}{l}2 \\
3 \\
\text { KC } \\
\text { KC } \\
\text { KC }\end{array}$} & 0.006 & 0.01 & 5.00 & 40.55 & & & & & \\
\hline & & 0.008 & 0.01 & 5.00 & 54.07 & & & & & \\
\hline & & 0.028 & 0.04 & 5.00 & 189.24 & 184.73 & 7.80 & & & \\
\hline & & 0.026 & 0.04 & 5.00 & 175.72 & & & & & \\
\hline & & 0.028 & 0.04 & 5.00 & 189.24 & & & & & \\
\hline \multirow[b]{6}{*}{ Holy Name } & 1 & 0.008 & 0.01 & 5.00 & 54.07 & 51.82 & 3.90 & \multirow[t]{6}{*}{128.41} & \multirow[t]{6}{*}{0.71} & \multirow[t]{6}{*}{0.02} \\
\hline & 2 & 0.008 & 0.01 & 5.00 & 54.07 & & & & & \\
\hline & 3 & 0.007 & 0.01 & 5.00 & 47.31 & & & & & \\
\hline & HNC & 0.026 & 0.04 & 5.00 & 175.72 & 180.23 & 3.90 & & & \\
\hline & HNC & 0.027 & 0.04 & 5.00 & 182.48 & & & & & \\
\hline & $\mathrm{HNC}$ & 0.027 & 0.04 & 5.00 & 182.48 & & & & & \\
\hline
\end{tabular}


Table A.21. P Removal by MM12 from Eutrophic Lakes and Low Conc. Synthetic Lab Water (Continued)

\begin{tabular}{|c|c|c|c|c|c|c|c|c|c|c|}
\hline Source & Sample & $\begin{array}{c}\text { Absorbance } \\
(\mathrm{nm})\end{array}$ & Conc. & $\begin{array}{c}\text { Dilution } \\
\text { Factor }\end{array}$ & $\begin{array}{c}\text { Adj. Conc } \\
\text { ug/L }\end{array}$ & Average & StdDev & $\begin{array}{c}\text { Sorbed } \\
\text { Phosphate } \\
\text { (mg/L) }\end{array}$ & Normalized & $\begin{array}{c}\text { Normalized } \\
\text { StdDev }\end{array}$ \\
\hline \multirow[b]{6}{*}{ Ardmore } & 1 & 0.007 & 0.01 & 5.00 & 47.31 & 47.31 & 0.00 & \multirow[t]{6}{*}{164.46} & \multirow[t]{6}{*}{0.78} & \multirow[t]{6}{*}{0.00} \\
\hline & \multirow{5}{*}{$\begin{array}{l}2 \\
3 \\
\mathrm{AC} \\
\mathrm{AC} \\
\mathrm{AC}\end{array}$} & 0.007 & 0.01 & 5.00 & 47.31 & & & & & \\
\hline & & 0.007 & 0.01 & 5.00 & 47.31 & & & & & \\
\hline & & 0.031 & 0.04 & 5.00 & 209.52 & 211.77 & 17.01 & & & \\
\hline & & 0.034 & 0.05 & 5.00 & 229.79 & & & & & \\
\hline & & 0.029 & 0.04 & 5.00 & 196.00 & & & & & \\
\hline \multirow[b]{6}{*}{ Independence } & 1 & 0.009 & 0.01 & 5.00 & 60.83 & \multirow[t]{3}{*}{51.82} & \multirow[t]{3}{*}{10.32} & \multirow[t]{6}{*}{135.17} & \multirow[t]{6}{*}{0.72} & \multirow[t]{6}{*}{0.06} \\
\hline & \multirow{5}{*}{$\begin{array}{l}2 \\
3 \\
\text { IC } \\
\text { IC } \\
\text { IC } \\
\end{array}$} & 0.006 & 0.01 & 5.00 & 40.55 & & & & & \\
\hline & & 0.008 & 0.01 & 5.00 & 54.07 & & & & & \\
\hline & & 0.025 & 0.03 & 5.00 & 168.96 & 186.99 & 15.61 & & & \\
\hline & & 0.029 & 0.04 & 5.00 & 196.00 & & & & & \\
\hline & & 0.029 & 0.04 & 5.00 & 196.00 & & & & & \\
\hline & 1 & 0.007 & 0.01 & 5.00 & 47.31 & 42.80 & 3.90 & 114.90 & 0.73 & 0.02 \\
\hline & 2 & 0.006 & 0.01 & 5.00 & 40.55 & & & & & \\
\hline & 3 & 0.006 & 0.01 & 5.00 & 40.55 & & & & & \\
\hline & HMC & 0.022 & 0.03 & 5.00 & 148.69 & 157.70 & 7.80 & & & \\
\hline & HMC & 0.024 & 0.03 & 5.00 & 162.21 & & & & & \\
\hline Half Moon & HMC & 0.024 & 0.03 & 5.00 & 162.21 & & & & & \\
\hline
\end{tabular}




\section{A.3.9. METAC Temperature Study}

Table A.22. P Removal Data by MM12 Under Varying Temperature Conditions

\begin{tabular}{|c|c|c|}
\hline $\begin{array}{c}\text { Temp } \\
\left({ }^{\circ} \mathrm{C}\right)\end{array}$ & $\begin{array}{c}\text { Normalized } \\
\text { P Removal }\end{array}$ & $\begin{array}{c}\text { Normalized } \\
\text { StdDev }\end{array}$ \\
\hline 4 & 0.919 & 0.015 \\
10 & 0.935 & 0.000 \\
15 & 0.915 & 0.011 \\
20 & 0.937 & 0.015 \\
25 & 0.928 & 0.007 \\
30 & 0.929 & 0.014 \\
35 & 0.941 & 0.008 \\
\hline
\end{tabular}

\section{A.3.10. METAC Partial-Selectivity Study}

Table A.23. Anion Removal by MM12 (Anion $C_{0}=110 \mathrm{meq} / \mathrm{L}$ )

\begin{tabular}{|c|c|c|c|c|}
\hline \multirow[b]{2}{*}{ Anion } & \multicolumn{2}{|c|}{ Pre-PO4- Introduction } & \multicolumn{2}{|c|}{ Post-PO4 $4^{3-}$ Introduction } \\
\hline & $\begin{array}{l}\text { Amount Sorbed } \\
\text { (meq) }\end{array}$ & StdDev & $\begin{array}{l}\text { Amount Sorbed } \\
\text { (meq) }\end{array}$ & StdDev \\
\hline $\mathrm{NO}_{3}^{-}$ & 0.340 & 0.050 & 0.048 & 0.002 \\
\hline $\mathrm{SO}_{4}^{2-}$ & 0.350 & 0.038 & 0.052 & 0.007 \\
\hline $\mathrm{Cl}^{-}$ & 0.337 & 0.031 & 0.043 & 0.005 \\
\hline
\end{tabular}

Table A.24. P Removal by MM12 after Anion Saturation (Anion $\left.C_{0}=110 \mathrm{meq} / \mathrm{L}\right)\left(P C_{0}=110\right.$ $\mathrm{meq} / \mathrm{L})$

\begin{tabular}{|c|c|c|}
\hline \multirow{2}{*}{$\begin{array}{c}\text { Anion } \\
\text { Present }\end{array}$} & \begin{tabular}{c} 
Post-Anion Introduction \\
\cline { 2 - 3 }
\end{tabular} & $\begin{array}{c}\text { StdDev } \\
\mathrm{mg}\left(\mathrm{PO}_{4} 4_{4}^{3-}\right. \\
\text { meq }\end{array}$ \\
\hline $\mathrm{NO}_{3}{ }^{-}$ & $16.94(0.535)$ & $1.67(0.053)$ \\
$\mathrm{SO}_{4}^{2-}$ & $16.64(0.526)$ & $1.16(0.037)$ \\
$\mathrm{Cl}^{-}$ & $17.35(0.548)$ & $2.28(0.072)$ \\
\hline
\end{tabular}




\section{A.3.11. METAC Statistical Analysis}

\section{7/4/2017 9:01:02 AM}

Welcome to Minitab, press F1 for help.

\section{One-way ANOVA: \% Removal versus pH}

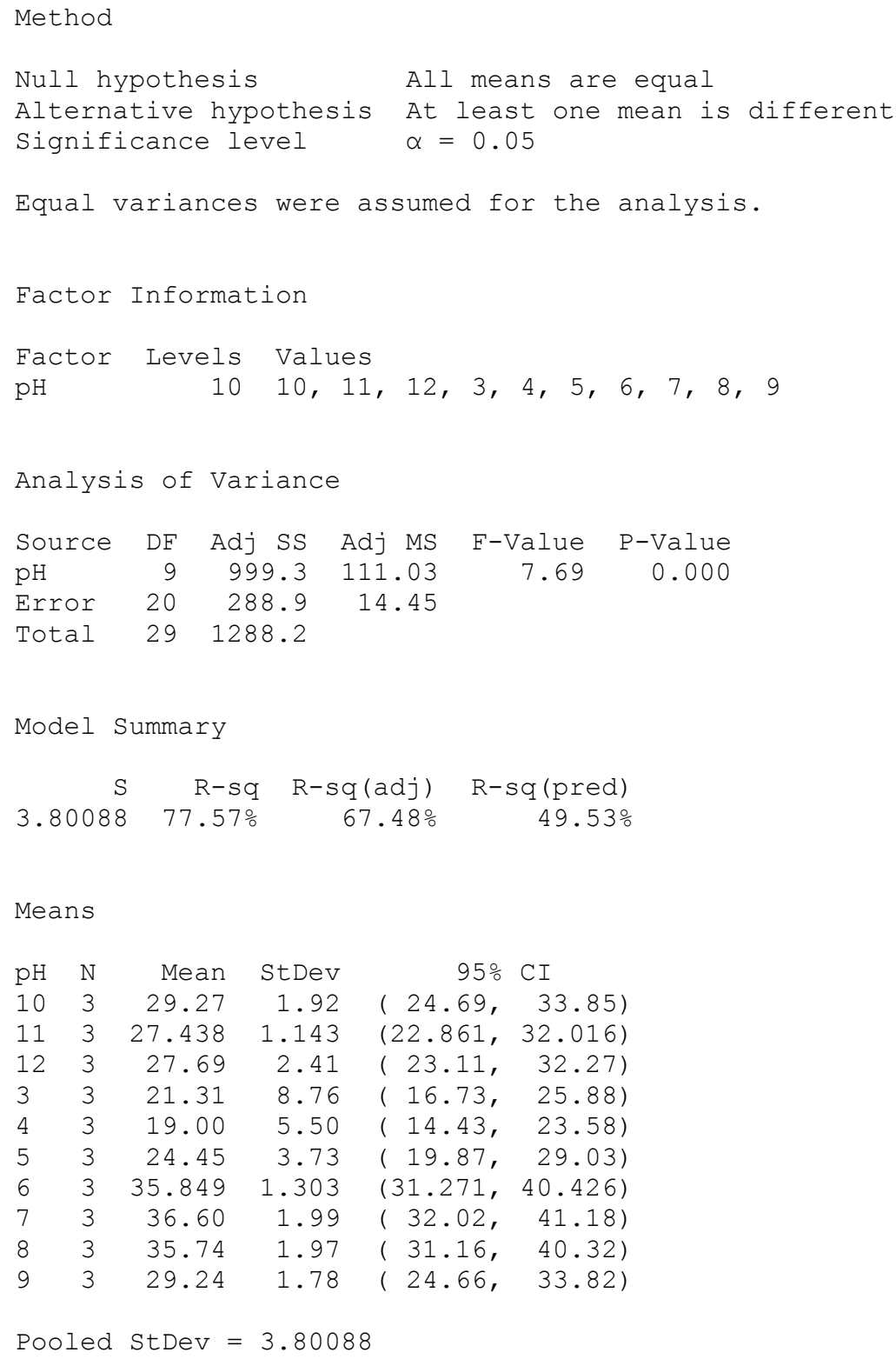

\section{Tukey Pairwise Comparisons}




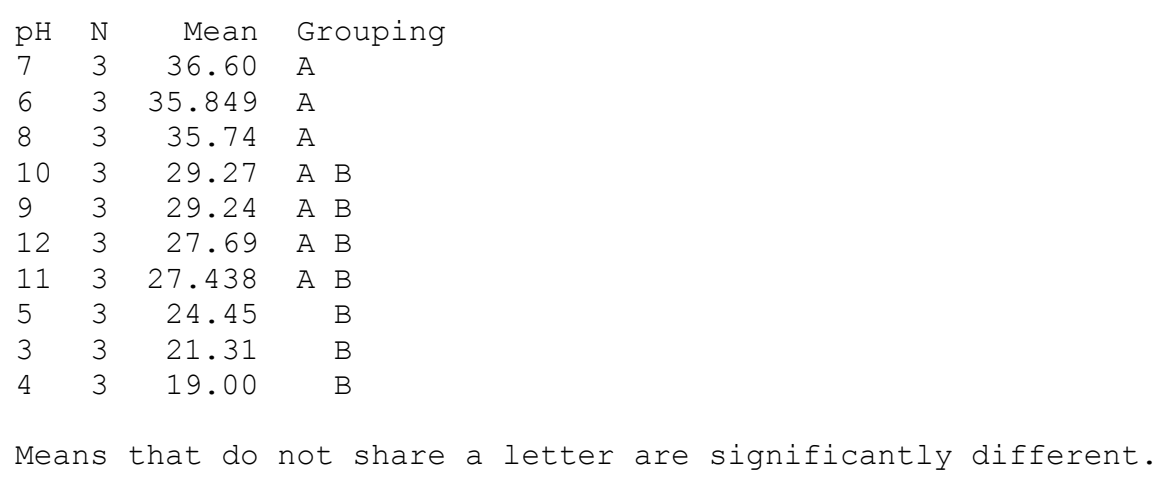

\section{Tukey Simultaneous 95\% Cls}

\section{Interval Plot of \% Removal vs pH}

\section{One-way ANOVA: \% Removal versus pH}

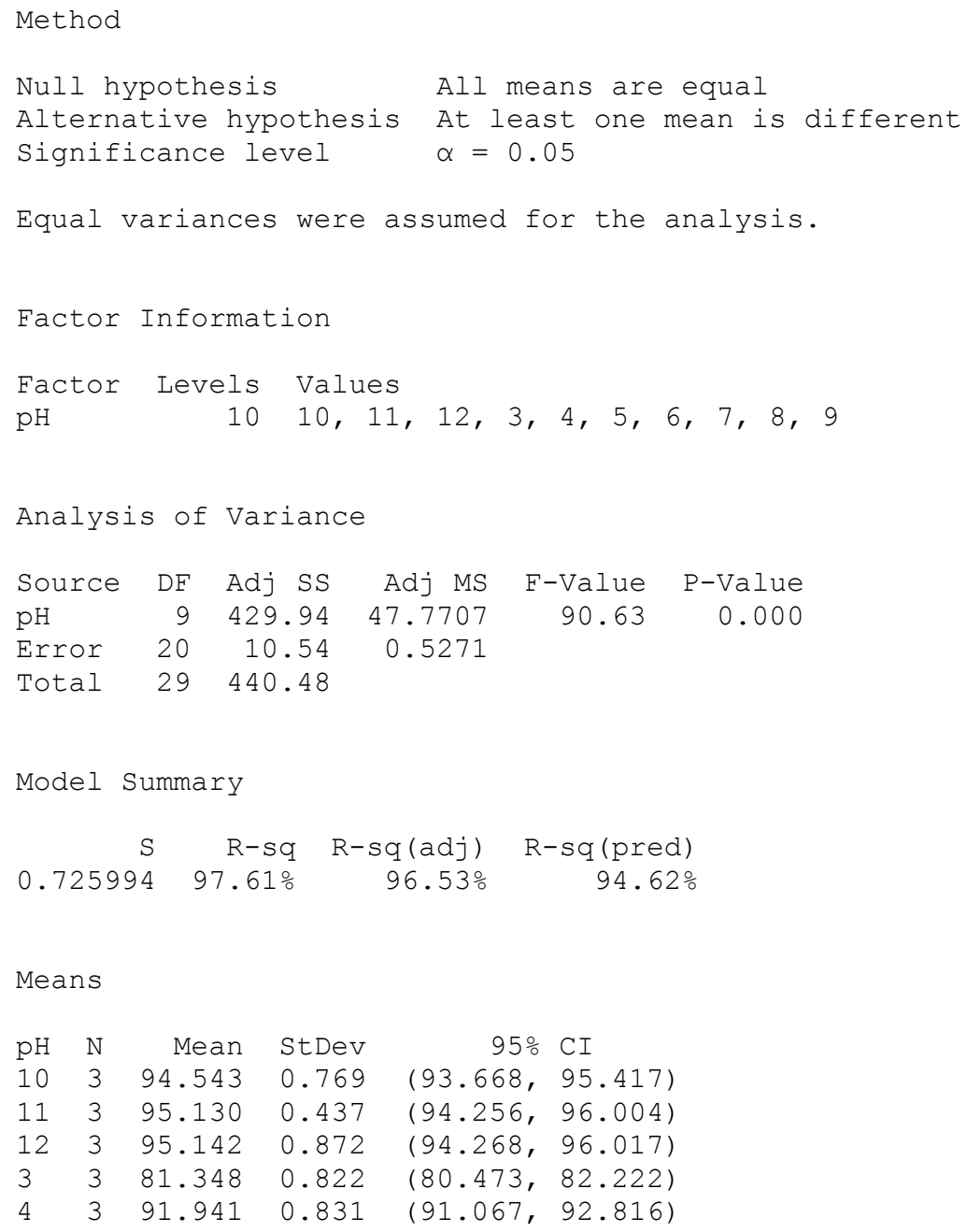




\begin{tabular}{|c|c|c|c|c|}
\hline 5 & 3 & 93.471 & 0.939 & (92.596, \\
\hline & 3 & 93.236 & 0.467 & (92.362, \\
\hline & 3 & 92.381 & 0.920 & (91.507, \\
\hline & 3 & 92.016 & 0.450 & (91.141, \\
\hline & 3 & 92.299 & 0.465 & $(91.425$, \\
\hline
\end{tabular}

Pooled StDev $=0.725994$

\section{Tukey Pairwise Comparisons}

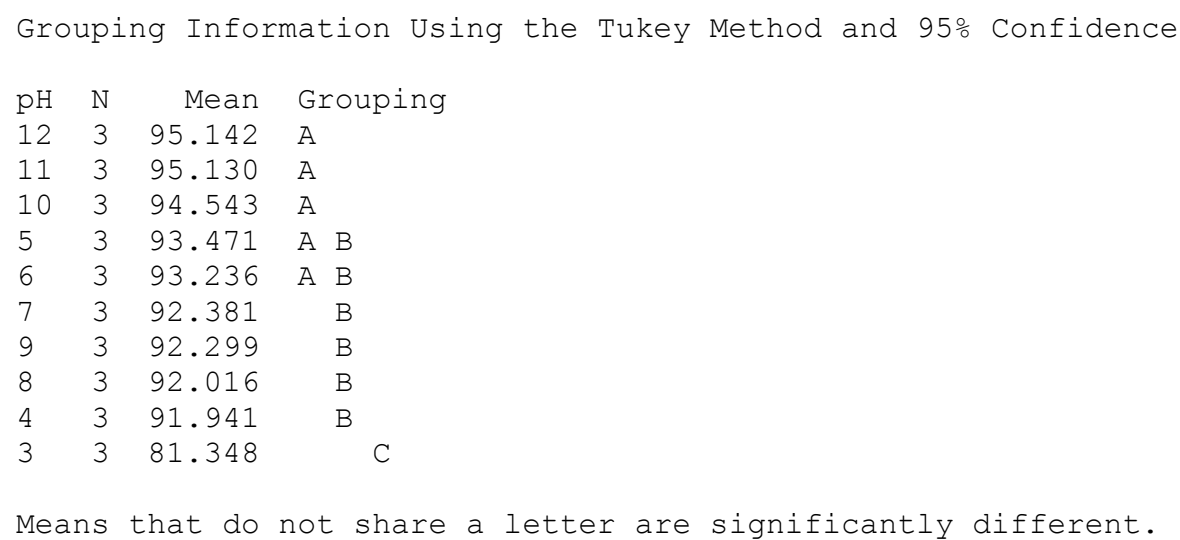

\section{Tukey Simultaneous 95\% Cls}

\section{Interval Plot of \% Removal vs pH}

\section{7/4/2017 10:35:23 AM}

Welcome to Minitab, press F1 for help.

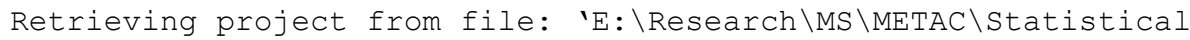

Analysis.MPJ'

\section{One-way ANOVA: \% Removal2 versus Water}

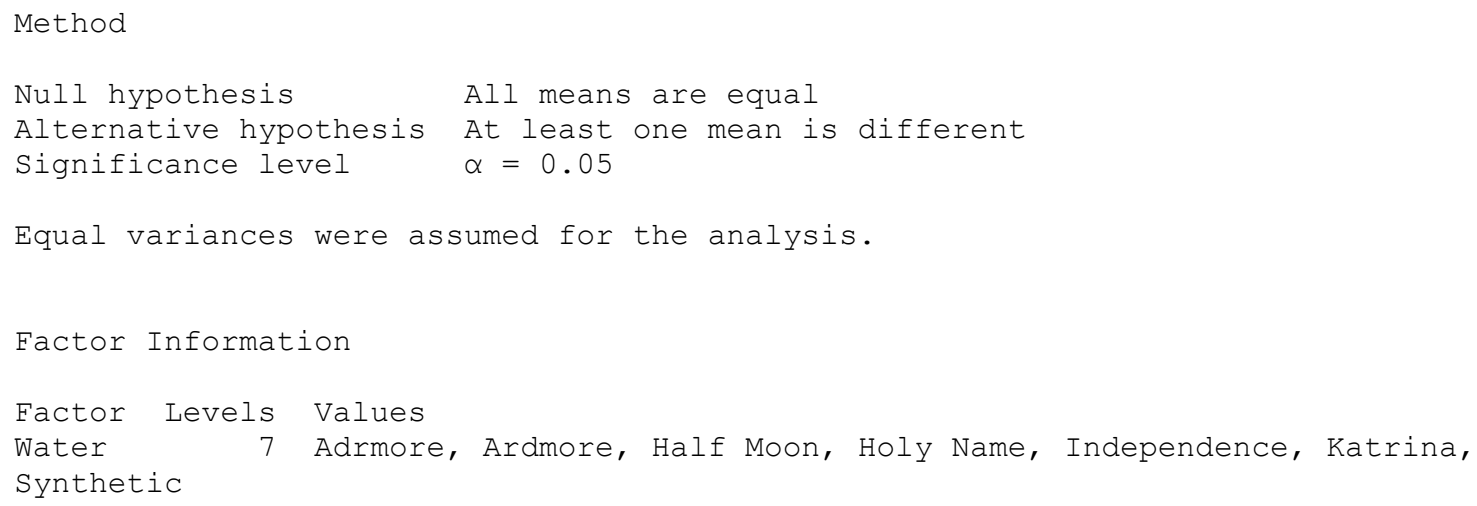




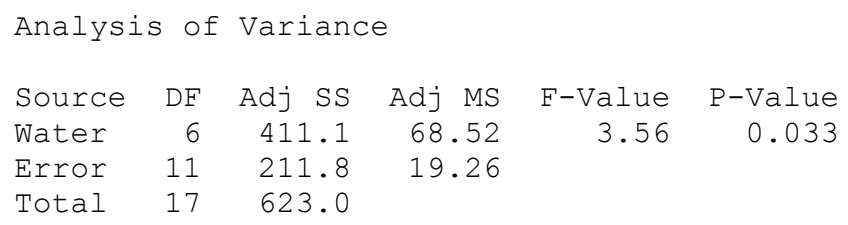

Means

$\begin{array}{lrrrrr}\text { Water } & \text { N } & \text { Mean } & \text { StDev } & 95 \% \\ \text { Adrmore } & 1 & 77.66 & \star & (68.00,87.32) \\ \text { Ardmore } & 2 & 77.66 & 0.00 & (70.83,84.49) \\ \text { Half Moon } & 3 & 72.86 & 2.47 & (67.28,78.43) \\ \text { Holy Name } & 3 & 71.25 & 2.17 & (65.67,76.83) \\ \text { Independence } & 3 & 72.29 & 5.52 & (66.71,77.87) \\ \text { Katrina } & 3 & 73.17 & 4.22 & (67.59,78.75) \\ \text { Synthetic } & 3 & 85.07 & 6.84 & (79.50, & 90.65) \\ \text { Pooled StDev } & & & & \end{array}$

\section{Tukey Pairwise Comparisons}

Grouping Information Using the Tukey Method and 95\% Confidence

$\begin{array}{llrl}\text { Water } & \text { N } & \text { Mean } & \text { Grouping } \\ \text { Synthetic } & 3 & 85.07 & \text { A } \\ \text { Ardmore } & 2 & 77.66 & \text { A B } \\ \text { Adrmore } & 1 & 77.66 & \text { A B } \\ \text { Katrina } & 3 & 73.17 & \text { A B } \\ \text { Half Moon } & 3 & 72.86 & \text { A B } \\ \text { Independence } & 3 & 72.29 & \text { B } \\ \text { Holy Name } & 3 & 71.25 & \text { B } \\ \text { Means that do not share a letter are significantly different. }\end{array}$

\section{Tukey Simultaneous 95\% Cls}

Interval Plot of \% Removal2 vs Water

\section{One-way ANOVA: \% RemovalT versus Temp}

Method

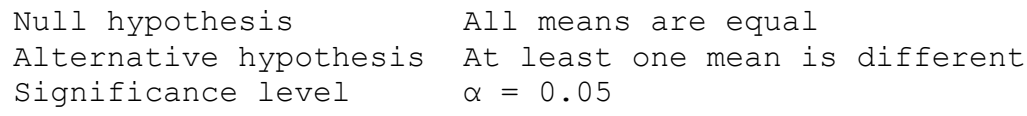


Equal variances were assumed for the analysis.

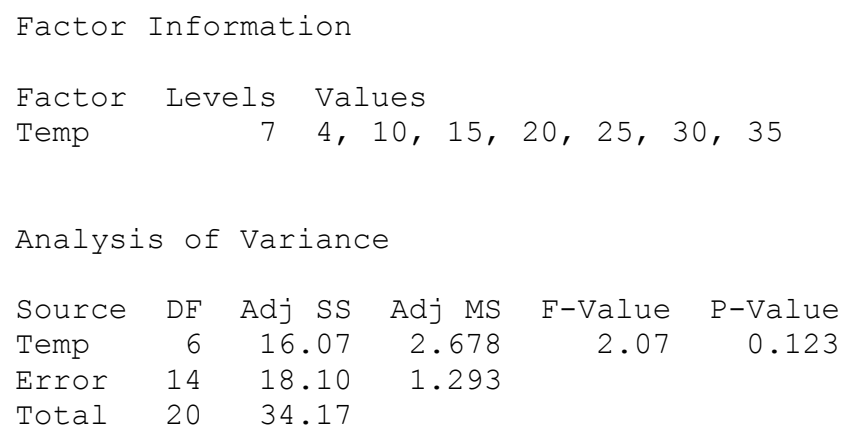

\section{Tukey Pairwise Comparisons}

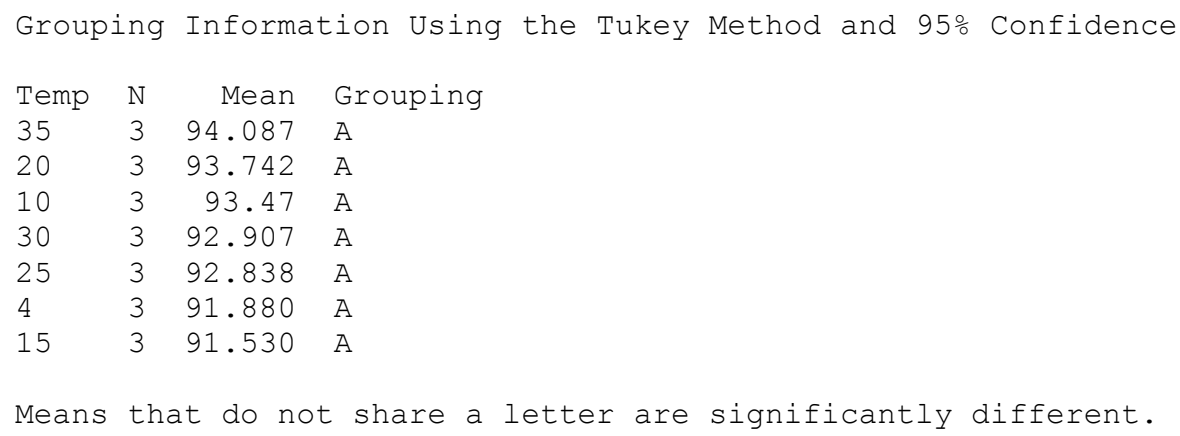

Tukey Simultaneous 95\% Cls

\section{Interval Plot of \% RemovalT vs Temp}




\section{One-way ANOVA: BOD versus Time}

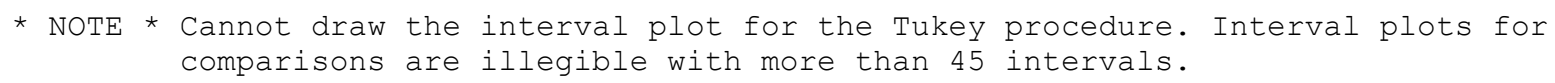

Method

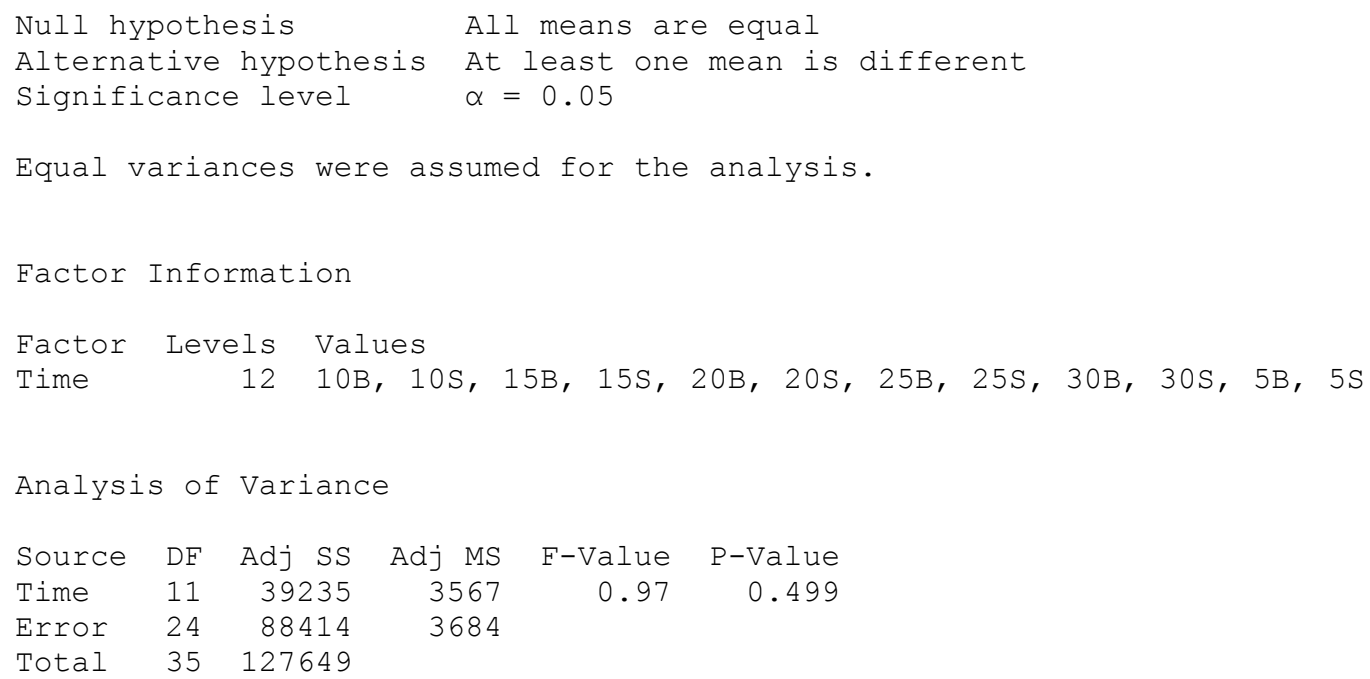

\section{Tukey Pairwise Comparisons}

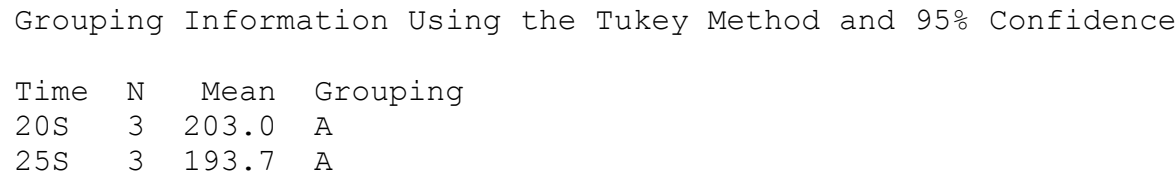




$\begin{array}{lrrl}\text { 30S } & 3 & 188.0 & \mathrm{~A} \\ 15 \mathrm{~S} & 3 & 184.7 & \mathrm{~A} \\ 10 \mathrm{~S} & 3 & 178.7 & \mathrm{~A} \\ 5 \mathrm{~S} & 3 & 160.0 & \mathrm{~A} \\ \text { 20B } & 3 & 141.3 & \mathrm{~A} \\ \text { 25B } & 3 & 132.7 & \mathrm{~A} \\ \text { 30B } & 3 & 128.3 & \mathrm{~A} \\ \text { 10B } & 3 & 125.0 & \mathrm{~A} \\ \text { 15B } & 3 & 119.0 & \mathrm{~A} \\ \text { 5B } & 3 & 99.0 & \mathrm{~A}\end{array}$

Means that do not share a letter are significantly different.

\section{Interval Plot of BOD vs Time}

\section{One-way ANOVA: Sorption (mg) versus Polymer}

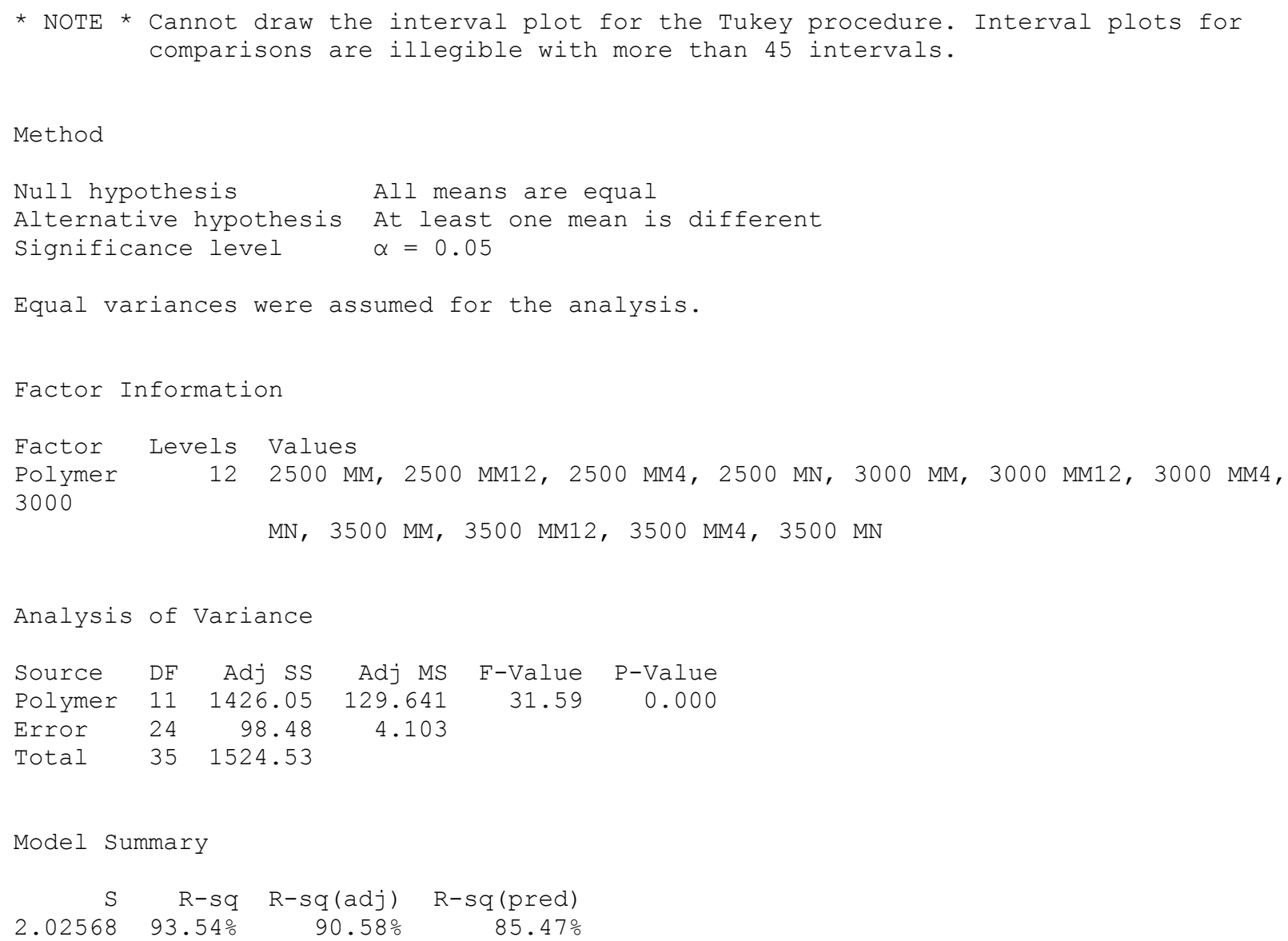




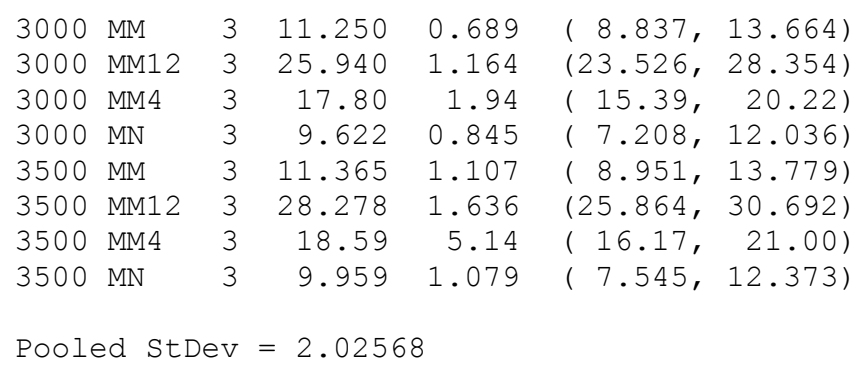

\section{Tukey Pairwise Comparisons}

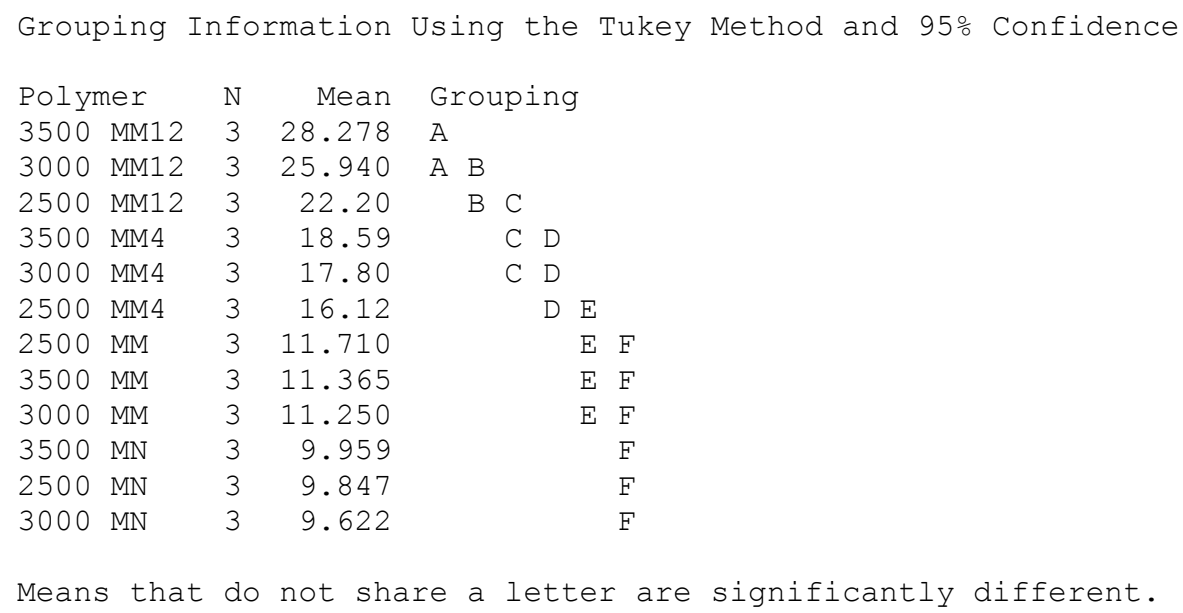

Interval Plot of Sorption (mg) vs Polymer

\section{One-way ANOVA: Normalized P Removal versus Interference}

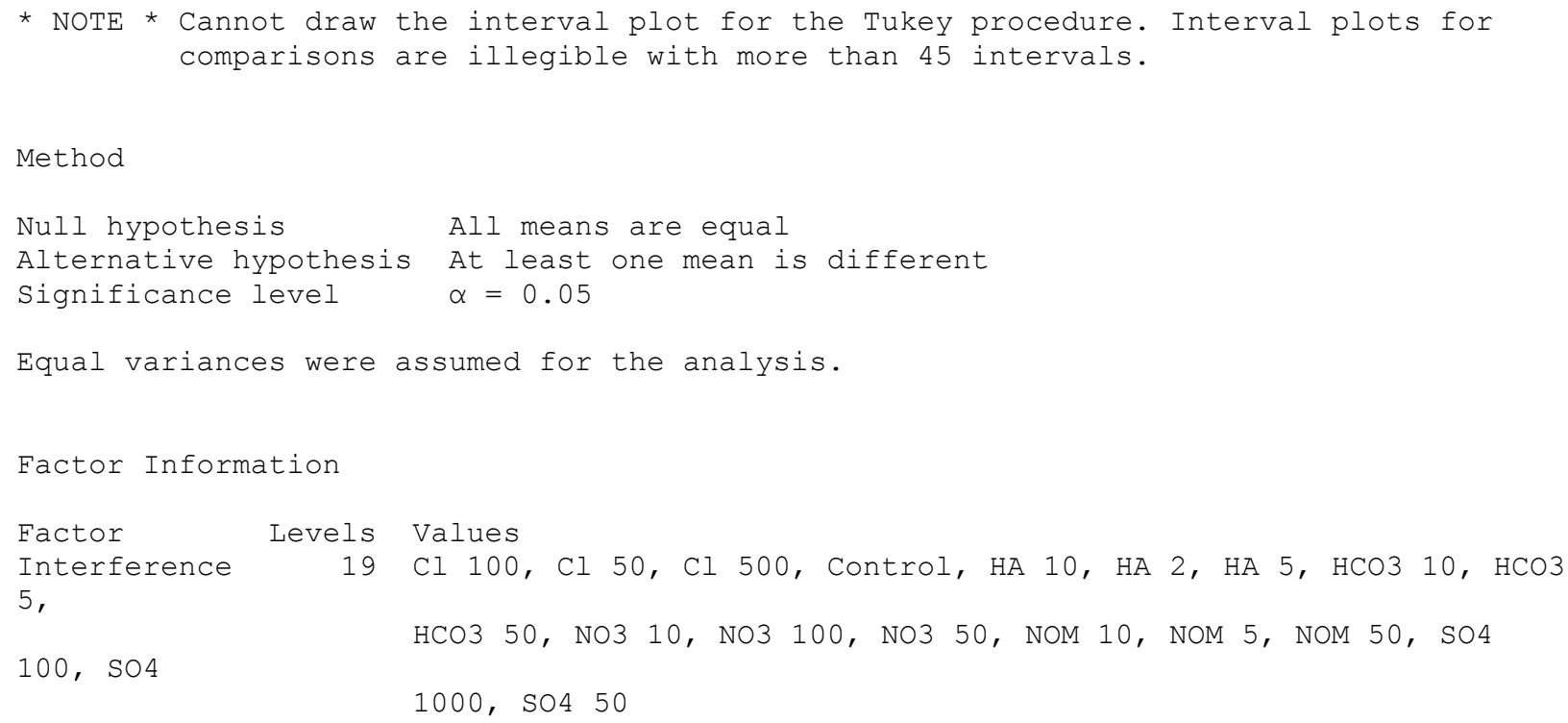


Analysis of Variance

$\begin{array}{lrrrrr}\text { Source } & \text { DF } & \text { Adj SS } & \text { Adj MS } & \text { F-Value } & \text { P-Value } \\ \text { Interference } & 18 & 3.63853 & 0.202141 & 699.25 & 0.000 \\ \text { Error } & 38 & 0.01099 & 0.000289 & & \\ \text { Total } & 56 & 3.64951 & & & \end{array}$

Model Summary

$\begin{array}{rrrr}S & R-s q & R-s q(\text { adj) } & R-s q(p r e d) \\ 0.0170024 & 99.70 \% & 99.56 \% & 99.32 \%\end{array}$

Means

\begin{tabular}{|c|c|c|c|c|c|}
\hline Interference & $\mathrm{N}$ & Mean & StDev & $95 \%$ & CI \\
\hline Cl 100 & 3 & 0.4505 & 0.0327 & $(0.4306$, & 0.4703 \\
\hline Cl 50 & 3 & 0.54942 & 0.01150 & $(0.52955$, & 0.56930 \\
\hline Cl 500 & 3 & 0.18654 & 0.01622 & (0.16666, & 0.20641 \\
\hline Control & 3 & 0.9243 & 0.0182 & $(0.9044$, & 0.9442 \\
\hline A 10 & 3 & 0.94200 & 0.00402 & (0.92212, & 0.96187 \\
\hline A 2 & 3 & 0.94226 & 0.00400 & (0.92239, & 0.96214 \\
\hline A 5 & 3 & 0.93911 & 0.00406 & (0.91924, & 0.9589 \\
\hline CO3 10 & 3 & 0.90242 & 0.00942 & $(0.8825$ & 0.9222 \\
\hline CO3 5 & 3 & 0.89075 & 0.00499 & $(0.87087$, & 0.910 \\
\hline CO3 50 & 3 & 0.94455 & 0.00483 & $(0.92468$, & 0.964 \\
\hline 0310 & 3 & 0.905 & 0.00821 & $(0.88574$, & 0.925 \\
\hline 100 & 3 & 0.60352 & 0.00469 & $(0.58365$, & 0.623 \\
\hline 50 & 3 & 0.7463 & 0.0249 & $(0.7264$, & 0.766 \\
\hline 10 & 3 & 0.94226 & 0.00400 & (0.92239, & 0.9621 \\
\hline NOM & 3 & 0.9253 & 0.0180 & $(0.9055$, & 0.9452 \\
\hline $\mathrm{NOM}$ & 3 & 0.88180 & 0.01083 & (0.86192, & 0.90167 \\
\hline 100 & 3 & 0.5321 & 0.0420 & $(0.5122$, & 0.5519 \\
\hline 1000 & 3 & 0.14383 & 0.01244 & (0.12395, & 0.1637 \\
\hline 50 & 3 & 0.7469 & 0.0207 & $(0.7270$, & 0.7668 \\
\hline
\end{tabular}

Pooled StDev $=0.0170024$

\section{Tukey Pairwise Comparisons}

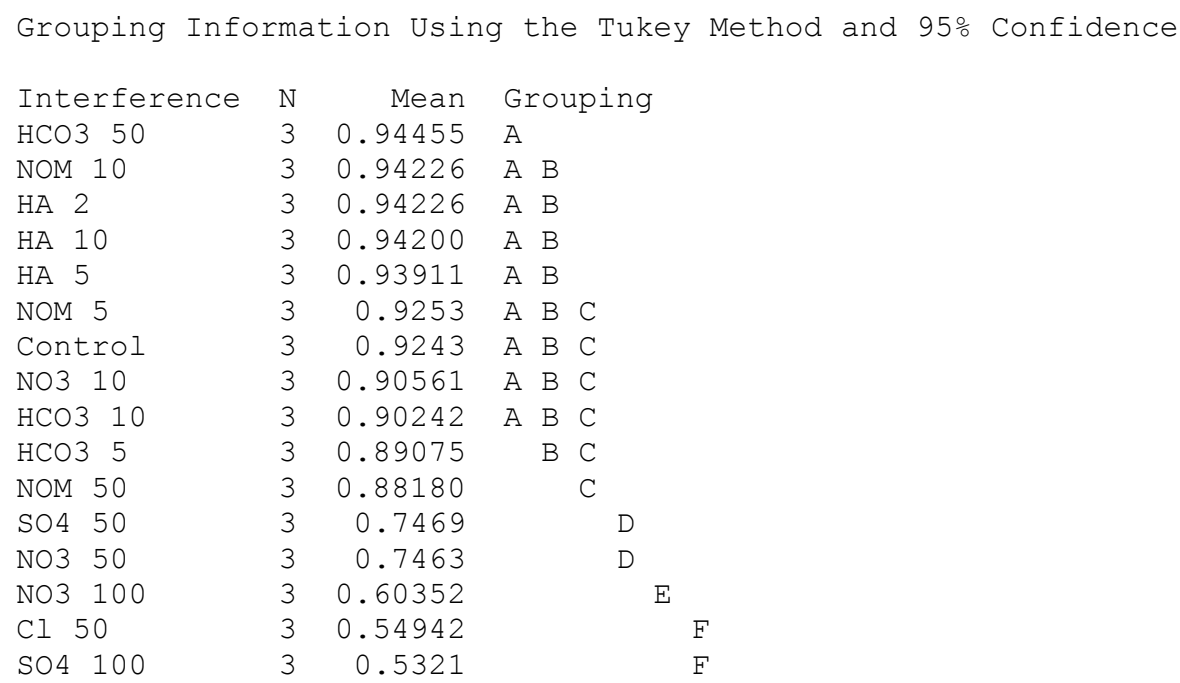



Cl 100
30.4505
Cl 500
30.18654
$\mathrm{SO} 41000$
30.14383
G
$\mathrm{H}$
Means that do not share a letter are significantly different.

Interval Plot of Normalized P Removal vs Interference

\section{7/4/2017 1:16:23 PM}

Welcome to Minitab, press F1 for help.

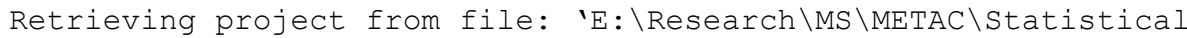

Analysis.MPJ' 